\title{
Protein metabolism and nutritional requirements in critically ill children = Eiwitmetabolisme en voedingsbehoefte van ernstig zieke kinderen
}

\author{
Citation for published version (APA):
}

van Waardenburg, D. A. (2008). Protein metabolism and nutritional requirements in critically ill children = Eiwitmetabolisme en voedingsbehoefte van ernstig zieke kinderen. [Doctoral Thesis, Maastricht University]. Universitaire Pers Maastricht. https://doi.org/10.26481/dis.20080918dw

Document status and date:

Published: 01/01/2008

DOI:

10.26481/dis.20080918dw

Document Version:

Publisher's PDF, also known as Version of record

Please check the document version of this publication:

- A submitted manuscript is the version of the article upon submission and before peer-review. There can be important differences between the submitted version and the official published version of record.

People interested in the research are advised to contact the author for the final version of the publication, or visit the DOI to the publisher's website.

- The final author version and the galley proof are versions of the publication after peer review.

- The final published version features the final layout of the paper including the volume, issue and page numbers.

Link to publication

\footnotetext{
General rights rights.

- You may freely distribute the URL identifying the publication in the public portal. please follow below link for the End User Agreement:

www.umlib.nl/taverne-license

Take down policy

If you believe that this document breaches copyright please contact us at:

repository@maastrichtuniversity.nl

providing details and we will investigate your claim.
}

Copyright and moral rights for the publications made accessible in the public portal are retained by the authors and/or other copyright owners and it is a condition of accessing publications that users recognise and abide by the legal requirements associated with these

- Users may download and print one copy of any publication from the public portal for the purpose of private study or research.

- You may not further distribute the material or use it for any profit-making activity or commercial gain

If the publication is distributed under the terms of Article $25 \mathrm{fa}$ of the Dutch Copyright Act, indicated by the "Taverne" license above, 
PROTEIN METABOLISM AND

NUTRITIONAL REQUIREMENTS IN

CRITICALLY ILL CHILDREN 
(C) Copyright D.A. van Waardenburg, Maastricht 2008 ISBN 9789052787428

Productie: Datawyse, Maastricht

The publication of this thesis was financially supported by: Nutricia Advanced Medical Nutrition, Maquet Netherlands BV 


\title{
PROTEIN METABOLISM AND NUTRITIONAL REQUIREMENTS IN CRITICALLY ILL CHILDREN
}

\author{
Eiwitmetabolisme en voedingsbehoefte van \\ ernstig zieke kinderen
}

\section{PROEFSCHRIFT}

ter verkrijging van de graad van doctor

aan de Universiteit van Maastricht

op gezag van de Rector Magnificus, Prof. mr. G.P.M.F. Mols, volgens het besluit van het College van Decanen, in het openbaar te verdedigen op donderdag 18 september 2008 om 16:00 uur

door

Dirk Adriaan van Waardenburg

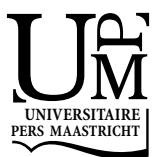




\section{Promotores}

Prof. dr. L.J. Zimmermann

Prof. dr. N.E.P. Deutz (University of Arkansas for Medical Sciences, USA)

\section{Copromotor}

Dr. K.F.M. Joosten (Erasmus Medisch Centrum, Rotterdam)

\section{Beoordelingscommissie}

Prof. dr. J. Zwaveling (voorzitter)

Prof. dr. H.N. Lafeber (Vrije Universiteit Medisch Centrum, Amsterdam)

Prof. dr. W.H. Lamers

Prof. dr. P.J.J. Sauer (Universitair Medisch Centrum, Groningen)

Prof. dr. P.B. Soeters

The study presented in this thesis is a research project of the Division of Pediatric Intensive Care, Department of Pediatrics, Maastricht University Medical Center and was performed within the Nutrition and Toxicology Research Institute Maastricht (NUTRIM), Maastricht University, The Netherlands. 


\section{TABLE OF CONTENTS}

$\begin{array}{lll}\text { Chapter } 1 \quad \text { General introduction } & 7\end{array}$

Chapter 2 Aspects of protein and amino acid metabolism in health and 15 during critical illness

Chapter 3 Assessment of whole body protein metabolism in critically ill children: can we use the $\left[{ }^{15} \mathrm{~N}\right]$ glycine single oral dose method?

Chapter $4 \quad$ Hyperglycemia in children with meningococcal sepsis and septic shock: the relation between plasma levels of insulin and inflammatory mediators

Chapter 5 Plasma arginine and citrulline concentrations In critically ill children: strong relationship with inflammation

Chapter 6 Nutritional effects of early administration of a protein and energy enriched formula in critically ill infants; a randomized controlled trial

Chapter 7 High protein and energy intakes promote anabolism in critically ill infants; a randomized controlled trial

Chapter 8 General discussion

Chapter 9 Summary and conclusions

Chapter 10 Samenvatting en conclusies

Dankwoord

Curriculum vitae

Publications 

CHAPTER 1

General introduction 
CHAPTER 1 
Adequate nutrition is an essential need of all children for survival, mental and motor development and for growth. When food supply is inadequate as is often the case in developing countries, due to socioeconomic, political or natural factors, primary malnutrition ensues, leading to high child morbidity and mortality.

In more developed countries primary malnutrition is an unusual event. Still, malnutrition is not uncommon in hospitalized children associated with underlying acute or chronic diseases and its prevalence and importance are often underappreciated. In critically ill children disease-related malnutrition may be present in $15-25 \%$ of all children admitted to a pediatric intensive care unit $(\mathrm{PICU})(1,2)$ and nutritional status has been shown to deteriorate during admission (3). Despite advances in medical care, prevalence of disease-related malnutrition did not change in these patients over the last 20 years or more (3).

Several studies of adult intensive care unit (ICU) patients have shown that diseaserelated malnutrition is associated with impaired wound healing, impaired immune response to infections, reduced gastrointestinal function, decreased function of muscles and an increase in morbidity and mortality (4-6). Also in children with (chronic) diseases inadequate feeding increases morbidity and mortality and negatively affects body composition and growth $(7,8)$. Critically ill children receiving better nutritional support show significant improvement in physiologic stability and outcome (9-11). There is also evidence for the importance of providing optimal nutritional support in conditions such as prematurity $(12,13)$ and pediatric burn injury (14).

Malnutrition and nutrient store depletion are particularly important in younger children because the ability to support and compensate for insufficient or unbalanced supplies is very limited due to small endogenous stores of a number of relevant substrates such as glycogen, fat and especially protein (15) while baseline requirements are higher. This is illustrated by the differences in expected survival time during total starvation between adults (60 to 70 days)(16), infants ( $<40$ days) and very low birth weight premature neonates $(<7$ days)(17). The supply and utilization of nutrients during the first 2 years of life are of greater biological relevance than during any other period of life. The quantity and quality of nutrient supply modulates the differentiation of tissues and organs and has short- and long-term effects for health and development. Immature metabolic pathways and physiological functions also play a role. This makes children more vulnerable and more dependent on the provision of adequate nutrition than adults. Studies have also associated proteinenergy malnutrition in infancy to decreased intelligence and neurological function $(18,19)$. Although a critical duration of nutritional deprivation has not been established, even infants undergoing relatively short periods of nutritional deprivation may have poorer learning abilities (20). Adequate nutritional support in order to prevent disease-related malnutrition should therefore play an important role in the clinical management of critically ill children both in acute illness and during recovery thereafter $(9,21,22)$. 
The major factors causing disease-related malnutrition in critically ill children are the protein catabolic response to injury and stress and the protein and energy deficits due to inadequate nutritional intake (39). Furthermore many children admitted to the PICU already have a history of disease or associated anomalies and show a high prevalence of malnutrition upon admission (3).

\section{The protein catabolic response to injury}

Critical illness is characterized by increased (muscle) protein breakdown, negative nitrogen balance and loss of lean body mass $(23,24)$. This protein catabolic response can be seen as an adaptation to severe stress and injury in order to secure or promote an optimal supply of amino acids to other organs to serve as substrates for gluconeogenesis and synthesis of acute phase proteins in the liver, as substrates for synthesis of proteins necessary for immune defense and wound repair and to serve as energy substrates for fast replicating cells such as immune cells and enterocytes $(25,26)$. In severe or prolonged critical illness, the increased protein degradation may lead to extensive muscle wasting with negative clinical consequences. Studies of critically ill adults have shown that up to $20 \%$ of total body protein may be lost in 3 weeks, most during the first 10 days after injury (4). Animal studies and observations in starving human beings have shown that loss of $>25 \%$ of total body nitrogen can be fatal. Biochemical measurements of cellular proliferation and inflammatory response are impaired after only 7 days of protein restriction after injury (27). Even a 10-15\% loss in lean body mass can lead to significant increases in infection rate (28), marked delay in wound healing (29) and delayed weaning from mechanical ventilation (30). Furthermore, persistent protein catabolism after large burn injury in children can result in growth delay for up to 2 years (31).

The protein catabolic response to severe injury and stress is induced by changes in the (neuro)endocrinological system and the immune system. Hallmarks of this response are an increased activity of the sympathetic system and changes in hormonal balance with increased secretion of catabolic hormones (adrenalin, glucagon and cortisol) and resistance to the activity of anabolic hormones (insulin and growth hormone). Proinflammatory cytokines (e.g. TNF- $\alpha$, IL-1 and IL-6) also play important roles. Although the nature of the response is uniform regardless of the cause, the extent and duration of the metabolic disturbances vary with the type and severity of the injury $(32,33) 35)$. In contrast to the wealth of studies of critically ill adults, considerably less knowledge exists about the pathophysiology of the protein catabolic response induced by critical illness in children (34). Also the role of nutritional support on this response is not well defined. Although the metabolic responses to stress and injury in children may qualitatively resemble the adult (35), important quantitative differences have also been described $(36,37)$. 


\section{Inadequate nutritional intake}

Inadequate nutritional intake is the second important factor causing disease-related malnutrition in critically ill children. Children admitted to the ICU have been shown to accumulate substantial energy and protein deficits compared to estimated requirements and these deficits are associated with decreases in anthropometric parameters and outcome $(3,38)$. Inadequate nutritional intake is most frequently caused by inadequate prescription and/or delivery of nutrients (39).

\section{Inadequate prescription}

Protein and energy requirements of critically ill children are not well established but may be significantly different from those of healthy children. Requirements may also depend on the nature and severity of the injury (35). In practice, the estimated protein need of children, admitted to a pediatric intensive care unit, is most frequently based on recommended dietary allowances (RDA) of healthy children with adaptations to account for increased nitrogen loss during disease states. However the validity of these adaptations is not well defined. Estimated energy needs, on the other hand, are most often based on predictive equations $(40,41)$. These predictive equations however have been shown to estimate individual energy needs incorrectly, especially in disease states, when compared with the measurement of energy expenditure using indirect calorimetry $(42,43)$. Due to the problems in assessing nutritional needs, many PICUs work with feeding protocols based on (estimated) body weight and predictive equations which are applied to all patients (44). Therefore, the prescription of calories and protein is not individualized and discrepancies between required and prescribed nutritional intake inevitably occur. Another important cause of inadequate prescription of nutritional intake is the restriction of the volume of enteral nutrition by the treating physician in order to compensate for the large volumes of fluids for drugs and intravenous infusions these children invariably receive. Since standard enteral formulas are most often used initially, this leads to an extended period of low caloric and protein intake especially in the first week(s) of admission $(21,45)$. A third cause of inadequate nutritional intake is the unfounded belief of many physicians and nursing staff that most critically ill children cannot tolerate significant amounts of enteral feeding shortly after admission and that enteral nutrition should be introduced very slowly in all patients. This too leads to unnecessary protein and energy deficits in the first days of admission.

\section{Inadequate delivery}

Important factors for inadequate delivery are interruption of feeds for medical or nursing interventions and for increased gastric retentions (38). These will not be further discussed in this thesis. 


\section{CONCLUSIONS}

Disease-related malnutrition is a frequent finding in critically ill children and is associated with adverse outcome. Important causes are the protein catabolic response to injury and stress combined with inadequate nutritional intake. To prevent malnutrition and improve outcome more insight is necessary into the alterations in protein and amino acid metabolism and the role of nutritional support in critically ill children in the acute phase of disease and during recovery.

\section{REFERENCES}

1. Pollack MM, Wiley JS, Holbrook PR. Early nutritional depletion in critically ill children. Crit Care Med 1981;9:580-3.

2. Merritt RJ, Suskind RM. Nutritional survey of hospitalized pediatric patients. Am J Clin Nutr 1979;32:13205.

3. Hulst J, Joosten K, Zimmermann L, et al. Malnutrition in critically ill children: from admission to 6 months after discharge. Clin Nutr 2004;23:223-32.

4. Biolo G, Toigo G, Ciocchi B, et al. Metabolic response to injury and sepsis: changes in protein metabolism. Nutrition 1997; 13:52S-57S.

5. Lochs H, Pichard C, Allison SP. Evidence supports nutritional support. Clin Nutr 2006;25:177-9.

6. Pichard C, Kyle UG, Morabia A, Perrier A, Vermeulen B, Unger P. Nutritional assessment: lean body mass depletion at hospital admission is associated with an increased length of stay. Am J Clin Nutr 2004;79:6138.

7. Motil KJ, Matthews DE, Bier DM, Burke JF, Munro HN, Young VR. Whole-body leucine and lysine metabolism: response to dietary protein intake in young men. Am J Physiol 1981;240:E712-21.

8. Stettler N, Kawachak DA, Boyle LL, et al. A prospective study of body composition changes in children with cystic fibrosis. Ann N Y Acad Sci 2000;904:406-9.

9. Pollack MM, Ruttimann UE, Wiley JS. Nutritional depletions in critically ill children: associations with physiologic instability and increased quantity of care. JPEN J Parenter Enteral Nutr 1985;9:309-13.

10. Briassoulis G, Zavras N, Hatzis T. Malnutrition, nutritional indices, and early enteral feeding in critically ill children. Nutrition 2001;17:548-57.

11. Chaloupecky V, Hucin B, Tlaskal T, et al. Nitrogen balance, 3-methylhistidine excretion, and plasma amino acid profile in infants after cardiac operations for congenital heart defects: the effect of early nutritional support. J Thorac Cardiovasc Surg 1997;114:1053-60.

12. te Braake FW, van den Akker CH, Wattimena DJ, Huijmans JG, van Goudoever JB. Amino acid administration to premature infants directly after birth. J Pediatr 2005;147:457-61.

13. Dunn L HS, Weiner J, et al. Beneficial effects of early hypocaloric enteral feeding on neonatal gastrointestinal fucntion: Preliminary report of a randomized trial. J Pediatr 1988;112:622-629.

14. Alexander JW, MacMillan BG, Stinnett JD, et al. Beneficial effects of aggressive protein feeding in severely burned children. Ann Surg 1980;192:505-17.

15. Cunningham JJ. Body composition and nutrition support in pediatrics: what to defend and how soon to begin. Nutr Clin Pract 1995;10:177-82.

16. Allison SP. The uses and limitations of nutritional support The Arvid Wretlind Lecture given at the 14th ESPEN Congress in Vienna, 1992. Clin Nutr 1992;11:319-30.

17. Heird WC, Driscoll JM, Jr., Schullinger JN, Grebin B, Winters RW. Intravenous alimentation in pediatric patients. J Pediatr 1972;80:351-72.

18. Winick M. Malnutrition and brain development. J Pediatr 1969;74:667.

19. Pollitt E, Saco-Pollitt C, Jahari A, Husaini MA, Huang J. Effects of an energy and micronutrient supplement on mental development and behavior under natural conditions in undernourished children in Indonesia. Eur J Clin Nutr 2000;54 Suppl 2:S80-90.

20. Klein P, Forbes G, Nader P. Effects of starvation in infancy (pyloric stenosis) on subsequent learning abilities. J Pediatr 1975;87:8-15.

21. Taylor RM, Preedy VR, Baker AJ, Grimble G. Nutritional support in critically ill children. Clin Nutr 2003;22:365-9. 
22. Chwals WJ. Overfeeding the critically ill child: fact or fantasy? New Horiz 1994;2:147-55.

23. Cuthbertson DP. Observations on the disturbance of metabolism produced by injury to the limbs. Quaterly Journal of Medicine 1932;1:223-246.

24. Beisel WR. Magnitude of the host nutritional responses to infection. Am J Clin Nutr 1977;30:1236-47.

25. Mitch WE, Goldberg AL. Mechanisms of muscle wasting. The role of the ubiquitin-proteasome pathway. N Engl J Med 1996;335:1897-905.

26. Rosenblatt S, Clowes GH, Jr., George BC, Hirsch E, Lindberg B. Exchange of amino acids by muscle and liver in sepsis. Arch Surg 1983;118:167-75.

27. Kinney JM, Elwyn DH. Protein metabolism and injury. Annu Rev Nutr 1983;3:433-66.

28. Windsor JA, Hill GL. Risk factors for postoperative pneumonia. The importance of protein depletion. Ann Surg 1988;208:209-14.

29. McClave SA, Mitoraj TE, Thielmeier KA, Greenburg RA. Differentiating subtypes (hypoalbuminemic vs marasmic) of protein-calorie malnutrition: incidence and clinical significance in a university hospital setting. JPEN J Parenter Enteral Nutr 1992;16:337-42.

30. Christensen $\mathrm{T}$, Bendix $\mathrm{T}$, Kehlet $\mathrm{H}$. Fatigue and cardiorespiratory function following abdominal surgery. Br J Surg 1982;69:417-9.

31. Rutan RL, Herndon DN. Growth delay in postburn pediatric patients. Arch Surg 1990;125:392-5.

32. Tashiro T, Yamamori H, Takagi K, Morishima Y, Nakajima N. Effect of severity of stress on whole-body protein kinetics in surgical patients receiving parenteral nutrition. Nutrition 1996;12:763-5.

33. Campbell IT. Limitations of nutrient intake. The effect of stressors: trauma, sepsis and multiple organ failure. Eur J Clin Nutr 1999;53 Suppl 1:S143-7.

34. Bodamer OA, Leonard JV, Tasker RC, Hoffmann GF, Halliday D. Protein turnover in critically ill children. Eur J Pediatr 1997; 156 Suppl 1:S59-61.

35. Agus MSD, Jaksic T. Nutritional support of the critically ill child. Current Opinion In Pediatrics 2002; $14: 470$.

36. Joosten KF, de Kleijn ED, Westerterp M, et al. Endocrine and metabolic responses in children with meningoccocal sepsis: striking differences between survivors and nonsurvivors. J Clin Endocrinol Metab 2000;85:3746-53.

37. Zamir O, Hasselgren PO, Frederick JA, Fischer JE. Is the metabolic response to sepsis in skeletal muscle different in infants and adults? An experimental study in rats. J Pediatr Surg 1992;27:1399-403.

38. Hulst JM, van Goudoever JB, Zimmermann LJ, et al. The effect of cumulative energy and protein deficiency on anthropometric parameters in a pediatric ICU population. Clin Nutr 2004;23:1381-9.

39. Hulst JM, Joosten KF, Tibboel D, van Goudoever JB. Causes and consequences of inadequate substrate supply to pediatric ICU patients. Curr Opin Clin Nutr Metab Care 2006;9:297-303.

40. Schofield WN. Predicting basal metabolic rate, new standards and review of previous work. Hum Nutr Clin Nutr 1985;39 Suppl 1:5-41.

41. White MS, Shepherd RW, McEniery JA. Energy expenditure in 100 ventilated, critically ill children: improving the accuracy of predictive equations. Crit Care Med 2000;28:2307-12.

42. Vazquez Martinez JL, Martinez-Romillo PD, Diez Sebastian J, Ruza Tarrio F. Predicted versus measured energy expenditure by continuous, online indirect calorimetry in ventilated, critically ill children during the early postinjury period. Pediatr Crit Care Med 2004;5:19-27.

43. Verhoeven JJ, Hazelzet JA, van der Voort E, Joosten KF. Comparison of measured and predicted energy expenditure in mechanically ventilated children. Intensive Care Med 1998;24:464-8.

44. van der Kuip M, Oosterveld MJ, van Bokhorst-de van der Schueren MA, de Meer K, Lafeber HN, Gemke RJ. Nutritional support in 111 pediatric intensive care units: a European survey. Intensive Care Med 2004;30:1807-13.

45. Rogers EJ, Gilbertson HR, Heine RG, Henning R. Barriers to adequate nutrition in critically ill children. Nutrition 2003;19:865-8. 



\section{CHAPTER 2}

Aspects of protein and amino acid metabolism in health and during critical illness 
CHAPTER 2 


\section{GENERAL}

Proteins form the major structural components of all cells in the body and also function as enzymes, in membranes, as transport carriers and as hormones. Their component amino acids serve as precursors for nucleic acids, peptide hormones, vitamins, and also as substrates for gluconeogenesis in the liver and as energy substrates for enterocytes and immune cells. Within the body, the bulk of proteins are present in the skeletal muscles (40-45\%) especially as myofibrillary proteins. Visceral tissues contain comparatively small amounts of protein (about $10 \%$ of the total) (1). Dietary proteins play an important role during health and disease. Dietary proteins are a source of energy but, more importantly, deliver the essential amino acids needed to synthesize proteins and nitrogen containing molecules that are necessary for the maintenance and growth of tissue, for the immune response and for recovery from injury and disease. Twenty different amino acids are used for protein synthesis and several others exist in the body (e.g. citrulline, ornithine). Amino acids can be classified as non-essential, essential and conditionally essential based upon the need for them to be supplied in the diet (see Table 1). The non-essential amino acids are those that can be synthesized within the body. Conditionally essential amino acids can be endogenously synthesized but become deficient when pathology modifies or impairs protein and amino acid metabolism and synthesis cannot meet the metabolic need.

Table 1

\begin{tabular}{|c|c|c|}
\hline Essential & Non essential & Conditionally essential \\
\hline Histidine & Alanine & Arginine (neonates, critical illness) \\
\hline Isoleucine & Aspartic acid & Glutamine (critical illness) \\
\hline Leucine & Asparagine & Cysteine (prematurity) \\
\hline Lysine & Glutamic acid & Glycine (neonates) \\
\hline Methionine & Serine & Proline (critical illness) \\
\hline Phenylalanine & & Tyrosine \\
\hline \multicolumn{3}{|l|}{ Threonine } \\
\hline \multicolumn{3}{|l|}{ Tryptophan } \\
\hline Valine & & \\
\hline
\end{tabular}

The nutritional quality of dietary protein depends on its amino acid composition, ideally approaching the amino acid composition of human proteins as much as possible. Restriction in the availability of even a single (essential) amino acid can limit the rate of whole body protein synthesis (2). In the human body proteins have no storage form (like glycogen and fat) but all have a biological function. Net protein breakdown (due to starvation or disease) therefore inevitably results in loss of function and preservation of body protein in adults and protein accretion during growth in children is an important goal both in health and disease. 


\section{PROTEIN METABOLISM}

\section{Protein turnover}

All proteins in the body undergo a continuous turnover, meaning that they are part of a constant cycle of protein synthesis and breakdown. The exchange between body protein and the free amino acid pool is illustrated in a simplified scheme in Figure 1.

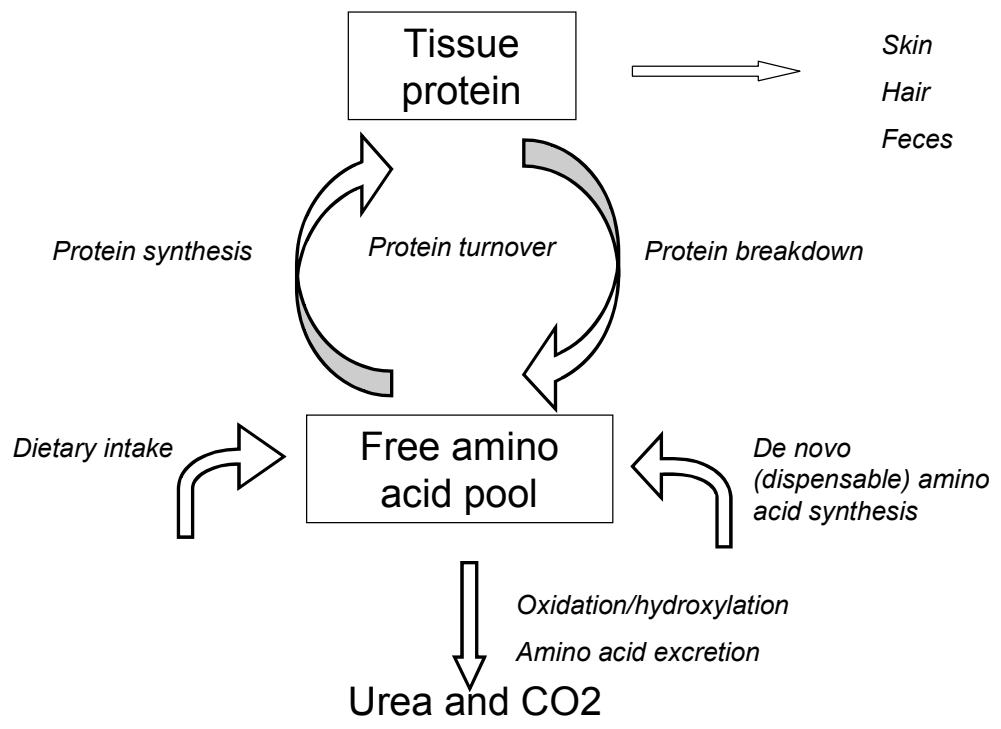

Figure 1 Two pool model of protein and amino acid metabolism

Apart from protein synthesis and breakdown, amino acids enter or leave the free amino acid pool by processes like dietary amino acid intake and de novo amino acid synthesis, urinary amino acid excretion and amino acid oxidation with urea production. The protein turnover rate signifies the rate by which body proteins are continuously broken down and resynthesized (adults $250 \mathrm{~g}$ protein/24h compared to an intake of 50-100 g protein/24h (3)). In infants and children the relative rates of protein turnover are increased compared to those of adults and gradually decrease with age (4). The rate of protein synthesis or breakdown can differ from one protein to the other by several fold. For instance gut mucosal proteins show high turnover while skeletal myofibrillary proteins show low rates of turnover (5). Protein metabolism also varies from one tissue or organ to another (6). The continuous destruction and rebuilding of body proteins may appear to be wasteful but serves several functions: cells selectively degrade proteins with abnormal conformation, degradation of regulatory proteins is necessary for control of metabolic pathways, and breakdown of (muscle) proteins during starvation or in response to infection or stress provides 
necessary amino acids for energy and protein synthesis in other parts of the body $(7$, 8). Physiological (e.g. postabsorptive vs. the postprandial state) and pathophysiologic processes (e.g. protein catabolism during severe illness) have an influence on the rates of these fluxes, leading to changes in protein (and nitrogen) balance depending on the direction and extent of these processes.

\section{Protein synthesis}

Protein synthesis starts with the transcription of genetic information from DNA to messenger RNA (mRNA) and translation of mRNA on ribosomes involving transferRNA (tRNA). Protein synthesis takes place in the cytoplasm or endoplasmatic reticulum of nucleated cells. The translation process consists of three stages: initiation, elongation and termination. The initiation step of translation is the most important step for the regulation of the rate of protein synthesis. The initiation complex is formed when the ribosome assembles on the mRNA in the presence of various eukaryotic initiation factors (elF). The ribosome moves down the mRNA to the start AUG codon and forms the $70 \mathrm{~S}$ initiation complex. Each amino acid has a specific aminoacyl tRNA synthetase, which catalyses the binding of the amino acid to an acceptor site on the tRNA, forming aminoacyl tRNA; this complex carries the amino acid to the ribosome, where it binds and is committed for protein synthesis (methionine is always incorporated first). Elongation involves the binding of subsequent aminoacyl-tRNA complexes. The ribosome moves one codon down the mRNA and the process is repeated. The protein is released when a stop codon is reached (termination). Protein synthesis is predominantly regulated by plasma concentrations of amino acids and hormones (especially insulin and glucocorticosteroids).

\section{Protein breakdown}

Protein breakdown occurs in three systems, the lysosomal system, the ATPdependent ubiquitine-proteasome system and the calcium-calpaine dependent system $(7,9)$.

Lysosomal protein breakdown is most actively expressed in the liver. Extracellular proteins (e.g. plasma lipoproteins or hormones) undergo endocytosis and are completely degraded within lysosomes while the same holds true for cell-membrane proteins. Some cytosolic proteins are degraded by being engulfed in autophagic vacuoles that fuse with lysosomes. Lysosomal proteolysis is regulated by hormones such as insulin, glucagon and glucocorticosteroids, and by amino acids (10).

The ATP-dependent ubiquitin-proteasome pathway degrades intracellular proteins. In this pathway, proteins targeted for degradation are conjugated to multiple molecules of ubiquitin. The ubiquitination of proteins is regulated by three sets of enzymes. The ubiquitinated proteins are recognized and degraded by a large proteolytic complex, the $26 \mathrm{~S}$ proteasome. The $26 \mathrm{~S}$ proteasome consists of a central proteolytic core (20S proteasome) and the capping 195 subunit. The 19S subunit recognizes, binds and unfolds the substrate protein that is then passed through the interior of the $20 \mathrm{~S}$ proteasome while it is degraded into peptides. In skeletal muscle, the ubiquitinproteasome system is regarded to be the main proteolytic pathway for bulk proteoly- 
sis. However the ubiquitin-proteasome may not be able to degrade intact myofibrils and the myofibrillary proteins, myosin and actin, must first be released from the sarcomere before they can be ubiquinated and degraded (9). A calcium-calpaine dependent release of these proteins from the sarcomere may therefore be an important and possibly also rate limiting step in muscle proteolysis. The ubiquitinproteasome system itself is not dependent on insulin and amino acids under healthy circumstances (basal conditions or after meals)(7). The findings that protein feeding (11) and even feeding leucine alone (12) can reduce muscle protein degradation in animals therefore suggest that lysosomes may also play a role in the proteolysis of myofibrillary proteins.

\section{Amino acid oxidation}

Amino acid oxidation occurs predominantly in the liver. In this process amino acids first loose their amino group by the process of deamination or transamination. Transamination is a reversible reaction that transfers the amino nitrogen to a ketoacid like pyruvate, oxaloacetate and $\alpha$-ketoglutarate. The carbon skeleton then can enter the Krebs cycle or can be used for synthesis of glucose, non-esterified fatty acids (NEFA) or ketones while the amino group enters the urea cycle with formation of urea that is subsequently excreted by the kidney. Deamination involves several processes in which amino acids (for instance glutamine and asparagine) lose their amino nitrogen to the formation of ammonia, which is also excreted by the kidney.

\section{Whole body protein metabolism (Wb-PM)}

\section{Wb-PM in health}

Whole body protein metabolism (Wb-PM) represents the average of the individual rates of protein synthesis and breakdown in all the tissues of the body. This overall rate is of physiological importance and can be expressed as whole body protein turnover (Wb-PT), synthesis (Wb-PS) and breakdown (Wb-PB). One of the principal goals of measuring $\mathrm{Wb}-\mathrm{PM}$ is to determine the protein balance ( $\mathrm{Wb}-\mathrm{PBal})$, meaning the rate of synthesis minus the rate of breakdown, that determines if an individual gains (as in children during growth), loses (as in catabolic states) or maintains lean body mass. In healthy adult human subjects, ingesting adequate amounts of dietary protein, protein synthesis equals protein breakdown on a $24 \mathrm{~h}$ basis implying that $\mathrm{Wb}$-PBal is zero. In (growing) children, Wb-PBal is positive since growth consists in a large part of protein deposition in the body. Whole body protein metabolism also varies as a consequence of food intake. After a meal there is a net accumulation of protein, whereas in the post-absorptive state a net loss of protein takes place.

\section{Wb-PM during critical illness}

Following injury or sepsis the absolute and relative rates of whole body protein synthesis and breakdown change. In general critical illness is characterized by a negative protein balance meaning that protein breakdown exceeds protein synthesis. The way protein is lost and the degree of protein loss however depends on the 
duration and severity of the injury (13). A minor injury (minor surgery) results in a depression of protein synthesis while breakdown is unaltered $(14,15)$ which results in net protein loss. With more severe injury the rate of protein breakdown strongly increases. Whole body protein synthesis however increases but to a lesser degree leading to net protein loss that further increases with the severity of injury (16). Although only few studies were performed in critically ill infants similar alterations in whole body protein metabolism were found in children with burn injury (17), severe malaria (18) and in infants with sepsis (19).

\section{Tissue protein metabolism}

Measurement of whole body protein metabolism does not give information on the relative contribution of various tissues and proteins. Of these tissues skeletal muscle and splanchnic protein metabolism are especially important and will be further discussed below. Both skeletal muscle and splanchnic protein metabolism are profoundly affected by many physiological conditions such as feeding, fasting, and disease states.

\section{Muscle protein metabolism in health}

Skeletal muscle is the largest tissue of the human body and forms the largest mass of protein ( $40 \%$ of body weight)(6). The main function of skeletal muscle is to provide power for locomotion. In addition, it has an important metabolic role. Skeletal muscle is the major reservoir of protein and free amino acids in the body.

Fasting is characterized by net muscle protein degradation under influence of alterations in plasma concentrations of amino acid and hormones (especially those of insulin and glucocorticosteroids). This results in a net amino acid efflux to the plasma predominantly the gluconeogenic amino acids glutamine and alanine. Alanine is taken up by the liver, stimulated by increased glucagon levels, and used for gluconeogenesis. Glutamine is used by the kidneys for gluconeogenesis and ammonia formation and also as energy substrate by the intestinal cells. Around $1.75 \mathrm{~g}$ of muscle protein must be broken down to provide each gram glucose since not all amino acids can be converted to glucose and are oxidized causing irreversible protein loss (6). During starvation not only the protein of muscle tissue is broken down since the protein content of the visceral organs also decreases with $40 \%$ (20).

After a protein containing meal plasma amino acid concentrations increase, especially those of the branched chain amino acids (BCAA) since they are relatively spared from first pass splanchnic metabolism. The BCAAs are preferentially taken up by muscle cells, primarily stimulated by their own plasma concentrations and not by insulin. In combination with increased plasma insulin levels and decreased glucagon and cortisol levels, the increased BCAA availability also stimulates muscle protein synthesis while muscle protein breakdown is suppressed leading to a net muscle protein synthesis. BCAA are also oxidized to generate energy for the muscle. 


\section{Muscle protein metabolism during critical illness}

During critical illness muscle protein metabolism is characterized by net protein degradation leading to muscle protein loss and muscle wasting $(8,21)$. Muscle protein loss is primarily caused by an increased breakdown of myofibrillary proteins due to activation of the ubiquitin-proteasome pathway $(22,23)$. Activation of this pathway occurs through increased plasma levels of catabolic hormones (glucocorticosteroids) and inflammatory cytokines (TNF alpha and IL-1 via activation of NF- $\mathrm{KB}$ ) (24) whose plasma levels are elevated during critical illness. The catabolic effect of glucocorticosteroids is further potentiated by bed rest (25). The primary involvement of the ubiquitin-proteasome may explain why muscle protein breakdown during critical illness responds poorly to nutritional interventions. The net muscle protein degradation combined with an inhibited uptake of amino acids by the muscles results in an net efflux of amino acids from muscle (predominantly glutamine and alanine) which supplies the substrates for the increased gluconeogenesis in the liver, hepatic acute phase protein synthesis and the increased protein synthesis in several other organs (liver, spleen, kidney, jejunum, diaphragm, lung and skin) (7, 8, 26, 27). Furthermore, glutamine is used as energy substrate by the enterocytes and other fast replicating cells like immune cells (lymphocytes and macrophages) (2).

Skeletal muscle protein synthesis is decreased during critical illness in adult and neonatal animals (both of myofibrillary and sarcoplasmatic proteins) which may be due to an inhibitory effect of TNF-a and IL-1 on mRNA translation initiation and muscle amino acids uptake $(26,28)$. Protein synthesis may also be decreased due to low IGF-1 levels and absence of a stimulatory effect of insulin due to insulin resistance (29). In septic neonatal pigs however muscle protein synthesis is less decreased than in adult animals and can still be stimulated by insulin and amino acids (34). Evidence also exists of resistance to the anabolic effects of leucine during sepsis probably through a combined effect of TNF-a and glucocorticosteroids. This may explain the disappointing results of clinical trials using nutritional support enriched with branched chain amino acids for instance in trauma patients (30). Similar to results in animal studies, a decreased muscle protein synthetic rate was also found in studies of adults after major surgery $(31,32)$ and in a heterogeneous group of ICU patients (33).

\section{Splanchnic protein metabolism in health}

The splanchnic organs (especially the liver and gut) play an important role in protein and amino acid metabolism although they contain only $10 \%$ of total body protein (1). After a protein containing meal the splanchnic organs extract essential and nonessential amino acids from the diet for their own requirements thereby reducing amino acid availability for the systemic circulation (first-pass splanchnic utilization of dietary amino acids). Studies using isotopically labeled amino acids have investigated utilization rates of various amino acids in animal, adults and neonates under different conditions (see for review $(35,36)$ ). First-pass utilization approaches $50 \%$ of dietary amino acids, the large majority by the gut, and differs significantly among the various amino acids (25-96\%) (37-39). In neonates utilization rates are higher than in adults (35). A large part of these amino acids are used for the synthesis of mucosal and 
secretory proteins (40), synthesis of other amino acids (like citrulline, arginine and proline) and glutathione (36) but amino acids are also used as energy substrates with concomitant irreversible oxidation to $\mathrm{CO}_{2}$, urea and ammonia (41). In the fed state both arterial and luminal amino acids are used simultaneously. Luminal glutamate and aspartate and arterial glutamine account for the majority of the energy generated in the small intestine (42) although essential amino acids such as lysine and leucine and also glucose play a significant role as fuel source. Almost one third of dietary glucose is utilized during first pass by the splanchnic tissues, irrespective of the amount of dietary intake, and used for energy generation (43). Since dietary amino acids are the primary source of amino acids for the intestinal mucosa, enteral feeding is obligatory for maintaining of intestinal mucosal mass and integrity and for recovery after mucosal damage.

It is often assumed that during fasting conditions protein breakdown and efflux of amino acids for gluconeogenesis and protein synthesis occurs predominantly in muscle tissue. The fractional synthesis rate of muscle, i.e. the percentage of the total muscle protein pool that is newly synthesized per day, is very low and therefore protein renewal after a meal can only occur in muscle to a limited degree (44). It is much more likely that protein accumulation after a meal takes place in the so-called "labile pool" of the splanchnic area, because the fractional synthesis rate is much higher (45). The splanchnic organs thus may play an important buffering role by preventing major plasma amino acid variations and in delivering amino acids for gluconeogenesis and meeting metabolic needs in peripheral tissues during non-fed conditions. Albumin synthesis in the liver for instance is stimulated during feeding and this increased synthesis may play an important role in the temporary "storage" of ingested essential amino acids in this labile pool (46) and in preventing irreversible losses of a significant fraction of ingested essential amino acids while it may also serve as a vehicle to capture excess dietary amino acids and transport them to peripheral tissues to sustain local protein synthesis. Furthermore the gut is able to release amino acids in the portal vein by increased proteolysis and by arterial amino acid uptake and thereby has the capacity to channel amino acids via the portal vein toward the liver for metabolism. By these actions intestinal amino acid metabolism has a strong influence on the pattern of amino acids entering the portal circulation (41) that differs markedly from that in the diet and on the pattern and amount of amino acids available for peripheral utilization.

\section{Splanchnic protein metabolism during critical illness}

During critical illness hepatic uptake of amino acids is stimulated and protein synthesis and gluconeogenesis in the liver are enhanced. Net hepatic protein synthesis is increased due to an increased synthesis of acute phase proteins $(27,47)$ induced by proinflammatory cytokines $(8,21)$. Acute phase proteins are proteins with a variety of immunological, transport and haemostatic functions. The increase in synthesis of these proteins may even be far greater than the change in plasma concentration (see for reference Obled et al. (48). For instance, the synthesis of albumin is enhanced (47) while the plasma concentration decreases in sepsis. The increase in hepatic acute phase synthesis is the major cause of the increased whole body protein synthesis 
during critical illness illustrated by the finding \% in polytrauma patients that the contribution of total plasma proteins to whole body protein synthesis is greatly increased from $7.2 \%$ in healthy volunteers to 15.5 (48).

\section{REGULATION OF PROTEIN METABOLISM}

Protein metabolism in health and during disease is predominantly regulated by substrate availability and hormonal concentrations while during disease the proinflammatory mediators also play important roles.

\section{Substrate availability}

\section{Plasma amino acid concentrations}

An increase in the plasma concentrations of essential amino acids is the most important factor stimulating muscle protein synthesis (muscle PS) (50). Although muscle PS takes place in the cytoplasm or endoplasmatic reticulum, extracellular amino acid concentrations serve as signals to activate protein synthesis although it is not known how amino acid availability is sensed by the cell. Once synthesis is activated this results in increased rate of inward transport of amino acids. Non-essential amino acids are not needed for the stimulation of muscle PS. The response to increased amino acid availability however may be time dependent. During a continuous intravenous amino acid infusion the rate of muscle PS has been shown to rapidly rise but to decrease again after 2 hours (68). Anthony et al. (69) further showed that leucine is the most potent of the (branched chain) amino acids in stimulating muscle PS. Other amino acids also stimulate muscle PS but significantly less effective. Leucine has no effect on global rates of protein synthesis in the liver suggesting that the regulatory role of leucine may be specific for the muscle.

Lysosomal proteolysis in the liver is also controlled by extracellular plasma amino acids concentrations, especially those of leucine, tyrosine, phenylalanine, glutamine, histidine, tryptophan, proline and methionine, also called regulatory amino acids, with alanine as a co-regulatory amino acid. Amino acid availability regulates lysosomal proteolysis in a suppressive manner, meaning that high plasma amino acid levels inhibit proteolysis in the liver and low amino acid levels stimulate proteolysis (70).

During critical illness the plasma and tissue concentration of most amino acid are decreased. This is especially true for the intracellular amino acid concentrations but also the large majority of plasma amino acids show a decline in concentration (71). The decrease in plasma amino acid concentrations occurs early during critical illness. In general it is believed that these changes are a reflection of starvation due to limited nutritional protein supply, increased hepatic utilization for acute-phase protein synthesis, gluconeogenesis and oxidation for energy supply $(27,71)$ and protein synthesis in immune cells. These changes persist as long as the infection persists and resolve during recovery. 


\section{Energy intake}

Energy intake has an important influence on protein metabolism. When energy intake is lower than energy expenditure (negative energy balance) either due to an inadequate dietary intake or an increased energy expenditure, catabolism of body energy stores occurs including increased breakdown of muscle protein (72-74). After deamination or transamination the carbon skeletons of amino acids are then used to meet energy needs (80). The famous Minnesota study in 1950 already showed that healthy volunteers develop substantial lean tissue loss during energy restriction despite adequate protein consumption (75).

When energy intake exceeds energy expenditure proteins are deposited in association with weight gain and development of adiposity leading to a positive nitrogen balance. In children the influence of energy intake on protein and amino acid requirements is more complex since the relationship between energy intake and protein accretion is strongly influenced by the rate of protein deposition as a consequence of growth. In studies of growing animals positive nitrogen balance could even be achieved in negative energy balance (76) while in growing children provision of extra protein can stimulate height growth at the expense of mobilization of body fat stores (77).

The type of energy does not influences protein utilization. Although carbohydrates are thought to be more insulinogenic and thereby more effective in stimulating protein utilization, carbohydrates and fat have been shown to be equally effective in maintaining nitrogen balance or growth in both adults and children when energy intake is sufficient (73). In fact dietary fat also stimulates insulin secretion by increasing plasma non esterified fatty acid concentrations (NEFA) (78) and by stimulation of glucose dependent insulinotropic polypeptide (GIP) (79).

\section{Dietary carbohydrate and fat intake}

Carbohydrates and fat alone have no direct effect on muscle protein synthesis but exert important influences on protein metabolism by their energy content and their hormonal effects for instance on glucagon and especially insulin secretion (73).

\section{Hormones}

\section{Insulin}

Secretion of insulin by pancreatic $\beta$-cells is primarily stimulated by increased plasma concentrations of glucose and amino acids, especially the branched chain amino acids (leucine, isoleucine, valine), leucine being the most potent (49). Insulin is an important factor stimulating muscle protein synthesis but only in the presence of sufficient extracellular amino acids meaning that both insulin and amino acids are required for maximal stimulation of muscle protein synthesis (50). Insulin also has a direct inhibitory effect on muscle protein breakdown (51) by an effect on lysosomal proteolysis (10) and by opposing the stimulating effect of glucocorticosteroids on proteolysis by the ubiquitin-proteasome system $(51,53)$. The ubiquitin-proteasome system itself is not dependent on insulin and amino acids under normal circumstances (basal conditions or after meals). 


\section{Glucocorticosteroids}

Glucocorticosteroids are produced in the adrenal cortex and their synthesis and secretion are regulated by adrenocorticotropic hormone (ACTH) from the anterior pituitary. Plasma glucocorticosteroid concentrations are increased during fasting conditions and during stress such as critical illness. Glucocorticosteroid treatment of rats prevents the stimulation of muscle protein synthesis that occurs in response to infusion of insulin and amino acids (52). Glucocorticosteroids activate the ubiquitinproteasome proteolytic system in skeletal muscle during fasting (53) but the catabolic effects of glucocorticosteroids are opposed by insulin (51). Thus, the activation of muscle proteolysis in the fasting state requires two signals: the presence of glucocorticosteroids and a decrease in insulin.

During injury and stress the increased levels of proinflammatory cytokines (TNF and IL-1) stimulate secretion of ACTH in the pituitary gland resulting in increased plasma glucocorticosteroid levels $(54,55)$. The increased plasma levels of glucocorticosteroids together with increased levels of proinflammatory cytokines activate the ubiquitin-proteasome pathway leading to muscle proteolysis (24). Indeed, in catabolic conditions, glucocorticosteroids are considered to be an important regulator of muscle protein mass (56).

\section{Glucagon}

Glucagon secretion is stimulated by low plasma glucose and amino acid concentrations. It exerts its effect predominantly in the liver and muscle cells contain a paucity of glucagon receptors. In the liver glucagon stimulates gluconeogenesis and also stimulates hepatic extraction of circulating amino acids. Critical illness in adults is associated with increased plasma glucagon levels.

\section{Plasma catecholamines}

Epinephrine and norepinephrine are secreted by the adrenal medulla under direct control of the brain. Catecholamines produce anabolic, protein sparing effects on skeletal muscle protein metabolism by an inhibitory effect on muscle calciumcalpaine dependent protein degradation, independently of other hormones (58). In addition, norepinephrine released from adrenergic terminals of the nerves may increase the rate of muscle protein synthesis, leading to increased protein accretion. These effects seem to be mediated by $\beta 2$-adrenoreceptors and cAMP-dependent pathways (58). Immediately after injury, there is a 10 -fold increase in plasma catecholamine concentrations. This produces a hyperdynamic circulation, increases basal energy expenditure, glycogenolysis and hepatic glucose production (59).

\section{Human Growth hormone (HGH)}

$\mathrm{HGH}$, synthetized and secreted by the pituitary, is the major physiologic stimulus for IGF-1 and IGF-2 production in the liver. Many of the actions of $\mathrm{HGH}$ are mediated through IGF-1. HGH stimulates protein synthesis in muscle and on the whole body level by increasing IGF-1 concentrations. Stress and critical illness in adults are associated with increased plasma $\mathrm{HGH}$ levels and $\mathrm{HGH}$ resistance (60). In critically ill 
children low, normal and high values for $\mathrm{HGH}$ have been reported while very high levels were found in non-surviving children with meningococcal sepsis $(61,62)$.

\section{Insulin like growth factor-1 (IGF-1)}

IGF-1 is synthesized and released to the blood primarily by the liver although most tissues can synthesize IGF-1 in an autocrine or paracrine way. IGF-1 is essential for growth and development as demonstrated by severe growth failure in IGF-1 knockout mice (63). IGF-1 also plays an important roll in regulation of muscle mass (66). IGF-1 increases protein synthesis in myocardial myocytes and muscle cell cultures. Infusion studies and amino acid clamp studies have shown an insulin-like effect (direct promoting effect on muscle protein synthesis in the presence of adequate supply of amino acids). During sepsis in adults and children, levels plasma levels of IGF-1 and its major binding protein IGFBP3 are below reference values $(61,64)$ in spite of normal or elevated $\mathrm{HGH}$ levels suggesting a state of hepatic $\mathrm{HGH}$ resistance (60). This is probably caused by increased levels of TNF-alpha an IL-1 either downregulating the hepatic HGH receptor (65) or inhibiting the local production of IGF-1 in muscle (66). Recovery from critical illness is associated with an increase in circulating levels of IGF1 and IGFBP-3 (67)

\section{Thyroid hormone (T3)}

T3 sets the general level of metabolism and regulates the sensitivity of metabolic processes to catecholamines. Its effects on protein metabolism are conflicting. Hypothyroidism may lead to decreased protein synthesis and breakdown while hyperthyroidism has the opposite effect. During stress T3 levels are decreased both in adults and children (61).

\section{Inflammatory mediators}

Critical illness is characterized by the activation of a strong inflammatory response associated with the synthesis and release of a variety of pro- and inflammatory cytokines that have an effect on both splanchnic and muscle protein metabolism (24).

$T N F-\alpha$

TNF- $\alpha$ is produced by mononuclear cells is responsible for many metabolic and nutritional changes that occur in catabolic disease states. TNF- $\alpha$ cannot always be detected in the acute phase of critical illness because of its short plasma half-life of 17 minutes and its sensitivity to sampling handling methods. TNF- $\alpha$ levels peak between $90 \mathrm{~min}$. and 2 hours after injection of endotoxin (81) and induce synthesis of IL-1, IL-6, IFN $\gamma$. TNF- $\alpha$ activates the hypothalamus-pituitary axis, producing elevated levels of ACTH and cortisol $(54,55)$. TNF- $\alpha$ also has a direct stimulatory effect on hepatic amino acid uptake and redirection of hepatic protein synthesis toward acute phase protein synthesis while it also stimulates hepatic gluconeogenesis (82). TNF- $\alpha$ inhibits muscle amino acid uptake, decreases muscle protein synthesis (66) and increases muscle proteolysis by stimulating the ubiquitine-proteasome pathway $(7,83)$. 


\section{IL-1}

IL-1 is also produced by mononuclear cells. Endotoxin is the primary stimulus for IL-1 release but TNF- $\alpha$ and IL-1 itself can stimulate IL-1 production as well. IL-1 levels are elevated within 1 hour after injection of endotoxin, peak around 2 hours and remain elevated up to 4 hours. Injection of IL-1 leads to release of ACTH, cortisol and insulin. IL-1 stimulates hepatic acute phase protein synthesis, gluconeogenesis (84) and muscle proteolysis.

\section{IL-6}

IL-6 is produced in large amounts by activated mononuclear phagocytes. IL-6 is the primary mediator of acute phase protein synthesis in the liver (with both pro- and inflammatory properties). Glucocorticosteroids augment the effects of this cytokine on hepatic acute phase protein synthesis.

\section{Soluble cytokine receptors}

Soluble cytokine receptors are shed by macrophages and endothelial cells upon activation. While expression of TNF- $\alpha$ and IL-1 is rapidly down regulated and only detectable in the most acute stage of the disease, levels of soluble TNF receptor 55, soluble TNF receptor 75 and soluble IL-1 receptor 2 are more stable and remain elevated for 5-6 days after onset of sepsis (85). Plasma levels of these soluble cytokine receptors are increased in children with meningococcal sepsis $(86,87)$ and differentiate between shock and non-shock patients while they also correlate with admission TNF- $\alpha$ and IL-1 levels (85) .

\section{METHODS TO EVALUATE PROTEIN AND AMINO ACID METABOLISM AND THE EFFECTS OF NUTRITIONAL INTERVENTIONS IN CRITICALLY ILL CHILDREN}

\section{General}

There are only few studies that have investigated the alterations of protein and amino acid metabolism during critical illness in children. Despite a high incidence of severe morbidity and mortality of these disorders there is little information on which to base nutritional or therapeutic strategies aimed at prevention or treatment of protein catabolism and muscle wasting. One of the major reasons for the limited number of studies on protein and amino acid metabolism in children is the fact that most stable isotope methods (precursor methods) require intravenous infusions of amino acids labeled with stable isotopes and repeated blood sampling, which is often difficult in children. Other methods that are used in adult patients, for instance the arteriovenous amino acid balance method to measure muscle protein synthesis, are not ethically acceptable in pediatric patients because catheterization of the femoral vein and artery is needed in combination with multiple muscle biopsies. Still in pediatric patients with severe burn injury the latter method has been occasionally used during surgery for burn wounds $(88,89)$. It has been shown that parents frequently refuse to give permission for participation in research ranging form $30 \%$ for anthropometrical 
measures to $70 \%$ for stable isotope intravenous infusion, gas-exchange measurement, and blood sampling (90). Among factors that influence parental refusal the most important are: the invasiveness of the research protocol, the severity of illness of the child as subjectively perceived by the parents (91) and the lack of benefit for the individual child. Research methods to study protein and amino acid metabolism in children therefore should have the lowest level of invasiveness as possible since the other factors cannot be easily influenced.

\section{Anthropometric methods}

Assessment of nutritional needs in healthy children has been traditionally based on ideal growth rates. The use of growth charts however cannot be used in critically ill children since changes in linear growth over the short period of intensive care admission are neglectable. Measurement of body weight, upper arm circumference and skin fold thickness may theoretically be used to detect weight loss and loss of lean body mass but have severe limitations since fluid retention and edema are very common in critically ill children. Even accurate measurement of body weight is often impossible during admission in unstable critically ill children. In order to investigate alterations in whole body protein and amino acid metabolism and the role of nutritional support in the acute phase of critical illness other methods are needed.

\section{Biochemical parameters}

Several plasma proteins show decreased concentrations during malnutrition, especially those proteins that are synthesized in the liver such as albumin, transferrin, transthyretin (formerly called prealbumin), and retinol-binding protein. During recovery from malnutrition, for instance with nutritional support measures, the plasma concentrations of these proteins return to normal levels reflecting increased hepatic synthesis in response to nutrient supply. Therefore the plasma levels of these proteins are often used to monitor the severity of malnutrition and the efficacy of nutritional interventions (92). However the plasma half-life of the majority of these proteins is too long (up to 20 days for albumin) to be used to evaluate the short-term effects of nutritional interventions in critically ill children. Furthermore the plasma concentrations of these proteins during critical illness are also strongly influenced by the disease process. For instance hypoalbuminemia is a very common phenomena during critical illness, due to redistribution to the interstitial space, and therefore cannot be used as a measure of disease related malnutrition. Plasma levels of transferrin and transthyretin are influenced by the severity of the inflammatory state and therefore are also not useful for the evaluation of nutritional interventions in critically ill children (93).

Plasma levels of IGF-1 have shown a strong relationship with nutritional status and have also been used to monitor the response to nutritional support in malnourished patients (94). However in a recent study in critically ill children (95) the adequacy of feeding did not affect the normalization of IGF-1. The value of plasma levels of IGF-1 to monitor nutritional interventions in critically ill children needs further investigation. 
Since protein and amino acid metabolism in health and during critical illness is strongly influenced by the plasma concentrations of the anabolic (insulin, $\mathrm{HGH}$ ) and catabolic hormones (glucagon, catecholamines and cortisol), assessment of these hormone levels may give information on mechanisms behind the alteration of protein and amino acid metabolism during critical illness. This is also true for the plasma levels of those inflammatory mediators that have been shown to play roles in protein and amino acid metabolism (TNF- $\alpha$, IL-1, IL-6).

\section{Energy expenditure and substrate utilization}

When total daily energy expenditure (TDEE) is not met by nutritional intake (negative energy balance) catabolism of body energy stores occurs including increased breakdown of protein. Knowledge of energy expenditure is therefore essential to define and evaluate nutritional interventions. Energy requirements can be estimated using prediction equations (96) but several studies of critically ill children have shown that the accuracy of these equations is low $(97,98)$. Reliable estimates of energy requirements can only be obtained by measuring energy expenditure in the individual child using indirect calorimetry, a method that has also been validated in mechanically ventilated critically ill children (99). During indirect calorimetry oxygen consumption $\left(\mathrm{VO}_{2}\right)$, carbon dioxide production $\left(\mathrm{VCO}_{2}\right)$ and respiratory quotient $(\mathrm{RQ})$ are measured using a metabolic monitor (for instance Deltatrac II MBM-200, Datex Division Instrumentarium Corp. Finland)(100) Measured energy expenditure (MEE) is calculated using the modified Weir formula (101) $\left(\mathrm{MEE}=5.5 \mathrm{VO}_{2}+1.76 \mathrm{VCO}_{2}\right.$; MEE in $\mathrm{kcal} /$ day; $\mathrm{VO}_{2}$ in $\mathrm{ml} / \mathrm{min} ; \mathrm{VCO}_{2}$ in $\mathrm{ml} / \mathrm{min}$ ). If the duration of measurement is sufficiently long ( $>2 \mathrm{hrs}$ ), the results can be considered to represent the total daily energy expenditure (TDEE) $(99,102)$. In ventilated patients REE can only be reliably measured when tube leakage is less than $10 \%$ and $\mathrm{FiO}_{2}$ less than 0.60 . From the measured values of $\mathrm{VO}_{2}, \mathrm{VCO}_{2}$ and total nitrogen excretion it is possible to calculate substrate utilization according to previously published methods (103): fat oxidation $(\mathrm{g} / \mathrm{min})=$ $1.67^{*} 10-3\left(\mathrm{VO}_{2}-\mathrm{VCO}_{2}\right)-1.92 \mathrm{~N}$; fat synthesis $(\mathrm{g} / \mathrm{min})=1.67^{*} 10-3\left(\mathrm{VCO}_{2}-\mathrm{VO}_{2}\right)+1.92 \mathrm{~N}$; glucose oxidation $(\mathrm{g} / \mathrm{min})$ in case of net fat oxidation $=4.55 * 10-3 \mathrm{xVCO}_{2}-3.21 * 10-3$ $\mathrm{xVO}_{2}-2.87 \mathrm{~N}$; glucose oxidation in case of net fat synthesis $=1.34 * 10-3\left(\mathrm{VCO}_{2}-4.88\right.$ $\mathrm{N}$ ), where $\mathrm{VO}_{2}$ is oxygen consumption in $\mathrm{ml} / \mathrm{min}, \mathrm{VCO}_{2}$ is carbon dioxide production in $\mathrm{ml} / \mathrm{min}$ and $\mathrm{N}$ is urinary urea nitrogen excretion in $\mathrm{g} / \mathrm{min}$.

\section{Urinary 3-methyl histidine excretion}

Methods that specifically determine muscle tissue breakdown are of special interest in studies evaluating effects of nutritional interventions in critical ill patients. The degradation of the contractile protein actin results in the release of the amino acid 3methylhistidine (104) that is excreted unmetabolized in urine at an increased rate in catabolic patients (105). The 24-hour urinary excretion of 3-methylhistidine (3-MEH) has been shown to reflect muscle protein breakdown (106). By using the urinary 3$\mathrm{MEH} /$ creatinin ratio, muscle protein degradation can also be determined from a single voiding specimen (107) whereas with stable isotope technology using isotopically 
labeled 3-MEH whole body production of 3-MEH can be measured directly (108). There are however some concerns: the nutritional intake must be totally free from 3$\mathrm{MEH}$ (meat) and the production of $3-\mathrm{MEH}$ from other tissues is considerable (splanchnic organs) especially in animals although this is probably less a problem in adults and children (106).

\section{Nitrogen balance}

Nitrogen balance is an apparently simple method, one measures nitrogen intake and excretion and the difference is the amount retained or lost by the body. It is generally accepted that normal adults, who neither gain nor lose weight, are in zero balance while growing children have positive nitrogen balance. In practice however accurate nitrogen balance studies are difficult to perform since reliable results (in order to be able to calculate absolute protein requirements) can only be obtained when all intake and all excretions (urine, faeces, sweat, blood, tears, saliva etc.) are measured and analyzed for their nitrogen content. Therefore, results obtained with nitrogen balance methods have a general tendency to overestimate nitrogen intake and underestimate nitrogen excretion. Another point of concern is that changes in urinary nitrogen excretion may lag behind changes in nitrogen intake (109). Finally, nitrogen balance methods give no information about the underlying processes that result in a positive or negative balance i.e. no information about rates of protein synthesis and degradation. Nitrogen balance however is a non-invasive method that can be useful in nutritional studies especially when relative rather than absolute values for nitrogen balance are wanted as in studies comparing the effects of different nutritional interventions. Given the fact that many critically ill children have a urinary catheter, reliable determination of total urinary nitrogen or urinary urea nitrogen is possible. Total nitrogen excretion can be approached by measuring total urinary nitrogen (TUN) or urinary urea nitrogen (UUN) (110-112). When using UUN to estimate TUN a correction factor of 1.25 is used to compensate for non-urea and insensible nitrogen loss. Nitrogen contents of different proteins vary somewhat, but on the average are close to $16 \%$ and the standard factor for converting nitrogen to protein is 6.25 .

\section{Plasma amino acid concentrations}

Changes in plasma amino acid concentrations can be detected more rapidly than weight gain or growth and have been used to detect deficiencies and excesses of dietary amino acid intakes in animals and children $(114,115)$. Assessment of plasma amino acid concentrations has also been used to develop parenteral amino acid solutions (113). Plasma amino acid concentrations are the result of their rate of appearance $(\mathrm{Ra})$ in plasma minus their rate of disappearance from plasma ( $\mathrm{Rd})$. $\mathrm{Ra}$ consist of 1) the nutritional amino acid intake after first-pass splanchnic amino acid metabolism 2) the amino acid release from protein breakdown in tissues and 3) the de novo amino acid synthesis. $\mathrm{Rd}$ is the sum of amino acid oxidation, amino acid metabolism, protein synthesis, and protein losses. The plasma pool of free amino acids is very small compared to the intracellular pool of free amino acids, which in his turn is small, compared to the pool of amino acids bound in proteins (98\%). Plasma amino 
acid concentrations show wide variation depending on the physiological condition under which they are measured, reflected by a wide variation in reported reference values both in adults and children. Therefore plasma amino acid concentrations are often considered difficult to interpret. Still determination of plasma amino acid concentration can be useful in nutritional science as long as the interpretation takes the physiologic situation into account (116). Protein intake modifies the plasma amino acid profiles, since some amino acids are extracted in large amounts by splanchnic tissues (glutamine, glutamate), others are hardly metabolized in the gut and liver (branched chain amino acids) while citrulline, which is not a part of food protein, is produced in the gut and released into the circulation. This is also reflected by the specific plasma amino acid patterns in infants receiving human milk, whey-protein based formulas, casein-protein based formulas or total parenteral nutrition (115). Organ dysfunction can influence plasma amino acid concentrations: renal failure increases citrulline levels, liver failure increases phenylalanine levels while terminal multiple organ failure is associated with generalized hyperaminoacidemia (116). The site of blood collection (venous versus arterial) also has influence on plasma amino acid concentrations especially of those amino acids that are taken up or released by peripheral tissue (branched chain amino acids, alanine, glutamine). Amino acid levels in arterial blood are more representative of amino acid homeostasis particularly during critical illness, a condition associated with redistribution of blood flow to vital organs, hypoperfusion of the extremities and increased muscle protein breakdown with release of gluconeogenic amino acids (116). Conditions of preparation and storage also have great influence on plasma amino acid concentrations since degradation of amino acids occurs in non-deproteinized plasma even at temperatures of $70^{\circ} \mathrm{C}(117)$.

\section{Stable isotope tracer methods}

\section{General}

Since pathophysiological processes can have an influence on both protein synthesis and breakdown, it is generally accepted that the best way to assess changes in protein and amino acid metabolism is through the use of stable isotope tracer methods. With these methods the rates of protein turnover, synthesis, breakdown and net protein balance can be evaluated. Since nutritional interventions can affect synthesis and breakdown tracer methods are also best suited to evaluate the responses of protein kinetics on nutrient ingestion. Stable isotopes are naturally occurring non-radioactive elements with a higher mass number due to the presence of a greater number of neutrons in the core (for instance ${ }^{13} \mathrm{C},{ }^{15} \mathrm{~N},{ }^{2} \mathrm{H}$ and ${ }^{18} \mathrm{O}$ ). Stable isotopes behave as the "normal" elements and have no known side effects when present in small amounts and therefore can be used safely for metabolic studies of infants, children and adults both in health and during disease states. Stable isotope tracer methods rely on the principle of isotope dilution: isotopically labeled amino acids are administered intravenously or orally and their plasma concentration (in the precursor methods) or the concentration of the isotope label in one of the end products of protein metabolism (for instance urea or ammonia in the end-product methods) is followed using 
one of the different types of mass spectrometry. The most often used tracer methods make use of $\left[{ }^{15} \mathrm{~N}\right]$ glycine $(118), \mathrm{L}-\left[1-{ }^{13} \mathrm{C}\right]$ leucine $(119)$ or L- $\left[{ }^{2} \mathrm{H}_{5}\right]$ phenylalanine $(120,121)$. In the last decades these tracer methods have been used in numerous studies of adults but also in newborns, infants and children. All tracer methods for the assessment of Wb-PM assume a two pool model in which amino acids are either free or protein bound (Figure 1).

\section{The $\left.{ }^{15} \mathrm{~N}\right]$ glycine single oral dose method}

The first method to be developed for use in human metabolic studies was the end product method using $\left[{ }^{15} \mathrm{~N}\right]$ glycine in either a continuous infusion or a single oral dose, followed by the measurement of ${ }^{15} \mathrm{~N}$ in plasma urea and urinary urea and ammonia or in urinary ammonia alone. As with most stable isotope tracer methods it is based on several assumptions, which include the existence of a single metabolic pool and the possibility of labeling it through the administration of an amino acid tracer. Although the $\left[{ }^{15} \mathrm{~N}\right]$ glycine single oral dose method has been the subject of methodological criticisms and is used less frequently, the non invasive nature of the method makes it more useful to assess protein kinetics in healthy and ill children than the invasive precursor methods that need intravenous infusions of amino acid tracers and multiple blood samples. The method has been used in studies of noncritically ill children to evaluate whole body protein metabolism in children with malnutrition (122), HIV (123), malaria (18) or leukemia (124), during recovery from burn injury and also in premature neonates (125). The method was also used in a single study in critically ill children with accidental trauma (126).

\section{The $L-\left[1-{ }^{13}\right.$ C]leucine method}

This precursor method is based on the continuous intravenous infusion of L-[1${ }^{13} \mathrm{C}$ lleucine. Rate of appearance $(\mathrm{Ra})$ of leucine is calculated by measuring the tracer dilution when a plateau arterial leucine enrichment (Matthews et al. 1980) or venous $\alpha$-ketoisocaproic acid ( $\alpha$-KIC) enrichment has been reached. The achievement of a plateau is accelerated by infusion of a priming dose of the tracer. The $\alpha$ ketoisocaproic acid (a transamination product of leucine) has been suggested to better reflect the enrichment of leucine in the free amino acid pool from which direct incorporation of the leucine into whole-body protein occurs (127). The rate of appearance $(\mathrm{Ra})$ in the free amino acid pool can be calculated from the tracer to tracee ratio observed at steady-state according to the formula $Q=R a=T T R / I$ where TTR is the tracer to tracee ratio, $I$ is the infusion rate of the tracer. At steady state, leucine turnover $(\mathrm{Q})$ equals both $\mathrm{Ra}(\mathrm{Ra}=$ protein synthesis + protein oxidation $)$ and the rate of disappearance $(\mathrm{Rd} ; \mathrm{Rd}=$ protein breakdown + dietary intake). Leucine turnover is converted to whole-body protein turnover using the average leucine content of body protein of $8 \mathrm{~g} / 100 \mathrm{~g}$ protein (119). The oxidation of L- $\left[1-{ }^{13} \mathrm{C}\right]$ leucine is quantified by measuring breath ${ }^{13} \mathrm{CO}_{2}$ enrichment and multiplying this enrichment by total $\mathrm{CO}_{2}$ production and a bicarbonate correction factor for losses of $\mathrm{CO}_{2}$ between the site of oxidation and appearance in the breath (128). Protein synthesis (or nonoxidative $\mathrm{Ra}$ ) can then be calculated. Most tracer studies are done in the overnightfasted state when the dietary protein intake (i.e. $I$ in the equation $R d=B+I$ ) is zero. In 
the latter case the turnover (i.e. $Q$ in the earlier equation) equals protein breakdown (i.e. B). In the fed state protein intake should be known and should be constant with time. This method has been used in numerous studies of children especially in neonates but only few studies have used this method in critically ill children (129, 130).

The L-[ring- ${ }^{2} \mathrm{H}_{5}$ ]phenylalanine / L-[ring- ${ }^{2} \mathrm{H}_{4}$ ]tyrosine / L-[ring- $\left.{ }_{-}^{2} \mathrm{H}_{2}\right]$ tyrosine method

In this method the L-[ring- ${ }^{2} \mathrm{H}_{5}$ ]phenylalanine tracer is given as a primed continuous intravenous infusion with an additional L- $\left[{ }^{2} \mathrm{H}_{4}\right]$ tyrosine prime. After about $2 \mathrm{~h}$ a plateau is reached in the plasma enrichment of both these tracers, and flux can be calculated from the arterial plasma L-[ring- $\left.{ }^{2} \mathrm{H}_{5}\right]$ phenylalanine TTR. The first step in the oxidation of phenylalanine is hydroxylation in the liver and kidney to tyrosine. The rate of oxidation, therefore, can be quantified from the enrichment of L- $\left[{ }^{2} \mathrm{H}_{4}\right]$ tyrosine at steady- state (for exact details of the assumptions behind the method and calculations, see Thompson et al. (120). In a modification of this method (121) a second tyrosine tracer $\left(\mathrm{L}-\left[{ }^{2} \mathrm{H}_{2}\right]\right.$ tyrosine) is infused in order to measure total tyrosine $\mathrm{Ra}$ in arterial plasma, analogous to the measurement of total $\mathrm{CO}_{2}$ production in the leucine method. This method too has been used only in few studies of critically ill children $(19,131)$.

\section{Dual tracer stable isotope methods}

When stable isotope tracer methods are used to estimate protein metabolism in the fed state, it is necessary to be able to estimate the first pass splanchnic amino acid extraction in order to make accurate calculations of the rates of appearance of the specific amino acids possible. Splanchnic amino acid extraction can be studied by the dual tracer method (38), in which different tracers of the same amino acid are administered simultaneously both intravenously and intragastrically. The splanchnic extraction results in a lower plasma enrichment of the intragastrically administered tracer compared to the tracer administered intravenously. The difference reflects the splanchnic extraction or utilization. For instance when L-[ring- $\left.{ }^{2} \mathrm{H}_{5}\right]$ phenylalanine is used as IV tracer and $\left[{ }^{13} \mathrm{C}\right]$ phenylalanine as enteral tracer: true protein intake of Phe $\left(\mathrm{PI}_{\text {Phe }}\right)=$ dietary intake of Phe $\left(\mathrm{DI}_{\mathrm{Phe}}\right) \times\left(1-\right.$ Splanchnic extraction of Phe $\left.\left(\mathrm{SPE}_{\mathrm{Phe}}\right){ }^{*} 0.01\right)$. Splanchnic extraction can be calculated as $\mathrm{SPE}_{\mathrm{Phe}}=\left(1-\mathrm{Ra}\left[{ }^{2} \mathrm{H}_{5}\right]\right.$ Phe $\left./ \mathrm{Ra}\left[{ }^{13} \mathrm{C}\right] \mathrm{Phe}\right){ }^{*}$ $100 \%$. In several studies of neonates splanchnic extraction of several amino acids was investigated (see for review Riedijk et al. (35)) and Beaufrere et al. (132). No data on splanchnic amino acid extraction in critically ill children have been reported.

\section{OUTLINE AND OBJECTIVES OF THE THESIS}

Adequate nutrition in healthy children should provide the optimal amount of nutrients and energy for maintenance, growth and specific functions of the body. In critically ill children the goal of nutritional support is to supply the body with sufficient energy to prevent catabolism of body stores as much as possible and supply the necessary substrates (amino acids) for synthesis of proteins involved in immune 
defense and injury repair. During the recovery phase extra protein and energy will be necessary for catch-up growth.

The objectives of this thesis are to obtain better insight in the alterations in protein and amino acid metabolism during critical illness in children and their consequences for nutritional requirements. Therefore the following questions must be answered:

- Which methods are useful and feasible to investigate protein and amino acid metabolism in critically ill children and the role of nutrient intake both in the acute phase of the disease and during recovery?

- What are the characteristics of the protein catabolic response in critically ill children?

- What are the effects of nutritional interventions on protein and amino acid metabolism in critically ill children?

In Chapter 3 we use a non-invasive stable isotope tracer method, the $\left[{ }^{15} \mathrm{~N}\right]$ glycinesingle-oral dose method, to evaluate the dynamic aspects of whole protein metabolism (turnover, synthesis, breakdown and net protein balance) in groups of healthy children, in children with pneumonia and in critically ill children. The questions to be answered are:

- What are the alterations in whole body protein metabolism during critical illness in I children (meningococcal septic shock) when compared to non-critically ill children (pneumonia) and when compared to healthy children in the fed and the fasted state?

- Is this method useful to evaluate whole body protein metabolism and the effects of nutritional interventions in critically ill children in the acute phase of the disease as well as during recovery?

In Chapter 4 we investigate the metabolic alterations during critical illness in children with meningococcal sepsis and septic shock with emphasis on the hyperglycemic response and the most important anabolic hormone, insulin. The questions to be answered are:

- What are the characteristics of the hyperglycemic response in critically ill children?

- What is the relationship between the metabolic alterations and the inflammatory response?

In Chapter 5 we study plasma amino acid concentrations in critically ill children with different underlying disorders. Emphasis is laid on arginine, citrulline and glutamine, being of particular interest in terms of nutritional management during severe injury and sepsis. The questions to be answered are:

- What is the effect of critical illness on plasma amino acid profiles in critically ill children?

- Is critical illness in children associated with specific amino acid depletions?

- Is supplementation of specific amino acids during critical illness in children warranted? 
In Chapter 6 and Chapter 7 we report the results of a double-blind randomized controlled study that investigates the effects of early administration of a protein and energy enriched formula (PE-formula) in comparison with a standard infant formula on nutritional parameters and whole body protein metabolism in mechanically ventilated infants with viral bronchiolitis.

In Chapter 6 the effects of the two infant formulas on nutrient delivery, tolerance, safety, protein and energy balance, substrate utilization and amino acid profiles are described. The questions to be answered are:

- Does early administration of a PE-formula improve nutrient delivery in critically ill infants in the first five days of admission?

- Is this formula well tolerated and safe?

- Does the use of this formula promote anabolism in critically ill infants?

In Chapter 7 we report the effects of the two infant formulas on splanchnic and whole body phenylalanine kinetics using combined infusions of an enteral and intravenous phenylalanine tracer. The questions to be answered are:

- Does a high protein and energy intake improves whole body protein balance by stimulating whole body protein synthesis, inhibiting protein breakdown or a combination of both?

- What is the influence of splanchnic phenylalanine utilization on whole body phenylalanine kinetics in critically ill infants in the fed state?

\section{REFERENCES}

1. Macronutrients RotPo. Dietary Reference Intakes for Macronutrients Washington: US National Academie of Sciences, 2005.

2. Reeds PJ, Fjeld CR, Jahoor F. Do the differences between the amino acid compositions of acute-phase and muscle proteins have a bearing on nitrogen loss in traumatic states? J Nutr 1994;124:906-10.

3. Waterlow JC, Golden J, Picou D. The measurements of rates of protein turnover, synthesis, and breakdown in man and the effects of nutritional status and surgical injury. Am J Clin Nutr 1977;30:1333-9.

4. Golden M, Waterlow JC, Picou D. The relationship between dietary intake, weight change, nitrogen balance, and protein turnover in man. Am J Clin Nutr 1977;30:1345-8.

5. Kinney JM, Elwyn DH. Protein metabolism and injury. Annu Rev Nutr 1983;3:433-66.

6. Frayn KN. Metabolic regulation, human perspective. second ed. Oxford: Blackwell publishing, 2003.

7. Mitch WE, Goldberg AL. Mechanisms of muscle wasting. The role of the ubiquitin-proteasome pathway. N Engl J Med 1996;335:1897-905.

8. Rosenblatt S, Clowes GH, Jr., George BC, Hirsch E, Lindberg B. Exchange of amino acids by muscle and liver in sepsis. Arch Surg 1983;118:167-75.

9. Hasselgren PO, Fischer JE. Muscle cachexia: current concepts of intracellular mechanisms and molecular regulation. Ann Surg 2001;233:9-17.

10. Inubushi T, Shikiji M, Endo K, Kakegawa H, Kishino Y, Katunuma N. Hormonal and dietary regulation of lysosomal cysteine proteinases in liver under gluconeogenesis conditions. Biol Chem 1996;377:539-42.

11. Nagasawa T, Hirano J, Yoshizawa F, Nishizawa N. Myofibrillar protein catabolism is rapidly suppressed following protein feeding. Biosci Biotechnol Biochem 1998;62:1932-7.

12. Nagasawa T, Kido T, Yoshizawa F, Ito Y, Nishizawa N. Rapid suppression of protein degradation in skeletal muscle after oral feeding of leucine in rats. J Nutr Biochem 2002;13:121-127.

13. Rennie MJ. Muscle protein turnover and the wasting due to injury and disease. Br Med Bull 1985;41:25764. 
14. O'Keefe SJ, Sender PM, James WP. "Catabolic" loss of body nitrogen in response to surgery. Lancet 1974;2:1035-8.

15. Crane CW, Picou D, Smith R, Waterlow JC. Protein turnover in patients before and after elective orthopaedic operations. Br J Surg 1977;64:129-33.

16. Arnold J, Campbell IT, Samuels TA, et al. Increased whole body protein breakdown predominates over increased whole body protein synthesis in multiple organ failure [published erratum appears in Clin Sci (Colch) 1993 Dec;85(6):following xxv]. Clin Sci (Colch) 1993;84:655-61.

17. Kien CL, Young VR, Rohrbaugh DK, Burke JF. Increased rates of whole body protein synthesis and breakdown in children recovering from burns. Ann Surg 1978;187:383-91.

18. Berclaz PY, Benedek C, Jequier E, Schutz Y. Changes in protein turnover and resting energy expenditure after treatment of malaria in Gambian children. Pediatr Res 1996;39:401-9.

19. Castillo L, Beaumier L, Ajami AM, Young VR. Whole body nitric oxide synthesis in healthy men determined from [15N] arginine-to-[15N]citrulline labeling. Proc Natl Acad Sci U S A 1996;93:11460-5.

20. Swick RW, Benevenga NJ. Labile protein reserves and protein turnover. J Dairy Sci 1977;60:505-15.

21. Jepson MM, Pell JM, Bates PC, Millward DJ. The effects of endotoxaemia on protein metabolism in skeletal muscle and liver of fed and fasted rats. Biochem J 1986;235:329-36.

22. Tiao G, Hobler S, Wang JJ, et al. Sepsis is associated with increased mRNAs of the ubiquitin-proteasome proteolytic pathway in human skeletal muscle. J Clin Invest 1997;99:163-8.

23. Wolfe RR. Regulation of skeletal muscle protein metabolism in catabolic states. Curr Opin Clin Nutr Metab Care 2005;8:61-5.

24. Wray CJ, Mammen JM, Hasselgren PO. Catabolic response to stress and potential benefits of nutrition support. Nutrition 2002;18:971-7.

25. Ferrando AA, Stuart CA, Sheffield-Moore M, Wolfe RR. Inactivity amplifies the catabolic response of skeletal muscle to cortisol. J Clin Endocrinol Metab 1999;84:3515-21.

26. Orellana RA, O'Connor PM, Nguyen HV, et al. Endotoxemia reduces skeletal muscle protein synthesis in neonates. Am J Physiol Endocrinol Metab 2002;283:E909-16.

27. Bruins MJ, Deutz NE, Soeters PB. Aspects of organ protein, amino acid and glucose metabolism in a porcine model of hypermetabolic sepsis. Clin Sci (Lond) 2003;104:127-41.

28. Lang $\mathrm{CH}$, Frost RA. Sepsis-induced suppression of skeletal muscle translation initiation mediated by tumor necrosis factor alpha. Metabolism 2007;56:49-57.

29. Vary TC, Jefferson LS, Kimball SR. Insulin fails to stimulate muscle protein synthesis in sepsis despite unimpaired signaling to 4E-BP1 and S6K1. Am J Physiol Endocrinol Metab 2001;281:E1045-53.

30. De Bandt JP, Cynober L. Therapeutic use of branched-chain amino acids in burn, trauma, and sepsis. J Nutr 2006;136:308S-13S.

31. Essen P, McNurlan MA, Sonnenfeld T, et al. Muscle protein synthesis after operation: effects of intravenous nutrition. Eur J Surg 1993;159:195-200.

32. Tjader I, Essen P, Thorne A, Garlick PJ, Wernerman J, McNurlan MA. Muscle protein synthesis rate decreases 24 hours after abdominal surgery irrespective of total parenteral nutrition. JPEN J Parenter Enteral Nutr 1996;20:135-8.

33. Essen P, McNurlan MA, Gamrin L, et al. Tissue protein synthesis rates in critically ill patients. Crit Care Med 1998;26:92-100.

34. Orellana RA, Kimball SR, Suryawan A, et al. Insulin stimulates muscle protein synthesis in neonates during endotoxemia despite repression of translation initiation. Am J Physiol Endocrinol Metab 2007;292:E629-36.

35. Riedijk MA, van Goudoever JB. Splanchnic metabolism of ingested amino acids in neonates. Curr Opin Clin Nutr Metab Care 2007;10:58-62.

36. Reeds PJ, Burrin DG. The gut and amino acid homeostasis. Nutrition 2000;16:666-8.

37. Hoerr RA, Matthews DE, Bier DM, Young VR. Leucine kinetics from [2H3]- and [13C]leucine infused simultaneously by gut and vein. Am J Physiol 1991;260:E111-7.

38. Biolo G, Tessari P, Inchiostro S, et al. Leucine and phenylalanine kinetics during mixed meal ingestion: a multiple tracer approach. Am J Physiol 1992;262:E455-63.

39. Matthews DE, Marano MA, Campbell RG. Splanchnic bed utilization of leucine and phenylalanine in humans. Am J Physiol 1993;264:E109-18.

40. Deutz NE, Ten Have GA, Soeters PB, Moughan PJ. Increased intestinal amino-acid retention from the addition of carbohydrates to a meal. Clin Nutr 1995;14:354-64.

41. Stoll B, Henry J, Reeds PJ, Yu H, Jahoor F, Burrin DG. Catabolism dominates the first-pass intestinal metabolism of dietary essential amino acids in milk protein-fed piglets. J Nutr 1998;128:606-14.

42. Windmueller HG, Spaeth AE. Respiratory fuels and nitrogen metabolism in vivo in small intestine of fed rats. Quantitative importance of glutamine, glutamate, and aspartate. J Biol Chem 1980;255:107-12. 
43. van der Schoor SR, Stoll B, Wattimena DL, et al. Splanchnic bed metabolism of glucose in preterm neonates. Am J Clin Nutr 2004;79:831-7.

44. Waterlow JC. Whole-body protein turnover in humans--past, present, and future. Annu Rev Nutr 1995; 15:57-92.

45. Soeters $\mathrm{PB}$, de Jong $\mathrm{CH}$, Deutz NE. The protein sparing function of the gut and the quality of food protein. Clin Nutr 2001;20:97-9.

46. De Feo P, Horber FF, Haymond MW. Meal stimulation of albumin synthesis: a significant contributor to whole body protein synthesis in humans. Am J Physiol 1992;263:E794-9.

47. Mansoor O, Cayol M, Gachon P, et al. Albumin and fibrinogen syntheses increase while muscle protein synthesis decreases in head-injured patients. Am J Physiol 1997;273:E898-902.

48. Obled C, Papet I, Breuille D. Metabolic bases of amino acid requirements in acute diseases. Curr Opin Clin Nutr Metab Care 2002;5:189-97.

49. Calbet JA, MacLean DA. Plasma glucagon and insulin responses depend on the rate of appearance of amino acids after ingestion of different protein solutions in humans. J Nutr 2002;132:2174-82.

50. Wolfe RR. Regulation of muscle protein by amino acids. J Nutr 2002;132:3219S-24S.

51. Gelfand RA, Barrett EJ. Effect of physiologic hyperinsulinemia on skeletal muscle protein synthesis and breakdown in man. J Clin Invest 1987;80:1-6.

52. Long W, Wei L, Barrett EJ. Dexamethasone inhibits the stimulation of muscle protein synthesis and PHASI and p70 S6-kinase phosphorylation. Am J Physiol Endocrinol Metab 2001;280:E570-5.

53. Wing SS, Goldberg AL. Glucocorticoids activate the ATP-ubiquitin-dependent proteolytic system in skeletal muscle during fasting. Am J Physiol 1993;264:E668-76.

54. Gwosdow AR, Kumar MS, Bode HH. Interleukin 1 stimulation of the hypothalamic-pituitary-adrenal axis. Am J Physiol 1990;258:E65-70.

55. Darling G, Goldstein DS, Stull R, Gorschboth CM, Norton JA. Tumor necrosis factor: immune endocrine interaction. Surgery 1989;106:1155-60.

56. Hasselgren PO. Glucocorticoids and muscle catabolism. Curr Opin Clin Nutr Metab Care 1999;2:201-5.

57. Joosten K. Metabolic, endocrine and nutritional aspects of critically ill children. Pediatric Intensive Care. Rotterdam: Erasmus University, 1999.

58. Navegantes LC, Resano NM, Migliorini RH, Kettelhut IC. Catecholamines inhibit Ca(2+)-dependent proteolysis in rat skeletal muscle through beta(2)-adrenoceptors and cAMP. Am J Physiol Endocrinol Metab 2001;281:E449-54.

59. Wilmore D, Long J, Mason A, Skreen R, Pruitt B. Catecholamines: Mediator of the hypermetabolic response to thermal injury. Ann Surg 1974;180:653-669.

60. Dahn MS, Lange MP, Jacobs LA. Insulinlike growth factor 1 production is inhibited in human sepsis. Arch Surg 1988;123:1409-14.

61. de Groof F, Joosten KF, Janssen JA, et al. Acute stress response in children with meningococcal sepsis: important differences in the growth hormone/insulin-like growth factor I axis between nonsurvivors and survivors. J Clin Endocrinol Metab 2002;87:3118-24.

62. Balcells J, Moreno A, Audi L, Roqueta J, Iglesias J, Carrascosa A. Growth hormone/insulin-like growth factors axis in children undergoing cardiac surgery. Crit Care Med 2001;29:1234-8.

63. Baker J, Liu JP, Robertson EJ, Efstratiadis A. Role of insulin-like growth factors in embryonic and postnatal growth. Cell 1993;75:73-82.

64. Van den Berghe G, de Zegher F, Bouillon R. The somatotrophic axis in critical illness: effects of growth hormone secretagogues. Growth Horm IGF Res 1998;8 Suppl B:153-5.

65. Denson LA, Menon RK, Shaufl A, Bajwa HS, Williams CR, Karpen SJ. TNF-alpha downregulates murine hepatic growth hormone receptor expression by inhibiting Sp1 and Sp3 binding. J Clin Invest 2001;107:1451-8.

66. Lang CH, Frost RA, Vary TC. Regulation of muscle protein synthesis during sepsis and inflammation. Am J Physiol Endocrinol Metab 2007;293:E453-9.

67. Teng Chung T, Hinds CJ. Treatment with GH and IGF-1 in critical illness. Crit Care Clin 2006;22:29-40, vi.

68. Bohe J, Low JF, Wolfe RR, Rennie MJ. Latency and duration of stimulation of human muscle protein synthesis during continuous infusion of amino acids. J Physiol 2001;532:575-9.

69. Anthony JC, Yoshizawa F, Anthony TG, Vary TC, Jefferson LS, Kimball SR. Leucine stimulates translation initiation in skeletal muscle of postabsorptive rats via a rapamycin-sensitive pathway. J Nutr 2000;130:24139.

70. hofKadowaki M, Kanazawa T. Amino acids as regulators of proteolysis. J Nutr 2003;133:2052S-2056S.

71. Beisel WR. Magnitude of the host nutritional responses to infection. Am J Clin Nutr 1977;30:1236-47.

72. Hoffer LJ. Protein and energy provision in critical illness. Am J Clin Nutr 2003;78:906-11. 
73. Millward DJ. Macronutrient intakes as determinants of dietary protein and amino acid adequacy. J Nutr 2004;134:1588S-1596S.

74. Biolo G, Ciocchi B, Stulle M, et al. Calorie restriction accelerates the catabolism of lean body mass during 2 wk of bed rest. Am J Clin Nutr 2007;86:366-72.

75. Keys A. The residues of malnutrition and starvation. Science 1950;112:371-3.

76. Coyer PA, Rivers JP, Millward DJ. The effect of dietary protein and energy restriction on heat production and growth costs in the young rat. Br J Nutr 1987;58:73-85.

77. Malcolm LA. Growth retardation in a New Guinea boarding school and its response to supplementary feeding. Br J Nutr 1970;24:297-305.

78. Dobbins RL, Chester MW, Stevenson BE, Daniels MB, Stein DT, McGarry JD. A fatty acid- dependent step is critically important for both glucose- and non-glucose-stimulated insulin secretion. J Clin Invest 1998;101:2370-6.

79. Vahl T, D'Alessio D. Enteroinsular signaling: perspectives on the role of the gastrointestinal hormones glucagon-like peptide 1 and glucose-dependent insulinotropic polypeptide in normal and abnormal glucose metabolism. Curr Opin Clin Nutr Metab Care 2003;6:461-8.

80. Duffy B, Gunn T, Collinge J, Pencharz P. The effect of varying protein quality and energy intake on the nitrogen metabolism of parenterally fed very low birthweight (less than $1600 \mathrm{~g}$ ) infants. Pediatr Res 1981;15:1040-4.

81. Michie HR, Manogue KR, Spriggs DR, et al. Detection of circulating tumor necrosis factor after endotoxin administration. N Engl J Med 1988;318:1481-6.

82. Petit F, Bagby GJ, Lang CH. Tumor necrosis factor mediates zymosan-induced increase in glucose flux and insulin resistance. Am J Physiol 1995;268:E219-28.

83. Flores EA, Bistrian BR, Pomposelli JJ, Dinarello CA, Blackburn GL, Istfan NW. Infusion of tumor necrosis factor/cachectin promotes muscle catabolism in the rat. A synergistic effect with interleukin 1. J Clin Invest 1989;83:1614-22.

84. Roh MS, Moldawer LL, Ekman LG, et al. Stimulatory effect of interleukin-1 upon hepatic metabolism. Metabolism 1986;35:419-24.

85. van Deuren M, Frieling JT, van der Ven-Jongekrijg J, et al. Plasma patterns of tumor necrosis factor-alpha (TNF) and TNF soluble receptors during acute meningococcal infections and the effect of plasma exchange. Clin Infect Dis 1998;26:918-23.

86. van Deuren M, van der Ven-Jongekrijg J, Bartelink AK, van Dalen R, Sauerwein RW, van der Meer JW. Correlation between proinflammatory cytokines and antiinflammatory mediators and the severity of disease in meningococcal infections. J Infect Dis 1995;172:433-9.

87. van Deuren $M$, van der Ven-Jongekrijg J, Vannier E, et al. The pattern of interleukin-1beta (IL-1beta) and its modulating agents IL-1 receptor antagonist and IL-1 soluble receptor type II in acute meningococcal infections. Blood 1997;90:1101-8.

88. Gore DC, Chinkes D, Sanford A, Hart DW, Wolf SE, Herndon DN. Influence of fever on the hypermetabolic response in burn-injured children. Arch Surg 2003;138:169-74; discussion 174.

89. Hart DW, Wolf SE, Chinkes DL, et al. Determinants of skeletal muscle catabolism after severe burn. Ann Surg 2000;232:455-65.

90. Pierro A, Spitz L. Informed consent in clinical research: the crisis in paediatrics. Lancet 1997;349:1703.

91. Hulst JM, Peters JW, van den Bos A, et al. Illness severity and parental permission for clinical research in a pediatric ICU population. Intensive Care Med 2005;31:880-4.

92. Bernstein LH. Utilizing laboratory parameters to monitor effectiveness of nutritional support. Nutrition 1994;10:58-60.

93. Raguso CA, Dupertuis YM, Pichard C. The role of visceral proteins in the nutritional assessment of intensive care unit patients. Curr Opin Clin Nutr Metab Care 2003;6:211-6.

94. Berne\&Levy. Physiology: Moshby Year Book, 1993.

95. Hulst JM, van Goudoever JB, Visser TJ, Tibboel D, Joosten KF. Hormone levels in children during the first week of ICU-admission: is there an effect of adequate feeding? Clin Nutr 2006;25:154-62.

96. Schofield WN. Predicting basal metabolic rate, new standards and review of previous work. Hum Nutr Clin Nutr 1985;39 Suppl 1:5-41.

97. Verhoeven JJ, Hazelzet JA, van der Voort E, Joosten KF. Comparison of measured and predicted energy expenditure in mechanically ventilated children. Intensive Care Med 1998;24:464-8.

98. Vazquez Martinez JL, Martinez-Romillo PD, Diez Sebastian J, Ruza Tarrio F. Predicted versus measured energy expenditure by continuous, online indirect calorimetry in ventilated, critically ill children during the early postinjury period. Pediatr Crit Care Med 2004;5:19-27. 
99. Joosten KF, Verhoeven JJ, Hop WC, Hazelzet JA. Indirect calorimetry in mechanically ventilated infants and children: accuracy of total daily energy expenditure with 2 hour measurements. Clin Nutr 1999;18:149-52.

100. Takala J, Keinanen O, Vaisanen P, Kari A. Measurement of gas exchange in intensive care: laboratory and clinical validation of a new device. Crit Care Med 1989;17:1041-7.

101. Weir J. New methods for calculating metabolic rate with special reference to protein metabolism. J Physiol 1949;109:1-9.

102. Bell EF, Rios GR, Wilmoth PK. Estimation of 24-hour energy expenditure from shorter measurement periods in premature infants. Pediatr Res 1986;20:646-9.

103. Ferrannini E. The theoretical bases of indirect calorimetry: a review. Metabolism 1988;37:287-301.

104. Hasselgren PO, James JH, Benson DW, et al. Total and myofibrillar protein breakdown in different types of rat skeletal muscle: effects of sepsis and regulation by insulin. Metabolism 1989;38:634-40.

105. Long CL, Schiller WR, Blakemore WS, Geiger JW, M OD, Henderson K. Muscle protein catabolism in the septic patient as measured by 3- methylhistidine excretion. Am J Clin Nutr 1977;30:1349-52.

106. Sjolin J, Stjernstrom H, Arturson G, Andersson E, Friman G, Larsson J. Exchange of 3-methylhistidine in the splanchnic region in human infection. Am J Clin Nutr 1989;50:1407-14.

107. Speek AJ, Thissen JT, Schrijver J. Urinary excretion of 3-methylhistidine and creatinine by healthy Dutch children during day and night. The influence of age and sex. J Clin Chem Clin Biochem 1986;24:465-70.

108. Vissers YL, von Meyenfeldt MF, Braulio VB, Luiking YC, Deutz NE. Measuring whole-body actin/myosin protein breakdown in mice using a primed constant stable isotope-infusion protocol. Clin Sci (Lond) 2003;104:585-90.

109. Martin CJ, Robison R. The Minimum Nitrogen Expenditure of Man and the Biological value of various Proteins for Human Nutrition. Biochem J 1922;16:407-47.

110. Boehm KA, Helms RA, Storm MC. Assessing the validity of adjusted urinary urea nitrogen as an estimate of total urinary nitrogen in three pediatric populations. JPEN J Parenter Enteral Nutr 1994;18:172-6.

111. Milner EA, Cioffi WG, Mason AD, Jr., McManus WF, Pruitt BA, Jr. Accuracy of urinary urea nitrogen for predicting total urinary nitrogen in thermally injured patients. JPEN J Parenter Enteral Nutr 1993;17:414-6.

112. Mickell JJ. Urea nitrogen excretion in critically ill children. Pediatrics 1982;70:949-55.

113. Heird WC, Dell RB, Helms RA, et al. Amino acid mixture designed to maintain normal plasma amino acid patterns in infants and children requiring parenteral nutrition. Pediatrics 1987;80:401-8.

114. McLaughlan JM, IIIman WI. Use of free plasma amino acid levels for estimating amino acid requirements of the growing rat. J Nutr 1967;93:21-4.

115. Janas LM, Picciano MF, Hatch TF. Indices of protein metabolism in term infants fed either human milk or formulas with reduced protein concentration and various whey/casein ratios. J Pediatr 1987;110:838-48.

116. Cynober LA. Plasma amino acid levels with a note on membrane transport: characteristics, regulation, and metabolic significance. Nutrition 2002;18:761-6.

117. Van Eijk HMH, DeJong CHC, Deutz NEP, Soeters PB. Influence of storage conditions on normal plasma amino-acid concentrations. Clinical Nutrition 1994;13:374.

118. Waterlow JC, Golden MH, Garlick PJ. Protein turnover in man measured with $15 \mathrm{~N}$ : comparison of end products and dose regimes. Am J Physiol 1978;235:E165-74.

119. Matthews DE, Motil KJ, Rohrbaugh DK, Burke JF, Young VR, Bier DM. Measurement of leucine metabolism in man from a primed, continuous infusion of L-[1-3C]leucine. Am J Physiol 1980;238:E473-9.

120. Thompson GN, Pacy PJ, Merritt H, et al. Rapid measurement of whole body and forearm protein turnover using a [2H5]phenylalanine model. Am J Physiol 1989;256:E631-9.

121. Marchini JS, Castillo L, Chapman TE, Vogt JA, Ajami A, Young VR. Phenylalanine conversion to tyrosine: comparative determination with L- [ring-2H5]phenylalanine and L-[1-13C]phenylalanine as tracers in man. Metabolism 1993;42:1316-22.

122. Golden $\mathrm{MH}$, Waterlow JC, Picou D. Protein turnover, synthesis and breakdown before and after recovery from protein-energy malnutrition. Clin Sci Mol Med 1977;53:473-7.

123. Henderson RA, Talusan K, Hutton N, Yolken RH, Caballero B. Whole body protein turnover in children with human immunodeficiency virus (HIV) infection. Nutrition 1999;15:189-94.

124. Kien CL, Camitta BM. Increased whole-body protein turnover in sick children with newly diagnosed leukemia or lymphoma. Cancer Res 1983;43:5586-92.

125. Van Goudoever JB, Sulkers EJ, Halliday D, et al. Whole-body protein turnover in preterm appropriate for gestational age and small for gestational age infants: comparison of [15N]glycine and [1-(13)C]leucine administered simultaneously. Pediatr Res 1995;37:381-8.

126. Winthrop AL, Wesson DE, Pencharz PB, Jacobs DG, Heim T, Filler RM. Injury severity, whole body protein turnover, and energy expenditure in pediatric trauma. J Pediatr Surg 1987;22:534-7. 
127. Matthews DE, Schwarz HP, Yang RD, Motil KJ, Young VR, Bier DM. Relationship of plasma leucine and alpha-ketoisocaproate during a L-[1-13C]leucine infusion in man: a method for measuring human intracellular leucine tracer enrichment. Metabolism 1982;31:1105-12.

128. van Hall G. Correction factors for $13 \mathrm{C}$-labelled substrate oxidation at whole-body and muscle level. Proc Nutr Soc 1999;58:979-86.

129. Argaman Z, Young VR, Noviski N, et al. Arginine and nitric oxide metabolism in critically ill septic pediatric patients. Crit Care Med 2003;31:591-7.

130. Cogo PE, Carnielli VP, Rosso F, et al. Protein turnover, lipolysis, and endogenous hormonal secretion in critically ill children. Crit Care Med 2002;30:65-70.

131. Patterson BW, Nguyen T, Pierre E, Herndon DN, Wolfe RR. Urea and protein metabolism in burned children: effect of dietary protein intake. Metabolism 1997;46:573-8.

132. Beaufrere B, Fournier V, Salle B, Putet G. Leucine kinetics in fed low-birth-weight infants: importance of splanchnic tissues. Am J Physiol 1992;263:E214-20. 



\section{CHAPTER 3}

\section{Assessment of whole body protein metabolism in critically ill children: can we use the $\left[{ }^{15} \mathrm{~N}\right]$ glycine single oral dose method}

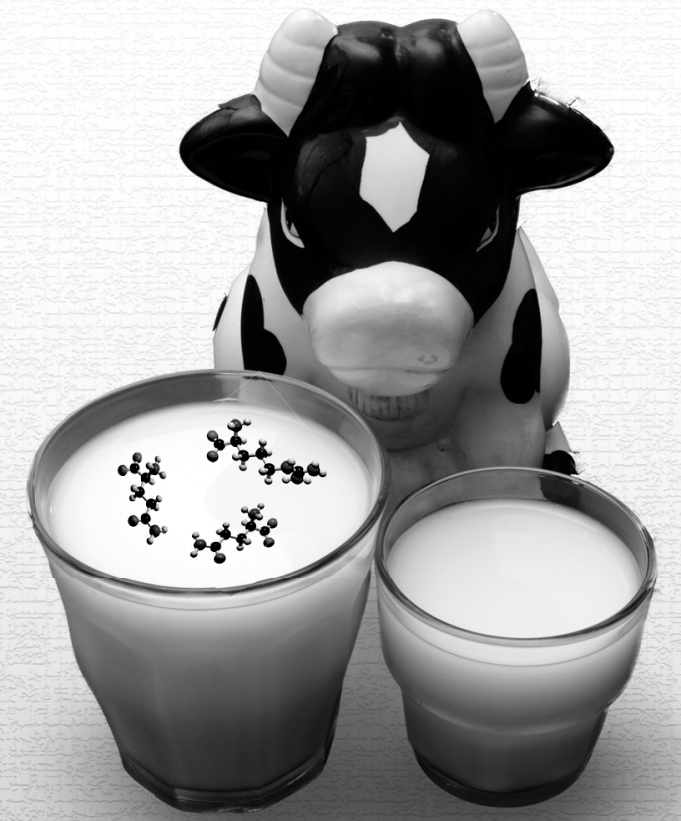

Dick A. van Waardenburg, Nicolaas E.P. Deutz, Marije B. Hoos, Nicolaas J.G. Jansen, Bernard K. van Kreel, Gijs D. Vos, Anton J. Wagenmakers, Pierre-Philippe Forget Clinical Nutrition (2004); 23: 153-160 


\section{ABSTRACT}

Background and aims: Most stable-isotope methods to evaluate whole body protein metabolism in patients are invasive and difficult to use in children. In this study protein metabolism was evaluated with the non-invasive $\left[{ }^{15} \mathrm{~N}\right]$ glycine single oral dose method in critically ill children and the value of the method discussed.

Methods: $\left[{ }^{15} \mathrm{~N}\right]$ glycine $(100 \mathrm{mg})$ was given orally to children (mean age $5.5 \mathrm{yr}$.; range 0.6-15.5 yr.) with meningococcal septic shock (MSS, $n=8)$, pneumonia $(n=5)$ and to healthy fed and post-absorptive children $(n=10)$. Urine was collected during 9 hours, total amount of $\mathrm{NH}_{3}$, labeled $\mathrm{NH}_{3}$ and nitrogen were measured, and protein turnover, synthesis and breakdown were calculated using urinary $\mathrm{NH}_{3}$ as end product.

Results: Mean protein turnover in children with MSS, pneumonia and fed and postabsorptive healthy children was $0.63 \pm 0.13,0.38 \pm 0.10,0.28 \pm 0.03$ and $0.28 \pm 0.02$ gram $\mathrm{N} / \mathrm{kg} / 9 \mathrm{~h}$ respectively. Mean protein synthesis was $0.55 \pm 0.12,0.29 \pm 0.09,0.18 \pm 0.02$, $0.20 \pm 0.02 \mathrm{gramN} / \mathrm{kg} / 9 \mathrm{~h}$. Mean protein breakdown was $0.56 \pm 0.14,0.28 \pm 0.12,0.08 \pm 0.03$, $0.28 \pm 0.02 \mathrm{gramN} / \mathrm{kg} / 9 \mathrm{~h}$. Protein turnover, synthesis and breakdown were significantly increased in MSS-patients compared to the fed healthy children $(p<0.01)$ and postabsorptive children $(\mathrm{p}<0.05)$. Protein turnover, protein synthesis, protein breakdown were significantly correlated with disease severity and body temperature $(p<0.05)$.

Conclusions: Results of whole body protein metabolism measured with the $\left[{ }^{15} \mathrm{~N}\right]$ glycine single oral dose method in children with MSS and in healthy children were in line with expectations based on results obtained in earlier reports and with different methods. 


\section{INTRODUCTION}

Acute disorders like sepsis, burns, trauma or major surgery are characterized by an increased breakdown of body proteins, negative nitrogen balance and depletion of body cell mass. Most data on protein metabolism during severe illness are derived from adult studies and few studies have focused on whole body protein metabolism (WBPM) in critically ill children. Protein energy malnutrition is a common finding (1) in these children and may either increase the incidence of complications or prolong the recovery phase (2-4). More insight into the mechanism of WBPM in the acute phase of critical illness and during the subsequent recovery may help to define rational therapeutic interventions aimed at preventing excessive protein breakdown in the acute phase the disease and optimizing catch-up growth in the recovery phase. One of the major reasons for the limited number of studies on protein metabolism in children is that most stable isotope methods (precursor methods) require intravenous infusions of amino acids labeled with stable isotopes and repeated blood sampling which can be difficult in children. Although it may be possible to use these methods in critically ill children in the acute phase of the disease, given the relatively short length of stay of most patients in de paediatric ICU (5-7 days), these precursor methods are neither suitable for serial evaluation of protein metabolism nor for the evaluation of therapeutic interventions in these children. It would similarly be impossible to obtain results in healthy children in order to make comparisons with a control group possible.

The $\left[{ }^{15} \mathrm{~N}\right]$ glycine single oral dose method proposed years ago by Waterlow et al. (5) is a method to evaluate WBPM in a non-invasive manner. In this method a single oral of dose of $\left[{ }^{15} \mathrm{~N}\right]$ glycine is given and rates of protein turnover are calculated from the ${ }^{15} \mathrm{~N}$ content of its end products (ammonia or urea) in urine collected over 9 hours. When ammonia is used as end product the method requires no blood sampling due to the small plasma pool, which makes it particularly suitable for use in the paediatric population. Several studies making use of this method have been reported in children with acute disorders such as burn injuries (6, 7), malaria (8), HIV (9), measles (10) or prematurity and very-low-birth-weight (11) but so far none in critically ill children after the neonatal period. The method has been the subject of criticism since uncertainties about the theoretical basis exists (see discussion) and although results obtained with this method in groups of subjects have been in agreement with those obtained by the more accepted precursor methods, (12-14) this was not the case in individual patients (15). The present study forms our first step in evaluating the value of the $\left[{ }^{15} \mathrm{~N}\right]$ glycine single oral dose method for the non-invasive assessment of whole body protein metabolism in critically ill children during different phases of the disease. We recognize that a definitive value of this method may only be obtained by using it simultaneously with a precursor method and comparing the results. Because continuous enteral feeding is started as soon as possible after admission in all patients in our paediatric intensive care unit as part of our standard treatment, we measured whole body protein metabolism in the fed state in all patients. Since energy and protein intake in these children is still very low, whole body protein metabolism 
results were compared both with a group of healthy children in the fed state and in the post-absorptive state.

\section{MATERIALS AND METHODS}

\section{Patients}

Children admitted to the paediatric intensive care unit of the university hospital Maastricht were enrolled in the study if they fulfilled the diagnosis of either meningococcal septic shock or severe bacterial pneumonia. Meningococcal septic shock (MSS) was defined as a clinical diagnosis of septic shock according to the criteria of the Society of Critical Care Medicine and the American College of Chest Physicians (SCCM/ACCP) as adapted to infants and children by Jafari et al. (16) in combination with petecchiae and/or purpura and a positive blood culture with Neisseria Meningitidis. Severe bacterial pneumonia was defined as temperature $>38.5$ degrees Celsius, a chest X-ray with pulmonary infiltrates, a CRP $>80 \mathrm{mg} / \mathrm{l}$ and respiratory distress. Evaluation of WBPM was performed after respiratory and circulatory functions had been stabilized either with or without mechanical ventilation and inotropic medication (dopamine and norepinephrine). Patients did not receive continuous blood products like plasma infusions or albumin at the time of the investigation. Patients with renal failure (manifested by urine production $<0.5 \mathrm{ml} / \mathrm{kg} / \mathrm{hour}$ and/or a glomerular filtration rate $<25 \mathrm{ml} /$ minute $/ 1.73 \mathrm{~m}^{2}$ ), extensive skin necrosis or limb amputation, (known) gastrointestinal disorders or patients that did not tolerate enteral feeding were excluded from the study. Patients were also excluded when urinary collection was unsuccessful. To allow comparison between patients and healthy children, WBPM was also evaluated in a group of 10 healthy Dutch children in the fed state. Seven of these children were measured a second time in the post-absorptive state (overnight).

\section{METHODS}

\section{$\left[{ }^{15} \mathrm{~N}\right]$ glycine single oral dose method}

WBPM was studied using the $\left[{ }^{15} \mathrm{~N}\right]$ glycine single oral dose method as described by Waterlow et al. (5). In this method a single oral of dose of $\left[{ }^{15} \mathrm{~N}\right]$ glycine is given and rates of protein turnover are calculated from the ${ }^{15} \mathrm{~N}$ content of ammonia in urine collected over 9 hours, the time taken for most of the label to clear the body ammonia pool. On the morning (between 8-10 AM) of the day of the investigation $\left[{ }^{15} \mathrm{~N}\right]$ glycine (100 mg 99-atom \% [ $\left.{ }^{15} \mathrm{~N}\right]$ glycine, Isotec Inc., Miamisburg, USA) dissolved in sterile water was given by nasogastric tube or by mouth. Urine was collected during the next 9 hours in a container acidified by $2 \mathrm{ml} 6 \mathrm{~N} \mathrm{HCl}$ and put at $+4^{\circ}$ Celsius. After the collection was completed urine was stored in the freezer at $-20^{\circ}$ Celsius until analysis. To evaluate protein metabolism in the post-absorptive state $\left[{ }^{15} \mathrm{~N}\right]$ glycine was given 5 hours after the evening meal (about 23:00 PM) and urine was collected during the 
next 9 hours. In these children no food intake was allowed during urinary collection. After mixing of the urine one $\mathrm{ml}$. was taken and ammonia isolated. After transformation into $\mathrm{N}_{2}$ gas the ${ }^{15} \mathrm{~N}$-enrichment was determined on an isotope ratio mass spectrometer (Mat 252 Finnigan, Bremen, Germany). The ${ }^{15} \mathrm{~N}$-enrichment of ammonia was corrected for background isotopic enrichment as measured in a urinary sample collected before tracer administration. Total urinary nitrogen excretion was considered to be the sum of ammonia and urea nitrogen. Whole body protein turnover was calculated using a single pool model according to Waterlow (4) using the equation: $Q$ $=\mathrm{D}^{*} \mathrm{E}_{\mathrm{NH} 3} / \mathrm{e}_{\mathrm{NH} 3}$ where $\mathrm{Q}=$ nitrogen turnover calculated from ammonia as end product (gram N/9h), D = tracer dose $\left(m g{ }^{15} \mathrm{~N}\right), \mathrm{E}_{\mathrm{NH} 3}=$ total nitrogen excreted as ammonia in the $9 \mathrm{~h}$ urine collection (gram N/9h.) and e $\mathrm{NH}_{3}=$ total ${ }^{15} \mathrm{~N}$ excreted as ammonia in the $9 \mathrm{~h}$ urine collection (gram N/9h). Protein synthesis and protein breakdown were calculated using the equation $\mathrm{Q}=\mathrm{S}+\mathrm{E}=\mathrm{B}+\mathrm{I}$ where $\mathrm{S}=$ nitrogen used for protein synthesis, $\mathrm{E}=$ nitrogen excreted in urine as urea and ammonia, $\mathrm{B}=$ nitrogen derived from protein breakdown and $I=$ dietary nitrogen intake. A factor of 6.25 was used to convert grams of nitrogen to grams of protein. Protein balance was calculated as the difference between protein synthesis and breakdown. All results were expressed as grams of nitrogen per kilo body weight per 9 hours.

\section{Nutrition}

All patients received standard paediatric enteral nutrition by continuous gastric drip at a rate decided by the treating physician. Parenteral administration of fluids, glucose and electrolytes were given according to the patient needs. Protein and caloric intake was registered in detail. In the healthy children measured in the fed state meals of known composition (only dairy products) were offered at 3 hourly intervals starting 2 hours before tracer administration and protein and caloric intake was registered.

\section{Severity of illness}

Severity of acute illness was assessed in the two patient groups using the Paediatric Index of Mortality (PIM)(17), a mortality prediction score that uses 8 physiological variables all collected within 1 hour after the time of admission to the paediatric intensive care unit. In this scoring system severity of illness is expressed as the mortality risk in percentage $(0-100 \%)$.

\section{Statistical analysis}

All data were analyzed using the statistical program SPSS (10.0) for Windows (SPSS Inc, Chicago, IL). The Mann-Whitney U test was used to compare differences between groups and Spearman's rank correlation coefficient was used to identify possible correlations between body temperature, PIM scores and protein parameter results. 


\section{Ethical considerations}

The study was approved by the Medical Ethical Committee of our hospital. Informed consent was obtained from either the patients and control subjects or their parents. The test was well tolerated by all patients and control subjects and no adverse reactions attributable to the test were observed.

\section{RESULTS}

\section{Whole body protein metabolism}

In the six months study period 10 patients with MSS and 6 patients with severe bacterial pneumonia were admitted to the paediatric intensive care unit. Two patients with MSS were excluded from the study (extensive skin necrosis: $n=1$, no informed consent: $n=1$ ) and one patient with pneumonia (urinary losses: $n=1$ ). In Table 1 the clinical and anthropometric details of the patients and controls are presented. There were no significant differences in mean age and mean body weight between the four groups. Caloric intake during the study period was significantly lower in the patients with MSS and pneumonia $(p<0.05)$ when compared to the healthy, fed controls. Protein intake (see Table 2 ) was only significantly lower in patients with MSS $(p<0.01)$ when compared to the group of healthy children in the fed state. WBPM was evaluated between 24 and 192 hours (median 48 hours) after admission in the children with MSS and between 28 and 144 hours (median 72 hours) after admission in children with pneumonia.

Results of WBPM evaluated with the $\left[{ }^{15} \mathrm{~N}\right]$ glycine single oral dose method in the patients and controls are presented in Table 2 and expressed as grams of nitrogen per kilogram body weight per 9 hours. Of the $100 \mathrm{mg}(1.32 \mathrm{mmol})\left[{ }^{15} \mathrm{~N}\right]$ glycine given an average of $1.5 \pm 0.12 \%$ was recovered in ammonia in the 9 hour urine collection without significant differences between groups. Mean protein turnover was significantly higher in children with MSS when compared to results found in healthy fed $(p<0.01)$ and post-absorptive $(p<0.01)$ children. The same was true for mean protein synthesis (both $p<0.01)$ and mean protein breakdown $(p<0.001$ and $p<0.05$ respectively). Although mean protein breakdown was increased to a higher degree than mean protein synthesis in patients with MSS, mean protein balance was not significantly different from zero. In children with pneumonia mean protein turnover, synthesis and breakdown were higher than in healthy subjects in the fed state and lower than in children with MSS but these difference failed to reach statistical significance. In the healthy children in the fed state mean protein synthesis was higher than protein breakdown leading to a positive protein balance as could be expected in healthy growing children. Changing from the fed state into the postabsorptive state had no effect on protein turnover or on protein synthesis. Protein breakdown however was significantly increased $(p<0.01)$ resulting in a negative protein balance. 
Table 1. Clinical and anthropometric details of patients and controls

\begin{tabular}{|c|c|c|c|c|c|c|c|}
\hline Group & Patient & Sex & $\begin{array}{l}\text { Age } \\
(y r)\end{array}$ & $\begin{array}{c}\text { Weight } \\
(\mathrm{kg})\end{array}$ & $\begin{array}{c}\text { Caloric } \\
\text { intake } \\
\text { (kcal/kg/9h) }\end{array}$ & Other diagnosis & $\begin{array}{l}\text { PIM- } \\
\text { score } \\
(\%)\end{array}$ \\
\hline \multirow[t]{10}{*}{ Healthy, fed } & 1 & $\mathrm{~F}$ & 4.5 & 16.4 & 56.6 & & - \\
\hline & 2 & $\mathrm{~F}$ & 3.2 & 16.7 & 45.6 & & - \\
\hline & 3 & $M$ & 0.6 & 11.1 & 67.4 & & - \\
\hline & 4 & $\mathrm{~F}$ & 7.3 & 24.0 & 47.5 & & - \\
\hline & 5 & $\mathrm{~F}$ & 4.4 & 15.0 & 65.5 & & - \\
\hline & 6 & $\mathrm{~F}$ & 7.3 & 37.0 & 14.4 & & - \\
\hline & 7 & M & 8.7 & 31.0 & 44.1 & & - \\
\hline & 8 & M & 3.5 & 14.0 & 79.6 & & - \\
\hline & 9 & M & 4.4 & 19.0 & 30.5 & & - \\
\hline & 10 & $\mathrm{~F}$ & 6.0 & 20.0 & 38.3 & & - \\
\hline \multirow{7}{*}{$\begin{array}{l}\text { Healthy, } \\
\text { postabsorptive }\end{array}$} & 11 & $\mathrm{~F}$ & 7.5 & 24.0 & 0 & & - \\
\hline & 12 & $\mathrm{~F}$ & 4.5 & 15.0 & 0 & & - \\
\hline & 13 & $\mathrm{~F}$ & 7.3 & 37.0 & 0 & & - \\
\hline & 14 & $M$ & 8.7 & 31.0 & 0 & & - \\
\hline & 15 & $M$ & 3.6 & 14.0 & 0 & & - \\
\hline & 16 & $M$ & 4.4 & 19.0 & 0 & & - \\
\hline & 17 & $\mathrm{~F}$ & 6.1 & 20.0 & 0 & & - \\
\hline \multirow[t]{5}{*}{ Pneumonia } & 18 & M & 6.9 & 24.0 & 9.3 & IPPV & 6.1 \\
\hline & 19 & $\mathrm{~F}$ & 4.6 & 11.1 & 56.3 & Dysraphism & 1.4 \\
\hline & 20 & M & 6.9 & 21.6 & 16.4 & & 0.9 \\
\hline & 21 & $M$ & 2.4 & 8.8 & 11.0 & $\begin{array}{l}\text { Noonan } \\
\text { Syndrome }\end{array}$ & 5.5 \\
\hline & 22 & $\mathrm{~F}$ & 8.9 & 33.0 & 17.6 & & 0.3 \\
\hline \multirow[t]{8}{*}{ MSS } & 23 & $M$ & 15.5 & 50.0 & 7.2 & & 5.6 \\
\hline & 24 & $M$ & 9.1 & 30.0 & 33.8 & $\begin{array}{l}\text { Inotropic drugs, } \\
\text { IPPV }\end{array}$ & 4.3 \\
\hline & 25 & $M$ & 0.6 & 8.5 & 53.4 & & 0.4 \\
\hline & 26 & $M$ & 5.0 & 18.0 & 8.6 & $\begin{array}{l}\text { Inotropic drugs, } \\
\text { IPPV }\end{array}$ & 8.9 \\
\hline & 27 & $\mathrm{~F}$ & 2.6 & 13.0 & 13.8 & & 1.4 \\
\hline & 28 & M & 8.1 & 30.0 & 6.0 & $\begin{array}{l}\text { Inotropic drugs, } \\
\text { IPPV }\end{array}$ & 12.9 \\
\hline & 29 & $\mathrm{~F}$ & 0.5 & 6.5 & 62.8 & & 1.7 \\
\hline & 30 & M & 1.5 & 11.0 & 5.1 & $\begin{array}{l}\text { Inotropic drugs, } \\
\text { IPPV }\end{array}$ & 19.5 \\
\hline Healthy, fed & \multicolumn{2}{|c|}{ Mean \pm SEM } & $5.0 \pm 0.8$ & $20.4 \pm 2.6$ & $49.0 \pm 6.1$ & & - \\
\hline $\begin{array}{l}\text { Healthy, } \\
\text { postabsorptive }\end{array}$ & \multicolumn{2}{|c|}{ Mean \pm SEM } & $6.0 \pm 0.7$ & $22.9 \pm 3.2$ & 0 & & - \\
\hline Pneumonia & \multicolumn{2}{|c|}{ Mean \pm SEM } & $5.9 \pm 1.1$ & $19.7 \pm 4.4$ & $22.1 \pm 8.7^{\mathrm{a}}$ & & $2.8 \pm 1.2$ \\
\hline MSS & \multicolumn{2}{|c|}{ Mean \pm SEM } & $5.4 \pm 1.9$ & $20.9 \pm 5.2$ & $23.8 \pm 8.2^{\mathrm{a}}$ & & $6.8 \pm 2.3$ \\
\hline
\end{tabular}

MSS =meningococcal septic shock; IPPV $=$ mechanical ventilation. ${ }^{a} p<0.05$ versus healthy fed children (Mann-Whitney U test) 


\section{CHAPTER 3}

Table 2. Rates of whole body protein metabolism in individual patients and healthy subjects.

\begin{tabular}{|c|c|c|c|c|c|c|}
\hline Group & Patient & $\mathrm{PI}$ & PT & PS & PB & PBal \\
\hline \multirow[t]{10}{*}{ Healthy, fed } & 1 & 0.29 & 0.26 & 0.15 & 0.00 & 0.15 \\
\hline & 2 & 0.24 & 0.29 & 0.14 & 0.05 & 0.09 \\
\hline & 3 & 0.27 & 0.46 & 0.35 & 0.19 & 0.16 \\
\hline & 4 & 0.19 & 0.21 & 0.11 & 0.02 & 0.09 \\
\hline & 5 & 0.26 & 0.29 & 0.17 & 0.03 & 0.13 \\
\hline & 6 & 0.06 & 0.15 & 0.10 & 0.09 & 0.01 \\
\hline & 7 & 0.18 & 0.24 & 0.17 & 0.07 & 0.11 \\
\hline & 8 & 0.32 & 0.29 & 0.17 & 0.00 & 0.18 \\
\hline & 9 & 0.10 & 0.29 & 0.19 & 0.16 & 0.03 \\
\hline & 10 & 0.13 & 0.32 & 0.21 & 0.22 & 0.00 \\
\hline \multirow{7}{*}{$\begin{array}{l}\text { Healthy, } \\
\text { postabsorptive }\end{array}$} & 11 & - & 0.28 & 0.21 & 0.28 & -0.07 \\
\hline & 12 & - & 0.31 & 0.20 & 0.31 & -0.11 \\
\hline & 13 & - & 0.19 & 0.15 & 0.19 & -0.04 \\
\hline & 14 & - & 0.25 & 0.18 & 0.25 & -0.07 \\
\hline & 15 & - & 0.38 & 0.29 & 0.38 & -0.08 \\
\hline & 16 & - & 0.30 & 0.21 & 0.30 & -0.09 \\
\hline & 17 & - & 0.25 & 0.19 & 0.25 & -0.06 \\
\hline \multirow[t]{5}{*}{ Pneumonia } & 18 & 0.04 & 0.71 & 0.56 & 0.67 & -0.11 \\
\hline & 19 & 0.30 & 0.24 & 0.14 & 0.00 & 0.15 \\
\hline & 20 & 0.10 & 0.54 & 0.44 & 0.44 & 0.00 \\
\hline & 21 & 0.02 & 0.19 & 0.16 & 0.17 & -0.01 \\
\hline & 22 & 0.13 & 0.23 & 0.17 & 0.10 & 0.07 \\
\hline \multirow[t]{8}{*}{ MSS } & 23 & 0.03 & 0.75 & 0.63 & 0.72 & -0.08 \\
\hline & 24 & 0.11 & 0.43 & 0.32 & 0.33 & 0.00 \\
\hline & 25 & 0.09 & 0.45 & 0.40 & 0.36 & 0.04 \\
\hline & 26 & 0.03 & 0.63 & 0.52 & 0.60 & -0.08 \\
\hline & 27 & 0.06 & 0.36 & 0.30 & 0.30 & 0.00 \\
\hline & 28 & 0.03 & 0.50 & 0.41 & 0.47 & -0.06 \\
\hline & 29 & 0.17 & 0.43 & 0.41 & 0.27 & 0.15 \\
\hline & 30 & 0.02 & 1.47 & 1.36 & 1.45 & -0.09 \\
\hline Healthy & Mean \pm SEM & $0.20 \pm 0.03$ & $0.28 \pm 0.03$ & $0.18 \pm 0.02$ & $0.08 \pm 0.03$ & $0.10 \pm 0.02$ \\
\hline $\begin{array}{l}\text { Healthy, } \\
\text { postabsorptive }\end{array}$ & Mean \pm SEM & 0 & $0.28 \pm 0.02$ & $0.20 \pm 0.02$ & $0.28 \pm 0.02^{\mathrm{a}}$ & $-0.08 \pm 0.01^{\mathrm{a}}$ \\
\hline Pneumonia & Mean \pm SEM & $0.12 \pm 0.05$ & $0.38 \pm 0.10$ & $0.29 \pm 0.09$ & $0.28 \pm 0.12$ & $0.03 \pm 0.05$ \\
\hline MSS & Mean \pm SEM & $0.07 \pm 0.02^{\mathrm{a}}$ & $0.63 \pm 0.13^{\mathrm{a}, \mathrm{c}}$ & $0.55 \pm 0.12^{\mathrm{a}, \mathrm{c}}$ & $0.56 \pm 0.14^{\mathrm{b}, \mathrm{d}}$ & $-0.02 \pm 0.03^{a}$ \\
\hline
\end{tabular}

$P I, P T, P S, P B, P B a l=$ respectively protein intake, turnover, synthesis, breakdown and protein balance expressed as gramN/kg/9 hours. ${ }^{a} p<0.01$ and ${ }^{b} p<0.001$ versus healthy fed children. ${ }^{c} p<0.01$ and ${ }^{d} p<0.05$ versus healthy post-absorptive children (Mann-Whitney $U$ test). 


\section{Relationships between clinical parameters and whole body protein metabolism}

Disease severity as expressed by the PIM score on the admission day was significantly and positively correlated with protein turnover $(\mathrm{r}=0.60 ; \mathrm{p}<0.05)$, protein synthesis $(r=0.59, p<0.05)$ and protein breakdown $(r=0.69, p<0.01)$ (Figure 1, panel $A)$ and negatively correlated with protein balance $(r=-0.80, p<0.01)$ (Figure 1 panel $B$ ). A significant correlation was also found between body temperature and protein turnover $(r=0.69$, $\mathrm{p}<0.01)$ protein synthesis $(\mathrm{r}=0.67, \mathrm{p}<0.05)$ and protein breakdown $(\mathrm{r}=0.57, \mathrm{p}<0.05)$.

A

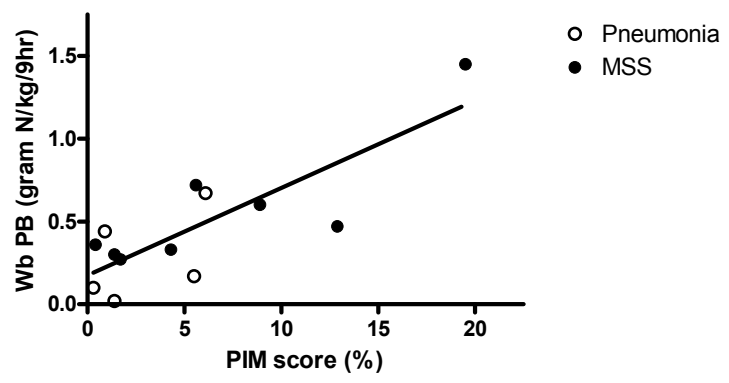

B

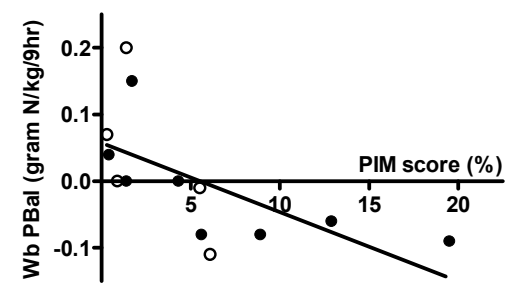

- Pneumonia

- MSS

Figure 1. Relationship between whole body protein breakdown (Wb PB)(Panel A), whole body protein balance (Wb PBal)(Panel B) and PIM score at admission in patients with meningococcal septic shock (MSS) and pneumonia. The solid lines indicate the correlation of the whole patient population. 


\section{DISCUSSION}

With the non-invasive $\left[{ }^{15} \mathrm{~N}\right]$ glycine single oral dose method, using $\left[{ }^{15} \mathrm{~N}\right]$ ammonia as end product, we were able to demonstrate a significant increase in whole body protein turnover, protein synthesis and protein breakdown in children with MSS when compared to healthy children. Protein balance tended to be negative but this did not reach statistical significance. Our results are in good agreement with studies performed with precursor methods in adult intensive care patients where a similar increase in protein turnover, protein synthesis and protein breakdown has been demonstrated after severe surgery (18), major trauma (19) and sepsis (20). Our results do also agree with the studies of pediatric patients that used $\left[{ }^{15} \mathrm{~N}\right]$ glycine as a tracer (Table 3).

Table 3. Rates of whole body protein metabolism in children obtained from different studies.

\begin{tabular}{|c|c|c|c|c|}
\hline Reference & Subjects & $\begin{array}{l}\text { Protein } \\
\text { intake }\end{array}$ & Protein synthesis & Protein breakdown \\
\hline \multirow[t]{2}{*}{ Tomkins et al. (10) } & Acute measles infection & $0.03 \pm 0.02$ & $1.66 \pm 0.31$ & $2.21 \pm 0.44$ \\
\hline & Malnourished & $0.07 \pm 0.01$ & $0.57 \pm 0.14$ & $0.50 \pm 0.13$ \\
\hline \multirow[t]{2}{*}{ Kien et al. (6) } & After burn injury & $0.62 \pm 0.31$ & $1.14 \pm 0.34$ & $1.01 \pm 0.29$ \\
\hline & Healthy controls & $0.37 \pm 0.09$ & $0.56 \pm 0.03$ & $0.49 \pm 0.03$ \\
\hline \multirow[t]{2}{*}{ Berclaz et al.(8) } & Acute malaria & 0.09 & $1.81 \pm 0.12$ & $1.99 \pm 0.14$ \\
\hline & Post-recovery & 0.09 & $0.94 \pm 0.05$ & $0.88 \pm 0.06$ \\
\hline Castillo et al. (23) & Critically ill infants & $0.19 \pm 0.13$ & $1.34 \pm 0.10$ & $1.49 \pm 0.10$ \\
\hline \multirow[t]{2}{*}{ This paper } & MSS & $0.07 \pm 0.02$ & $1.45 \pm 0.33$ & $1.50 \pm 0.37$ \\
\hline & Healthy controls & $0.20 \pm 0.03$ & $0.47 \pm 0.06$ & $0.20 \pm 0.07$ \\
\hline
\end{tabular}

Tomkins et al. (10) found similar results when studying WBPM in children with acute viral infections (measles) and mild malnutrition. In their study $\left[{ }^{15} \mathrm{~N}\right]$ glycine was administered intravenously which has been shown to give slightly lower results (3$14 \%$ ) (21) since, when given orally, a small part of the tracer is excreted in faeces and some uptake in the splanchnic area takes place. Berclaz et al. (8) also found comparable results in children suffering from acute malaria. In their study protein turnover was calculated from the excretion of ${ }^{15} \mathrm{~N}$ in ammonia in a 12-hour urine collection. Grove et al. (22) showed that most of the ${ }^{15} \mathrm{~N}$-label, excreted in urinary $\mathrm{NH} 3$, is passed over 3 hours with a rapid fall to low levels within 12 hours. Calculation of protein turnover from excretion of ${ }^{15} \mathrm{NH}_{3}$ in either a 9-hour or 12-hour urine collections gave comparable results. Kien et al. (7), studying protein metabolism in children after burn injury used a modification of the method described by Picou and Taylor-Roberts (21) in which $\left[{ }^{15} \mathrm{~N}\right]$ glycine is given intragastrically or intravenously at 3 hour intervals for about 30 hours and protein turnover is calculated from plateau enrichment of urinary urea. This intermittent-dose regimen has been shown to give results that are consistently lower $(25 \%)$ than the single dose regimen although the reason for this has not 
been clarified (22). Finally, Castillo et al. (23) studied amino acid metabolism in parenterally fed new-borns and infants with sepsis using a precursor method in which a primed constant intravenous infusion of $\mathrm{L}-\left[1-{ }^{13} \mathrm{C}\right]$ phenylalanine and $\mathrm{L}-[3,3-$ ${ }^{2} \mathrm{H}_{2}$ ]tyrosine was given. All children were parenterally fed. Rates of whole body protein synthesis and breakdown using this method were comparable to those of the septic patients in our study.

Protein catabolism in adults has been shown to be proportional to the magnitude of the trauma (19). In children positive correlations between protein turnover and either body temperature (8) or percentage of total body surface area burned (7) have been reported. In our study we could demonstrate a positive correlations between protein metabolism parameters, body temperature and disease severity expressed by the PIM score.

In spite of the high rate of protein breakdown in the children with MSS in our study, protein balance was not significantly negative due an equal increase in protein synthesis. Although protein breakdown in sepsis predominantly reflects muscle protein breakdown and protein synthesis reflects visceral protein synthesis (24), two separate processes, this is still somewhat surprising since critical illness is generally associated with negative protein balance. An explanation for this observation may be the fact that we did not measure total urinary nitrogen excretion (TUN) but calculated TUN from the sum of urinary urea and NH3 excretion. Although this is an accepted and often used method (25), TUN may have been underestimated. Indeed Boehm et al. demonstrated that calculation of TUN from either urinary urea nitrogen alone or in combination with urinary ammonia in critically ill children could lead to an underestimation of TUN of up to $30 \%$ (26). From the equation $\mathrm{Q}=\mathrm{S}+\mathrm{E}=\mathrm{B}+\mathrm{I}$ follows that underestimation of TUN can lead to overestimation of protein synthesis and therefore also protein balance. A second explanation may also be found in the variability in disease severity. Indeed we could demonstrate a significant negative correlation between protein balance and disease severity as expressed by the PIM score. A negative protein balance could consequently only be found in the more severe cases. Protein turnover and synthesis in the healthy controls showed similar results in either the fed or the post-absorptive state. Although others found protein turnover to be increased in the fed state, the response to nutritional intake has been contradictory in different studies $(27,28)$ and dependent on the amount of protein ingested (29). Indeed protein intake in the healthy, fed controls was relatively low due to the low protein content of the feeding offered to these children (dairy products). Protein breakdown however was significantly increased in our post-absorptive control children and protein balance was negative. This is in accordance with the concept that protein breakdown is the major process regulating body protein mass with changes in dietary intake and that food intake has relatively little effect on protein synthesis $(27,30)$. However, the lower protein intake in the children with MSS, compared to the healthy controls in the fed state, can only partially explain the elevated rate of protein breakdown since protein breakdown was even significantly higher than in the healthy controls in the post-absorptive state.

Although the results obtained with the $\left[{ }^{15} \mathrm{~N}\right]$ glycine single oral dose method in our study are in line with expectations based on results obtained both in adult patients 
with precursor methods and in children with different disorders using different methods, this does not necessarily imply that the method is suitable for studies of critically ill paediatric patients. As mentioned in the introduction the $\left[{ }^{15} \mathrm{~N}\right]$ glycine single oral dose method has been subject of criticism. The metabolism of glycine is not well understood and sources of error may therefore be difficult to recognize. Theoretically tracer sequestration in glycine-rich acute-phase proteins with a short turnover could occur which could result in lower urinary excretion of label in the end product and overestimation of protein turnover (31). Also the underlying assumption of the method, concerning the even distribution of label among all amino acids in a homogeneous metabolic pool, is clearly an oversimplification. This is reflected by the observation that different rates of protein turnover can be calculated when either ammonia or urea is used as end product. The precursors from which urinary $\mathrm{NH}_{3}$ is derived are clearly not the same as the precursors for urea. Fern et al. (12) therefore proposed the use of the harmonic mean of the values obtained with $\left[{ }^{15} \mathrm{~N}\right]$ ammonia and $\left[{ }^{15} \mathrm{~N}\right]$ urea as end product. Unfortunately, in order to use $\left[{ }^{15} \mathrm{~N}\right]$ urea data, two blood samples are necessary to determine the amount of $\left[{ }^{15} \mathrm{~N}\right]$ urea retained within the urea pool because of the large size of this pool and the delayed excretion of isotope. The method would thereby lose one of its major advantages that of its non-invasiveness. Another point of concern is that Van Goudoever et al. (15), studying whole body protein metabolism in fed preterm infants and using two different tracer methods simultaneously, $\left[{ }^{15} \mathrm{~N}\right]$ glycine as a 72 hour intragastric infusion and $\left[1-{ }^{13} \mathrm{C}\right]$ leucine as a 4 hourly intragastric infusion, found that although group means were comparable with both methods, individual rates obtained from the different methods did not correspond well. Therefore before the $\left[{ }^{15} \mathrm{~N}\right]$ glycine single oral dose can be advised for the assessment of protein metabolism in critically ill children further validation of the method is necessary, for instance by comparing results of end-product and precursor methods used simultaneously in the same patients. We consider this worth the effort since a non-invasive method has definitive practical advantages over more invasive methods and may facilitate more research on protein metabolism in paediatric patients in the acute phase and recovery phase of critically illness.

In conclusion, whole body protein turnover, protein synthesis and breakdown measured with the non-invasive $\left[{ }^{15} \mathrm{~N}\right]$ glycine single oral dose method, are significantly increased in critically ill children when compared to healthy children. Although further validation of the method in these patients is necessary, our present results are in line with results obtained both in critically adult patients and in children with different disorders using different methods.

\section{REFERENCES}

1. Pollack M M, Wiley J S, Holbrook P R. Early nutritional depletion in critically ill children. Crit Care Med 1981; 9:580-3.

2. Pollack MM R U, Wiley JS. Nutritional depletions in critically ill children: associates with physiologic instability and increased quantity of care. Journal of parenteral and enteral nutrition 1985; 9:309-313.

3. Windsor J A, Hill G L. Risk factors for postoperative pneumonia. The importance of protein depletion. Ann Surg 1988; 208:209-14. 
4. Petersson B, Vinnars E, Waller S O, Wernerman J. Long-term changes in muscle free amino acid levels after elective abdominal surgery. Br J Surg 1992; 79:212-6.

5. Waterlow J C, Golden M H, Garlick P J. Protein turnover in man measured with $15 \mathrm{~N}$ : comparison of end products and dose regimes. Am J Physiol 1978; 235:E165-74.

6. Kien C L, Rohrbaugh D K, Burke J F, Young V R. Whole body protein synthesis in relation to basal energy expenditure in healthy children and in children recovering from burn injury. Pediatr Res 1978; 12:211-6.

7. Kien C L, Young V R, Rohrbaugh D K, Burke J F. Increased rates of whole body protein synthesis and breakdown in children recovering from burns. Ann Surg 1978; 187:383-91.

8. Berclaz P Y, Benedek C, Jequier E, Schutz Y. Changes in protein turnover and resting energy expenditure after treatment of malaria in Gambian children. Pediatr Res 1996; 39:401-9.

9. Henderson R A, Talusan K, Hutton N, Yolken R H, Caballero B. Whole body protein turnover in children with human immunodeficiency virus (HIV) infection. Nutrition 1999; 15:189-94.

10. Tomkins A M, Garlick P J, Schofield W N, Waterlow J C. The combined effects of infection and malnutrition on protein metabolism in children. Clin Sci 1983; 65:313-24.

11. van Lingen R A, van Goudoever J B, Luijendijk I H, Wattimena J L, Sauer P J. Effects of early amino acid administration during total parenteral nutrition on protein metabolism in pre-term infants. Clin Sci (Lond) 1992; 82:199-203.

12. Fern E B, Garlick P J, McNurlan M A, Waterlow J C. The excretion of isotope in urea and ammonia for estimating protein turnover in man with [15N]glycine. Clin Sci 1981; 61:217-28.

13 Fern E B, Garlick P J, Sheppard H G, Fern M. The precision of measuring the rate of whole-body nitrogen flux and protein synthesis in man with a single dose of [15N]-glycine. Hum Nutr Clin Nutr 1984; 38:63-73.

14. Pannemans D L, Wagenmakers A J, Westerterp K R, Schaafsma G, Halliday D. The effect of an increase of protein intake on whole-body protein turnover in elderly women is tracer dependent. J Nutr 1997; 127:1788-94.

15. Van Goudoever J B, Sulkers E J, Halliday D, Degenhart H J, Carnielli V P, Wattimena J L, Sauer P J. Wholebody protein turnover in preterm appropriate for gestational age and small for gestational age infants: comparison of [15N]glycine and [1-(13)C]leucine administered simultaneously. Pediatr Res 1995; 37:381-8.

16. Jafari H S, McCracken G H, Jr. Sepsis and septic shock: a review for clinicians. Pediatr Infect Dis J 1992; 11:739-48.

17. Shann F, Pearson G, Slater A, Wilkinson K. Paediatric index of mortality (PIM): a mortality prediction model for children in intensive care [see comments]. Intensive Care Med 1997; 23:201-7.

18. Yamamori H, Tashiro T, Mashima Y, Okui K. Effects of severity of surgical trauma on whole body protein turnover in patients receiving total parenteral nutrition. JPEN J Parenter Enteral Nutr 1987; 11:454-7.

19. Clague $M$ B, Keir M J, Wright P D, Johnston I D. The effects of nutrition and trauma on whole-body protein metabolism in man. Clin Sci 1983; 65:165-75.

20. Long C L, Jeevanandam M, Kim B M. Whole body protein synthesis and catabolism in septic man. Am J Clin Nutr 1977; 30:1340-4.

21. Picou D, Taylor-Roberts T. The measurement of total protein synthesis and catabolism and nitrogen turnover in infants in different nutritional states and receiving different amounts of dietary protein. Clin Sci 1969; 36:283-96.

22. Grove G, Jackson A A. Measurement of protein turnover in normal man using the end-product method with oral [15N]glycine: comparison of single-dose and intermittent-dose regimens. Br J Nutr 1995; 74:491507.

23. Castillo L, Yu Y M, Marchini J S, Chapman T E, Sanchez M, Young V R, Burke J F. Phenylalanine and tyrosine kinetics in critically ill children with sepsis. Pediatr Res 1994; 35:580-8.

24. Rosenblatt S, Clowes G H, Jr., George B C, Hirsch E, Lindberg B. Exchange of amino acids by muscle and liver in sepsis. Arch Surg 1983; 118:167-75.

25. Burge JC C P, McKnight T, Kyler MK, Flancbaum L. Urinary ammonia plus urinary urea nitrogen as an estimate of total urinary nitrogen in patients receiving parenteral nutrition support. JPEN J Parenter Enteral Nutr. 1993; 17:529-31.

26. Boehm K A, Helms R A, Storm M C. Assessing the validity of adjusted urinary urea nitrogen as an estimate of total urinary nitrogen in three pediatric populations. JPEN J Parenter Enteral Nutr 1994; 18:172-6.

27. Melville S, McNurlan M A, McHardy K C, Broom J, Garlick P J. The role of degradation in the acute control of protein balance in adult man: failure of feeding to stimulate protein synthesis as assessed by L[1-13C]leucine infusion. Metabolism 1989; 38:248-55.

28. Pacy P J, Price G M, Halliday D, Quevedo M R, Millward D J. Nitrogen homeostasis in man: the diurnal responses of protein synthesis and degradation and amino acid oxidation to diets with increasing protein intakes. Clin Sci (Lond) 1994; 86:103-16. 


\section{CHAPTER 3}

29. Millward D J, Fereday A, Gibson N, Pacy P J. Aging, protein requirements, and protein turnover. Am J Clin Nutr 1997; 66:774-86.

30. Garlick P J, McNurlan M A, Ballmer P E. Influence of dietary protein intake on whole-body protein turnover in humans. Diabetes Care 1991; 14:1189-98.

31. Preston T, Fearon K C, McMillan D C, Winstanley F P, Slater C, Shenkin A, Carter D C. Effect of ibuprofen on the acute-phase response and protein metabolism in patients with cancer and weight loss. Br J Surg $1995 ; 82: 229-34$. 
Hyperglycemia in children with meningococcal sepsis and septic shock:

the relation between plasma levels of insulin and inflammatory mediators

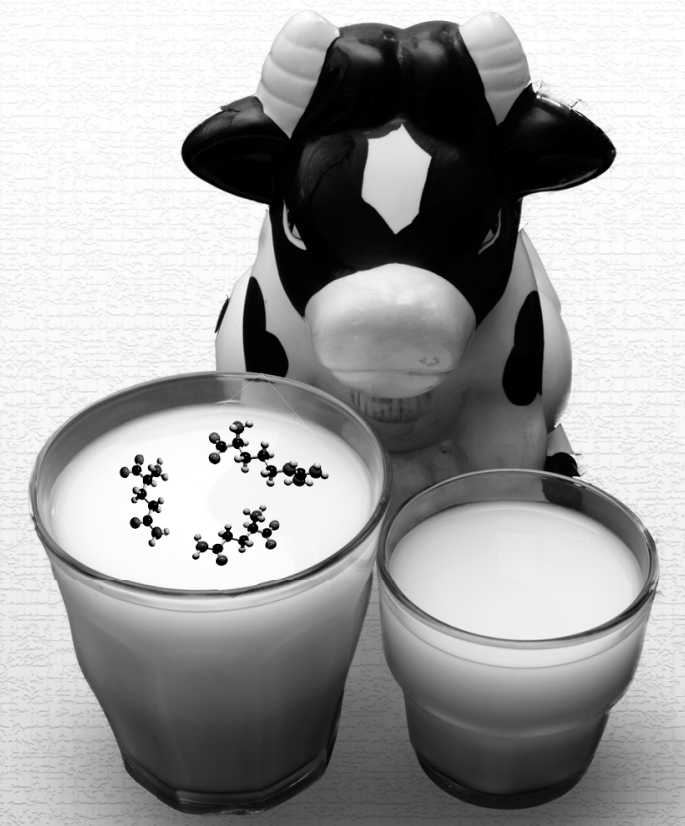

Dick A. Van Waardenburg, Tim C. Jansen, Gijs D. Vos, Wim A. Buurman

J Clin Endocrinol Metab. (2006); 91(10): 3916-21 


\section{ABSTRACT}

Context: Hyperglycemia and insulin resistance are common findings in critically ill adult patients and associated with increased morbidity and mortality.

Objectives: The objective of this study was to investigate the hyperglycemic response to critical illness in children

Design: The study was designed as an observational cohort study

Setting: The study was set in a university-affiliated pediatric intensive care unit

Patients: Six children with meningococcal sepsis (MS) without shock and 10 children with meningococcal septic shock (MSS) were patients

Main Outcome Measures: Differences in blood glucose levels (measured during $72 \mathrm{~h}$ after admission), differences in plasma levels of glucoregulatory hormones (insulin, GH, IGF-1, cortisol, glucagon, leptin), soluble cytokine receptors (sTNF-R55 and R75, sIL-1-R2) and IL-6 (measured on d 3) between MS and MSS patients were assessed

Results: Blood glucose levels on day 2 and 3 were higher in MSS than in MS patients (7.5 (3.9-13.0) vs. 5.1 (4.0-6.0) and 6.5 (4.0-9.9) vs. 5.5 (4.8-6.8) $\mathrm{mmol} / \mathrm{l}$, both $\mathrm{P}<0.05)$. Maximum blood glucose values recorded in individual patients during the study were higher in MSS patients $(9.3(6.5-13)$ vs. $7.2(6.2-9.9, \mathrm{p}<0.05)$ and correlated with severity of illness $(r=0.833, p<0.001)$. Insulin levels in MSS patients were significantly lower than in MS patients (7.2 vs. $19.0 \mathrm{mU} / \mathrm{l}, \mathrm{p}<0.001)$ compatible with insufficient insulin response to hyperglycemia while MS patients showed insulin resistance. Plasma insulin levels correlated inversely with levels of sTNF-R55 and R75 ( $r=-0.814$ and 0.878 , both $\mathrm{p}<0.001$ ) suggesting a suppression of the pro-inflammatory response on insulin secretion.

Conclusion: Hyperglycemia associated with hypoinsulinemia rather than insulin resistance seems to be the normal pathophysiological response in acute meningococcal septic shock in children. Our study emphasizes that application of intensive insulin therapy in critically ill children demands further investigation. 


\section{INTRODUCTION}

Hyperglycemia and insulin resistance are universal findings in critically ill adult patients $(1,2)$. In the acutely stressed state this metabolic response can be regarded as an adaptive response, promoting cellular glucose uptake in non-insulin-dependent tissue and as such important for survival. However more prolonged hyperglycemia has been associated with increased risk of complications like infections (3), polyneuropathy, multiple organ dysfunction syndrome (MODS)(4) and even death in adults $(5,6)$ and recently also in children (7). Prevention of hyperglycemia with intensive insulin therapy has been shown to decrease morbidity and mortality in critically patients in surgical intensive care units (ICU) (4) and is now widely propagated although the mechanisms by which insulin exerts its beneficial effects are uncertain. This is underscored by the fact that high doses of insulin in the acute setting of critical illness have also been associated with adverse outcome (8). In a recent study in patients on a medical ICU, mortality was not reduced by intensive insulin therapy and even increased in those patients who stayed in the ICU for less than three days (9).

The mechanisms underlying hyperglycemia and insulin resistance are not well understood. Increased hepatic gluconeogenesis combined with hepatic and skeletal muscle insulin resistance (10-12) are considered important factors while the role of plasma insulin levels is less well defined. Insulin resistance typically presents with hyperglycemia despite normal or increased insulin levels (10) although low insulin levels have been reported in the acute phase of injury (13-15). Pro-inflammatory cytokines play crucial roles in these mechanisms and have been shown to promote hyperglycemia either by a direct effect or via de stimulation of glucoregulatory hormones. Hepatic gluconeogenesis, for instance, is promoted by increased levels of TNF- $\alpha$, IL-1, glucagon and catecholamines $(16,17)$ while increased levels of TNF- $\alpha$ and other cytokines reduce insulin induced tyrosine phosphorylation of insulin receptor substrate-1 (IRS-I) leading to defective glucose transporter-4 (GLUT-4) translocation and thereby to a diminished glucose uptake and insulin resistance in insulin dependent tissues as skeletal and heart muscle and adipocytes. Finally, a direct inhibitory effect of TNF- $\alpha$ and/or IL-1 on pancreatic $\beta$-cells has been described in vitro (18).

Sepsis in adults has often a gradual and not well-defined onset and occurs in patients with coexisting disorders such as chronic or acute nutrient depletion, cancer or recent surgery. In contrast meningococcal sepsis in children is a fulminant form of sepsis with an acute and well-defined onset and occurring in previously healthy children. Still meningococcal sepsis features most of the secondary outcome parameters used in the Van de Berghe study such as a high incidence of MODS, renal insufficiency and red blood cell transfusion (4). This makes meningococcal sepsis in children interesting to study mechanisms of hyperglycemia in the acute phase of sepsis. Such insight into the pathophysiology of this response in this age group is necessary before exogenous insulin therapy can be safely applied to children. The objective of the present study therefore was to investigate the hyperglycemic response in children with meningococcal sepsis and septic shock with the emphasis on plasma levels of insulin and inflammatory mediators. 


\section{MATERIAL AND METHODS}

\section{Study protocol}

Children in the age between 3 months and 16 years admitted to the pediatric intensive care unit (PICU) of the university hospital Maastricht, between December 1998 and December 2000, were enrolled in the study if they fulfilled the diagnosis of severe meningococcal disease. Patients were retrospectively classified as having either meningococcal sepsis (MS) or as having meningococcal septic shock (MSS). MS was defined according to the sepsis criteria of the Society of Critical Care Medicine and the American College of Chest Physicians (SCCM/ACCP), adapted to infants and children (19), in combination with petecchiae and/or purpura and a positive blood or spinal fluid culture with neisseria meningitidis. MSS was defined as MS in combination with the presence of systolic hypotension occurring within the first 12 hours after admission refractory to one or more fluid bolus and requiring inotropic medication or vasopressors. In children younger than 4 years systolic blood pressure had to be $<75 \mathrm{mmHg}$ and in children between 4 and 12 years $<85 \mathrm{mmHg}$. Exclusion criteria were: death within 24 hours, acute renal failure (manifested by urine production less than $0.25 \mathrm{ml} / \mathrm{kg} /$ hour), and extensive skin and/or limb necrosis. By definition all MSS patients received inotropic medication or vasopressor therapy (dopamine and/or norepinephrine) and were mechanically ventilated. All patients were treated with intravenous antibiotics and did not receive corticosteroids or insulin. The study was approved by the local Medical Ethical Committee and informed consent was obtained from the parents.

\section{Enteral and parenteral intake}

All patients received intravenous dextrose solution at a rate of approximately 4 $\mathrm{mg} / \mathrm{kg} / \mathrm{min}$. as part of the standard care. Continuous enteral feeding was started at low rates within the first 24 hours after admission (Nutrison Pediatric, Nutricia, Zoetermeer, the Netherlands) and slowly increased during the next days. The rates of administration of both enteral feeding and intravenous dextrose were not changed in the 6-hour prior to blood sampling. Patients did not receive either amino acids or lipids parenterally.

\section{Clinical parameters}

The physiologic stability index (PSI) (20) was calculated over the first 24 hours after admission. Other clinical parameters that were recorded included use of mechanical ventilation, maximum doses of inotropic medication and vasopressors given and total carbohydrate and nutritional intake. 


\section{Blood analysis}

\section{Blood sampling}

Serial determinations of blood glucose levels were performed in both patient groups starting at admission and continuing at 8-hour intervals during the subsequent 3 days of their stay in the PICU. Arterial blood samples for the determination of plasma levels of insulin, glucagon, GH, IGF-1, cortisol, leptin and plasma levels of soluble TNF receptor 55 and 75 (sTNF-R55 and R75), soluble IL-1 receptor 2 (sIL-1R2) and IL-6 were collected on the third day after admission (61.7 \pm 3.3 hours after admission; mean \pm SEM), between 9:00 and 10:00 AM from an indwelling arterial catheter. At this time all patients were in a circulatory and respiratory stable condition. To calculate insulin/glucose ratios a blood glucose level was determined from the same blood sample. Blood for cytokine analysis was collected in EDTA containing tubes and immediately centrifuged for 15 minutes at $4000 \mathrm{rpm}$ at $4^{\circ} \mathrm{C}$. Plasma was then frozen at $-70^{\circ} \mathrm{C}$ until analysis.

\section{Laboratory determinations}

Blood glucose levels (Uni Kit III; Roche, Basel, Switzerland) were analyzed with the COBAS FARA semiautomatic analyzer (Roche). Plasma insulin (Insulin RIA 100 kit; Pharmacia, Uppsala, Sweden), glucagon (DPS, Los Angeles, CA) and IGF-I (DSL-5600 ACTIVE; DSL Deutschland, Sinsheim, Germany) concentrations were analyzed by radioimmunoassay. Immunometric assays were used to determine plasma $\mathrm{GH}$ (Nichols Institute Diagnostis, San Juan Capistrano, CA) and cortisol (Chiron Diagnostics, East Walpole, MA) concentrations. Urinary dopamine and epinephrine excretion was measured in an 8-hour urinary collection. sTNF-R55 and R75, sIL-1R2 and IL-6 were determined in EDTA plasma using available double-sandwich enzyme-linked immunosorbent assays (ELISA) kits (Hycult Biotechnology, Uden, The Netherlands). Assays were carried out according to the manufacturer's instructions. For detection of plasma leptin levels by ELISA reagents, kindly provided by Dr. R. Devos (Hoffmann LaRoche, Welwyn Garden City, UK), were used. The detection limit of this leptin assay is $0.04 \mathrm{ng} / \mathrm{ml}$. CRP was measured on a routine clinical chemistry analyzer, Synchron LX 20, by immunoturbidimetry, with a detection limit of $5.0 \mathrm{mg} / \mathrm{L}$ and a measuring range of 5.0-488 mg/L (Beckman Coulter, Inc., Fullerton, CA).

\section{Statistical analysis}

The Mann-Whitney U test was used to compare differences between two groups and Spearman's rank correlation coefficients were used to identify possible correlations between plasma levels of soluble TNF receptors, plasma glucose and hormone concentrations and PSI. Statistical analysis was defined as a two-tailed $p<0.05$. Analysis was performed with the SPSS statistical software package for Windows ${ }^{\circledR}$ (version 11.5; SPSS inc., Chicago, USA). Data are presented either as mean \pm SEM or median (range). 


\section{RESULTS}

\section{Patient characteristics}

16 patients admitted to the pediatric intensive care were included in the study. Ten patients were classified as meningococcal septic shock (MSS patients) and six patients as meningococcal sepsis/meningitis without shock (MS patients). Patient characteristics are shown in Table 1. Median age and body weight were similar in both groups. MSS patients had significantly higher disease severity scores as expressed by PSI. Amount of enteral intake was still low at the moment of blood sampling $(<25 \%$ of estimated requirements) but similar in both groups. Total carbohydrate intake (both intravenous and enteral) did not differ between both groups (MSS vs. MS patients: $3.67 \pm 0.76$ vs. $3.86 \pm 0.28 \mathrm{mg} / \mathrm{kg} / \mathrm{min}$., data not shown). No significant difference in renal function as expressed by plasma creatinine levels was found (MS vs. MSS patients: $48.5 \pm 10.1$ and $42.7 \pm 5.2 \mathrm{ug} / \mathrm{l}$ respectively)

Table 1. Baseline characteristics of MSS and MS patients

\begin{tabular}{|c|c|c|}
\hline & MSS patients & MS patients \\
\hline Number & 10 & 6 \\
\hline Sex & $5 \mathrm{~F} / 5 \mathrm{M}$ & $3 \mathrm{~F} / 3 \mathrm{M}$ \\
\hline Age (months) & $31.5(9-145)$ & $48.5(18-183)$ \\
\hline Body weight (kg) & $15.0(9-30)$ & $15.9(11-65)$ \\
\hline PSI & $16.5(13-30)^{*}$ & $4.0(1-7)$ \\
\hline Inotropic medication & 10 & 0 \\
\hline Mechanical ventilation & 10 & 0 \\
\hline
\end{tabular}

\section{Blood glucose levels}

Differences in severity of the hyperglycemic response between MSS and MS patients were analyzed by comparing median blood glucose levels at admission and in the subsequent three 24 hour intervals. Further the percentage of elevated blood glucose values and the maximum blood glucose value (peak blood glucose level) recorded in individual patients in the three-day study period were analyzed. To this end blood glucose levels were measured serially in all patients starting at admission and subsequently at 8-hour intervals ( $2.8 \pm 01$ measurements per patient per day). Hyperglycemia was defined using three cutoff values $(6.1,7.8$ and $11.1 \mathrm{mmol} / \mathrm{l})$, based on earlier studies reporting adverse outcome of high blood glucose values in either adult critically ill patients (4), pediatric burn patients (21) or diabetic patients (22). Median blood glucose levels in MSS and MS patients at admission and in the three subsequent 24-hour intervals are shown in Table 2. 
Table 2. Blood glucose levels in MSS and MS patients

\begin{tabular}{|c|c|c|}
\hline & MSS & MS \\
\hline Admission & $7.5(2.6-11.0)$ & $6.9(4.0-9.9)$ \\
\hline $0-24$ hours (day 1 ) & $5.4(4.0-11.3)$ & $5.7(4.0-8.8)$ \\
\hline $24-48$ hours (day 2) & $7.5(3.9-13.0)^{\#}$ & $5.1(4.0-6.0)$ \\
\hline $48-72$ hours (day 3 ) & $6.5(4.0-9.9)^{\#}$ & $5.5(4.8-6.8)$ \\
\hline
\end{tabular}

No differences were found at admission and in the first 24-hour period but blood glucose levels were significantly higher in MSS patients on day 2 and 3. In MSS patients $57.0 \%$ of all measured blood glucose levels were higher than $6.1 \mathrm{mmol} / \mathrm{l}$ while $23.3 \%$ and $3.1 \%$ exceeded $7.8 \mathrm{mmol} / \mathrm{l}$ and $11.1 \mathrm{mmol} / \mathrm{l}$ respectively. In MS patients these percentages were $42.2 \%, 13.6 \%$ and $0 \%$ (Chi-square, not significant). In MSS patients the peak blood glucose levels were higher than in MS patients (9.3 (6.5-13) vs. $7.2(6.2-9.9, \mathrm{p}<0.05)$. Furthermore the relationship between hyperglycemia and severity of illness was assessed by correlating the peak blood glucose levels with the PSI resulting in a strong correlation $(r=0.833, p<0.001)$.

\section{Mediators of the hyperglycemic response to sepsis}

To obtain better insight in the pathophysiology of hyperglycemia in sepsis, the association between glucose levels and metabolic and inflammatory parameters was assessed. Table 3 shows the results of the metabolic evaluation in MSS and MS patients. Interestingly plasma insulin levels were low in most MSS patients while normal to elevated in MS patients, resulting in a highly significant difference in median insulin levels between both groups. Insulin/glucose ratios were also significantly lower in MSS patients compared to MS patients. Although plasma insulin levels were low in MSS patients (Table 3), blood glucose levels correlated positively with plasma insulin levels $(r=0.782, p<0.01)$ (Figure 1$)$. This indicates that the pancreatic $\beta$ cells in these patients still respond to glucose levels but at a lower overall level. These findings are supportive for normal or enhanced insulin sensitivity in these patients. MS patients however were insulin resistant as shown by their high insulin/glucose ratios ( $>2.5$ ). Median plasma levels of the glucoregulatory hormones showed no significant differences between both groups (Table 3 ). Interestingly plasma levels of leptin, a hormone that participates in the regulation of insulin sensitivity, were low in both groups of patients.

Plasma triglyceride levels were elevated in both groups of patients compatible with increased lipolysis or increased hepatic lipogenesis although levels of non-esterified fatty acids (NEFA) were within normal limits. Sympathico-adrenal activity, expressed as urinary excretion of epinephrine, was similar in both patients groups. 


\section{CHAPTER 4}

Table 3. Hormonal, metabolic and inflammatory parameters on day 3 in MSS and MS patients

\begin{tabular}{|c|c|c|c|}
\hline & MSS & MS & Reference values \\
\hline Glucose $(\mathrm{mmol} / \mathrm{l})$ & $6.0(4.2-9.0)$ & $5.3(4.7-7.0)$ & $3.1-6.1$ \\
\hline Insulin (mU/l) & $7.2(1-14)^{*}$ & $19.0(16-38)$ & $4-25$ \\
\hline Ins/glucose ratio & $1.1(0.4-2.2)^{*}$ & $3.4(2.7-7.3)$ & $<2.5$ \\
\hline Cortisol (nmol/l) & $524(121-1020)$ & $402(207-862)$ & $200-700$ \\
\hline Growth hormone $(\mathrm{mU} / \mathrm{l})$ & $6.1(2.2-24.0)$ & $9.1(0.4-16.0)$ & $0-20$ \\
\hline IGF-1 (mg/ml) & $44(10-65)$ & $65(27-270)$ & $51-288$ \\
\hline Glucagon (pmol/l) & $36(14-46)$ & $37(10-38)$ & $11-37$ \\
\hline Leptin ( $\mathrm{ng} / \mathrm{ml})$ & $0.8(0.3-3.2)$ & $0.6(0.1-1.8)$ & $1-5$ \\
\hline Non esterified fatty acids $(\mathrm{mmol} / \mathrm{l})$ & $0.5(0.1-0.9)$ & $0.34(0.15-0.81)$ & $0.10-0.60$ \\
\hline Triglycerides $(\mathrm{mmol} / \mathrm{l})$ & $1.6(0.7-4.0)$ & $1.7(0.9-2.2)$ & $0.40-1.40$ \\
\hline Urinary dopamine ( $\mathrm{nmol} / \mathrm{mol}$ creat) & $3510(943-12590)^{\#}$ & $140(77-836)$ & $80-640$ \\
\hline Urinary epinephrine ( $\mathrm{nmol} / \mathrm{mol}$ creat) & $11(1-75)$ & $13(5-16)$ & $1-20$ \\
\hline sTNF-R55 (ng/ml) & $3.4(2.0-8.8)^{*}$ & $1.2(0.8-2.1)$ & \\
\hline STNF-R75 (ng/ml) & $6.5(2.8-9.7)^{*}$ & $2.1(1.2-3.6)$ & \\
\hline IL-6 (pg/ml) & 524 (72-9849) & 354 (107-4021) & \\
\hline slL-1R2 (ng/ml) & $12.2(9.9-20.5)^{\#}$ & $7.0(3.2-12.4)$ & \\
\hline $\mathrm{CRP}(\mathrm{mg} / \mathrm{l})$ & $330(230-465)^{\#}$ & $243(69-282)$ & $0-10$ \\
\hline
\end{tabular}

Data expressed as median (range). MSS=meningococcal septic shock. MS=meningococcal sepsis. ${ }^{*} p<0.05$, ${ }^{*} p<0.001$ versus MS patients

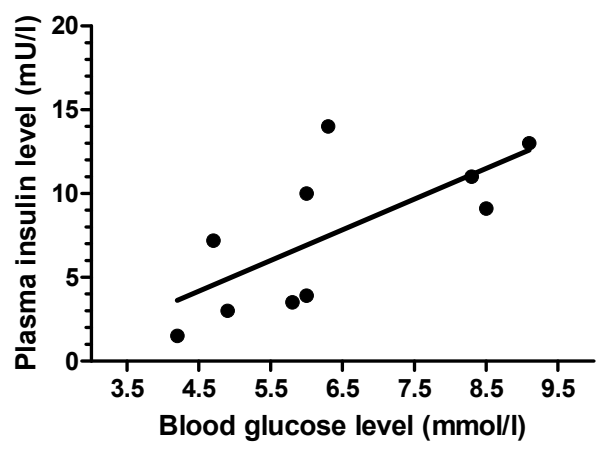

Figure 1. Relationship between plasma insulin levels and blood glucose levels in meningococcal septic shock patients. 
Analysis of inflammatory mediators revealed that plasma levels of sTNF-R55 and R75, sIL-1R2, IL-6 and CRP were all strongly elevated in both MS and MSS patients. Plasma levels of sTNF-R55 and R75, sIL-1R2, CRP but not IL-6 were significantly higher in MSS patients than in MS patients (Table 3). Levels of inflammatory mediators correlated well with clinical severity of illness as shown by a strong correlation between plasma levels of the soluble cytokines (sTNF-R75, R55 and sIL-1R2) and PSI score ( $r=0.803$, $r=0.712$ and $r=0.530$, respectively $p<0.001, p<0.001$ and $p<0.05$, data not shown).

Taken together these data show that plasma levels of both insulin and inflammatory mediators differ significantly between MSS and MS patients. This led us to further analyze the correlation between parameters of glucose metabolism and inflammation. A highly significant inverse correlation was found between plasma levels of insulin on the one hand and levels of sTNF-R55 and R75 on the other hand both for the whole patient population (Table 4) as for the MSS group ( $r=-0.754$ and $r=-0.850$, both $\mathrm{p}<0.01$ ) (Figure 2: insulin vs. sTNF-R75). Blood glucose levels correlated with severity of illness as mentioned before but not with inflammatory mediators besides a weak association with sIL-1R2 (Table 4). Also a correlation was found between blood glucose and plasma leptin levels, suggesting a role for this hormone in the regulation of glucose metabolism in our septic patients. Other glucoregulatory hormones were not significantly correlated with either inflammatory parameters or with disease severity.

Table 4. Spearman's correlation coefficients in MSS and MS patients

\begin{tabular}{|l|c|c|c|}
\hline & Glucose & Insulin & Insulin/glucose \\
\hline sTNF-R55 & 0.053 & $-0.814^{*}$ & $-0.829^{*}$ \\
\hline sTNF-R75 & -0.077 & $-0.878^{*}$ & $-0.868^{*}$ \\
\hline IL-1sRS2 & $0.618^{\#}$ & -0.488 & $-0.550^{\#}$ \\
\hline IL-6 & 0.210 & 0.213 & 0.134 \\
\hline CRP & 0.031 & -0.293 & -0.481 \\
\hline PSI & 0.134 & $-0.760^{\ddagger}$ & $-0.821^{*}$ \\
\hline Insulin & 0.220 & - & - \\
\hline Cortisol & 0.104 & -0.108 & -0.121 \\
\hline Growth hormone & -0.334 & -0.215 & -0.204 \\
\hline IGF-1 & 0.237 & 0.344 & 0.247 \\
\hline Glucagon & 0.031 & -0.077 & -0.116 \\
\hline Leptin & $0.716^{\ddagger}$ & 0.044 & -0.209 \\
\hline
\end{tabular}

MSS, meningococcal septic shock, MS, meningococcal sepsis, PSI, physiologic stability index, ${ }^{*} p<0.05$, ${ }^{\ddagger} p<0.01,{ }^{*} p<0.001$. 


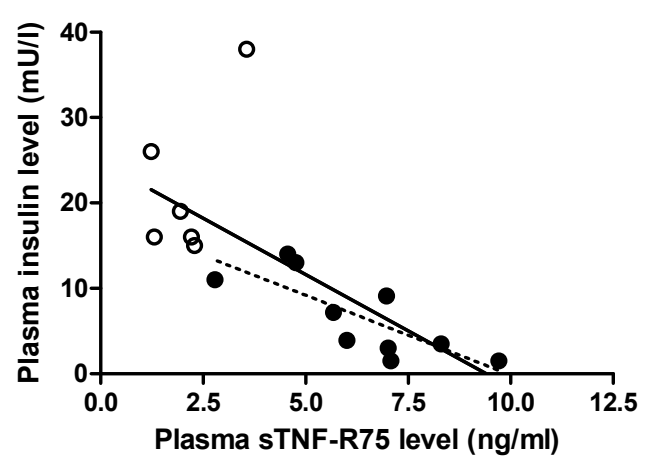

Figure 2. Relationship between plasma insulin levels and plasma levels of soluble TNF receptor 75 in meningococcal septic shock patients (MSS)(black circles) and meningococcal sepsis patients (open circles). The solid line indicates correlation of the whole patient population ( $r=-$ $0.878, p<0.001)$, the dashed line the correlation of the MSS population ( $r=-$ $0.850, p<0.01)$

\section{DISCUSSION}

Our study clearly shows that MSS and MS patients have frequent and significant hyperglycemic episodes during acute disease. The data are supported by Joosten et al. (23) who reported elevated blood glucose levels in children with MSS at admission and 24 and 48 hours later. In line, a retrospective study of blood glucose levels in a heterogeneous group of PICU patients found comparable elevated blood glucose levels both at admission and up to ten days later (7). The prevalence and severity of hyperglycemia in critically ill children is not known which can be partially explained by the absence of an accepted definition of hyperglycemia in critical illness. While hyperglycemia is defined by WHO criteria as a random blood glucose $>11.1 \mathrm{mmol} / \mathrm{l}$, lower levels have been associated with adverse outcome in both adult and pediatric critically ill patients $(4,7,21)$. In view of the Leuven Intensive Insulin Trial (4) hyperglycemia should be considered in any adult patient with a blood glucose $>6.1 \mathrm{mmol} / \mathrm{l}$. Since hyperglycemia may have severe consequences when untreated, uniform criteria for hyperglycemia in critical illness in adults and children should be established and threshold values defined above which interventions are necessary.

In our prospective study with standardized blood sampling during 72 hours after admission we demonstrate that hyperglycemia is strongly correlated with severity of illness as expressed by the PSI which is supported by Faustino et al. (7) Although a causal relationship cannot be conferred from our data, it shows that children with the highest risk of dying have the highest blood glucose values and may benefit most from treatment aimed at reducing hyperglycemia. Further, our study shows significant differences in plasma insulin levels and insulin-glucose ratios between MS and MSS patients. While MSS patients showed signs of insufficient insulin response to hyperglycemia, MS patients were insulin resistant. The relationship between insulin levels 
and severity of illness was further illustrated by the strong inverse correlation between insulin and PSI. Similarly, Joosten et al. (23) reported low insulin levels and low insulin/glucose ratios in surviving children with MSS with even lower values in non-surviving children. In surviving patients both parameters increased gradually in the first 48 hours. However we demonstrate that insulin levels and insulin/glucose ratios remained lower in MSS than in MS patients up to 72 hours. This contrasts with findings in adult critically ill patients in which low insulin levels are only reported during hypovolemic shock (13) or in early stages of sepsis $(14,24)$ while in later stages hyperinsulinemia is a constant feature. Low insulin levels in early sepsis have been attributed to suppressed insulin secretion due to strong -adrenergic inhibition of pancreatic $\beta$-cells. Our patients however were in a stabilized circulatory state although receiving inotropic support. However we cannot exclude the role of (endogenous or exogenous) catecholamines on either the systemic or splanchnic circulation in our septic patients. Neural influences may also have contributed to the differences in insulin levels in our patients since the autonomic nervous system has the potential to play a major role in control of insulin secretion in response to glucose (25) while insulin secretion is also under influence of gastrointestinal hormones as glucagon-like peptide-1 and glucose-dependent insulinotropic polypeptide (26).

In contrast to the differences in plasma insulin levels between MS and MSS patients, levels of cortisol, GH, IGF-1 and glucagon did not discriminate between the MS and MSS patients, which is supported by earlier studies of children with meningococcal disease. $(23,27)$ Leptin levels were low in both groups of patients as reported by Blanco-Quiros et al. (28) while in adults with sepsis both high and unchanged leptin data were reported (29-31). Leptin is a pleiotrope adipocyte derived hormone that regulates feeding behavior, substrate utilization and energy balance but also the inflammatory response. Leptin levels are increased related to body fat stores and decline early in starvation due to a down-regulation of human adipose tissue leptin production resulting from changes in free fatty acid levels as well as to changes in glycemia/insulinemia (32). Prolonged fasting may explain the low leptin levels in our patients since both before and during admission nutritional intake was well below estimated requirements.

MS and MSS in our patients were characterized by high levels of the soluble cytokine receptors (sTNF-R55 and 75, sIL-1R2), IL-6 and CRP with significantly higher levels in the MSS patients. Soluble cytokine receptors are shed by macrophages and endothelial cells upon activation. While expression of TNF- $\alpha$ and IL-1 is rapidly down regulated and only detectable in the most acute stage of the disease, levels of sTNF-R55, R75 and sIL-1R2 are more stable (33). Our data are supported by van Deuren et al. (34, 35) who found similar levels of soluble cytokine receptors in a group of pediatric patients with meningococcal disease. In their studies sTNF-R55, R75 and sIL-1R2 levels differentiated between shock and non-shock patients and correlated with admission TNF- $\alpha$ and IL-1 levels. In the present study levels of soluble cytokine receptors strongly correlated with the admission PSI, supporting the relationship between soluble cytokine receptor levels clinical disease severity in meningococcal disease.

Analysis of the relationship between parameters of glucose metabolism and inflammatory state in MS and MSS patients resulted in highly significant but inverse correla- 
tions between plasma insulin levels and levels of sTNF-R55 and R75. Although a causal relationship cannot be conferred from the data, our findings are compatible with an inhibitory effect of the inflammatory response on insulin secretion. This is supported by several in vitro studies showing IL-1 and TNF $\alpha$ mediated inhibition of insulin secretion by pancreatic $\beta$-cells $(18,36)$.

The metabolic response to critical illness involves multiple neuroendocrine alterations with different features in the acute and chronic stages. The acute hyperglycemic response is an adaptive process to ensure provision of essential metabolic substrates for survival. Pro-inflammatory cytokines (TNF $\alpha$, IL-1) play a crucial role by promoting hepatic gluconeogenesis and diminishing glucose uptake in insulin dependent nonimmune tissues via inhibition of insulin secretion. However insulin resistance does not play an important role as evidenced by the normal or even enhanced insulin sensitivity in our MSS patients.

The differences between adults and children may be explained by the important differences between adult and pediatric sepsis. Sepsis in adults often develops gradually after major surgery or injury and is superposed on an underlying illness while meningococcal sepsis occurs abruptly in otherwise healthy children. Next, while most deaths in adult sepsis are caused by progressive organ failure after several days of intensive care treatment most deaths in children with MSS occur in the first 24 hours after admission from refractory circulatory shock.

Our findings of prolonged hypoinsulinemic hyperglycemia in children with MSS may have important consequences for the management of hyperglycemia in meningococcal sepsis in children. Since tight glycemic control with exogenous insulin therapy has beneficial effects in adult sepsis, pediatric intensivists consider applying this treatment in pediatric septic patients. However, our study shows that the acute phase of sepsis in children is quite different from the hyperinsulinemic hyperglycemia associated with insulin resistance in adult sepsis. Our data suggest that suppression of the hyperglycemic and pro-inflammatory responses in sepsis with exogenous insulin when these responses are still crucial in the phase of overwhelming bacterial infection may not be supportive and even potentially detrimental. However further investigations are warranted to unravel the role of insulin and insulin therapy in septic children. These studies should include a greater number of pediatric patients with sepsis and septic shock and a more intensive follow up of plasma levels of glucose, insulin, catecholamines and inflammatory mediators in combination with markers of splanchnic circulation (gastric tonometry). This will necessitate a multicenter design given the relatively low incidence of meningococcal sepsis and septic shock. It would also be of particular interest to compare the hyperglycemic response between children with meningococcal and postoperative sepsis in order to look for possible explanations for the differences in clinical response to intensive insulin therapy found in adults $(4,9)$.

In conclusion, MSS in children is characterized by significant hyperglycemia associated with low plasma insulin levels. Plasma insulin levels are inversely correlated with levels of soluble cytokine receptors suggesting a suppressive effect of proinflammatory mediators on insulin secretion. Our findings emphasize that the use of intensive insulin therapy in children with MSS demands further investigation. 


\section{REFERENCES}

1. Carlson GL 2004 Hunterian Lecture: Insulin resistance in human sepsis: implications for the nutritional and metabolic care of the critically ill surgical patient. Ann R Coll Surg Engl 86:75-81

2. Wolfe R 1997 Substrate utilization/insulin resistance in sepsi/trauma. Balliere's Clinical Endocrinology and Metabolism 4:645-657

3. Zerr KJ, Furnary AP, Grunkemeier GL, Bookin S, Kanhere V, Starr A 1997 Glucose control lowers the risk of wound infection in diabetics after open heart operations. Ann Thorac Surg 63:356-61

4. van den Berghe G, Wouters P, Weekers F, Verwaest C, Bruyninckx F, Schetz M, Vlasselaers D, Ferdinande P, Lauwers P, Bouillon R 2001 Intensive insulin therapy in the critically ill patients. N Engl J Med 345:135967

5. Capes SE, Hunt D, Malmberg K, Gerstein HC 2000 Stress hyperglycaemia and increased risk of death after myocardial infarction in patients with and without diabetes: a systematic overview. Lancet 355:773-8

6. Malmberg K, Ryden L, Efendic S, Herlitz J, Nicol P, Waldenstrom A, Wedel H, Welin L 1995 Randomized trial of insulin-glucose infusion followed by subcutaneous insulin treatment in diabetic patients with acute myocardial infarction (DIGAMI study): effects on mortality at 1 year. J Am Coll Cardiol 26:57-65

7. Faustino EV, Apkon M 2005 Persistent hyperglycemia in critically ill children. J Pediatr 146:30-4

8. Finney SJ, Zekveld C, Elia A, Evans TW 2003 Glucose control and mortality in critically ill patients. Jama 290:2041-7

9. Van den Berghe G, Wilmer A, Hermans G, Meersseman W, Wouters PJ, Milants I, Van Wijngaerden E, Bobbaers H, Bouillon R 2006 Intensive insulin therapy in the medical ICU. N Engl J Med 354:449-61

10. Mizock BA 2001 Alterations in fuel metabolism in critical illness: hyperglycaemia. Best Pract Res Clin Endocrinol Metab 15:533-51

11. Virkamaki A, Yki-Jarvinen H 1994 Mechanisms of insulin resistance during acute endotoxemia. Endocrinology 134:2072-8

12. Lang $\mathrm{CH}$, Dobrescu C, Meszaros K 1990 Insulin-mediated glucose uptake by individual tissues during sepsis. Metabolism 39:1096-107

13. Carey LC, Cloutier CT, Lowery BD 1971 Growth hormone and adrenal cortical response to shock and trauma in the human. Ann Surg 174:451-60

14. Clowes GH, Jr., Martin H, Walji S, Hirsch E, Gazitua R, Goodfellow R 1978 Blood insulin responses to blood glucose levels in high output sepsis and spetic shock. Am J Surg 135:577-83

15. Dahn MS, Lange MP, Mitchell RA, Lobdell K, Wilson RF 1987 Insulin production following injury and sepsis. J Trauma 27:1031-8

16. Petit F, Bagby GJ, Lang CH 1995 Tumor necrosis factor mediates zymosan-induced increase in glucose flux and insulin resistance. Am J Physiol 268:E219-28

17. Roh MS, Moldawer LL, Ekman LG, Dinarello CA, Bistrian BR, Jeevanandam M, Brennan MF 1986 Stimulatory effect of interleukin-1 upon hepatic metabolism. Metabolism 35:419-24

18. Mehta VK, Hao W, Brooks-Worrell BM, Palmer JP 1994 Low-dose interleukin 1 and tumor necrosis factor individually stimulate insulin release but in combination cause suppression. Eur J Endocrinol 130:208-14

19. Jafari HS, McCracken GH, Jr. 1992 Sepsis and septic shock: a review for clinicians. Pediatr Infect Dis J 11:739-48

20. Yeh TS, Pollack MM, Ruttimann UE, Holbrook PR, Fields AI 1984 Validation of a physiologic stability index for use in critically ill infants and children. Pediatr Res 18:445-51

21. Gore DC, Chinkes D, Heggers J, Herndon DN, Wolf SE, Desai M 2001 Association of hyperglycemia with increased mortality after severe burn injury. J Trauma 51:540-4

22. Umpierrez GE, Isaacs SD, Bazargan N, You X, Thaler LM, Kitabchi AE 2002 Hyperglycemia: an independent marker of in-hospital mortality in patients with undiagnosed diabetes. J Clin Endocrinol Metab 87:978-82

23. Joosten KF, de Kleijn ED, Westerterp M, de Hoog M, Eijck FC, Hop WCJ, Voort EV, Hazelzet JA, HokkenKoelega AC 2000 Endocrine and metabolic responses in children with meningoccocal sepsis: striking differences between survivors and nonsurvivors. J Clin Endocrinol Metab 85:3746-53.

24. Dahn MS, Jacobs LA, Smith S, Hans B, Lange MP, Mitchell RA, Kirkpatrick JR 1985 The relationship of insulin production to glucose metabolism in severe sepsis. Arch Surg 120:166-72

25. Campfield LA, Smith FJ 1983 Neural control of insulin secretion: interaction of norepinephrine and acetylcholine. Am J Physiol 244:R629-34

26. Holst JJ, Gromada J 2004 Role of incretin hormones in the regulation of insulin secretion in diabetic and nondiabetic humans. Am J Physiol Endocrinol Metab 287:E199-206 


\section{CHAPTER 4}

27. de Groof F, Joosten KF, Janssen JA, de Kleijn ED, Hazelzet JA, Hop WC, Uitterlinden P, van Doorn J, Hokken-Koelega AC 2002 Acute stress response in children with meningococcal sepsis: important differences in the growth hormone/insulin-like growth factor I axis between nonsurvivors and survivors. J Clin Endocrinol Metab 87:3118-24

28. Blanco-Quiros A, Casado-Flores J, Arranz E, Garrote JA, Asensio J, Perez A 2002 Influence of leptin levels and body weight in survival of children with sepsis. Acta Paediatr 91:626-31

29. Arnalich F, Lopez J, Codoceo R, Jim nez M, Madero R, Montiel C 1999 Relationship of plasma leptin to plasma cytokines and human survivalin sepsis and septic shock. J Infect Dis 180:908-11

30. Bornstein SR, Licinio J, Tauchnitz R, Engelmann L, Negrao AB, Gold P, Chrousos GP 1998 Plasma leptin levels are increased in survivors of acute sepsis: associated loss of diurnal rhythm, in cortisol and leptin secretion. J Clin Endocrinol Metab 83:280-3

31. Carlson GL, Saeed M, Little RA, Irving MH 1999 Serum leptin concentrations and their relation to metabolic abnormalities in human sepsis. Am J Physiol 276:E658-62

32. Sonnenberg GE, Krakower GR, Hoffmann RG, Maas DL, Hennes MM, Kissebah AH 2001 Plasma leptin concentrations during extended fasting and graded glucose infusions: relationships with changes in glucose, insulin, and FFA. J Clin Endocrinol Metab 86:4895-900

33. van Deuren M, Frieling JT, van der Ven-Jongekrijg J, Neeleman C, Russel FG, van Lier HJ, Bartelink AK, van der Meer JW 1998 Plasma patterns of tumor necrosis factor-alpha (TNF) and TNF soluble receptors during acute meningococcal infections and the effect of plasma exchange. Clin Infect Dis 26:918-23

34. van Deuren M, van der Ven-Jongekrijg J, Bartelink AK, van Dalen R, Sauerwein RW, van der Meer JW 1995 Correlation between proinflammatory cytokines and antiinflammatory mediators and the severity of disease in meningococcal infections. J Infect Dis 172:433-9

35. van Deuren M, van der Ven-Jongekrijg J, Vannier E, van Dalen R, Pesman G, Bartelink AK, Dinarello CA, van der Meer JW 1997 The pattern of interleukin-1beta (IL-1beta) and its modulating agents IL-1 receptor antagonist and IL-1 soluble receptor type II in acute meningococcal infections. Blood 90:1101-8

36. Hughes JH, Colca JR, Easom RA, Turk J, McDaniel ML 1990 Interleukin 1 inhibits insulin secretion from isolated rat pancreatic islets by a process that requires gene transcription and mRNA translation. J Clin Invest 86:856-63 


\section{CHAPTER 5}

\section{Plasma arginine and citrulline}

concentrations in critically ill children: strong relation with inflammation

Dick A. van Waardenburg, Carlijn T.I.de Betue, Yvette C. Luiking, Monique Engel, Nicolaas E.P. Deutz.

Am J Clin Nutr (2007); 86(5): 1438-44

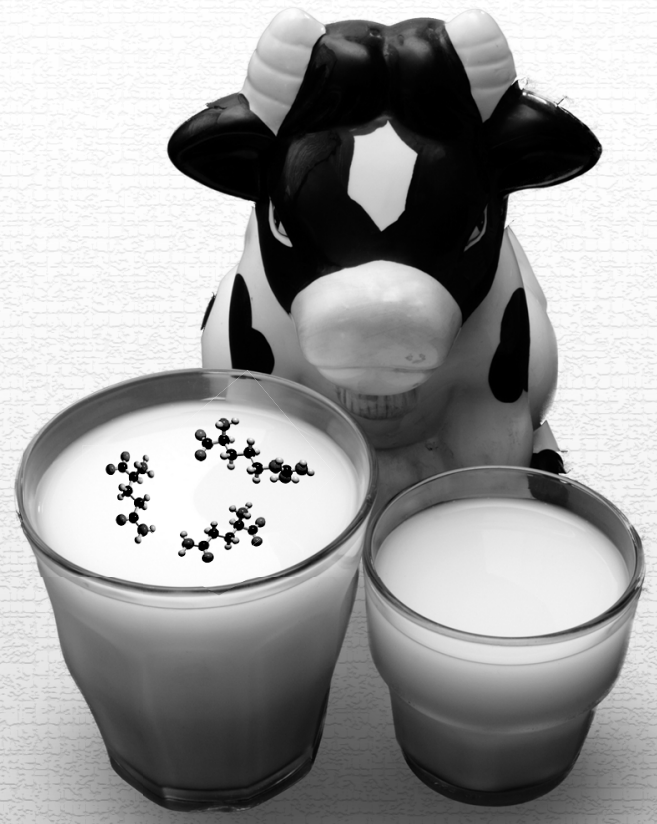




\section{ABSTRACT}

Background: The amino acid arginine plays a key role in many metabolic processes in health and disease. Low arginine concentrations are found in various illnesses in children.

Objective: To investigate the relationship between plasma concentrations of arginine (and precursor amino acids) and severity of inflammation in critically ill children.

Design: Observational cohort study in children with viral respiratory disease $(n=21$, control group), accidental/surgical trauma $(n=19)$ or sepsis $(n=19)$ admitted to a pediatric intensive care unit.

Results: Plasma arginine and citrulline concentrations were lower in sepsis and trauma than in viral disease (arginine: $33 \pm 4$ and $37 \pm 4$ vs. $69 \pm 8 \mu \mathrm{mol} / \mathrm{L}$, both $\mathrm{p}<0.01$; citrulline: $10 \pm 1$ and $14 \pm 1$ vs. $23 \pm 2 \mu \mathrm{mol} / \mathrm{L}$, both $\mathrm{p}<0.01)$ and correlated strongly and inversely with severity of inflammation expressed by plasma CRP concentration ( $r=-$ 0.645 and $r=-0.660$, respectively, both $p<0.001$ ). During recovery plasma arginine and citrulline concentrations increased, also strongly related to the reduction in inflammation as shown by the inverse correlation between arginine and citrulline concentrations and CRP concentration on days $3(r=-0.832$ and $r=-0.756$, both $p<0.001)$ and 7 $(r=-0.784$ and $r=-0.694$, both $p<0.001)$.

Conclusions: Plasma concentrations of arginine and citrulline are low during the acute phase of critical illness in children and normalize again during recovery. Plasma arginine and citrulline are strongly related to the severity of inflammation indicated by plasma CRP levels. 


\section{INTRODUCTION}

The amino acid arginine plays a key role in many metabolic processes in health and disease (1) such as detoxification of ammonia (urea cycle), synthesis of polyamines and creatine, modulation of immune function, release of anabolic hormones and synthesis of nitric oxide (NO)(2). It is considered a conditionally essential amino acid since endogenous arginine synthesis may not be sufficient to meet metabolic needs especially during growth (infants and children) (3) and during highly catabolic conditions such as sepsis $(4)$ and burns $(5,6)$. Children with critical illness may therefore particularly be at risk to develop arginine deficiency.

Low plasma arginine concentrations have been described in children with various pathological conditions such as in premature infants with necrotizing enterocolitis (NEC) (7) and children with asthma (8), cerebral malaria (9) or sickle cell crisis (10). Arginine supplementation can increase arginine concentrations and has shown beneficial effects such as prevention of NEC in premature infants and lowering of pulmonary pressure during sickle cell crisis $(10,11)$. However data on plasma arginine concentrations during critical illness in children are lacking. Critical illness is often associated with a strong inflammatory response that is related to increased $\mathrm{NO}$ production, increased arginase activity (4) and decreased renal de novo arginine synthesis (12). Inflammation could therefore play a key role in the arginine depletion and anticipated need for arginine supplementation in these conditions.

We therefore studied arterial plasma concentrations of arginine and amino acids involved in arginine metabolism (citrulline, glutamine and ornithine) in critically ill children with different diagnoses associated with mild (viral infection), moderate (accidental/surgical trauma) or severe inflammation (sepsis) and evaluated the relationship between plasma concentrations of these amino acids and inflammatory parameters.

\section{SUBJECTS AND METHODS}

\section{Subjects}

Children admitted to the pediatric intensive care unit (PICU) of the University Hospital Maastricht between January 2004 and December 2005 were enrolled in the study if they fulfilled the following criteria: (1) age between one month to 16 years; (2) diagnosis of viral respiratory disease, accidental/surgical trauma or sepsis; (3) indwelling arterial catheter. Sepsis was defined according to the criteria of the Society of Critical Care Medicine and the American College of Chest Physicians (SCCM/ACCP), adapted to infants and children (13). Exclusion criteria were known metabolic or endocrine disease. The Medical Ethical Committee of the University Hospital Maastricht approved the study. Written informed consent was obtained from all patients and/or caregivers. 


\section{Methods}

\section{Blood sampling}

Arterial blood samples were collected from an indwelling arterial catheter. Day 1 samples were collected within 24 hours after admission in the acute phase of the disease and after a fasting period of at least 6 hours. In a subgroup of 10 patients, with either viral disease or sepsis, additional blood samples were collected during recovery on days 3 and 7 during enteral feeding. Patients with accidental/surgical trauma were not included in this follow-up analysis due to their predominantly short stay in the PICU. From all blood samples plasma amino acid concentrations and plasma concentrations of glucose, insulin, cortisol, albumin, C-reactive protein (CRP) and leucocytes were determined.

\section{Blood analyses}

Arterial blood $(500 \mu \mathrm{l})$ for amino acid analysis was collected into pre-cooled heparincontaining tubes (BD Microtainer, Becton-Dickinson, United States) and immediately put on ice. Within $30 \mathrm{~min}$ the samples were centrifuged for $10 \mathrm{~min}$ at $4000 \mathrm{rpm}, 4{ }^{\circ} \mathrm{C}$, and the plasma was deproteinized by mixing with sulfosalicylic acid ( $8 \mathrm{mg}$ per $100 \mu \mathrm{L}$ plasma). Samples were subsequently frozen in liquid nitrogen and stored at $-80^{\circ} \mathrm{C}$ until analysis. Amino acid concentrations were measured in plasma by highperformance liquid chromatography (HPLC) as described by van Eijk et al. (14) with variation coefficients $<3 \%$. Glucose, albumin and CRP were determined on a Sychron LX20 PRO (Beckman Coulter, Inc., Fullerton, CA, USA). The methods used were Glucose Oxidase (Glucm), Bromcresol Purple (BCP, ALBm) and immunoturbidimetry (CRP). Plasma insulin concentrations were determined on the AutoDelfia (Perkin Elmer Life and Analytical Sciences, Wellesley, MA, USA) by an Immunofluorimetric monoclonal antibody (IFMA) assay and cortisol by using a Counting immunoassay (CIA) on an Immulite 2000 system (DPC, Los Angeles, CA, USA). Blood cells count was measured using a Beckman Coulter LH 750 (Beckman Coulter, Fullerton, CA, USA).

\section{Clinical parameters}

Severity of illness was assessed by the pediatric risk of mortality score (PRISM) (15). Other clinical parameters recorded included use of mechanical ventilation, inotropic and vasopressor therapy and corticosteroids.

\section{Nutritional intake}

All patients received intravenous dextrose at a rate of approximately $4 \mathrm{mg} / \mathrm{kg} / \mathrm{min}$. In the subgroup of patients who were also studied on days 3 and 7 , a continuous enteral drip feeding (Nutrison Pediatric, Nutricia, Zoetermeer, The Netherlands) was started 24 hours after admission (after the first blood sampling) and the drip rate was increased daily according to the treating physician. Nutritional intake, including protein intake, was registered in detail. 


\section{Statistical analysis}

All data were analyzed using the statistical program SPSS (12.0) for Windows ${ }^{\circledast}$ (SPSS Inc., Chicago, USA). A normal distribution of the data was evaluated by KolmogorovSmirnov test. Variables with a normal distribution were compared among the groups with a one-way ANOVA with post-hoc Bonferroni analysis. When a variable had no normal distribution, Kruskal-Wallis and post hoc Mann-Whitney $U$ analysis with adjustment for multiple comparisons was applied. Correlations between amino acid concentrations, protein intake and clinical and laboratory parameters were tested by using Spearman's $\rho$. The influence of CRP and protein intake on amino acid concentrations was further analyzed using (stepwise multiple) linear regression analysis. Significance was defined as $p<0.05$. Data are presented as means \pm SEM.

\section{RESULTS}

\section{Patient characteristics.}

During the study period 59 patients were included: 21 patients with viral respiratory disease, 19 patients with accidental/surgical trauma and 19 patients with sepsis. Patient characteristics are shown in Table 1. Mean age, body weight and total fasting time did not differ between patients with viral respiratory disease and those with sepsis. Trauma patients however were significantly older, had a higher body weight and more prolonged fasting time compared to both other groups. Interestingly, disease severity expressed by the PRISM score did not differ between groups. Patients with sepsis were more often treated with inotropic support (dopamine and/or norepinephrine) compared to both other groups while corticosteroid treatment was not different among the groups.

Table 1. Baseline characteristics of the study groups

\begin{tabular}{|c|c|c|c|c|c|c|c|c|c|}
\hline \multirow[b]{2}{*}{ Age $(y r)^{1}$} & \multicolumn{3}{|c|}{$\begin{array}{l}\text { Viral respiratory } \\
\text { disease } \\
(n=21)\end{array}$} & \multicolumn{3}{|c|}{$\begin{array}{c}\text { Accidental/surgical } \\
\text { trauma } \\
(n=19)\end{array}$} & \multicolumn{3}{|c|}{$\begin{array}{l}\text { Sepsis } \\
(n=19)\end{array}$} \\
\hline & 2.2 & \pm & $0.7^{\mathrm{a}}$ & 10.3 & \pm & $1.4^{\mathrm{b}}$ & 2.7 & \pm & $0.6^{\mathrm{a}}$ \\
\hline Body weight $(\mathrm{kg})^{1}$ & 12.5 & \pm & $2.4^{\mathrm{a}}$ & 35.2 & \pm & $4.0^{\mathrm{b}}$ & 13.7 & \pm & $1.7^{\mathrm{a}}$ \\
\hline Gender & \multicolumn{3}{|c|}{$3 F / 18 M$} & \multicolumn{3}{|c|}{$10 \mathrm{~F} / 9 \mathrm{M}$} & \multicolumn{3}{|c|}{$4 \mathrm{~F} / 15 \mathrm{M}$} \\
\hline PRISM $^{1}$ & 16.0 & \pm & $2.8^{\mathrm{a}}$ & 12.3 & \pm & $2.0^{\mathrm{a}}$ & 20.2 & \pm & $2.2^{\mathrm{a}}$ \\
\hline Temperature $\left({ }^{\circ} \mathrm{C}\right)^{1,2}$ & 37.1 & \pm & $0.2^{\mathrm{a}}$ & 37.2 & \pm & $0.2^{\mathrm{a}}$ & 37.0 & \pm & $0.1^{\mathrm{a}}$ \\
\hline Fasting time $(h)^{1,2}$ & 13.3 & \pm & $2.2^{\mathrm{a}}$ & 34.5 & \pm & $3.7^{\mathrm{b}}$ & 19.3 & \pm & $3.7^{\mathrm{a}}$ \\
\hline $\begin{array}{l}\text { Mechanical ventilation } \\
\text { (yes/no) }\end{array}$ & \multicolumn{3}{|c|}{$17 / 4$} & \multicolumn{3}{|c|}{$8 / 11$} & \multicolumn{3}{|c|}{$16 / 3$} \\
\hline $\begin{array}{l}\text { Inotropic support } \\
\text { (yes/no) }\end{array}$ & \multicolumn{3}{|c|}{$0 / 21$} & \multicolumn{3}{|c|}{$2 / 17$} & \multicolumn{3}{|c|}{$11 / 8$} \\
\hline $\begin{array}{l}\text { Corticosteroids } \\
\text { (yes/no) }\end{array}$ & \multicolumn{3}{|c|}{$7 / 14$} & \multicolumn{3}{|c|}{$4 / 15$} & \multicolumn{3}{|c|}{$5 / 14$} \\
\hline
\end{tabular}


The subgroup of patients in whom blood was also analyzed on days 3 and 7, consisted of 5 patients with viral disease (median age 0.4 years, range $0.3-0.8$ years; median body weight $4.6 \mathrm{~kg}$, range $4.3-7.3 \mathrm{~kg}$ ) and 5 patients with sepsis (median age 0.74 years, range 0.1-6.3 years, median body weight $6.0 \mathrm{~kg}$, range $4-24 \mathrm{~kg}$ ). Patients with sepsis in this subgroup were older and had higher body weights than patients with viral disease (both $\mathrm{p}<0.05$ ). Mean protein intake was zero, $1.0 \pm 0.3$ and $1.8 \pm 0.2 \mathrm{gram} / \mathrm{kg} /$ day on days 1, 3 and 7 respectively.

\section{Arterial plasma amino acid concentrations}

Plasma arginine concentrations were significantly lower in patients with severe inflammation (sepsis and trauma) than in patients with mild inflammation (viral disease) (Figure 1: A). This was also true for plasma citrulline and glutamine concentrations, precursors for de novo arginine synthesis (Figure 1: A-C). Plasma concentrations of ornithine, a product of arginine catabolism via the enzyme arginase, were only decreased in the patients with accidental/surgical trauma (Figure 1: D).

A

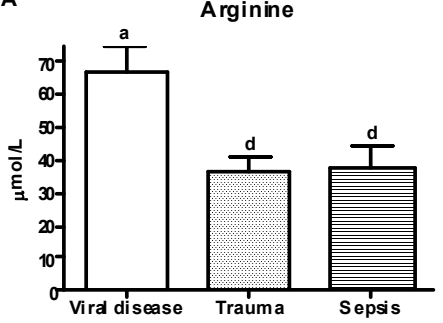

C

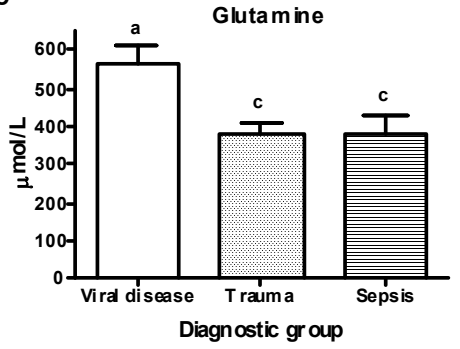

B

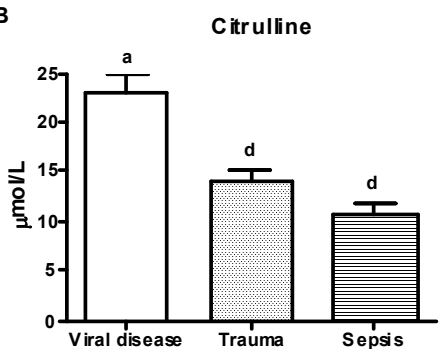

D

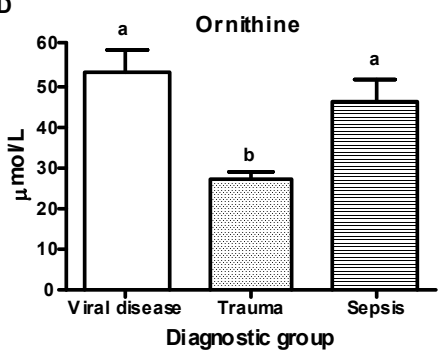

Figure 1. Plasma concentrations of arginine, citrulline, glutamine and ornithine in children with viral respiratory disease ( $n=21)$, surgical/accidental trauma ( $n=19)$ and sepsis $(n=19)$. Data are expressed as mean \pm SEM. Bars with different letters are significantly different, ${ }^{b} P<0.05,{ }^{c} P<0.01,{ }^{d} P<0.001$ (ANOVA or KruskalWallis with adjustment for multiple comparisons).

The arginine to ornithine ratio was significantly lower in septic patients when compared to the other diagnostic groups, which may indicate increased arginase activity in septic patients (Table 2). The sum of the concentration of all measured amino acids 
was also lower in the patients with sepsis and trauma than in children with viral disease. Other amino acids that showed lower concentrations included tyrosine, glycine, alanine, serine, tryptophan and lysine, while histidine showed higher plasma concentrations in septic patients when compared to patients with viral disease (Table 2).

Table 2. Arterial amino acid concentrations in the different study groups ${ }^{1}$

\begin{tabular}{|c|c|c|c|c|c|c|c|c|c|}
\hline \multirow[b]{2}{*}{ Tyrosine } & \multicolumn{3}{|c|}{$\begin{array}{c}\text { Viral Respiratory } \\
\text { Disease } \\
(n=21)\end{array}$} & \multicolumn{3}{|c|}{$\begin{array}{c}\text { Accidental/surgical } \\
\text { trauma } \\
(n=19)\end{array}$} & \multicolumn{3}{|c|}{$\begin{array}{l}\text { Sepsis } \\
(n=19)\end{array}$} \\
\hline & 48 & \pm & $3^{\mathrm{a}}$ & 37 & \pm & $2^{b}$ & 36 & \pm & $3^{b}$ \\
\hline Taurine & 36 & \pm & $3^{\mathrm{a}}$ & 37 & \pm & $4^{\mathrm{a}}$ & 28 & \pm & $4^{\mathrm{a}}$ \\
\hline Glycine & 372 & \pm & $9^{a}$ & 178 & \pm & $11^{\mathrm{b}}$ & 172 & \pm & $20^{\mathrm{b}}$ \\
\hline Glutamate & 104 & \pm & $9^{a}$ & 60 & \pm & $5^{c}$ & 52 & \pm & $5^{c}$ \\
\hline Asparagine & 47 & \pm & $4^{a}$ & 31 & \pm & $3^{b}$ & 34 & \pm & $5^{a, b}$ \\
\hline Alanine & 188 & \pm & $15^{\mathrm{a}}$ & 154 & \pm & $13^{\mathrm{a}, \mathrm{b}}$ & 130 & \pm & $13^{b}$ \\
\hline Serine & 139 & \pm & $8^{\mathrm{a}}$ & 86 & \pm & $7^{c}$ & 82 & \pm & $10^{c}$ \\
\hline Methionine & 20 & \pm & $2^{\mathrm{a}}$ & 15 & \pm & $2^{\mathrm{a}}$ & 15 & \pm & $1^{\mathrm{a}}$ \\
\hline Phenylalanine & 52 & \pm & $3^{\mathrm{a}}$ & 50 & \pm & $2^{\mathrm{a}}$ & 55 & \pm & $5^{\mathrm{a}}$ \\
\hline Tryptophan & 31 & \pm & $2^{\mathrm{a}}$ & 30 & \pm & $2^{\mathrm{a}}$ & 18 & \pm & $3^{c}$ \\
\hline Isoleucine & 48 & \pm & $5^{\mathrm{a}}$ & 44 & \pm & $5^{a}$ & 35 & \pm & $5^{a}$ \\
\hline Leucine & 84 & \pm & $7^{\mathrm{a}}$ & 83 & \pm & $7^{a}$ & 66 & \pm & $8^{\mathrm{a}}$ \\
\hline Valine & 133 & \pm & $10^{\mathrm{a}}$ & 137 & \pm & $10^{\mathrm{a}}$ & 115 & \pm & $10^{\mathrm{a}}$ \\
\hline Histidine & 66 & \pm & $3^{a, b}$ & 55 & \pm & $3^{\mathrm{a}}$ & 73 & \pm & $7^{\mathrm{b}}$ \\
\hline Lysine & 139 & \pm & $14^{\mathrm{a}}$ & 89 & \pm & $8^{c}$ & 88 & \pm & $10^{c}$ \\
\hline Threonine & 107 & \pm & $11^{\mathrm{a}}$ & 69 & \pm & $9^{a}$ & 68 & \pm & $14^{\mathrm{a}}$ \\
\hline Ratio arginine:ornithine & 1.4 & \pm & $0.1^{\mathrm{a}}$ & 1.5 & \pm & $0.1^{\mathrm{a}}$ & 0.8 & \pm & $0.1^{c}$ \\
\hline BCAA & 267 & \pm & $22^{\mathrm{a}}$ & 263 & \pm & $21^{\mathrm{a}}$ & 216 & \pm & $22^{\mathrm{a}}$ \\
\hline Sum AA & 2328 & \pm & $123^{\mathrm{a}}$ & 1610 & \pm & $104^{c}$ & 1538 & \pm & $137^{c}$ \\
\hline
\end{tabular}

${ }^{1}$ amino acid concentrations in $\mu \mathrm{mol} / L$, expressed as mean \pm SEM. BCAA, branched-chain amino acids; Sum $A A$, sum of all measured amino acids (incl. arginine, citrulline, glutamine and ornithine). Means within a row with different superscript letters are significantly different, ${ }^{b} P<0.05,{ }^{c} P<0.01$ (ANOVA or Kruskal-Wallis with adjustment for multiple comparisons).

\section{Inflammatory and metabolic parameters}

Table 3 shows the results of the inflammatory and metabolic evaluation in the different study groups. Plasma concentration of CRP, a marker of the acute phase response during inflammatory states, was significantly higher in patients with sepsis than in patients with either trauma or viral respiratory disease while CRP concentration in trauma patients was significantly higher than in patients with viral disease. Plasma concentration of albumin was lower in the septic patients than in both other groups. Leukocyte count was significantly higher in the septic patients when compared to patients with viral disease. Plasma insulin concentration was lower in the septic patients when compared to both other groups while glucose and cortisol concentrations were not significantly different among the groups. 
Table 3. Inflammatory and metabolic parameters in the different study groups ${ }^{1}$

\begin{tabular}{|c|c|c|c|c|c|c|c|c|c|c|}
\hline \multirow[b]{2}{*}{$\mathrm{CRP}(\mathrm{mg} / \mathrm{L})$} & \multicolumn{3}{|c|}{$\begin{array}{l}\text { Viral respiratory } \\
\text { disease } \\
(n=21)\end{array}$} & \multicolumn{3}{|c|}{$\begin{array}{l}\text { Accidental/surgical } \\
\text { trauma } \\
(n=19)\end{array}$} & \multicolumn{3}{|c|}{$\begin{array}{l}\text { Sepsis } \\
(n=19)\end{array}$} & \multirow{2}{*}{$\begin{array}{c}\text { Refer- } \\
\text { ence } \\
\text { values } \\
<10\end{array}$} \\
\hline & 21 & \pm & $5^{\mathrm{a}}$ & 117 & \pm & $22^{\mathrm{b}}$ & 242 & \pm & $24^{c}$ & \\
\hline $\begin{array}{l}\text { Leucocytes } \\
\left(\times 10^{9} / \mathrm{L}\right)\end{array}$ & 15 & \pm & $2^{\mathrm{a}}$ & 14 & \pm & $2^{\mathrm{a}}$ & 19 & \pm & $3^{b}$ & $8-14$ \\
\hline Glucose (mmol/L) & 5.7 & \pm & $0.3^{\mathrm{a}}$ & 6.2 & \pm & $0.4^{\mathrm{a}}$ & 5.5 & \pm & $0.3^{\mathrm{a}}$ & $3.1-5.6$ \\
\hline Insulin (mU/L) & 12.0 & \pm & $1.6^{\mathrm{a}}$ & 9.4 & \pm & $1.7^{\mathrm{a}}$ & 4.8 & \pm & $0.9^{b}$ & $4-25$ \\
\hline Cortisol (nmol/L) & 433 & \pm & $79^{a}$ & 553 & \pm & $119^{\mathrm{a}}$ & 818 & \pm & $213^{a}$ & $100-700$ \\
\hline Albumin (g/L) & 29 & \pm & $1^{\mathrm{a}}$ & 28 & \pm & $1^{\mathrm{a}}$ & 20 & \pm & $1^{\mathrm{b}}$ & $35-50$ \\
\hline
\end{tabular}

${ }^{1}$ All values are means $\pm S E M ; C R P, C$-reactive protein. Means within a row with different superscript letters are significantly different, ${ }^{b, c} P<0.01$ (ANOVA or Kruskal-Wallis with adjustment for multiple comparisons).

\section{Correlation between plasma amino acids and inflammatory an metabolic parameters}

To obtain better insight in the relation between inflammation and arginine metabolism, we investigated the association between plasma amino acid concentrations on the one hand and metabolic and inflammatory parameters on the other hand. The most striking finding was a strong but inverse correlation between plasma arginine, citrulline and glutamine concentrations on the one hand and severity of inflammation as expressed by the CRP concentration on the other hand $(r=-0.645, r=-0.660$ and $r=-$ 0.525 respectively, all $P<0.001)$. CRP was also significantly correlated with the arginine to ornithine ratio $(r=-0.518, P<0.01)$.

Regression analysis revealed that the slopes and intercepts of the regression lines of the relation between CRP and arginine and between CRP and citrulline in the three diagnostic groups were not significantly different. Therefore one regression equation could be calculated for the relation between arginine and CRP (plasma arginine = 120.1-41.6* $\log$ CRP) and between citrulline and CRP (plasma citrulline $=31.1$ $8.9 * \log C R P)$.

Plasma citrulline and arginine concentrations were positively correlated with plasma albumin concentration ( $\mathrm{r}=0.436$ and $\mathrm{r}=0.279, P<0.001$ and $P<0.01$, respectively) but no correlation was found between plasma amino acid concentrations and leukocyte count. Contrary to expectations, plasma concentration of insulin, an anabolic hormone that suppresses amino acid release from muscle tissue and stimulates amino acid uptake, was positively correlated with low concentrations of several amino acids such as glutamine and arginine $(r=0.400$ and $r=0.315$, respectively, both $P<0.01)$ while levels of cortisol, a catabolic hormone that promote net protein breakdown and amino acid output from muscle, showed an inverse correlation with glutamine and arginine concentrations $(\mathrm{r}=-0.377$ and $\mathrm{r}=-0.402$, both $P<0.01)$.

\section{Amino acid concentrations during recovery}

To investigate plasma arginine, citrulline, glutamine and ornithine concentrations during recovery, we measured amino acid concentrations (and plasma CRP concen- 
tration) also on post admission days 3 and 7 in a subgroup of patients with either sepsis or viral disease while they were receiving continuous enteral feeding. In septic patients a significant increase was found in plasma concentrations of arginine $(27 \pm 7$ vs. $68 \pm 15 \mu \mathrm{mol} / \mathrm{L})$, citrulline $(11 \pm 3$ vs. $20 \pm 3 \mu \mathrm{mol} / \mathrm{L})$, glutamine $(410 \pm 70$ vs. $807 \pm 180$ $\mu \mathrm{mol} / \mathrm{L})$ and ornithine $(59 \pm 8 \mathrm{vs} .109 \pm 30 \mu \mathrm{mol} / \mathrm{L}$ )(all $P<0.05)$ between day 1 and 7 of admission, while mean plasma CRP concentration decreased $(229 \pm 51$ vs. $57 \pm 12 ; P$ $<0.05)$. In the children with viral disease the concentrations of arginine, citrulline, glutamine and ornithine also increased and CRP decreased but the differences were not significant. Similar to the observations on day 1 , strong inverse correlations were found between plasma arginine and citrulline concentrations and plasma CRP concentration on days 3 and 7 (day 3: $r=-0.832$ and $r=-0.756$ for arginine and citrulline respectively, both $\mathrm{P}<0.01$; day $7: \mathrm{r}=-0.784$ and $\mathrm{r}=-0.694$ for arginine and citrulline respectively, both $\mathrm{P}<0.001$ )(data not shown). Regression analysis showed that the slopes and intercepts of the regression lines of the relation between CRP and arginine and between CRP and citrulline in the three diagnostic groups were not significantly different on all separate days. Therefore one regression equation could be calculated for the relation between arginine and CRP and between citrulline and CRP in both groups on days 1, 3 and 7 (for days 3 and 7 see Figure 2).
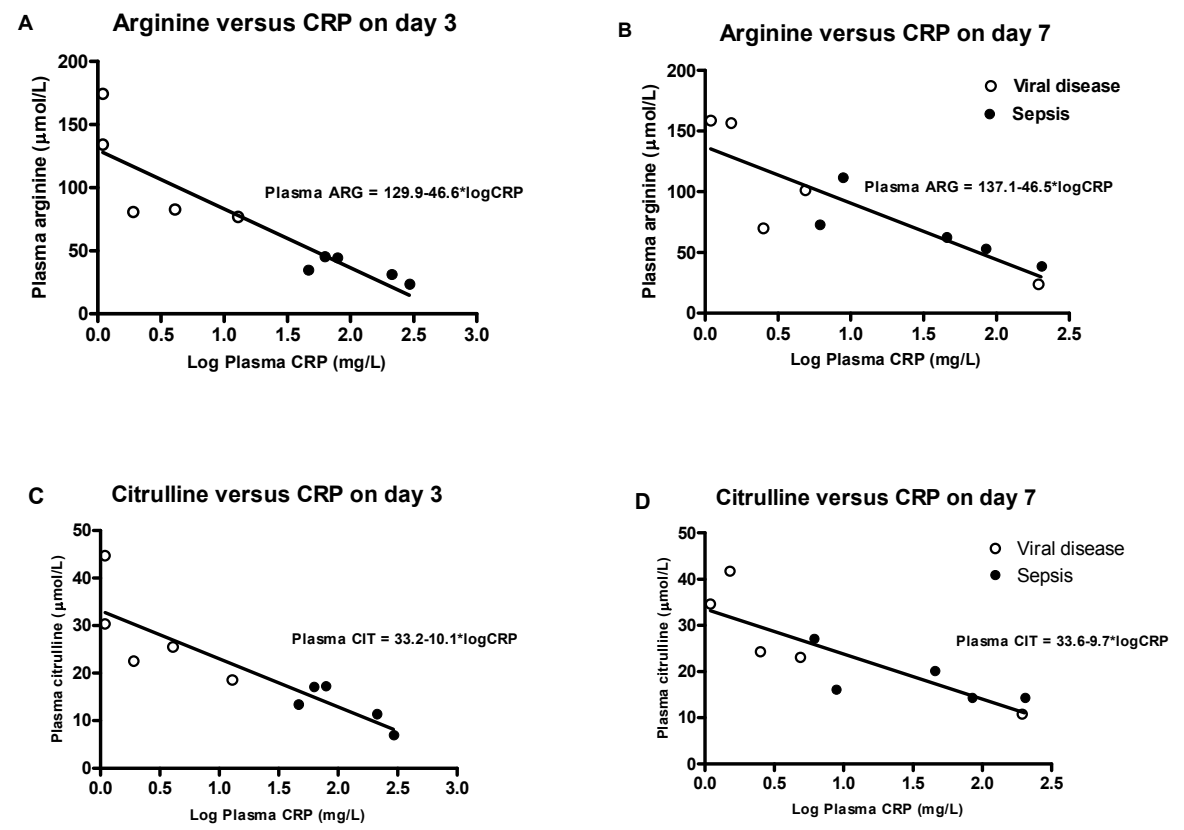

Figure 2. Relationship between plasma arginine, plasma citrulline and CRP levels on day 3 and 7 after admission in patients with viral respiratory disease (open circles, $n=5$ ) and sepsis (filled circles, $n=5$ ). The solid lines indicate the regression lines of the pooled data of patients with viral disease and sepsis on each day, with the corresponding regression equation. Log transformation of CRP values was performed because of the exponential form of the CRP curve. 
Arginine and citrulline concentrations were positively correlated with protein intake $(\mathrm{r}=0.502, \mathrm{p}<0.001$ and $\mathrm{r}=0.302, P<0.05$ for arginine and citrulline respectively) in the total group of patients. Stepwise linear regression using either plasma arginine or citrulline concentrations as dependent variable and dietary protein intake and CRP concentrations as independent variables showed that CRP was the only significant factor of plasma arginine and citrulline concentrations explaining $66 \%$ of the variation in arginine and $76 \%$ of citrulline concentrations.

\section{DISCUSSION}

In the present study we investigated arterial plasma concentrations of arginine and other amino acids involved in arginine metabolism (citrulline, glutamine and ornithine) in different diagnostic groups of critically ill children both in the acute phase and during recovery. Our results clearly show that plasma arginine concentrations are decreased in the acute phase of critical illness while during recovery a gradual increase in plasma concentrations is observed. This may indicate that arginine depletion develops in the early course of acute illness. Similar results were found for citrulline, glutamine and ornithine. Moreover, an interesting and new observation is that the reduction in arginine and citrulline concentrations in critical illness is predominantly related to the severity of systemic inflammation as expressed by the plasma CRP, a very sensitive non-specific biochemical marker of inflammation and tissue damage.

Reference values for plasma amino acid concentrations in healthy children are only available in venous blood (16), often collected in the postprandial state and under less uniform and optimal conditions. This may explain the large variation in reference values reported (16-18) and makes comparison of these values with the arterial plasma amino acid concentrations obtained in our patients under optimal conditions according to van Eijk et al. (19), difficult. For obvious ethical reasons it was impossible to obtain arterial reference values from a control group of healthy children. However, children with respiratory insufficiency due to viral upper or lower airway disease are admitted to the PICU primarily because of airway obstruction. Although these children need intensive care treatment they have only mild inflammatory disease $(\mathrm{CRP}<50 \mathrm{mg} / \mathrm{L})$ and were therefore chosen as control/reference group. Indeed their plasma amino acid concentrations are close to reported reference values (16-18). Still, in this group of patients a comparable relation was found between plasma arginine and citrulline concentrations and CRP concentration, both in the acute phase and during the recovery. Although there are limited data on plasma amino acid concentrations in critically ill children our results are supported by studies that have reported low arginine concentrations in other childhood diseases associated with inflammation such as necrotizing enterocolitis in premature infants (7), cerebral malaria (9), sickle cell disease during vaso-occlusive crises (20) and asthma during acute exacerbations (8). In the latter two studies normalization was also seen during recovery as in the present study. A direct relationship between plasma arginine concentration and level of inflammation however was not described in these studies. Only in a single 
study in adult patients with chronic kidney disease a relationship between chronic inflammation expressed by plasma CRP concentration and reduced plasma concentrations of specific plasma amino acids including arginine, has been reported (21).

The strong association between plasma arginine and citrulline concentrations and systemic inflammation that we found in the children in our study may have several explanations. Concentrations of these amino acids are determined by different metabolic processes that are altered in inflammatory conditions. Arginine concentrations may be decreased by increased arginase 1 and 2 activity (with formation of ornithine and urea) $(4,22)$, increased NO synthesis by isoforms of the enzyme NO synthase (with formation of NO and citrulline)(4) or secondary to decreased endogenous de novo arginine synthesis from citrulline in the proximal renal tubule (1) which is a major pathway for the maintenance of plasma arginine concentrations $(12,23)$. Arginine concentrations may also be decreased by increased protein synthesis (formation of acute phase reactants) or decreased dietary protein intake. Citrulline, a non protein amino acid, is predominantly produced by intestinal conversion of arterial and luminal glutamine, glutamate and proline through the glutamate-toornithine pathway $(1,24)$ but also by NO synthesis $(4)$ and by breakdown of asymmetrical dimethyl arginine, a important non-selective NOS-inhibitor (25) of which plasma concentration is increased in critical illness (26). Citrulline is metabolized by conversion into arginine in the kidney (endogenous arginine synthesis)(1). Decreased citrulline levels may be caused by decreased substrate availability in the gut (glutamine, glutamate), but since low citrulline levels have been associated with decreased gut function (27) we hypothesize that severe systemic inflammation may also have negative effects on gut function (for instance through splanchnic hypoperfusion) and thereby on citrulline production.

Argaman et al. (4) and Yu et al. $(5,28)$ studied whole body arginine metabolism using stable isotope methods in pediatric patients with sepsis and in pediatric patients with burn injury respectively. In both studies an increased whole body arginine breakdown was found whereas de novo arginine synthesis was unchanged leading to negative arginine balance. The increased arginine breakdown was associated with increased NO production and increased oxidation (by arginase) to urea and ornithine. Our results are in good agreement with these studies but also show that the changes in arginine metabolism are directly related to the severity of inflammation. In our septic patients low arginine levels were associated with increased arginase activity as shown by a low arginine to ornithine ratio while this ratio too was inversely correlated to severity of inflammation. Low arginine levels were also strongly associated with low citrulline concentrations suggesting that decreased citrulline availability for arginine production in the kidney may play a role in the genesis of arginine depletion. However to further investigate the mechanisms behind the effects of inflammation on plasma arginine and citrulline concentrations an in depth study of arginine and citrulline metabolism is needed using stable isotope methods.

Analysis of the relationship between plasma arginine concentrations and hormonal and metabolic parameters revealed a positive correlation between concentrations of insulin and those of arginine and glutamine while an inverse correlation was found between these amino acids and cortisol concentrations. This is unexpected because 
under normal conditions insulin is known to lower plasma amino acid concentration (by suppressing amino acid release from muscle tissue and by stimulation of amino acid uptake) and cortisol is known to induce hyperaminoaciduria (by promoting net protein breakdown and amino acid output from muscle). Since severe inflammation is also strongly associated with high cortisol and low insulin concentrations (29) we suggest that the change in plasma amino acid levels is primarily the result of inflammation. However the low arginine levels may also have limited the normal stimulatory effect of arginine on insulin secretion (30).

Dietary protein intake may modify amino acid profiles but plasma amino acid concentrations in all children in our study were obtained in the fasting state on day 1 . Fasting time, however, was more prolonged in the trauma patients but similar in patients with viral disease and sepsis therefore it cannot explain the differences in amino acid concentrations we found in this study. Moreover, in the subgroup of patients who were also studied during recovery while they received continuous enteral feeding, CRP was the only significant determinant of plasma arginine and citrulline levels and dietary protein intake had no further effect, although our study may not have been adequately powered to detect an effect of diet.

Our results show that arginine and citrulline depletion develops early in the course of critical illness and is proportional to the severity of the inflammatory state. Standard pediatric enteral nutrition may not contain sufficient amounts of arginine or its precursors citrulline and glutamine to correct for this depletion while the need for supplementation is probably also related to the severity of inflammation. Plasma CRP concentration, the most commonly used biochemical marker for inflammatory illness in most hospitals, may therefore be a good marker for the metabolic alterations in inflammatory states and may even predict the need for supplementation of arginine and citrulline. Citrulline availability could be an important factor in arginine depletion in the critically ill and could also indicate that inflammation affects gut function, although the latter needs further proof.

In conclusion, plasma concentrations of arginine and citrulline are low during the acute phase of critical illness in children and normalize again during recovery. Plasma arginine and citrulline are strongly related to the severity of inflammation indicated by plasma CRP levels.

\section{REFERENCES}

1. Wu G, Morris SM, Jr. Arginine metabolism: nitric oxide and beyond. Biochem J 1998;336 (Pt 1):1-17.

2. $\quad$ Morris SM, Jr. Arginine: beyond protein. Am J Clin Nutr 2006;83:508S-512S.

3. Wu G, Jaeger LA, Bazer FW, Rhoads JM. Arginine deficiency in preterm infants: biochemical mechanisms and nutritional implications. J Nutr Biochem 2004;15:442-51.

4. Argaman Z, Young VR, Noviski N, et al. Arginine and nitric oxide metabolism in critically ill septic pediatric patients. Crit Care Med 2003;31:591-7.

5. Yu YM, Sheridan RL, Burke JF, Chapman TE, Tompkins RG, Young VR. Kinetics of plasma arginine and leucine in pediatric burn patients. Am J Clin Nutr 1996;64:60-6.

6. Yu YM, Ryan CM, Castillo L, et al. Arginine and ornithine kinetics in severely burned patients: increased rate of arginine disposal. Am J Physiol Endocrinol Metab 2001;280:E509-17.

7. Zamora SA, Amin HJ, McMillan DD, et al. Plasma L-arginine concentrations in premature infants with necrotizing enterocolitis. J Pediatr 1997;131:226-32. 
8. Morris CR, Poljakovic M, Lavrisha L, Machado L, Kuypers FA, Morris SM, Jr. Decreased arginine bioavailability and increased serum arginase activity in asthma. Am J Respir Crit Care Med 2004;170:148-53.

9. Lopansri BK, Anstey NM, Weinberg JB, et al. Low plasma arginine concentrations in children with cerebral malaria and decreased nitric oxide production. Lancet 2003;361:676-8.

10. Morris CR, Morris SM, Jr., Hagar W, et al. Arginine therapy: a new treatment for pulmonary hypertension in sickle cell disease? Am J Respir Crit Care Med 2003;168:63-9.

11. Amin HJ, Zamora SA, McMillan DD, et al. Arginine supplementation prevents necrotizing enterocolitis in the premature infant. J Pediatr 2002;140:425-31.

12. Luiking YC, Steens L, Poeze M, Ramsay G, Deutz NEP. Low plasma arginine concentration in septic patients is related to diminished de novo arginine production from citrulline. Clinical Nutrition 2003;22:S26.

13. Jafari HS, McCracken GH, Jr. Sepsis and septic shock: a review for clinicians. Pediatr Infect Dis J 1992;11:739-48.

14. van Eijk HM, Rooyakkers DR, Deutz NE. Rapid routine determination of amino acids in plasma by highperformance liquid chromatography with a 2-3 microns Spherisorb ODS II column. J Chromatogr 1993;620:143-8.

15. Pollack MM RU, Getson PR. Pediatric risk of mortality (PRISM) score. Crit Care Med 1988;16:1110-1116.

16. Lepage N, McDonald N, Dallaire L, Lambert M. Age-specific distribution of plasma amino acid concentrations in a healthy pediatric population. Clin Chem 1997;43:2397-402.

17. Shapira E, Blitzer M, Miller J, Africk D. Biochemical Genetics. A Laboratory Manual. New York: Oxford University Press, 1989.

18. Sweetman L. Techniques in Diagnostic Human Biochemical Laboratoria, a Laboratory Manual. New York: Wiley Liss, 1989.

19. Van Eijk HMH, DeJong CHC, Deutz NEP, Soeters PB. Influence of storage conditions on normal plasma amino-acid concentrations. Clinical Nutrition 1994;13:374.

20. Morris CR, Kuypers FA, Larkin S, Vichinsky EP, Styles LA. Patterns of arginine and nitric oxide in patients with sickle cell disease with vaso-occlusive crisis and acute chest syndrome. J Pediatr Hematol Oncol 2000;22:515-20.

21. Suliman ME, Qureshi AR, Stenvinkel $P$, et al. Inflammation contributes to low plasma amino acid concentrations in patients with chronic kidney disease. Am J Clin Nutr 2005;82:342-9.

22. Salimuddin, Nagasaki A, Gotoh T, Isobe H, Mori M. Regulation of the genes for arginase isoforms and related enzymes in mouse macrophages by lipopolysaccharide. Am J Physiol 1999;277:E110-7.

23. Luiking YC, Poeze M, Dejong CH, Ramsay G, Deutz NE. Sepsis: an arginine deficiency state? Crit Care Med 2004;32:2135-45.

24. Windmueller HG, Spaeth AE. Source and fate of circulating citrulline. Am J Physiol 1981;241:E473-80.

25. Tran CT, Leiper JM, Vallance P. The DDAH/ADMA/NOS pathway. Atheroscler Suppl 2003;4:33-40.

26. Nijveldt RJ, Teerlink T, Van Der Hoven B, et al. Asymmetrical dimethylarginine (ADMA) in critically ill patients: high plasma ADMA concentration is an independent risk factor of ICU mortality. Clin Nutr 2003;22:23-30.

27. Crenn P, Vahedi K, Lavergne-Slove A, Cynober L, Matuchansky C, Messing B. Plasma citrulline: A marker of enterocyte mass in villous atrophy-associated small bowel disease. Gastroenterology 2003;124:1210-9.

28. Yu YM, Young VR, Castillo L, et al. Plasma arginine and leucine kinetics and urea production rates in burn patients. Metabolism 1995;44:659-66.

29. van Waardenburg DA, Jansen TC, Vos GD, Buurman WA. Hyperglycemia in Children with Meningococcal Sepsis and Septic Shock: The Relation between Plasma Levels of Insulin and Inflammatory Mediators. J Clin Endocrinol Metab 2006.

30. Dura E, Jijakli H, Zhang HX, Oguzhan B, Sener A, Malaisse WJ. Insulinotropic action of amino acids at their physiological concentrations: I. Experiments in incubated islets. Int J Mol Med 2002;9:527-31. 



\section{CHAPTER 6}

Nutritional effects of early administration of a protein and energy enriched formula in critically ill infants; a randomized controlled trial

Supported by a grant of Nutricia Advanced Medical Nutrition, Zoetermeer, The Netherlands.

Dick A. van Waardenburg, Carlijn T. de Betue, Johannes B. van Goudoever, Luc J. Zimmermann, Koen F. Joosten. Submitted for publication 


\section{ABSTRACT}

Background and aims: Nutritional support improves outcome in critically ill infants but is impeded by fluid restriction, gastric intolerance and feeding interruptions. Protein-energy enriched infant formulas may help to achieve nutritional targets earlier during admission and promote anabolism.

Methods: Randomized controlled design. Infants with respiratory failure due to RSVbronchiolitis received a protein-energy enriched formula (PE-formula, $n=8$ ) or a standard formula ( $\mathrm{S}$-formula, $\mathrm{n}=10$ ) during 5 days after admission. Primary outcome: nutrient delivery, energy and nitrogen balance and plasma amino acid concentrations. Secondary outcome: tolerance and safety.

Results: Nutrient intakes were higher in PE fed infants and met RDA by day 3-5 whilst in S-fed infants RDA was met on day 5 only. Cumulative nitrogen balance (cNB) and energy balances (cEB) were higher in PE-infants compared to S-infants (cNB: $866 \pm 113$ vs. $296 \pm 71 \mathrm{mg} / \mathrm{kg}$; cEB: $151 \pm 31$ and $26 \pm 17 \mathrm{kcal} / \mathrm{kg}$, both $\mathrm{p}<0.01)$. Essential amino acid levels were higher in PE-infants but within reference limits whereas below these limits in S-infants. Both formulas were well tolerated.

Conclusions: Early administration of a protein and energy enriched formula in critically ill infants is well tolerated, promotes a more adequate nutrient intake and improves energy and nitrogen balance without adverse effects. 


\section{INTRODUCTION}

Nutritional support is an important aspect of the clinical management of pediatric intensive care patients. Critically ill children receiving better nutritional support show significant improvement in physiologic stability and outcome (1). There is also evidence for the importance of providing adequate nutritional support in conditions such as prematurity $(2)$ and pediatric burn injury $(3,4)$. Malnutrition and nutrient store depletion may be particularly harmful in infants since this is the most critical period of brain growth and endogenous stores of a number of relevant substrates such as glycogen, fat and especially protein are small (5). Malnutrition in infancy is associated with decreased intelligence and neurological function and even infants undergoing relatively short periods of nutritional deprivation may have poorer learning abilities (6).

Several factors may impede adequate delivery of nutritional support to critically ill infants such as fluid restriction, frequent interruptions of enteral feeding for procedures and relative gastrointestinal intolerance (7). Therefore enteral nutritional intake frequently differs from the amount prescribed by the physician and protein energy deficits are often observed.

One of the most important targets of nutritional support in critically ill children is to prevent increased protein breakdown and loss of lean body mass associated with critical illness, whilst at the same time promoting tissue synthesis. It also means preventing under- or overfeeding and ultimately improving clinical outcome to ascertain normal growth and development. Protein-energy enriched infant formulas (PE-formulas) may help to achieve nutritional targets in critically ill infants in the early phase of the disease. However, it is not known if these enriched formulas are tolerated by these vulnerable infants or if they could lead to overfeeding and thereby further increase the metabolic demands of the acute illness (8). The primary goal of the present study was therefore to compare the nutritional effects (nutrient delivery, energy and nitrogen balances, and plasma amino acid profiles) of a protein and energy enriched infant formula (PE-formula) with a standard infant formula (Sformula) in a double blind randomized controlled manner, in ventilated critically ill infants. Secondary aims were to assess tolerance and safety of these formulas.

\section{SUBJECTS AND METHODS}

\section{Subjects and randomization}

Patients were recruited between December 2003 and February 2006 in the pediatric ICU's (PICU) of the Maastricht University and Medical Center (MUMC) and the Erasmus Medical Center/Sophia Rotterdam (Erasmus MC), both in the Netherlands. Infants admitted with respiratory failure due to respiratory syncytial virus (RSV) infection (positive RSV immunofluorescence in nasopharyngeal aspirate) were enrolled if they met the following inclusion criteria: 1) age between 4 weeks and 12 months; 2) born at term, or born preterm but $>40$ weeks postmenstrual age; 3 ) mechanical ventilation; 4) indwelling arterial and venous catheter; 5) stable haemody- 
namic condition (normal blood pressure with or without inotropic medication). Exclusion criteria were: 1) breastfeeding; 2) parenteral nutrition besides intravenous dextrose; 3) congenital Gl obstructions (duodenal atresia, anal atresia etc.); 4) congenital metabolic disease; 5) abnormal liver or kidney function tests or active upper Gl bleeding; 6) known chromosomal disorder; 7) diarrhea, vomiting or gastric distension before randomization

After obtaining informed consent from the parents/caregivers, infants were randomized within 24-hours of admission to receive the PE-formula (Infatrini ${ }^{\oplus}$ ) or the Sformula (Nutrilon $1^{\circledR}$ )(both from Nutricia Nederland B.V. Zoetermeer, The Netherlands) during 5 days. The compositions of both formulas are summarized in Table 1. Both study formula, indistinguishable by smell or consistency, were manufactured, prepared and delivered in identical masked and numbered bottles. Doctors, researchers, nursing staff, parents and caregivers were blinded to the feeds given. Randomization took place separately (parallel) in both centers by permuted block randomization and sequentially numbered, opaque and sealed envelopes. The code of the numbered bottles was guarded by Nutricia and only revealed after completion of the data collection in both centers.

\section{Clinical parameters}

Anthropometric measurements were taken at inclusion in the study using calibrated equipment but were not repeated because the severity of illness, with concomitant edema formation in all infants, precluded accurate measurements, whereas the study period was too brief to cause significant alterations in anthropometric values. Severity of illness was assessed by the pediatric risk of mortality score (PRISM) (9). Clinical parameters recorded during the study period-included number of ventilator days and length of stay in the PICU.

\section{Nutritional regimen and tolerance}

After randomization the study formulas were started as continuous drip-feeding by nasogastric (MUMC) or nasoduodenal catheter (Erasmus MC) according to institutional guidelines and using a calibrated feeding pump. Infants who already received enteral formula at inclusion in the study were switched to the study formulas. In order to optimize nutritional intake, the target volume of the enteral feed was 130 $\mathrm{ml} / \mathrm{kg} / 24 \mathrm{~h}$ for all infants. This was estimated to be the maximum achievable volume of fluid available for enteral nutrition in these critically ill ventilated infants. Study feeds were started at $25 \%$ of the target volume and increased with steps of $25 \%$ of the target volume every 12 hours with the aim of reaching the target volume after 36 hours. The treating physician however could limit the total volume of enteral intake when fluid restriction was deemed necessary on clinical grounds. Total macronutrient intake (enteral and intravenous) was recorded and compared to recommended dietary allowances (RDA) for healthy infants below 6 months of age (10). Tolerance of both formulas was evaluated by monitoring the volume of gastric retention every 4 hours, 
Table 1. Composition of the two enteral formulas

\begin{tabular}{|c|c|c|}
\hline Average content per $100 \mathrm{ml}$ & PE-formula & S-formula \\
\hline Energy (kcal) & 100 & 67 \\
\hline Protein (g) & 2.6 & 1.4 \\
\hline En\% & 10 & 8 \\
\hline Casein (g) & 1.0 & 0.6 \\
\hline Whey-protein (g) & 1.6 & 0.8 \\
\hline \multicolumn{3}{|l|}{ Amino acids } \\
\hline L-Alanine (mg) & 117 & 55 \\
\hline L-Arginine (mg) & 83 & 46 \\
\hline L-Aspartic acid / L-Asparagine (mg) & 225 & 120 \\
\hline L-Cystine (mg) & 39 & 22 \\
\hline L-Glutamic acid / L-Glutamine (mg) & 556 & 260 \\
\hline Glycine (mg) & 52 & 27 \\
\hline L-Histidine (mg) & 60 & 35 \\
\hline L-Isoleucine (mg) & 159 & 74 \\
\hline L-Leucine (mg) & 278 & 130 \\
\hline L-Lysine (mg) & 257 & 120 \\
\hline L-Methionine (mg) & 68 & 34 \\
\hline L-Phenylalanine (mg) & 112 & 55 \\
\hline L-Proline (mg) & 198 & 110 \\
\hline L-Serine (mg) & 156 & 69 \\
\hline L-Threonine (mg) & 169 & 73 \\
\hline L-Tryptophan (mg) & 39 & 21 \\
\hline L-Tyrosine (mg) & 107 & 44 \\
\hline L-Valine (mg) & 169 & 82 \\
\hline Carbohydrates(g) & 10.3 & 7.5 \\
\hline $\mathrm{En} \%$ & 41 & 45 \\
\hline Fat (g) & 5.4 & 3.5 \\
\hline En\% & 49 & 47 \\
\hline P:E ratio (g protein $/ 100 \mathrm{kcal}$ ) & 2.6 & 2.1 \\
\hline
\end{tabular}

the frequency and volume of vomiting and volume, frequency, and consistency of stools by the nursing staff. Intolerance was defined as gastric retentions $>50 \%$ of the administered volume over the previous 4 hours on more than one occasion, occurrence of any gastric distension or vomiting and/or diarrhea defined as $>4$ stools per day of watery consistency and leading to substantial fluid loss as either shown by negative fluid balance or haemodynamic consequences (extra fluid requirement, signs of dehydration, tachycardia or hypotension). Nitrogen balance was assessed by measuring urinary urea concentration in urine collected 24 hourly by urinary catheter. Urea was determined by an enzymatic method (Urease) on a routine clinical chemistry analyzer (Synchron LX20 Pro, Beckman Coulter Inc., Fullerton, CA, USA). Urinary urea concentration $(\mathrm{mmol} / \mathrm{L})$ was converted to urinary urea nitrogen excretion (UUN) 
and subsequently total urinary nitrogen excretion (TUN) with the following equations. Equation 1: UUN $(\mathrm{mg} / \mathrm{kg} / 24 \mathrm{~h})=$ urinary urea concentration $(\mathrm{mmol} / \mathrm{L}){ }^{*}$ urine volume $(\mathrm{L} / 24 \mathrm{~h}) * 28.02(\mathrm{mg} / \mathrm{mmol}) * \mathrm{BW}(\mathrm{kg})^{-1}$. Equation 2: TUN $(\mathrm{mg} / \mathrm{kg} / 24 \mathrm{~h})=$ UUN * 1.25, the factor 1.25 was used to correct for non-urea nitrogen. Equation 3: Nitrogen balance $(\mathrm{NB})=$ total daily protein intake $(\mathrm{mg} / \mathrm{kg} / 24 \mathrm{~h}) / 6.25-\mathrm{TUN}$, the factor 6.25 representing the average amount of nitrogen in protein. Cumulative nitrogen balance was calculated by summation of the nitrogen balances of day 1 to 5 .

\section{Energy expenditure and substrate utilization}

Resting energy expenditure was measured (MREE) daily by indirect calorimetry using a previously validated metabolic monitor (Deltatrac II MBM-200, Datex Division Instrumentarium Corp. Finland) (11). The measurement was only performed in infants fulfilling previously described criteria (tube leakage $<10 \%, \mathrm{FiO}_{2}<60 \%$ ), to assure accurate measurement. Total energy expenditure (TEE) was then calculated by adding $10 \%$ to MREE for patient activity related to nursing care. If assessment of MREE was not possible, resting energy expenditure was predicted (PREE) using the Schofield equation, adapted for age and sex (12) and used instead of MREE. Energy balances were calculated by subtracting TEE from the total daily energy intakes. Cumulative energy balances were calculated by summation of the energy balances of day 1 to 5 . Respiratory quotient (RQ) was defined as $\mathrm{VCO}_{2} / \mathrm{VO}_{2}$ and lipogenesis was defined as an $\mathrm{RQ}>1.0$. Values obtained by indirect calorimetry $\left(\mathrm{VO}_{2}, \mathrm{VCO}_{2}\right)$ and $\mathrm{UUN}$ on day 5 were used to calculate rates of protein, fat and glucose utilization during continuous enteral feeding as previously described (13). Protein, carbohydrate and fat balances were calculated by subtracting the values of nutrient utilization from the daily nutrient intake.

\section{Biochemical parameters and plasma amino acid concentrations}

Plasma concentrations of glucose, insulin, triglycerides (TG), non-esterified fatty acids (NEFA), urea and creatinine were determined in arterial blood collected on day 1 (before start of the study formula) and on day 5 (at the end of the study period). Severity of inflammation was assessed by measuring plasma C-reactive protein (CRP) concentrations on days 1 and 5. Amino acid concentrations in plasma were measured on day 5 by high-performance liquid chromatography (HPLC) as described by van Eijk et al. (14) with variation coefficients $<3 \%$. For this purpose arterial blood (500 $\mu \mathrm{l}$ ) was collected into heparin-containing tubes (BD Microtainer, Becton-Dickinson, United States) and immediately put on ice. Within $30 \mathrm{~min}$ the samples were centrifuged for 10 min at $3500 \mathrm{~g}, 4{ }^{\circ} \mathrm{C}$, and the plasma was deproteinized by mixing with sulfosalicylic acid ( $8 \mathrm{mg}$ per $100 \mu \mathrm{L}$ plasma). Samples were subsequently frozen in liquid nitrogen and stored at $-80^{\circ} \mathrm{C}$ until analysis. Determination of glucose, TG, NEFA, urea, 
creatinine and CRP were done on a routine clinical chemistry analyzer. Plasma insulin concentrations were determined in the MUMC and Erasmus MC on an AutoDelfia (Perkin Elmer Life and Analytical Sciences, Wellesley, MA, USA) by an Immunofluorimetric monoclonal antibody assay.

\section{Statistical Analysis}

Power analysis was performed based on results of nitrogen balance studies of critically ill infants (15). With two-sided significance of 0.05 and sensitivity of 0.80 the number of patients needed in both groups was 8 . Data were analyzed using the statistical program SPSS 12.0 for Windows (SPSS Inc, Chicago, IL). Normality of all data was verified by the Kolmogorov-Smirnov test. Variables with a normal distribution were compared among the groups with the independent samples t-test. When a variable had no normal distribution the Mann-Whitney $U$ analysis was applied. Results are expressed as mean \pm SEM, unless otherwise indicated. A P-value $<0.05$ was considered significant.

\section{Ethics}

Approval of the Central Committee on Research Involving Human Subject (The Hague, The Netherlands) and the local ethical committees in both centers was obtained. Written informed consent was obtained from all parents/caregivers.

\section{RESULTS}

\section{Patient characteristics}

20 critically ill infants with respiratory failure due to RSV-infection were included in the study (MUMC: $n=10$; Erasmus MC: $n=10$ ). Of these patients 10 were randomized to receive $\mathrm{PE}$-formula and 10 to receive $\mathrm{S}$-formula. Two infants in the PE-group were withdrawn from the study because they were switched by mistake to non-study formula after extubation before day 5 in both cases. Patient characteristics are shown in Table 2. Gestational age was significantly lower in the PE-group, but no other differences between the groups were found. Also there were no differences noted between patients enrolled in either center (data not shown). Duration of ventilation and length of stay on the pediatric ICU did not differ significantly between the groups. 
Table 2. Baseline patient characteristics

\begin{tabular}{|c|c|c|c|c|c|c|}
\hline & \multicolumn{3}{|c|}{ PE group $(n=8)$} & \multicolumn{3}{|c|}{$S$ group $(n=10)$} \\
\hline MUMC/Erasmus MC & \multicolumn{3}{|c|}{$4 / 4$} & \multicolumn{3}{|c|}{$6 / 4$} \\
\hline Gender (M/F) & \multicolumn{3}{|c|}{$2 / 6$} & \multicolumn{3}{|c|}{$3 / 7$} \\
\hline Age (months) & 2.7 & \pm & 0.5 & 3.0 & \pm & 0.6 \\
\hline Body weight (gram) & 3967 & \pm & 357 & 4791 & \pm & 371 \\
\hline Crown-heel length $(\mathrm{cm})$ & 52.1 & \pm & 1.4 & 55.2 & \pm & 1.5 \\
\hline Gestational age (weeks) & $35.0^{*}$ & \pm & 1.2 & 37.3 & \pm & 0.4 \\
\hline Postmenstrual age (weeks) & 46.8 & \pm & 2.9 & 49.9 & \pm & 3.0 \\
\hline Birth weight (gram) & 2299 & \pm & 341 & 2846 & \pm & 71 \\
\hline PRISM score & 20.3 & \pm & 1.6 & 18.6 & \pm & 1.5 \\
\hline CRP on admission (mg/l) & 76.7 & \pm & 23.2 & 64.4 & \pm & 20.1 \\
\hline Mechanical ventilation (days) & 7.1 & \pm & 2.2 & 5.5 & \pm & 0.7 \\
\hline Length of PICU stay (days) & 9.0 & \pm & 2.7 & 6.7 & \pm & 0.7 \\
\hline
\end{tabular}

PE group, protein energy enriched formula group; $S$ group, standard formula group; MUMC, Maastricht University Medical Center; Erasmus MC, Erasmus Medical Center; PRISM, Pediatric Risk of Mortality; CRP, Creactive protein. Data are presented either as number of subjects or mean $\pm S E M$; ${ }^{*} P<0.05$ (independent samples t-test or Mann-Whitney U).

\section{Nutrent delivery and tolerance}

Most infants (6 patients in the PE group and 7 in the $S$ group) received infant formula before start of the study and were switched to the study formula after randomization. Study formulas were started $25.3 \pm 5.6$ and $23.4 \pm 5.4$ hours after admission to the PICU in the PE- and S-group respectively and increased every 12 hours, according to the study protocol, until the target volume was reached or the treating physician decided to limit further increases of the fluid volume. Volumes of enteral intake increased during the study period but were not significantly different between the groups on any of the 5 study days (Figure 1)(day 5: $109 \pm 4$ and $111 \pm 5 \mathrm{ml} / \mathrm{kg} / 24 \mathrm{~h}$ in the PE- and Sgroup respectively). The same was true for volumes of intravenous fluids (day 5: $20.2 \pm$ 6.4 and $20.3 \pm 4.2 \mathrm{ml} / \mathrm{kg} / 24 \mathrm{~h}$ in the PE- and S-group respectively). In the majority of patients in both groups $(75 \%$ and $80 \%$ of patients in the PE-group and S-group respectively) the target volume of enteral intake $(130 \mathrm{ml} / \mathrm{kg} / 24 \mathrm{~h})$ was not reached during the study period due to fluid restriction measures by the treating physician.

Total intake of energy, protein, carbohydrate and fat on day 1 to 5 in both groups are depicted in Figure 2. Energy, protein and fat intake were significantly higher on days 3,4 and 5 in infants in the PE-group compared to the S-group, whilst total carbohydrate intake was higher on days 4 and 5.

Nutritional intake in the PE-infants met the RDA for energy (85-95 kcal $/ \mathrm{kg} / 24 \mathrm{~h})$, protein $(1.52 \mathrm{~g} / \mathrm{kg} / 24 \mathrm{~h})$, carbohydrates $(10 \mathrm{~g} / \mathrm{kg} / 24 \mathrm{~h})$ and fat $(4.7 \mathrm{~g} / \mathrm{kg} / 24 \mathrm{~h})$ already by days 3 to 5 , whilst in S-infants this was only the case by day 5 . Both formulas were well tolerated and gastric distension, vomiting and diarrhea did not occur and feed delivery was not reduced or stopped for reasons of intolerance in any of the patients in both groups 


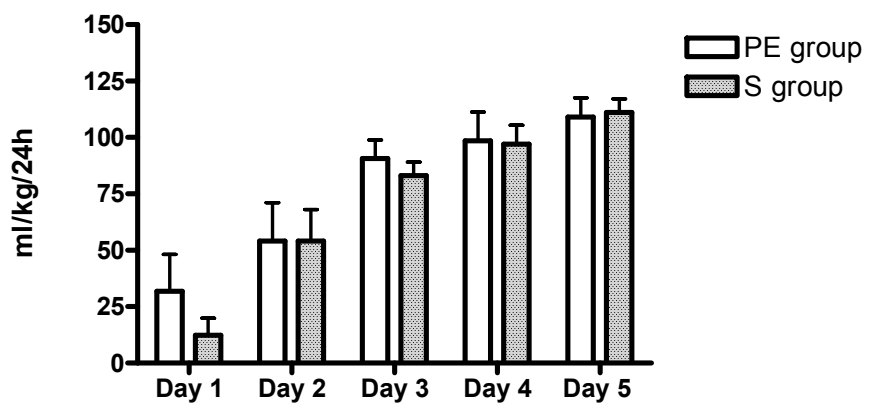

Figure 1. Volumes of enteral intake on days 1 to 5. Data are presented as mean with error bars representing SEM. PE group, protein energy enriched formula fed group $(n=8)$; $S$ group, standard formula fed group $(n=10)$

A Total energy intake

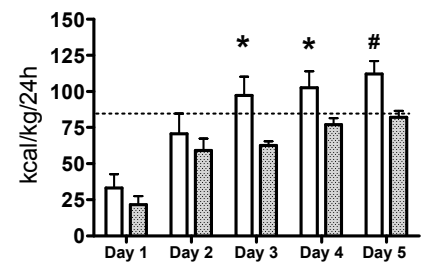

C Total $\mathrm{CHO}$ intake

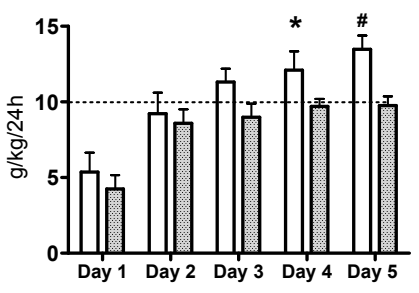

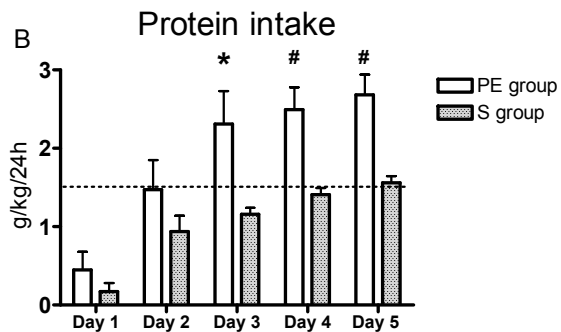

D

Fat intake

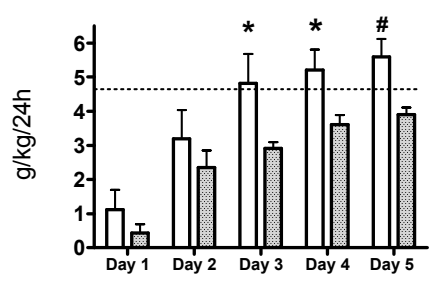

Figure 2. Total energy and macronutrient intake on days 1 to 5. Data are presented as mean with error bars representing SEM. Dotted lines represent recommended dietary allowances (RDA) for energy, protein, fat and carbohydrates. PE-group, protein-energy enriched formula fed group $(n=8) ; S$-group, standard formula fed group $(n=10)$. ${ }^{*} P<0.05, \# P<0.01$ vs. the $S$-group (independent samples t-test or Mann-Whitney $U$ ). 
during the study period. Gastric retention volumes however were significantly higher in the PE group $(9.8 \pm 2.7$ and $4.7 \pm 2.4 \mathrm{ml} / 24 \mathrm{hrs}$ in the PE-group and S-group respectively, $\mathrm{p}<0.01)$. Volume of stools did not differ between the groups $(6.4 \pm 1.6$ and $5.8 \pm$ 1.7 gram/24 hrs in the PE-group and S-group respectively). Duodenal drip-feed was given in 4 infants in the PE group and 4 in the $S$ group. There were no significant differences in the amount of feed given between infants receiving nasogastric or nasoduodenal feed and there were no differences in gastric retention volumes or stool volumes (data not shown).

\section{Nitrogen balance and plasma amino acid concentrations}

Because of incomplete urinary collections in the majority of patients on the first day of admission, 24 hour-nitrogen balances and therefore cumulative nitrogen balances could only be calculated using data from days 2 to 5 . The nitrogen balance increased during the study period in both groups but was significantly higher in infants in the PE-group on days 2 to 5 (Figure 3). Data of day 5 are also shown in Table 3. From the second day onwards all infants receiving PE-formula were anabolic whereas some infants receiving S-formula remained catabolic until day 4. Significantly higher concentrations of several essential amino acids (histidine, lysine, phenylalanine, methionine and valine) and of the non-essential amino acid ornithine were found in the PE-group compared to the S-group on day 5 (Table 4). This was also true for the sum of the branched chain amino acids (BCAA: isoleucine, leucine and valine) and the sum of all essential amino acids (methionine, histidine, phenylalanine, tryptophane, lysine, threonine and BCAA). Plasma concentrations of most amino acids did not exceed age related reference values (16), except for concentrations of glycine, lysine and threonine, which were elevated in both groups. In the S-group levels of histidine, glutamic acid, valine and isoleucine were below these reference values.
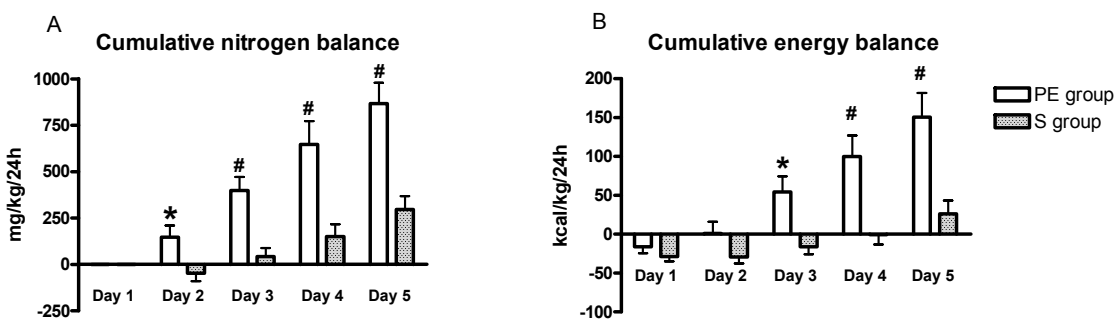

Figure 3. Cumulative nitrogen and energy balances on days 1 to 5. Data are presented as mean with error bars representing SEM. PE-group, protein-energy enriched formula fed group ( $n=8$ ); S-group, standard formula fed group ( $n=10) .{ }^{*} P<0.05,{ }^{\#} P<0.01$ vs. the $S$-group (independent samples t-test or Mann-Whitney $U$ ). 
Table 4. Plasma amino acid concentrations on day $5^{1}$

\begin{tabular}{|c|c|c|c|c|c|c|}
\hline \multirow[b]{2}{*}{ Methionine $^{2}$} & \multicolumn{3}{|c|}{ PE-group $((n=8)$} & \multicolumn{3}{|c|}{ S-group $((n=10)$} \\
\hline & $36^{*}$ & \pm & 2 & 28 & \pm & 2 \\
\hline Histidine $^{2}$ & $72^{*}$ & \pm & 5 & 58 & \pm & 4 \\
\hline Phenylalanine $^{2}$ & $77^{*}$ & \pm & 4 & 64 & \pm & 3 \\
\hline Tryptophan ${ }^{2}$ & 75 & \pm & 5 & 65 & \pm & 6 \\
\hline Lysine $^{2}$ & $238^{*}$ & \pm & 27 & 155 & \pm & 14 \\
\hline Threonine $^{2}$ & 244 & \pm & 44 & 195 & \pm & 20 \\
\hline Isoleucine ${ }^{2,3}$ & 35 & \pm & 4 & 27 & \pm & 2 \\
\hline Leucine $^{2,3}$ & 128 & \pm & 6 & 113 & \pm & 5 \\
\hline Valine $^{2,3}$ & $142^{*}$ & \pm & 9 & 112 & \pm & 4 \\
\hline Ornithine & $104^{*}$ & \pm & 9 & 80 & \pm & 8 \\
\hline Glutamic acid & 198 & \pm & 21 & 191 & \pm & 20 \\
\hline Asparagine & 68 & \pm & 8 & 67 & \pm & 6 \\
\hline Serine & 154 & \pm & 8 & 143 & \pm & 9 \\
\hline Glutamine & 646 & \pm & 61 & 610 & \pm & 30 \\
\hline Glycine & 257 & \pm & 20 & 250 & \pm & 13 \\
\hline Citrulline & 22 & \pm & 3 & 22 & \pm & 2 \\
\hline Arginine & 101 & \pm & 13 & 89 & \pm & 7 \\
\hline Alanine & 332 & \pm & 63 & 294 & \pm & 20 \\
\hline Taurine & 28 & \pm & 6 & 27 & \pm & 3 \\
\hline Tyrosine & 70 & \pm & 5 & 59 & \pm & 5 \\
\hline Sum of all AA & 3026 & \pm & 226 & 2648 & \pm & 98 \\
\hline Sum of EAA & $1047^{*}$ & \pm & 80 & 817 & \pm & 4 \\
\hline Sum of BCAA & $305^{\#}$ & \pm & 17 & 252 & \pm & 9 \\
\hline
\end{tabular}

\section{Energy expenditure and substrate utilization}

Indirect calorimetry was performed daily in a subgroup of 14 infants (5 PE-infants and $9 \mathrm{~S}$-infants) fulfilling the entry criteria (tube leakage $<10 \%, \mathrm{FiO}_{2}<60 \%$ ). 57 measurements were performed ( $2.9 \pm 0.6$ measurements per patient). The results of day 5 in these infants are shown in Table 3. MREE did not differ significantly between PE- and S-infants on days 1 to 5 . The cumulative E-balance (calculated in all infants) increased in both groups during the study period but was significantly higher in the PE-group on days 3-5 (Figure 3). RQ on day 4 and 5 was significantly higher in PE-patients than in S-patients. A RQ > 1.0, indicative of overfeeding, was found in two infants in the PE group but only on a single occasion (one on day 4 and one on day 5) out of a total of 22 measurements. Substrate utilization was calculated in the subgroup of patients in whom indirect calorimetry could be performed (Table 3). 
Glucose oxidation was significantly higher in infants receiving PE-formula in who carbohydrate intake was also higher. Carbohydrate balance was not significantly different. Fat oxidation was significantly lower in the PE-group compared to the Sgroup, in spite of a higher fat intake. This resulted in a significantly higher fat balance in the PE-group.

Table 3. Parameters of substrate utilization on day 5

\begin{tabular}{|c|c|c|c|c|c|c|c|}
\hline \multirow[b]{2}{*}{ Energy intake $^{2}$} & \multirow[b]{2}{*}{ kcal/kg/day } & \multicolumn{3}{|c|}{ PE-group } & \multicolumn{3}{|c|}{ S-group } \\
\hline & & $112^{\#}$ & \pm & 13 & 82 & \pm & 4 \\
\hline $\mathrm{MEE}^{1}$ & kcal/kg/day & 54 & \pm & 3 & 50 & \pm & 3 \\
\hline $\mathrm{RQ}^{1}$ & & $0.96^{\#}$ & \pm & 0.02 & 0.91 & \pm & 0.01 \\
\hline Cumulative energy balance $^{2}$ & $\mathrm{kcal} / \mathrm{kg}$ & $151^{\#}$ & \pm & 31 & 26.1 & \pm & 17.2 \\
\hline Protein intake ${ }^{2}$ & $\mathrm{~g} / \mathrm{kg} /$ day & $2.8^{\#}$ & \pm & 0.3 & 1.5 & \pm & 0.1 \\
\hline TUN2 & $m g / k g / d a y$ & 151 & \pm & 43 & 117 & \pm & 29 \\
\hline Cumulative nitrogen balance ${ }^{2}$ & $\mathrm{mg} / \mathrm{kg}$ & $866^{\#}$ & \pm & 113 & 296 & \pm & 71 \\
\hline Carbohydrate intake $^{1}$ & $m g / k g / d a y$ & $13.1^{*}$ & \pm & 1.3 & 9.9 & \pm & 0.6 \\
\hline Glucose utilization ${ }^{1}$ & $m g / k g / d a y$ & $14.3^{*}$ & \pm & 1.3 & 10.7 & \pm & 1.6 \\
\hline Carbohydrate balance $^{1}$ & $m g / k g / d a y$ & -0.9 & \pm & 1.0 & -0.7 & \pm & 1.7 \\
\hline Fat intake $^{1}$ & $\mathrm{~g} / \mathrm{kg} /$ day & $5.8^{*}$ & \pm & 0.4 & 3.8 & \pm & 0.2 \\
\hline Fat utilization ${ }^{1}$ & $\mathrm{~g} / \mathrm{kg} /$ day & $0.7^{*}$ & \pm & 0.3 & 1.4 & \pm & 0.2 \\
\hline Fat balance $^{1}$ & $\mathrm{~g} / \mathrm{kg} / \mathrm{day}$ & $5.1^{*}$ & \pm & 0.7 & 2.4 & \pm & 0.4 \\
\hline
\end{tabular}

${ }^{1}$ Subgroup of patients (5 PE-patients and 9 S-patients in whom indirect calorimetry could be performed). ${ }^{2}$ all patients. PE-group, protein-energy enriched formula fed group; S-group, standard formula fed group; $R Q$, respiratory quotient; MEE, measured energy expenditure; TUN, total urinary nitrogen excretion; Data are presented as mean \pm SEM. ${ }^{*} P<0.05{ }^{\#} P<0.01$ versus the $S$-group (independent samples $t$ - test or MannWhitney $U$ ).

Table 5. Biochemical parameters on day 1 and 5

\begin{tabular}{|c|c|c|c|c|c|c|c|c|c|c|c|c|c|}
\hline & & \multicolumn{6}{|c|}{ Day 1} & \multicolumn{6}{|c|}{ Day 5} \\
\hline & & \multicolumn{3}{|c|}{$\begin{array}{l}\text { PE group } \\
(n=8)\end{array}$} & \multicolumn{3}{|c|}{$\begin{array}{l}S \text { group } \\
(n=10)\end{array}$} & \multicolumn{3}{|c|}{$\begin{array}{l}\text { PE group } \\
(n=8)\end{array}$} & \multicolumn{3}{|c|}{$\begin{array}{l}S \text { group } \\
(n=10)\end{array}$} \\
\hline Glucose & $\mathrm{mmol} / \mathrm{L}$ & 5.4 & \pm & 0.3 & 5.5 & \pm & 0.3 & 5.6 & \pm & 0.2 & 5.2 & \pm & 0.1 \\
\hline Insulin & $m U / L$ & 19 & \pm & 5 & 9 & \pm & 3 & 17 & \pm & 4 & 12 & \pm & 3 \\
\hline Triglycerides & $\mathrm{mmol} / \mathrm{L}$ & 0.99 & \pm & 0.14 & 0.87 & \pm & 0.17 & 1.36 & \pm & 0.22 & 1.85 & \pm & 0.35 \\
\hline$N E F A$ & $\mathrm{mmol} / \mathrm{L}$ & 0.37 & \pm & 0.10 & 0.25 & \pm & 0.04 & 0.30 & \pm & 0.08 & 0.42 & \pm & 0.12 \\
\hline Urea & $\mathrm{mmol} / \mathrm{L}$ & 2.45 & \pm & 0.48 & 2.27 & \pm & 0.42 & 1.88 & \pm & 0.59 & 1.25 & \pm & 0.20 \\
\hline Creatinine & $\mu \mathrm{mol} / \mathrm{L}$ & 27 & \pm & 4 & 25 & \pm & 3 & 27 & \pm & 3 & 27 & \pm & 3 \\
\hline$C R P$ & $m g / L$ & 75 & \pm & 23 & 75 & \pm & 18 & $23^{*}$ & \pm & 7 & $28^{*}$ & \pm & 8 \\
\hline
\end{tabular}

$P E$, protein-energy enriched formula fed group; $S$, standard formula fed group; NEFA, non-esterified fatty acids; CRP, C-reactive protein. Data are presented as mean $\pm S E M$. ${ }^{*} P<0.05$ day 5 vs day 1 in same group (independent samples t-test or Mann-Whitney $U$ ). 


\section{Biochemical parameters}

There were no significant differences in biochemical parameters between the study groups on day 1 and 5 (Table 5). CRP decreased significantly between day 1 and 5 in both study groups.

\section{DISCUSSION}

The present double-blind randomized controlled study compared the nutritional effects of a protein-energy enriched formula (PE-formula, providing $2.6 \mathrm{~g}$ protein and $100 \mathrm{kcal} / 100 \mathrm{ml}$ ) with a standard infant formula (S-formula, providing $1.4 \mathrm{~g}$ protein and $67 \mathrm{kcal} / 100 \mathrm{ml}$ ) in similar groups of critically ill infants in the first 5 days of admission to a pediatric ICU. Our results show that the use of a PE-formula in critically ill infants promotes a higher and more adequate nutrient delivery and improves energy and nitrogen balance.

Gastrointestinal intolerance did not occur in any of the infants in our study and both formulas were well tolerated. This is in agreement with studies showing that gastrointestinal dysfunction is not a major reason for reduced intakes in critically ill infants and children Rogers, 2003 \#2610] It is also consistent with the finding of Evans et al. (17) demonstrating that PE-formula is generally well tolerated in infants even when given at full strength from the first day of usage. Further support for the safety of PEformula in critically ill children was found by the evaluation of biochemical parameters; plasma levels of triglycerides, NEFA, glucose and insulin were all within normal ranges and without significant differences between both groups. The higher protein and energy intake in infants in the PE-group resulted in a significantly higher net positive nitrogen balance suggestive of improved protein accretion and growth in the first days after admission, which is considered the most important target of nutritional support. This is in agreement with the study of Clarke et al. (18) who demonstrated that a high energy, high protein feed can improves length growth in infants with growth faltering with various disease states. Is also in agreement with earlier studies of preterm infants showing that protein balance and growth can be improved by amino acid supplementation (19), while positive effects of a high protein intake have also been found in severely ill children $(3,20)$.

The positive effect of increasing nutrient intake on protein metabolism is thought to be primarily mediated by its effect on the availability of essential amino acids. The level of carbohydrate intake alone has no effect on protein metabolism but may have an additive effect by stimulating insulin secretion (21). Increase of the plasma concentration of essential amino acids and especially the branched chain amino acids have been shown to stimulate (muscle) protein synthesis (21), suppress protein breakdown (22) and improve net protein balance. Indeed in the present study, infants receiving PE-formula had significantly higher plasma concentrations of many essential amino acids, especially the branched chain amino acids in comparison to the infants receiving S-formula.

High protein intake in infants is associated with hyper aminoacidemia and increased blood urea levels (16). However, this did not occur in the infants in the present study. 
Most plasma essential amino acid concentrations were within normal limits in the PEgroup whilst reduced concentrations of several essential amino acids were found in infants in the S-group. Since limitation in the availability of essential amino acids may limit the protein synthetic rate, insufficient intake of essential amino acids in the Sgroup may have contributed to differences in nitrogen balance found in the present study.

Optimal energy intake in infants recovering from critical illness is not well defined. Measurement of energy expenditure (MREE) with indirect calorimetry for tailoring energy supply is therefore often advocated (23). However, MREE should be seen as the minimum level of intake for maintenance of body functions and not the optimal energy intake for critically ill infants because it does not take in account the losses of energy via stools (up to $10 \%$ in infants) and energy deposition in tissues for growth that may be as high as $50 \mathrm{kcal} / \mathrm{kg} / 24 \mathrm{~h}$ (24). Since the acute metabolic response to severe stress will resolve rapidly $(<48 \mathrm{hrs})$ in most infants, normal growth and even catch up growth may resume early and energy and protein requirements might be equal to RDA. However, a considerable risk of overfeeding also exists, especially due to high carbohydrates intake (8), which was the reason for us to evaluate substrate utilization by indirect calorimetry. Infants receiving PE-formula indeed showed a higher RQ, a higher rate of glucose oxidation and a lower rate of fat oxidation. This is in agreement with earlier studies showing that glucose oxidation increased in a linear manner with increasing carbohydrate intake whilst fat utilization concomitantly decreased (25). In two infants receiving PE-formula a RQ $>1.0$ was found in a single measurement during the study (two out of the 22 measurements), which may indicate carbohydrate overfeeding. Total carbohydrate intake (intravenous and enteral) in these two infants was 8.1 and $10.2 \mathrm{mg} / \mathrm{kg} / \mathrm{min}$ at the time of measurement. Previous studies have shown a maximum glucose oxidation capacity ranging from 5 to 9 $\mathrm{mg} / \mathrm{kg} / \mathrm{min}$ in critically ill children $(26,27)$ and up to $12.5 \mathrm{mg} / \mathrm{kg} / \mathrm{min}$ in infants $(25)$. This large variation may be explained by differences in methodology (26), the severity of the underlying illness (27) and also by individual oxidation capacity of carbohydrates (28). Although a RQ $>1.0$ is often used to detect overfeeding, one should be cautious in using it on a single occasion because other factors may also affect RQ, for instance a period of tachypnea during weaning from the mechanical ventilation and measurement errors $(23,28)$.

Although the medical teams in both hospitals were strongly encouraged to maximize the delivery of enteral feeding in order to achieve the target volume of enteral intake, the actual volume of feeding delivered did not match this target in the majority of infants in both groups. This was primarily due to limiting the enteral feeds by the treating physician to compensate for fluids given with drugs and infusions and to a lesser degree also due to interruptions of enteral feeding for procedures. This is a recognized problem in ICU's and has been reported previously in critically ill children as well as in infants (29). In spite of the volume limits of the enteral feeds, nutrient intakes in infants receiving the PE-formula matched recommended daily allowances (RDA) for protein, fat and carbohydrates as early as the third day of admission while Sfed infants achieved RDA by day 5 . The importance of our findings is supported by the study of Hulst et al. (30) who prospectively studied energy and protein intake in 
pediatric ICU patients. In the course of their admission these children showed significant cumulative nutritional deficits compared to RDA associated with declined weight and arm circumference. Since deficits accumulated most rapidly during the first days of admission, they emphasized that special attention should be paid to the adequacy of feeding during the first days of admission. As shown by our data, a protein and energy enriched formula may be of particular benefit to reach nutritional goals in critically ill infants in this early phase without the risk of overfeeding.

In conclusion, early enteral administration of PE-formula to critically ill infants is well tolerated and safe, promotes an adequate nutrient delivery early in admission and improves energy and nitrogen balance without adverse metabolic effects. Further research is needed to provide insights into the potential long-term benefits of using PE-formula in critically ill infants.

\section{REFERENCES}

1. Pollack MM, Ruttimann UE, Wiley JS. Nutritional depletions in critically ill children: associations with physiologic instability and increased quantity of care. JPEN J Parenter Enteral Nutr 1985;9:309-13.

2. Dunn L HS, Weiner J, et al. Beneficial effects of early hypocaloric enteral feeding on neonatal gastrointestinal fucntion: Preliminary report of a randomized trial. J Pediatr 1988;112:622-629.

3. Alexander JW, MacMillan BG, Stinnett JD, et al. Beneficial effects of aggressive protein feeding in severely burned children. Ann Surg 1980;192:505-17.

4. Patterson BW, Nguyen T, Pierre E, Herndon DN, Wolfe RR. Urea and protein metabolism in burned children: effect of dietary protein intake. Metabolism 1997;46:573-8.

5. Cunningham JJ. Body composition and nutrition support in pediatrics: what to defend and how soon to begin. Nutr Clin Pract 1995;10:177-82.

6. Klein P, Forbes G, Nader P. Effects of starvation in infancy (pyloric stenosis) on subsequent learning abilities. J Pediatr 1975;87:8-15.

7. Hulst JM, Joosten KF, Tibboel D, van Goudoever JB. Causes and consequences of inadequate substrate supply to pediatric ICU patients. Curr Opin Clin Nutr Metab Care 2006;9:297-303.

8. Chwals WJ. Overfeeding the critically ill child: fact or fantasy? New Horiz 1994;2:147-55.

9. Pollack MM, Ruttimann UE, Getson PR. Pediatric risk of mortality (PRISM) score. Crit Care Med 1988;16:1110-6.

10. Macronutrients RotPo. Dietary Reference Intakes for Macronutrients. Washington: US National Academie of Sciences, 2005.

11. Joosten KF, Verhoeven JJ, Hop WC, Hazelzet JA. Indirect calorimetry in mechanically ventilated infants and children: accuracy of total daily energy expenditure with 2 hour measurements. Clin Nutr 1999;18:149-52.

12. Schofield WN. Predicting basal metabolic rate, new standards and review of previous work. Hum Nutr Clin Nutr 1985;39 Suppl 1:5-41.

13. Consolazio FC, Johnson RE, Pecora LJ. The computation of metabolic balances. Physiological Measurements of Metabolic Function in Man. New York: McGraw-Hill Book Company, 1963:313-339.

14. van Eijk HM, Rooyakkers DR, Soeters PB, Deutz NE. Determination of amino acid isotope enrichment using liquid chromatography-mass spectrometry. Anal Biochem 1999;271:8-17.

15. Chaloupecky V, Hucin B, Tlaskal T, et al. Nitrogen balance, 3-methylhistidine excretion, and plasma amino acid profile in infants after cardiac operations for congenital heart defects: the effect of early nutritional support. J Thorac Cardiovasc Surg 1997;114:1053-60.

16. Janas LM, Picciano MF, Hatch TF. Indices of protein metabolism in term infants fed either human milk or formulas with reduced protein concentration and various whey/casein ratios. J Pediatr 1987;110:838-48.

17. Evans S, Twaissi H, Daly A, Davies P, Macdonald A. Should high-energy infant formula be given at full strength from its first day of usage? J Hum Nutr Diet 2006;19:191-7; quiz 199-201. 


\section{CHAPTER 6}

18. Clarke SE, Evans S, Macdonald A, Davies P, Booth IW. Randomized comparison of a nutrient-dense formula with an energy-supplemented formula for infants with faltering growth. J Hum Nutr Diet 2007;20:329-39.

19. te Braake FW, van den Akker CH, Wattimena DJ, Huijmans JG, van Goudoever JB. Amino acid administration to premature infants directly after birth. J Pediatr 2005;147:457-61.

20. Patterson B, Nguyen T, Pierre E, Herndon D, Wolfe R. Urea and protein metabolism in burned children: effect of dietary protein intake. Metabolism 1997;46:573-578.

21. Wolfe RR. Regulation of muscle protein by amino acids. J Nutr 2002;132:3219S-24S.

22. Poindexter BB, Karn CA, Ahlrichs JA, et al. Amino acids suppress proteolysis independent of insulin throughout the neonatal period. Am J Physiol 1997;272:E592-9.

23. Joosten KF, Verhoeven JJ, Hazelzet JA. Energy expenditure and substrate utilization in mechanically ventilated children. Nutrition 1999;15:444-8.

24. Butte NF. Energy requirements of infants. Public Health Nutr 2005;8:953-67.

25. Jones MO, Pierro A, Hammond P, Nunn A, Lloyd DA. Glucose utilization in the surgical newborn infant receiving total parenteral nutrition. J Pediatr Surg 1993;28:1121-5.

26. Sheridan RL, Yu YM, Prelack K, Young VR, Burke JF, Tompkins RG. Maximal parenteral glucose oxidation in hypermetabolic young children: a stable isotope study [see comments]. JPEN J Parenter Enteral Nutr 1998;22:212-6.

27. Coss-Bu JA, Jefferson LS, Walding D, David Y, Smith EO, Klish WJ. Resting energy expenditure in children in a pediatric intensive care unit: comparison of Harris-Benedict and Talbot predictions with indirect calorimetry values. Am J Clin Nutr 1998;67:74-80.

28. Verhoeven J, JA H, Joosten K. Indirect calorimetry in mechanically ventilated infants and children. Intensive Care Med 1996;22:s195.

29. Rogers EJ, Gilbertson HR, Heine RG, Henning R. Barriers to adequate nutrition in critically ill children. Nutrition 2003;19:865-8.

30. Hulst JM, van Goudoever JB, Zimmermann LJ, et al. The effect of cumulative energy and protein deficiency on anthropometric parameters in a pediatric ICU population. Clin Nutr 2004;23:1381-9. 


\section{CHAPTER 7}

\section{High protein and energy intakes promote anabolism in critically ill infants; a randomized controlled trial}

Supported by a grant of Nutricia Advanced Medical Nutrition, Zoetermeer, The Netherlands.

Dick A. van Waardenburg, Carlijn T. de Betue, Nicolaas E. Deutz, Hans M. van Eijk, Johannes B. van Goudoever, Yvette C. Luiking, Luc J. Zimmermann, Koen F. Joosten

Submitted for publication 


\section{ABSTRACT}

Background: Critical illness in infants and children is associated with net protein degradation, negative nitrogen balance and loss of lean body mass. Nutritional support improves outcome in critically ill adults and children. However, requirements for critically ill infants are not well defined.

Objective: To compare the effects of (enteral) feeding with high versus standard protein and energy content on whole body protein balance in critically ill infants.

Design: Double blind randomized controlled trial. Critically ill infants (<1year) with respiratory failure due to RSV infection were randomized to receive a protein and energy enriched formula, PE-formula $(\mathrm{n}=8$ ) (providing $3.0 \pm 0.2 \mathrm{~g}$ protein $/ \mathrm{kg} / 24 \mathrm{~h}$ and $118 \pm 5 \mathrm{kcal} / \mathrm{kg} / 24 \mathrm{~h}$ or standard formula, S-formula ( $\mathrm{n}=10$ ) (providing $1.6 \pm 0.1 \mathrm{~g} / \mathrm{kg} / 24 \mathrm{~h}$ protein and $84 \pm 3 \mathrm{kcal} / \mathrm{kg} / 24 \mathrm{~h}$, equivalent to RDA for healthy infants) during the first 5 admission days. Primary outcome measures were whole body protein synthesis, breakdown and balance, measured by combined intravenous and enteral phenylalanine and tyrosine isotope infusions on day 5.

Results: Whole body protein synthesis $(9.6 \pm 1.6$ vs. $5.2 \pm 0.8 \mathrm{~g} / \mathrm{kg} / 24 \mathrm{~h} ; \mathrm{p}=0.019)$, protein breakdown $(8.9 \pm 1.6$ vs. $5.2 \pm 0.8 \mathrm{~g} / \mathrm{kg} / 24 \mathrm{~h} ; \mathrm{p}=0.046)$ and net protein balance $(0.7 \pm 0.2$ vs. $-0.03 \pm 0.16 \mathrm{~g} / \mathrm{kg} / 24 \mathrm{~h} ; \mathrm{p}=0.026)$ were significantly higher in PE-fed infants compared to S-fed infants.

Conclusions: Feeding critically ill infants a high protein and energy formula from the first days of admission leads to net protein anabolism. 


\section{INTRODUCTION}

Critical illness in children is associated with profound changes in protein metabolism like increased net protein degradation, negative nitrogen balance and loss of lean body mass. This protein catabolism is aggravated by inadequate nutritional intake in relation to the substantial protein and energy deficits that are present early during admission (1). Protein energy malnutrition is found in $16-24 \%$ of these children $(2,3)$ and is associated with adverse outcome (4-6) while critically ill children receiving more adequate amounts of nutritional support show significant improvement in physiologic stability and outcome (5-8).

Nutritional supplementation with amino acids can improve net protein balance and growth by increasing protein synthesis in preterm infants (9-11). Beneficial effects of high protein intake (> recommended dietary allowances (RDA) for healthy children) have been described in neonates undergoing surgery $(2.5 \mathrm{~g} / \mathrm{kg} / 24 \mathrm{~h})(12)$, children with burns (2.9-4 g/kg/24h) (13) (14) and cystic fibrosis (5 g/kg/24h)(15). In addition, energy intake is of importance as it is well established that energy deficiency worsens nitrogen balance $(16,17)$. The goal of nutritional therapy in critical illness is to protect lean body mass and function as much as possible and to improve health state by providing adequate amounts of substrates. Although high intakes of protein and energy may also benefit critically ill infants and children, knowledge on nutritional requirements is limited and requires further study.

Stable isotope methods are most appropriate to determine the effect of nutritional interventions on parameters of protein metabolism. Dietary protein is partly extracted by the splanchnic area where it serves both the synthesis of liver proteins and the accumulation of proteins in the so-called labile protein pool in the gut (18). By the simultaneous administration of an intravenous and an enteral tracer, the first-pass splanchnic utilization of dietary protein can be measured and accounted for when calculating the whole body effects of nutrition on protein metabolism (19).

In the present study we measured whole body protein synthesis and breakdown on the fifth day of admission, using combined intravenous and enteral phenylalanine and tyrosine isotope infusions to study the effect of two infant formulas with different protein and energy contents $(2.6 \mathrm{~g}$ protein and $100 \mathrm{kcal} / 100 \mathrm{ml} \mathrm{vs} .1 .4 \mathrm{~g}$ protein and 67 $\mathrm{kcal} / 100 \mathrm{ml}$ formula) in two comparable groups of critically ill infants. The primary aim of this study was to compare the effects of two levels of dietary protein and energy intake on whole body protein balance in these critically ill infants. The second aim was to assess splanchnic amino acid utilization during continuous enteral nutrition.

\section{SUBJECTS AND METHODS}

\section{Patient population}

Infants with respiratory insufficiency and need for mechanical ventilation admitted to the pediatric intensive care unit (PICU) of Erasmus Medical Center-Sophia Children's Hospital (Erasmus MC) or Maastricht University and Medical Center (MUMC) were enrolled if they fulfilled the following inclusion criteria: 1) diagnosis of respiratory 
syncytial virus (RSV) bronchiolitis (positive RSV immunofluorescence in nasopharyngeal aspirate); 2) age between 4 weeks-12 months; 3) >40 weeks postmenstrual age; 4) ability to start enteral feeding within $24 \mathrm{~h}$ after admission; 5) expected length of stay $>72$ hours; 6) exclusively formula fed; 7) venous and arterial catheter. Exclusion criteria were 1) history of gastrointestinal, metabolic or chromosomal disorder; 2) renal or hepatic disease; 3) parenteral nutrition besides intravenous dextrose.

The Central Committee on Research Involving Human Subjects (CCMO, The Hague, the Netherlands) and the local ethical committee reviewed and approved this study. Written informed consent was obtained from the parents of the infants who served as study subjects.

Table 1. Macronutrient composition of the infant formulas

\begin{tabular}{|c|c|c|}
\hline Average content per $100 \mathrm{ml}$ & PE-formula & S-formula \\
\hline Energy (kcal) & 100 & 67 \\
\hline Protein (g) & 2.6 & 1.4 \\
\hline En\% & 10 & 8 \\
\hline Casein / whey (g) & $1.0 / 1.6$ & $0.6 / 0.8$ \\
\hline \multicolumn{3}{|l|}{ Amino acids } \\
\hline L-Alanine (mg) & 117 & 55 \\
\hline L-Arginine (mg) & 83 & 46 \\
\hline L-Aspartic acid / L-Asparagine (mg) & 225 & 120 \\
\hline L-Cystine (mg) & 39 & 22 \\
\hline L-Glutamic acid / L-Glutamine (mg) & 556 & 260 \\
\hline Glycine (mg) & 52 & 27 \\
\hline L-Histidine (mg) & 60 & 35 \\
\hline L-Isoleucine (mg) & 159 & 74 \\
\hline L-Leucine (mg) & 278 & 130 \\
\hline L-Lysine (mg) & 257 & 120 \\
\hline L-Methionine (mg) & 68 & 34 \\
\hline L-Phenylalanine (mg) & 112 & 55 \\
\hline L-Proline (mg) & 198 & 110 \\
\hline L-Serine (mg) & 156 & 69 \\
\hline L-Threonine (mg) & 169 & 73 \\
\hline L-Tryptophan (mg) & 39 & 21 \\
\hline L-Tyrosine (mg) & 107 & 44 \\
\hline L-Valine (mg) & 169 & 82 \\
\hline Carbohydrates(g) & 10.3 & 7.5 \\
\hline En \% & 41 & 45 \\
\hline Fat (g) & 5.4 & 3.5 \\
\hline En\% & 49 & 47 \\
\hline $\mathrm{P}:$ E ratio (g protein $/ 100 \mathrm{kcal}$ ) & 2.6 & 2.1 \\
\hline
\end{tabular}

PE-formula, protein-energy enriched formula; S-formula, standard infant formula; En\%, energy-percentage. $P:$ ratio, protein:energy ratio. 


\section{Nutritional regimen}

Patients were randomized within $24 \mathrm{~h}$ of admission to the PICU to receive a standard infant formula (Nutrilon $1^{\circ}$, S-formula: $1.4 \mathrm{~g}$ protein and $67 \mathrm{kcal} / 100 \mathrm{ml}$ ) or a proteinenergy enriched formula (Infatrini ${ }^{\circ}$, PE-formula: $2.6 \mathrm{~g}$ protein and $100 \mathrm{kcal} / 100 \mathrm{ml}$ ) both from Nutricia Nederland BV, Zoetermeer, The Netherlands. Randomization took place separately (parallel) in the two centers by using sequentially numbered, opaque and sealed envelopes. Both formulas were administered as nasogastric $(n=10)(M U M C)$ or as nasoduodenal $(n=8)$ (Erasmus MC) continuous drip using calibrated syringe pumps conform institutional guidelines. Compositions of both formulas are summarized in Table 1. The study formulas were manufactured, prepared and delivered in identical masked and numbered bottles. Researchers, medical and nursing staff and patients were blinded to the study formula given. When informed consent was obtained, the study formulas were started at $25 \%$ of target enteral intake $(130 \mathrm{ml} / \mathrm{kg} / 24 \mathrm{~h})$, estimated to be the maximum achievable volume of fluid available for enteral nutrition in these critically ill ventilated infants. Infants already receiving enteral feeding at inclusion in the study were switched to the study formula. Enteral intake was increased every 12-hours with steps of $25 \%$ of the target volume of intake with the aim of reaching this target after 36 hours. The treating physician however could limit the enteral intake when fluid restriction was deemed necessary on clinical grounds. Enteral intake was not changed in the 6 hours before, and during the stable isotope tracer measurement.

\section{Whole body protein kinetics}

On the $5^{\text {th }}$ day of admission whole body protein metabolism was assessed in the fed state. An intravenous priming dose was given over a 3-minute period followed by 2 hours constant intravenous infusion using a calibrated syringe pump. The following intravenous isotope infusion rates and priming doses were used: L-[ring${ }^{2} \mathrm{H}_{5}$ ]phenylalanine, infusion rate $=4.5 \mu \mathrm{mol} / \mathrm{kg} / \mathrm{h}$, priming dose $=4.4 \mu \mathrm{mol} / \mathrm{kg}$; L-[ring${ }^{2} \mathrm{H}_{2}$ ]tyrosine, infusion rate $=1.5 \mu \mathrm{mol} / \mathrm{kg} / \mathrm{h}$, priming dose $=1.9 \mu \mathrm{mol} / \mathrm{kg} ; \mathrm{L}$-[ring${ }^{2} \mathrm{H}_{4}$ tyrosine, priming dose $=0.63 \mu \mathrm{mol} / \mathrm{kg}$. Splanchnic phenylalanine utilization was assessed by enteral administration of an additional prime-continuous infusion of L-[1${ }^{13} \mathrm{C}$ ]phenylalanine $=9.0 \mu \mathrm{mol} / \mathrm{kg} / \mathrm{h}$, priming dose $=4.4 \mu \mathrm{mol} / \mathrm{kg}$. All isotope tracers $(>$ 98 atom percent excess) were purchased from Cambridge Isotope Laboratories (Woburn, MA, USA) as sterile pyrogen-free powders. Infusates were prepared aseptically by the clinical pharmacists at the participating centers. Before and during tracer administration $500 \mu \mathrm{l}$ arterial blood samples were taken at $0,60,90$, and 120 minutes time points in tubes containing heparin, immediately put on ice and subsequently centrifuged at $4^{\circ} \mathrm{C}$ for $10 \mathrm{~min}$. (3500 g) to obtain plasma. Plasma was deproteinized with sulfosalicylic acid (5\%) and immediately frozen in liquid nitrogen and stored at $-80^{\circ} \mathrm{C}$ until analysis. Plasma amino acid concentrations were analyzed at MUMC using a fully automated high-performance liquid chromatography (HPLC)(Pharmacia, Woerden, The Netherlands) as described by van Eijk et al. (20) with variation coefficients $<3 \%$. The tracer-to-tracee ratios (TTRs) of L-[ring- $\left.{ }^{2} \mathrm{H}_{5}\right] \mathrm{Phe}, \mathrm{L}-[1-$ 
$\left.{ }^{13} \mathrm{C}\right] \mathrm{Phe}$ and L-[ring- $\left.{ }^{2} \mathrm{H}_{2}\right] \mathrm{Tyr}$ and L-[ring- $\left.{ }^{2} \mathrm{H}_{4}\right]$ Tyr were analyzed using a liquid chromatography-mass spectrometry system (LC-MS; Thermoquest LCQ, Veenendaal, The Netherlands), after pre-column derivatization with 9-fluorenylmethylchloroformate (21).

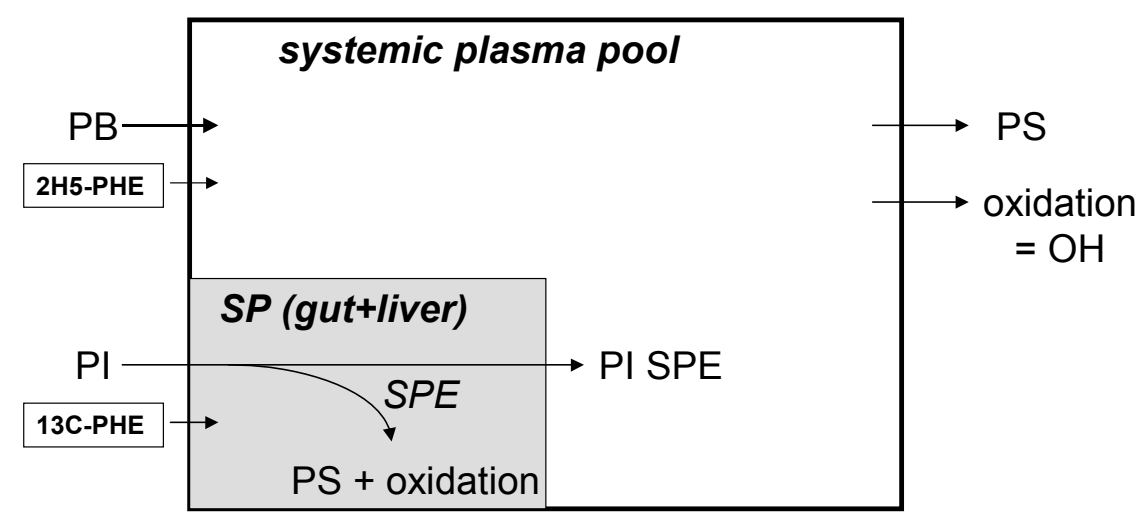

Figure 1. Single pool model of protein metabolism and amino acid tracer fluxes as used In the present study. $P B$, protein breakdown; PI, protein intake; PS, protein synthesis; $O H$, hydroxylation; SP, splanchnic pool; SPE, splanchnic extraction; $P I_{\text {spe, }}$ protein intake available for protein synthesis/oxidation.

\section{Calculations}

We used a 2-pool model in which the whole body amino acid pool is assumed to be homogeneous with a constant exchange of amino acids that enter and exit from a metabolic pool of amino acids, because all proteins are constantly being synthesized and simultaneously degraded (Figure 1). TTRs were corrected for background enrichment, and, when multiple masses of one amino acid were enriched, contribution of isotopomers from lower masses to the measured TTRs were accounted for as described by Vogt et al. (22). The flux of amino acids or protein turnover is defined under steady state conditions as the total flux into or out of the active metabolic amino acid pool. The influx into the metabolic pool is from protein breakdown (PB) and protein intake (PI). The efflux from the metabolic pool includes amino acids used for protein synthesis (PS) and for oxidation/hydroxylation. In case of phenylalanine, oxidation resembles phenylalanine hydroxylation $(\mathrm{OH})$ to tyrosine. During feeding: protein turnover $=\mathrm{PB}+\mathrm{PI}=\mathrm{PS}+\mathrm{OH}(23)$. Splanchnic extraction $\left(\mathrm{SPE}_{\mathrm{Phe}}\right)$ represents the fraction (in \%) of nutritional Phe that is taken up by the gut and liver during its first pass and metabolized via oxidation or protein synthesis. SPE as (24): 
- $\quad \mathrm{SPE}_{\mathrm{Phe}}=\left[1-\left(\mathrm{Wb} \mathrm{Ra}\left[{ }^{2} \mathrm{H}_{5}\right] \mathrm{Phe} / \mathrm{Wb} \mathrm{Ra}\left[{ }^{13} \mathrm{C}\right] \mathrm{Phe}\right)\right]^{*} 100 \%$

where $\mathrm{Wb} \mathrm{Ra}\left[{ }^{2} \mathrm{H}_{5}\right]$ Phe and $\mathrm{Wb} \mathrm{Ra}\left[{ }^{13} \mathrm{C}\right]$ Phe represent whole-body rate of appearances of Phe calculated from the intravenous $\left[{ }^{2} \mathrm{H}_{5}\right]$ Phe and enteral $\left[{ }^{13} \mathrm{C}\right] \mathrm{Phe}$, respectively. Phenylalanine intake available for peripheral protein synthesis and oxidation $\left(\mathrm{PI}_{\mathrm{SPE}}\right.$ in $\mu \mathrm{mol} / \mathrm{kg} / \mathrm{h}$ ) is calculated as:

- $\quad \mathrm{PI}_{\mathrm{SPE}}=$ Dietary intake of Phe $\mathrm{x}\left(1-\mathrm{SPE}_{\mathrm{Phe}}{ }^{*} 0.01\right)$

The absolute splanchnic extraction (ASPE) of Phe from the meal (in $\mu \mathrm{mol} / \mathrm{kg} / \mathrm{h}$ ) can be calculated by multiplying $\mathrm{SPE}_{\mathrm{Phe}}$ and the nutritional Phe intake.

Further equations used (all rates are expressed as $\mu \mathrm{mol} / \mathrm{kg} / \mathrm{h}$ ):

- Whole body rate of tracer appearance $(\mathrm{WbRa})=$ intravenous or enteral amino acid tracer infusion rate / TTR where TTR is the tracer-to-tracee ratio in arterial plasma.

- Hydroxylation of Phe into Tyr $\left(\mathrm{OH}_{\text {Phe>Tyr }}\right)=\mathrm{WbRa}\left[{ }^{2} \mathrm{H}_{2}\right] \mathrm{Tyr} \times\left(\mathrm{TTR}^{2} \mathrm{H}_{4}\right] \mathrm{Tyr} /$ TTR $\left[{ }^{2} \mathrm{H}_{5}\right]$ Phe).

- Whole body Breakdown $(\mathrm{WbPB})=$ Whole body endogenous rate of appearance of Phe $\left(\mathrm{Wb}\right.$ end $\left.\mathrm{Ra}_{\mathrm{Phe}}\right)=\mathrm{WbRa} \mathrm{P}_{\text {Phe }}-\mathrm{PI}_{\mathrm{SPE}}$

- Whole body Protein Synthesis $(\mathrm{WbPS})=\mathrm{WbRa}_{\text {Phe }}-\mathrm{OH}^{\text {Phe>Tyr }}$

- Whole body Protein Balance $(\mathrm{Wb}-\mathrm{PBal})=\mathrm{Wb}-\mathrm{PS}-\mathrm{Wb}-\mathrm{PB}$

To calculate the rates of whole body protein kinetics in $\mathrm{g} / \mathrm{kg} / 24 \mathrm{~h}$, we used a molecular weight of Phe of $165.2 \mathrm{~g} / \mathrm{mol}$ and a phenylalanine content of human protein of 280 $\mathrm{mol} / \mathrm{g}$ protein (25).

\section{Nitrogen balance}

As a second estimate of whole body protein metabolism, we assessed the 24-hours nitrogen balance on the study day by measuring urinary urea concentration in urine collected by urinary catheter. Urea was determined by an enzymatic method (Urease) on a routine clinical chemistry analyzer (Synchron LX20 Pro, Beckman Coulter Inc., Fullerton, CA, USA). Urinary urea concentration $(\mathrm{mmol} / \mathrm{L})$ was converted to urinary urea nitrogen excretion (UUN) and subsequently total urinary nitrogen excretion (TUN) with the following equations. Equation 1: UUN $(\mathrm{mg} / \mathrm{kg} / 24 \mathrm{~h})=$ urinary urea concentration $(\mathrm{mmol} / \mathrm{L}) *$ urine volume $(\mathrm{L} / 24 \mathrm{~h}) * 28.02(\mathrm{mg} / \mathrm{mmol}) * \mathrm{BW}(\mathrm{kg})^{-1}$. Equation 2: TUN $(\mathrm{mg} / \mathrm{kg} / 24 \mathrm{~h})=\mathrm{UUN} * 1.25$, the factor 1.25 was used to correct for non-urea nitrogen. Equation 3: Nitrogen balance $(\mathrm{NB})=$ total daily protein intake $(\mathrm{mg} / \mathrm{kg} / 24 \mathrm{~h}) /$ 6.25 - TUN, the factor 6.25 representing the average amount of nitrogen in protein. 


\section{Further blood analyses}

Plasma concentrations of C-reactive protein (CRP), glucose, insulin, and urea were determined in arterial blood obtained before start of the protein kinetic study. Determination of glucose, urea, and CRP were done on a routine clinical chemistry analyzer (Synchron LX20 Pro, Beckman Coulter Inc., Fullerton, CA, USA). Urea was determined by an enzymatic rate method (Urease), glucose was determined using Glucose Oxidase (GOD-PAP), and CRP with immunoturbidimetry (CRPLX). Plasma insulin concentrations were determined on an AutoDelfia (Perkin Elmer Life and Analytical Sciences, Wellesley, MA, USA) by an Immunofluorimetric monoclonal antibody (IFMA) assay.

\section{Clinical parameters}

Anthropometric measurements were taken at inclusion in the study but were not repeated because the severity of illness with concomitant edema formation in all infants precluded accurate measurements, whereas the study-feeding period was too brief to cause significant alterations in anthropometric values. Severity of illness, calculated over the first 24 hours of admission, was assessed by the Pediatric Risk of Mortality (PRISM II) (26) score. Outcome measures like duration of mechanical ventilation and length of stay in the PICU were registered.

\section{Statistical analysis}

Power analysis was performed based on results of protein metabolism parameters in infants obtained in earlier reports (27). With two-sided significance of 0.05 and sensitivity of 0.80 the number of patients needed in both groups was 6 . All data were analyzed with the SPSS statistical software package (version 12.0; SPSS, Chicago, IL). Normality of all data was verified by the Kolmogorov-Smirnov test. Variables with a normal distribution were compared among the groups with the independent samples t-test. When a variable had no normal distribution the Mann-Whitney $U$ analysis was applied. Correlations amongst whole body protein metabolism parameters and between whole body protein metabolism and plasma amino acids were tested by using Spearman correlation coefficients. Statistical significance was defined as a twotailed $\mathrm{P}<0.05$. Data are presented as mean $\pm \mathrm{SEM}$.

\section{RESULTS}

20 critically ill infants with respiratory failure due to RSV-infection were included in the study (MUMC: $n=10$; Erasmus MC: $n=10$ ). Of these patients 10 were randomized to receive PE-formula and 10 to receive $S$-formula. Baseline patient characteristics are shown in Table 2. Two patients in the PE-group were excluded from the final analysis because they were switched by mistake to non-study feeding before the tracer infusion protocol. Gestational age was significantly lower in the PE-group, but birth weight, postmenstrual age, length and body weight on admission did not differ 
significantly between groups. CRP and PRISM score on admission, duration of ventilation and length of stay on the pediatric ICU did not differ significantly between groups. There were no significant differences in baseline characteristics between patients enrolled in the two centers (data not shown).

Table 2. Baseline patient characteristics

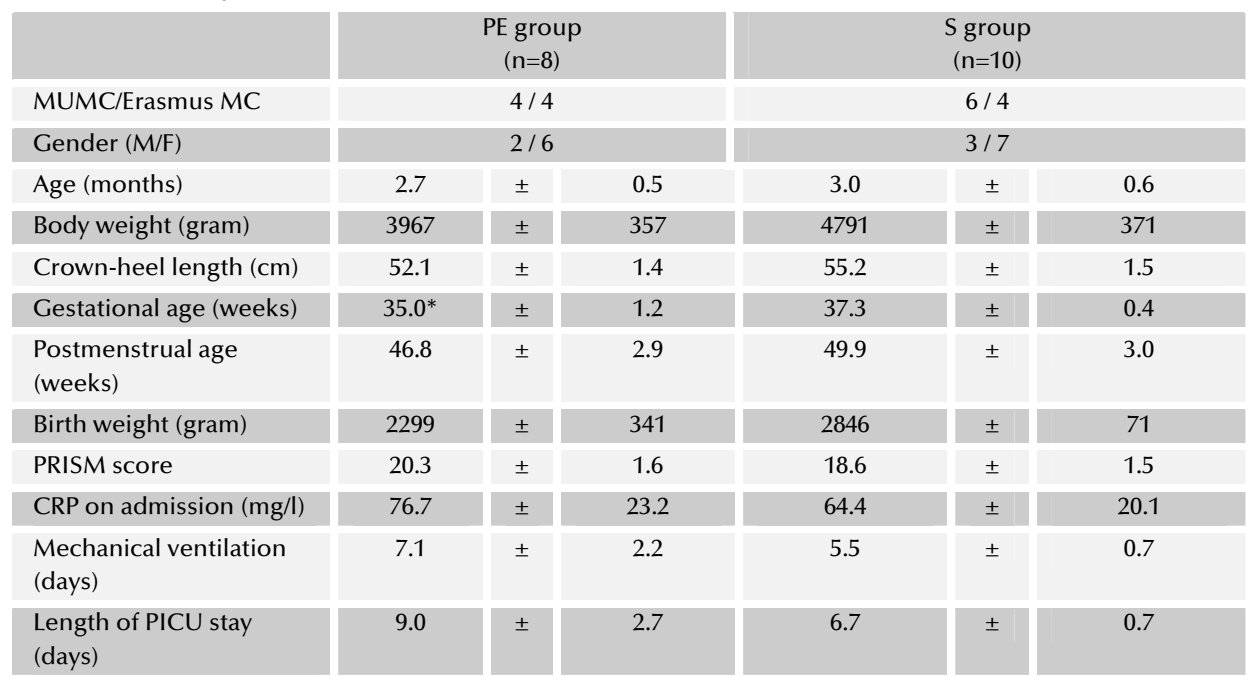

PE group, protein energy enriched formula fed group; $S$ group, standard formula fed group; MUMC, Maastricht University and Medical Center; Erasmus MC, Erasmus Medical Center; PRISM, Pediatric Risk of Mortality; CRP, C-reactive protein. Data are presented either as number of subjects or mean $\pm S E M ; * P<0.05$ (independent samples t-test or Mann-Whitney $U$ ).

\section{Nutritional intake}

Study formulas were started $25 \pm 6$ and $23 \pm 5$ hours after admission in PE- and Sinfants respectively and increased according to protocol. Although the volume of enteral intake did not differ between the groups on any of the 5 study days $(22 \pm 12,67$ $\pm 8,87 \pm 7,101 \pm 11,109 \pm 7 \mathrm{ml} / \mathrm{kg} / 24 \mathrm{~h}$ respectively in the combined group of infants on days 1-5). the target enteral intake was not reached in the majority of infants in both groups within the 5 days of the study period. This was primarily due to fluid restriction measures by the treating physician and to a lesser degree to interruptions of enteral intake for procedures. Table 3 shows the rates of nutrient intake during the stable isotope study. Protein, energy, carbohydrate and fat intake were significantly higher in PE-fed compared to S-fed infants. PE-infants had higher protein $(200 \%)$ and energy (140\%) intake compared to RDA for healthy infants below 6 months (1.5 g protein $/ \mathrm{kg} / 24 \mathrm{~h}, 85-95 \mathrm{kcal} / \mathrm{kg} / 24 \mathrm{~h}$ ) (28) while protein and energy intake matched RDA in S-infants. No differences in protein and energy intake between centers were found (data not shown). 
Table 3. Rate of nutrient intake during the tracer infusion protocol on day 5

\begin{tabular}{|c|c|c|c|c|c|c|c|}
\hline \multirow[b]{2}{*}{ Energy } & \multirow[b]{2}{*}{ kcal/kg/24h } & \multicolumn{3}{|c|}{$\begin{array}{c}\text { PE group } \\
(n=8)\end{array}$} & \multicolumn{3}{|c|}{$\begin{array}{c}\text { S group } \\
(n=10)\end{array}$} \\
\hline & & $118^{\#}$ & \pm & 5 & 84 & \pm & 3 \\
\hline \multicolumn{8}{|c|}{ Carbohydrates: } \\
\hline intravenous & $\mathrm{g} / \mathrm{kg} / 24 \mathrm{~h}$ & 1.3 & \pm & 0.5 & 1.7 & \pm & 0.6 \\
\hline enteral & $\mathrm{g} / \mathrm{kg} / 24 \mathrm{~h}$ & $11.8^{\#}$ & \pm & 0.5 & 8.5 & \pm & 0.4 \\
\hline Fat & $\mathrm{g} / \mathrm{kg} / 24 \mathrm{~h}$ & $6.2^{\#}$ & \pm & 0.6 & 4.0 & \pm & 0.2 \\
\hline Protein & $\mathrm{g} / \mathrm{kg} / 24 \mathrm{~h}$ & $3.0^{\#}$ & \pm & 0.2 & 1.6 & \pm & 0.1 \\
\hline
\end{tabular}

Data presented as mean \pm SEM. PE group, protein and energy enriched formula fed group; S-group, standard formula fed group. ${ }^{\# P}<0.01$ versus the $S$-group (independent samples t-test or Mann-Whitney $U$ ).

\section{Whole body phenylalanine kinetics}

Isotopic enrichment reached a steady state level after 1 hour of tracer infusion as shown by the lack of a statistically significant slope of the plasma L-[ring${ }^{2} \mathrm{H}_{5}$ ]phenylalanine, L- $\left[1-{ }^{13} \mathrm{C}\right]$ phenylalanine, L-[ring- $\left.{ }^{2} \mathrm{H}_{2}\right]$ tyrosine and L-[ring${ }^{2} \mathrm{H}_{4}$ ]tyrosine tracer-to-tracee ratios (Figure 2). The coefficients of variation at plateau for the L-[ring- $\left.{ }^{2} \mathrm{H}_{5}\right]$ phenylalanine, L- $\left[1-{ }^{13} \mathrm{C}\right]$ phenylalanine, L-[ring- $\left.{ }^{2} \mathrm{H}_{2}\right]$ tyrosine and L[ring- ${ }^{2} \mathrm{H}_{4}$ ]tyrosine enrichments were $6 \%, 8 \%$ and $8 \%, 9 \%$ respectively. Results of splanchnic and whole body phenylalanine kinetics are shown in Table 5. No significant differences were found between infants fed by the nasogastric or nasoduodenal route (data not shown).

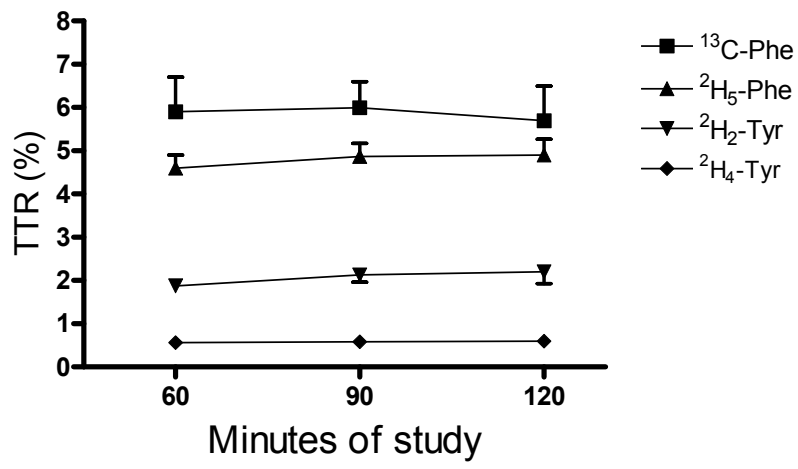

Figure 2. Tracer-to-tracee ratios of L-[ring- $\left.{ }^{2} \mathrm{H}_{5}\right]$ phenylalanine, L-[1${ }^{13}$ C]phenylalanine, L-[ring- $\left.{ }^{2} \mathrm{H}_{2}\right]$ tyrosine and L-[ring- $\left.{ }^{2} \mathrm{H}_{4}\right]$ tyrosine during the 2 hour tracer infusion, corrected for baseline enrichment. Data presented as mean \pm SEM. 
Table 5. Splanchnic and whole body phenylalanine kinetics on the fifth day of admission ${ }^{1}$

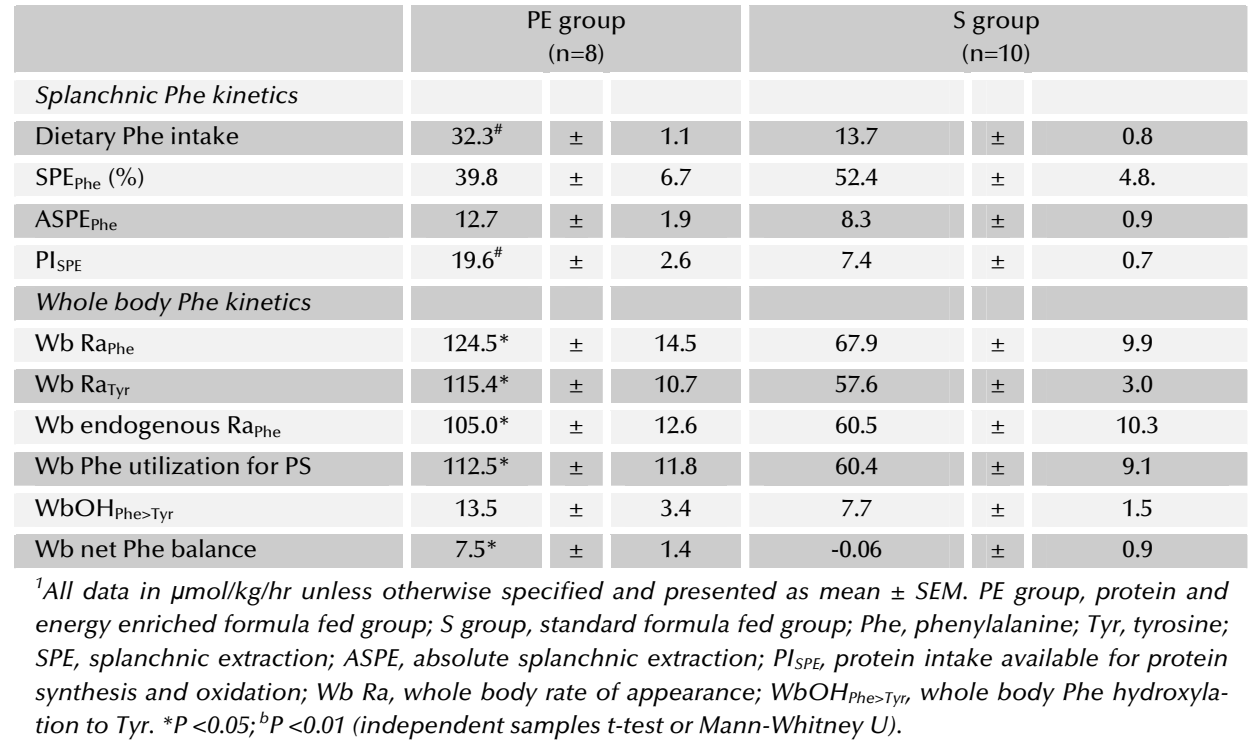

The higher protein intake in PE-infants resulted in significantly higher phenylalanine intake compared to S-infants. Splanchnic phenylalanine extraction (SPEPhe), expressed as a percentage of phenylalanine intake tended to be lower in PE- compared to Sinfants $(\mathrm{P}=0.08)$ while absolute splanchnic phenylalanine extraction ( $A S P E_{p h e}$ ) (in $\mathrm{mol} / \mathrm{kg} / \mathrm{h})$ did not differ between groups $(\mathrm{P}=0.16)$. Dietary phenylalanine intake available for peripheral protein synthesis and oxidation $\left(\mathrm{PI}_{\mathrm{SPE}}\right.$ was significantly higher in the PE-group.

Whole body $\mathrm{Ra}$ of phenylalanine (WbRaPhe) (reflecting protein turnover) was significantly higher in PE-infants compared to S-infants. This was also the case for the endogenous phenylalanine $\mathrm{Ra}$ (WbendRaPhe, reflecting $\mathrm{Wb}$ protein breakdown, $\mathrm{WbPB}$ ) and the Phe utilization for protein synthesis (reflecting Wb protein synthesis, WbPS). Although WbPB and WbPS were both higher in PE-infants, Wb net Phe balance (reflecting net protein balance, WbPBal) was positive in these infants, i.e. indicating net protein synthesis or anabolism, and significantly higher than in Sinfants, in whom WbPBal was not significantly different from zero. A negative WbPBal (reflecting catabolism) was found in one patient $(12.5 \%)$ in the PE-group but in four infants in the S-group (40\%). Figure 3 depicts the rates of WbPS, WbPB and WbPBal in g protein $/ \mathrm{kg} / 24 \mathrm{~h}$.

Phenylalanine hydroxylation to tyrosine (WbOHPhe>Tyr) was higher in PE-infants compared to $\mathrm{S}$-infants but differences were not significant $(\mathrm{P}=0.24)$. A significant but negative correlation however was found between phenylalanine hydroxylation and WbPBal in both groups of patients $(r=-0.76$ and $r=-0.69$ in PE and S infants respectively, both $\mathrm{p}<0.05)$. When phenylalanine kinetics were calculated without correction for first pass splanchnic phenylalanine extraction WbPB was $15 \%$ lower in PE-infants and $18 \%$ lower in S-infants (92 \pm 11 vs. $52 \pm 8 \mu \mathrm{mol} / \mathrm{kg} / \mathrm{h}$ in PE- and S-infants respec- 
tively) while WbPBal was 74\% higher in PE- and 58\% higher in S-infants (20.4 \pm 2 vs. 8.5 $\pm 1 \mu \mathrm{mol} / \mathrm{kg} / \mathrm{h}$ ). Figure 3 depicts the rates of $\mathrm{WbPS}, \mathrm{WbPB}$ and $\mathrm{WbPBal}$ in $\mathrm{g}$ protein/kg/24h.
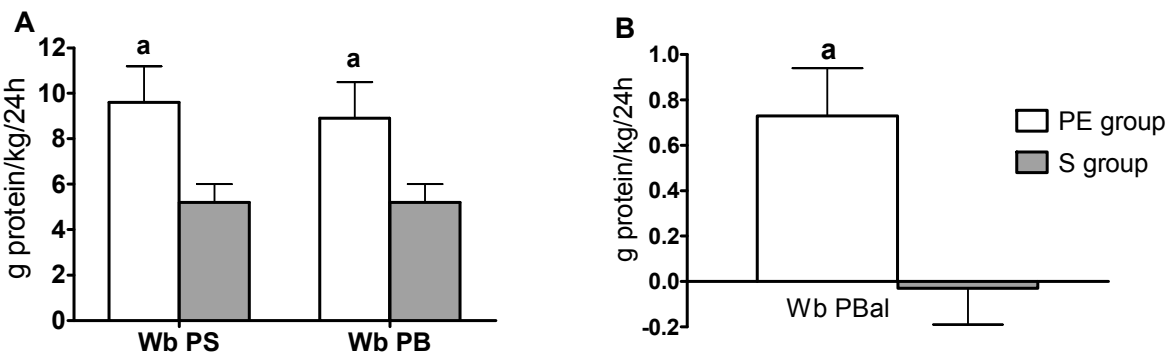

Figure 3. Whole body protein synthesis (WbPS), protein breakdown (WbPB) (Panel A) and whole body net protein balance (WbPBal) (Panel B) in protein and energy enriched formula fed infants (PE-group, open bars) and standard infant formula fed infants ( -group hatched bars). Data presented as mean $\pm S E M$. ${ }^{*} P<0.05$ vs. the $S$-group (independent samples t-test or Mann-Whitney $U$ ).

\section{Nitrogen balance}

The results of the phenylalanine and tyrosine kinetics were in line with the results of the 24-hour total urinary nitrogen excretion (TUN). TUN, as a measure of amino acid oxidation, was higher in the PE-formula fed infants compared to the S-fed infants, but not significantly so ( $151 \pm 43$ and $117 \pm 29 \mathrm{mg} / \mathrm{kg} / 24 \mathrm{~h}$ respectively). 24-hours nitrogen balance was significantly higher in the PE fed infants compared to S-fed infants (297 \pm 56 and $123 \pm 28 \mathrm{mg} / \mathrm{kg} / 24 \mathrm{~h}$ respectively; $\mathrm{p}<0.05)$.

\section{Plasma metabolites}

In the fed state on day 5, plasma concentrations of urea $(1.9 \pm 0.6$ and $1.3 \pm 0.2 \mathrm{mmol} / \mathrm{l})$, glucose $(5.6 \pm 0.2$ and $5.2 \pm 0.1 \mathrm{mmol} / \mathrm{l})$ and insulin $(17 \pm 4$ and $12 \pm 3 \mathrm{mU} / \mathrm{l}) \mathrm{did}$ not differ between PE- and S-infants. This was also the case for plasma concentrations of $\mathrm{CRP}$, a sensitive measure of inflammation $(23 \pm 7$ and $28 \pm 8 \mathrm{mg} / \mathrm{l}$ in PE- and S-infants respectively). To evaluate the effect of both formulas on amino acid metabolism we measured plasma amino acid concentrations in arterial blood taken just before tracer administration on day 5 (Table 4). Concentrations of histidine, valine, methionine, phenylalanine and lysine were significantly higher in PE-infants compared to Sinfants. This was also the case for the sum of the branched chain amino acids (BCAA) and the sum of essential amino acids. To understand if plasma amino acid concentrations possibly could drive protein anabolism in these critically ill children, we calculated the correlations between the plasma amino acid concentration, WbPS and WbPBal. WbPS was positively correlated with plasma concentrations of histidine $(r=0.46, p<0.05)$, methionine $(r=0.64, p<0.01)$, tryptophan $(r=0.51, p<0.05)$, leucine 
$(\mathrm{r}=0.56, \mathrm{p}<0.05)$, isoleucine $(\mathrm{r}=0.47, \mathrm{p}<0.05)$ and also with the sum of BCAA $(r=0.51$, $\mathrm{p}<0.05)$ and the sum of essential amino acids $(r=0.51, p<0.05)$. WbPBal was positively correlated with isoleucine $(r=0.52, p<0.05)$, valine $(r=0.46, p<0.05)$ and sum of BCAA $(r=0.53, p<0.05)$. Whole body phenylalanine kinetics were not related to severity of inflammation (plasma CRP concentration) or with parameters of glucose metabolism (plasma glucose or insulin concentrations).

Table 4. Plasma amino acid concentrations on day $5^{1}$

\begin{tabular}{|c|c|c|c|c|c|c|}
\hline \multirow[b]{2}{*}{ Methionine $^{2}$} & \multicolumn{3}{|c|}{$\begin{array}{l}\text { PE group } \\
\qquad(\mathrm{n}=8)\end{array}$} & \multicolumn{3}{|c|}{$\begin{array}{c}\text { S group } \\
(n=10)\end{array}$} \\
\hline & $35^{*}$ & \pm & 2 & 28 & \pm & 2 \\
\hline Histidine $^{2}$ & $73^{*}$ & \pm & 5 & 58 & \pm & 4 \\
\hline Phenylalanine $^{2}$ & $78^{*}$ & \pm & 4 & 64 & \pm & 3 \\
\hline Tryptophane $^{2}$ & 75 & \pm & 5 & 65 & \pm & 6 \\
\hline Lysine $^{2}$ & $223 *$ & \pm & 27 & 155 & \pm & 14 \\
\hline Threonine $^{2}$ & 205 & \pm & 44 & 195 & \pm & 20 \\
\hline Isoleucine ${ }^{2,3}$ & 34 & \pm & 4 & 27 & \pm & 2 \\
\hline Leucine $^{2,3}$ & 129 & \pm & 6 & 113 & \pm & 5 \\
\hline Valine $^{2,3}$ & $141^{*}$ & \pm & 9 & 112 & \pm & 4 \\
\hline Ornithine & 104 & \pm & 9 & 80 & \pm & 8 \\
\hline Glutamic acid & 197 & \pm & 21 & 191 & \pm & 20 \\
\hline Asparagine & 62 & \pm & 8 & 67 & \pm & 6 \\
\hline Serine & 146 & \pm & 8 & 143 & \pm & 9 \\
\hline Glutamine & 630 & \pm & 61 & 610 & \pm & 30 \\
\hline Glycine & 240 & \pm & 20 & 250 & \pm & 13 \\
\hline Citrulline & 20 & \pm & 3 & 22 & \pm & 2 \\
\hline Arginine & 95 & \pm & 13 & 89 & \pm & 7 \\
\hline Alanine & 291 & \pm & 63 & 294 & \pm & 20 \\
\hline Taurine & 24 & \pm & 6 & 27 & \pm & 3 \\
\hline Tyrosine & 70 & \pm & 5 & 59 & \pm & 5 \\
\hline Sum of all AA & 2873 & \pm & 226 & 2648 & \pm & 98 \\
\hline Sum of EAA & $994 *$ & \pm & 69 & 817 & \pm & 42 \\
\hline Sum of BCAA & $304^{\#}$ & \pm & 19 & 252 & \pm & 9 \\
\hline
\end{tabular}

${ }^{1}$ All data in $\mu$ mol/l and presented as mean \pm SEM. PE group, protein and energy enriched formula fed group; $S$ group, standard formula fed group; $A A$, amino acids; sum of all $A A$, sum of all measured $A A ;{ }^{2} E A A$, essential $A A ;{ }^{3} B C A A$, branched chain $A A .{ }^{*} P<0.05,{ }^{*} P<0.01$ (independent samples t-test or Mann-Whitney $U)$.

\section{DISCUSSION}

In the present study we compared the effects of a standard infant formula (S-formula; providing $1.6 \mathrm{~g}$ protein $/ \mathrm{kg} / 24 \mathrm{~h}$ and $84 \mathrm{kcal} / \mathrm{kg} / 24 \mathrm{~h}$ ) with a protein and energy enriched formula (PE-formula; providing $3.0 \mathrm{~g}$ protein $/ \mathrm{kg} / 24 \mathrm{~h}$ and $118 \mathrm{kcal} / \mathrm{kg} / 24 \mathrm{~h}$, equivalent to RDA for healthy infants) on whole body protein balance (Wb-PBal) in critically ill infants. Wb-PBal was measured by combined intravenous and enteral phenylalanine and tyrosine isotope infusions on the fifth day of admission. Our results clearly show 
that the provision of high protein and energy intakes, achieved with the PE-formula, promote anabolism in these critically ill infants as shown by a significantly higher and positive WbPBal. This was due to an increased rate of whole body protein synthesis (WbPS) that exceeded the rate of protein breakdown (WbPB). Phenylalanine hydroxylation to tyrosine, as a measure of amino acid oxidation was not increased in the infants receiving the PE-formula and did not induce a rise in plasma urea. Results of the 24-hour nitrogen balance were in line with these results.

Most knowledge about the effect of nutritional interventions on whole body protein metabolism in infancy has been obtained in studies of parenterally fed premature and term neonates $(9,27,29-31)$, using leucine or phenylalanine and tyrosine kinetics. Comparable to our findings, these studies have shown that (intravenous) amino acid supplementation can improve WbPBal by stimulating WbPS $(9,27,29,31,32)$. Our study, however, demonstrates for the first time that in critically ill infants the enteral provision of high amounts of protein and energy can stimulate WbPS and improve WbPBal without significant side effects.

The higher rate of whole body protein breakdown (WbPB) in the critically infants receiving the $\mathrm{PE}$ formula in our study seems to contrast with results of some earlier reports that demonstrated lower rates of WbPB during amino acid supplementation. However, a suppressive effect of amino acid supplementation on WbPB was only found in those studies $(31,33)$ that compared the rates of WbPS and WbPB obtained in the basal (fasted) state with those obtained after short term (intravenous) amino acids supplementation. In contrast, in studies more similar to our study design, that evaluated the effects of continuous amino acid supplementation, no decrease $(9,29)$ or even an increase in WbPB (34) was found. Wolfe et al. (35) studied leucine kinetics in critically ill adults with burn injury and also found that both WbPB and WbPS were higher in patients receiving a high protein intake $(2.2 \mathrm{~g} / \mathrm{kg} / 24 \mathrm{~h})$ when compared to those receiving a low protein intake $(1.4 \mathrm{~g} / \mathrm{kg} / 24 \mathrm{~h})$ for three days. WbPBal however did not improve with the higher protein intake. Patterson et al. (14) studied phenylalanine and tyrosine kinetics in critically ill children with severe burn injury receiving normal enteral protein intake $(1.2 \mathrm{~g} / \mathrm{kg} / 24 \mathrm{~h})$, high protein intake $(1.84 \mathrm{~g} / \mathrm{k} / 24 \mathrm{~h})$ or very high protein intake $(2.9 \mathrm{~g} / \mathrm{k} / 24 \mathrm{~h})$ for 4 days. No significant differences in the rates of $\mathrm{WbPB}$ were found between the groups although WbPB increased gradually (70.8, 76.8 to 78.6 $\mu \mathrm{mol} / \mathrm{kg} / \mathrm{hr}$ in the three groups respectively). Although WbPS was not calculated, net skin protein synthesis was increased in the group receiving the very high protein intake. In children recovering from malnutrition, the rates of whole body protein turnover, synthesis and breakdown obtained with $\left[{ }^{15} \mathrm{~N}\right]$ glycine kinetics were found to be twice as high several days after introduction of enteral feeding than on admission (36) while WbPBal was positive. These studies in different patient groups and with different tracer methodologies in combination with animals experiments (37), support our findings that increasing protein intake can stimulate both WbPB and WbPS at the same time, possibly by increasing whole body protein turnover (35). Furthermore the present study in critically ill infants shows that high protein and energy intakes stimulate $\mathrm{WbPS}$ more than $\mathrm{WbPB}$ resulting in a positive $\mathrm{WbPbal}$.

When protein intake exceeds nutritional needs, excess amino acids are oxidized in the liver with the formation of urea (or hydroxylated in the case of phenylalanine). In 
the present study however, phenylalanine hydroxylation, as a measure of amino acid oxidation, tended to be higher in the PE formula fed infants when compared to the $S$ fed infants but differences were not significant. Earlier reports in premature and term neonates have demonstrated that amino acid oxidation and urea genesis increases with increasing amino acid supplementation. The lack of a significant difference in phenylalanine hydroxylation between the groups in the present study may suggest that the level of protein intake did not exceed amino acid requirements for protein synthesis. This is further supported by the absence of increased plasma urea concentrations in the PE formula fed infants. In the enterally fed infants in the present study splanchnic phenylalanine extraction amounted to $50 \%$ of phenylalanine intake. Although our study is the first to report values for splanchnic phenylalanine utilization in critically ill infants on continuous enteral nutrition, comparable values have been described in normal volunteers after a complete meal (19) and in enterally fed piglets. Splanchnic phenylalanine extraction was not significantly affected by differences in protein intake in the infants in the present study, although studies of premature infants (38) and piglets (39) have shown that during restriction of enteral protein intake splanchnic phenylalanine extraction increases in comparison with adequate enteral feeding. The lack of a difference between the groups in our study may be explained by the fact that although the infants in the S-group received less protein than the PE group they were not protein restricted. Furthermore our results show that when phenylalanine and tyrosine kinetics are investigated in enterally fed subjects, the influence of first pass splanchnic amino acid utilization should be taken in account. Without correction for splanchnic phenylalanine extraction Wb PB would have been underestimated with at least $15 \%$ while whole body protein balance would be overestimated with $60 \%$.

Although our study design, comparing the effect of two clinically available infant formulas with different nutrient composition, makes it difficult to discern the influences of the separate macronutrients on whole body protein metabolism, studies of adults and children have shown that protein is the major dietary determinant of whole body protein metabolism as long as energy intake is sufficient (40). Furthermore our finding of a positive relationship between WbPS and WbPBal on the one hand and plasma concentrations of several essential amino acids on the other hand suggests that increased dietary amino acid intake is the major stimulus for the increased WbPS and WbPBal in the PE fed infants in our study. This also fits with previous observations in healthy adults, which indicated that essential amino acids are the primary stimuli for (muscle) protein synthesis (41). Studies of premature and term newborn infants have also shown that protein synthesis and protein deposition can be stimulated by increasing amino acid intake while energy intake is kept constant (29). Although carbohydrates and fat can exert a positive effect on protein metabolism due to their insulinogenic effects, plasma insulin concentrations did not differ between the infants receiving the PE- or S-formula in our study. Earlier studies also have shown that the type of energy does not influence protein synthesis and that carbohydrates and fats are equally effective in maintaining nitrogen balance or growth as long as energy intake is sufficient (17). 
In conclusion, high protein and energy intakes in critically ill infants in the first days of admission using a protein and energy enriched formula lead to protein anabolism by stimulating whole body protein synthesis in spite of a concomitant increase in whole body protein breakdown and without signs of protein intolerance. Splanchnic phenylalanine extraction is significant and should be taken into account when phenylalanine kinetics are measured in enterally fed infants. Further research is needed to study to the effects of protein and energy enriched formulas on outcome in critically ill infants.

\section{REFERENCES}

1. Hulst JM, van Goudoever JB, Zimmermann LJ, et al. The effect of cumulative energy and protein deficiency on anthropometric parameters in a pediatric ICU population. Clin Nutr 2004;23:1381-9.

2. Hulst J, Joosten K, Zimmermann L, et al. Malnutrition in critically ill children: from admission to 6 months after discharge. Clin Nutr 2004;23:223-32.

3. Pollack MM, Wiley JS, Holbrook PR. Early nutritional depletion in critically ill children. Crit Care Med 1981;9:580-3.

4. Pollack M. Nutritional support of children in the intensive care unit. In: Suskind R, Lewinter-Suskind L, eds. Textbook of Pedaitric Nutrition. 2nd ed. New York: Raven Press, 1993.

5. Pollack MM, Ruttimann UE, Wiley JS. Nutritional depletions in critically ill children: associations with physiologic instability and increased quantity of care. JPEN J Parenter Enteral Nutr 1985;9:309-13.

6. Briassoulis G, Zavras N, Hatzis T. Malnutrition, nutritional indices, and early enteral feeding in critically ill children. Nutrition 2001;17:548-57.

7. Gurgueira GL, Leite HP, Taddei JA, de Carvalho WB. Outcomes in a pediatric intensive care unit before and after the implementation of a nutrition support team. JPEN J Parenter Enteral Nutr 2005;29:176-85.

8. Briassoulis GC, Zavras NJ, Hatzis MT. Effectiveness and safety of a protocol for promotion of early intragastric feeding in critically ill children. Pediatr Crit Care Med 2001;2:113-21.

9. van Lingen RA, van Goudoever JB, Luijendijk IH, Wattimena JL, Sauer PJ. Effects of early amino acid administration during total parenteral nutrition on protein metabolism in pre-term infants. Clin Sci (Lond) 1992;82:199-203.

10. Rivera A, Jr., Bell EF, Bier DM. Effect of intravenous amino acids on protein metabolism of preterm infants during the first three days of life. Pediatr Res 1993;33:106-11.

11. te Braake FW, van den Akker CH, Wattimena DJ, Huijmans JG, van Goudoever JB. Amino acid administration to premature infants directly after birth. J Pediatr 2005;147:457-61.

12. Reynolds RM, Bass KD, Thureen PJ. Achieving positive protein balance in the immediate postoperative period in neonates undergoing abdominal surgery. J Pediatr 2008;152:63-7.

13. Alexander JW, MacMillan BG, Stinnett JD, et al. Beneficial effects of aggressive protein feeding in severely burned children. Ann Surg 1980;192:505-17.

14. Patterson B, Nguyen T, Pierre E, Herndon D, Wolfe R. Urea and protein metabolism in burned children: effect of dietary protein intake. Metabolism 1997;46:573-578.

15. Geukers VG, Oudshoorn JH, Taminiau JA, et al. Short-term protein intake and stimulation of protein synthesis in stunted children with cystic fibrosis. Am J Clin Nutr 2005;81:605-10.

16. Calloway $\mathrm{DH}$, Spector $\mathrm{H}$. Nitrogen balance as related to caloric and protein intake in active young men. Am J Clin Nutr 1954;2:405-12.

17. Millward DJ. Macronutrient intakes as determinants of dietary protein and amino acid adequacy. J Nutr 2004;134:1588S-1596S.

18. Soeters PB, de Jong $\mathrm{CH}$, Deutz NE. The protein sparing function of the gut and the quality of food protein. Clin Nutr 2001;20:97-9.

19. Biolo G, Tessari $P$, Inchiostro $S$, et al. Leucine and phenylalanine kinetics during mixed meal ingestion: a multiple tracer approach. Am J Physiol 1992;262:E455-63.

20. van Eijk HM, Rooyakkers DR, Deutz NE. Rapid routine determination of amino acids in plasma by highperformance liquid chromatography with a 2-3 microns Spherisorb ODS II column. J Chromatogr 1993;620:143-8. 
21. van Eijk HM, Suylen DP, Dejong CH, Luiking YC, Deutz NE. Measurement of amino acid isotope enrichment by liquid chromatography mass spectroscopy after derivatization with 9fluorenylmethylchloroformate. J Chromatogr B Analyt Technol Biomed Life Sci 2007;856:48-56.

22. Vogt JA, Chapman TE, Wagner DA, Young VR, Burke JF. Determination of the isotope enrichment of one or a mixture of two stable labelled tracers of the same compound using the complete isotopomer distribution of an ion fragment; theory and application to in vivo human tracer studies. Biol Mass Spectrom 1993;22:600-12.

23. Tessari P, Barazzoni R, Zanetti M, Kiwanuka E, Tiengo A. The role of substrates in the regulation of protein metabolism. Baillieres Clin Endocrinol Metab 1996;10:511-32.

24. Matthews DE, Marano MA, Campbell RG. Splanchnic bed utilization of leucine and phenylalanine in humans. Am J Physiol 1993;264:E109-18.

25. Castillo L, Yu YM, Marchini JS, et al. Phenylalanine and tyrosine kinetics in critically ill children with sepsis. Pediatr Res 1994;35:580-8.

26. Pollack MM, Ruttimann UE, Getson PR. Pediatric risk of mortality (PRISM) score. Crit Care Med 1988;16:1110-6.

27. Poindexter BB, Karn CA, Leitch CA, Liechty EA, Denne SC. Amino acids do not suppress proteolysis in premature neonates. Am J Physiol Endocrinol Metab 2001;281:E472-8.

28. Macronutrients RotPo. Dietary Reference Intakes for Macronutrients. Washington: US National Academie of Sciences, 2005.

29. van den Akker $\mathrm{CH}$, te Braake FW, Wattimena DJ, et al. Effects of early amino acid administration on leucine and glucose kinetics in premature infants. Pediatr Res 2006;59:732-5.

30. Castillo L, Beaumier L, Ajami AM, Young VR. Whole body nitric oxide synthesis in healthy men determined from [15N] arginine-to-[15N]citrulline labeling. Proc Natl Acad Sci U S A 1996;93:11460-5.

31. Poindexter BB, Karn CA, Ahlrichs JA, et al. Amino acids suppress proteolysis independent of insulin throughout the neonatal period. Am J Physiol 1997;272:E592-9.

32. Denne SC, Rossi EM, Kalhan SC. Leucine kinetics during feeding in normal newborns. Pediatr Res 1991;30:23-7.

33. Denne SC, Karn CA, Ahlrichs JA, Dorotheo AR, Wang J, Liechty EA. Proteolysis and phenylalanine hydroxylation in response to parenteral nutrition in extremely premature and normal newborns. J Clin Invest 1996;97:746-54.

34. Mitton SG, Garlick PJ. Changes in protein turnover after the introduction of parenteral nutrition in premature infants: comparison of breast milk and egg protein-based amino acid solutions. Pediatr Res 1992;32:447-54.

35. Wolfe RR, Goodenough RD, Burke JF, Wolfe MH. Response of protein and urea kinetics in burn patients to different levels of protein intake. Ann Surg 1983;197:163-71.

36. Kita K, Muramatsu T, Okumura J. Effect of dietary protein and energy intakes on whole-body protein turnover and its contribution to heat production in chicks. Br J Nutr 1993;69:681-8.

37. Golden $\mathrm{MH}$, Waterlow JC, Picou D. Protein turnover, synthesis and breakdown before and after recovery from protein-energy malnutrition. Clin Sci Mol Med 1977;53:473-7.

38. van der Schoor SR, Reeds PJ, Stellaard F, et al. Lysine kinetics in preterm infants: the importance of enteral feeding. Gut 2004;53:38-43.

39. van der Schoor SR, van Goudoever JB, Stoll B, et al. The pattern of intestinal substrate oxidation is altered by protein restriction in pigs. Gastroenterology 2001;121:1167-75.

40. Garlick PJ, McNurlan MA, Ballmer PE. Influence of dietary protein intake on whole-body protein turnover in humans. Diabetes Care 1991;14:1189-98.

41. Volpi E, Mittendorfer B, Rasmussen BB, Wolfe RR. The response of muscle protein anabolism to combined hyperaminoacidemia and glucose-induced hyperinsulinemia is impaired in the elderly. J Clin Endocrinol Metab 2000;85:4481-90. 

CHAPTER 8

General discussion 
CHAPTER 8 


\section{INTRODUCTION}

The critically ill child is subject to two important metabolic responses, the protein catabolic response to stress combined with the response to (semi)starvation. This leads to rapid development of protein and energy deficits and disease related malnutrition associated with negative effects on recovery and outcome $(1,98)$. Nutritional support should supply sufficient protein and energy to prevent catabolism of body stores, supply substrates for synthesis of proteins involved in immune defense and injury repair and extra protein and energy for catch-up growth in the recovery phase. Little information however exists on the optimal amounts of macronutrients that should be administered to critically ill children to achieve these goals. In the studies of this thesis we investigated the alterations in protein and amino acid metabolism during critical illness in infants and children and the consequences for nutritional support by using different methodologies.

\section{METHODS TO MEASURE PROTEIN AND AMINO ACID METABOLISM IN CRITICALLY ILL CHILDREN}

In paragraph 2.9 we addressed the difficulties in assessing protein and amino acid metabolism in critically ill children, due to the fact that many research methods that are acceptable for use in critically ill adults are too invasive and therefore not acceptable for use in critically ill children. We summarized the methods that can be used in critically ill children and were used in the studies in this thesis (Table 1).

\section{Plasma amino acid concentrations}

Determination of plasma amino acid concentrations can be useful in nutritional science to detect deficiencies and excesses of dietary amino acid intake $(2,3)$ as long as the interpretation takes the (patho)physiologic situation into account (4). In Chapter 5 we investigated plasma amino acid concentrations in groups of critically ill children with viral respiratory disease, accidental or surgical trauma or with meningococcal septic shock. Measurements were performed in arterial blood, collected at admission, in the fasted state and under standardized and optimal conditions as described by van Eijk et al. $(5,6)$. In a subgroup of children the measurements were repeated on day 3 and 7 while they were receiving a continuous enteral infusion of standard pediatric enteral nutrition. Our results show that critical illness in children is characterized by decreased plasma concentrations of most amino acids and especially those of arginine, glutamine and citrulline occurring in the early and acute phase of critical illness. A strong inverse relationship was found between plasma amino acid concentrations and severity of illness but a striking and new finding was that plasma arginine, citrulline and glutamine concentrations were strongly but inversely related to the severity of the inflammatory response as expressed by the plasma CRP concentration. Although Beisel et al. (7) also described generalized hypoaminoacidemia during critical illness but others found normal amino acid levels or even increased levels and without a relationship with severity of illness (8). Our findings are in line 
with the concept that changes in plasma amino acid levels may be a reflection of increased amino acid utilization in spite of an increased amino acid efflux from muscle protein breakdown. Low plasma amino acid levels may have potential negative effects on net protein balance given the fact that protein synthesis is most strongly regulated by the plasma amino acid availability (9). Although parenteral amino acid administration has been shown to correct low plasma amino acid concentrations in preterm infants and promote anabolism (10) the benefits of correcting low amino acid levels with enteral or parenteral amino acid supplementation in the acute phase of critical illness remains to be established both in critically ill adults and children.

In Chapter 6 and 7 we assessed plasma amino acid concentrations in critically ill infants to compare the metabolic effects of early administration of two enteral formulas with different protein and energy content. In infants receiving a protein and energy enriched infant formula the plasma concentrations of most essential amino acids were significantly higher but within normal reference limits compared to the infants receiving the standard formula in which plasma amino acid levels were below reference limits. This demonstrates that early enteral administration of sufficient amounts of protein can improve plasma amino acid concentrations in critically ill infants. In Chapter 7 we also showed that increasing the plasma levels of BCAA's and other essential amino acids improved whole body protein synthesis and net protein balance. Together the results of our studies suggest that assessment of plasma amino acid concentrations is a useful tool to investigate protein and amino acid metabolism and the effects of nutritional in critically ill children. Furthermore, our results demonstrate that increasing plasma amino acid availability by early enteral administration of sufficient protein lead to anabolism as shown by the positive nitrogen balance and increased protein synthesis and net protein balance.

\section{Whole body protein metabolism}

It is generally accepted that the best way to evaluate changes in protein and amino acid metabolism is through the use of stable isotope tracer methods. The most often used stable isotope tracer methods make use of $\left[{ }^{15} \mathrm{~N}\right]$ glycine $(11), \mathrm{L}-\left[1-{ }^{13} \mathrm{C}\right]$ leucine(12) or $\mathrm{L}-\left[{ }^{2} \mathrm{H}_{5}\right]$ phenylalanine $(13,14)$. However most stable isotope methods require intravenous infusions of amino acids labeled with stable isotopes and repeated blood sampling, which is often considered as an unacceptable burden for the child. Critically ill children however often have need for placement of venous and arterial catheters in the acute phase of the disease and therefore these methods can be used more easily in these children. However given the relatively short length of stay of most patients in de pediatric ICU (5-7 days), intravenous tracer methods are less suitable for serial evaluation of protein metabolism in critically ill children, for instance to monitor the effect of nutritional interventions. It is also impossible to obtain results in healthy children in order to make comparisons with a control group possible. 


\section{The $\left.{ }^{15} \mathrm{~N}\right]$ glycine single oral dose method}

The $\left[{ }^{15} \mathrm{~N}\right]$ glycine single oral dose method proposed years ago by Waterlow et al. (11) is a method to evaluate whole body protein metabolism (WbPM) in a non-invasive manner. In this method a single oral of dose of $\left[{ }^{15} \mathrm{~N}\right]$ glycine is given and rates of protein turnover are calculated from the ${ }^{15} \mathrm{~N}$ content of its end products (ammonia or urea) in urine collected over 9 hours. When ammonia is used as end product the method requires no blood sampling due to the small plasma pool of ammonia, which makes it particularly suitable for use in the pediatric population. In Chapter 3 we used this method to measure whole body protein metabolism in critically ill children with meningococcal septic shock and compared the results with those obtained in noncritically ill children with pneumonia outside the pediatric intensive care and also in a group of healthy children in which measurements were made both during feeding and in the fasted state. Whole body protein metabolism in children with meningococcal septic shock was characterized by increased protein turnover, increased protein synthesis and protein breakdown compared to healthy children. Protein breakdown exceeded protein synthesis in the most severely ill children leading to negative protein balance. In the children with pneumonia, protein breakdown and protein synthesis were also increased compared to the healthy children but to a lesser degree. The results found in our study were comparable to results found in earlier reports on critically ill children and adults using intravenous tracer protocols $(15,16)$. A close relation was found between the alterations in whole body protein metabolism and differences in severity of illness as expressed by the PIM score, demonstrating the close interaction between the degree of catabolism and the magnitude of the stress imposed as described earlier in studies using both nitrogen balance and stable isotope methods $(15,17-18)$. Although our results obtained with the $\left[{ }^{15} \mathrm{~N}\right]$ glycine single oral dose method were in line with results obtained in earlier studies, this does not imply that the method can be validly used in critically ill pediatric patients. The metabolism of glycine is not well understood and sources of error may be difficult to recognize. This is reflected by the observation that different rates of protein turnover can be calculated when either ammonia or urea is used as end product (19). Van Goudoever et al. (153) assessed whole body protein metabolism in preterm infants, using intragastric infusions of $\left[{ }^{15} \mathrm{~N}\right]$ glycine and $\left[{ }^{13} \mathrm{C}\right]$ leucine but on two separate days. Although the group means were comparable, individual rates obtained from the different methods did not correspond well. Still, this noninvasive method has significant advantages over the intravenous tracer methods but needs further validation before it can be advocated for the assessment of whole body protein metabolism in critically ill children. This should be done by the assessment of whole body protein metabolism using this method and one or more of the more accepted intravenous tracer methods simultaneously. In a recent study in adults with peritoneal dialysis with comparable design, a good correlation was found between results of whole body net protein synthesis obtained with the $\left[{ }^{15} \mathrm{~N}\right]$ glycine single oral dose method and the $\left[{ }^{13} \mathrm{C}\right]$ leucine method used simultaneously (152). 
Table 1 Methods to investigate protein and amino acid metabolism in critically ill children

\begin{tabular}{|c|c|c|}
\hline Methods & Clinical use & Limitations \\
\hline Anthropometrics & $\begin{array}{l}\text { Assessment of body weight, } \\
\text { body composition (skin folds, } \\
\text { mud upper arm circumference) } \\
\text { and growth }\end{array}$ & $\begin{array}{l}\text { - Changes often undetectable during } \\
\text { (short) PICU admission } \\
\text { - } \quad \text { Unreliable results due to edema } \\
\text { - Often impossible in clinically } \\
\text { unstable children }\end{array}$ \\
\hline Nitrogen balance & $\begin{array}{l}\text { Assessment net protein balance } \\
\text { (catabolism versus anabolism) }\end{array}$ & $\begin{array}{l}\text { Black box (no information about } \\
\text { synthesis and breakdown } \\
\text { Difficult (all sources of nitrogen loss } \\
\text { need to be determined) } \\
\text { Inaccuracy (overestimation of } \\
\text { nitrogen balance) } \\
\text { Nitrogen excretion lags behind } \\
\text { changes in nitrogen intake }\end{array}$ \\
\hline $\begin{array}{l}\text { Urinary 3-methyl } \\
\text { histidine excretion }\end{array}$ & $\begin{array}{l}\text { Assessment of the rate of muscle } \\
\text { protein breakdown }\end{array}$ & $\begin{array}{l}\text { - Other sources of 3-methylhistidine } \\
\text { body not well defined }\end{array}$ \\
\hline $\begin{array}{l}\text { Plasma amino acid } \\
\text { levels }\end{array}$ & $\begin{array}{l}\text { Assessment of specific amino } \\
\text { acid depletions or unbalanced } \\
\text { nutritional support }\end{array}$ & $\begin{array}{l}\text { Influenced by many factors that are } \\
\text { not all well defined during critical } \\
\text { illness } \\
\text { Plasma amino acid pool small in } \\
\text { comparison with intracellular pool } \\
\text { Clinical relevance of specific amino } \\
\text { acid depletions and target levels not } \\
\text { well defined }\end{array}$ \\
\hline Oral isotope methods & $\begin{array}{l}\text { Assessment of whole body } \\
\text { protein synthesis, breakdown } \\
\text { and net protein balance }\end{array}$ & $\begin{array}{l}\text { - Validity of methods not defined } \\
\text { Influence of splanchnic amino acid } \\
\text { utilization not accounted for. }\end{array}$ \\
\hline $\begin{array}{l}\text { Intravenous isotope } \\
\text { methods }\end{array}$ & $\begin{array}{l}\text { Assessment of whole body } \\
\text { protein synthesis, breakdown } \\
\text { and balance }\end{array}$ & $\begin{array}{l}\text { Invasive (intravenous infusion and } \\
\text { blood sampling necessary) } \\
\text { Choice of tracer }\end{array}$ \\
\hline $\begin{array}{l}\text { Splanchnic amino acid } \\
\text { extraction }\end{array}$ & $\begin{array}{l}\text { Assessment of first pass } \\
\text { splanchnic amino acid } \\
\text { utilization. }\end{array}$ & $\begin{array}{l}\text { Invasive (intravenous infusion and } \\
\text { blood sampling necessary) }\end{array}$ \\
\hline
\end{tabular}

The L-[ring- $\left.{ }^{2} \mathrm{H}_{5}\right]$ phenylalanine / L-[ring- $\left.{ }^{2} \mathrm{H}_{4}\right]$ tyrosine method (phenylalanine and tyrosine kinetics)

This method as well as the L-[1- $\left.{ }^{13} \mathrm{C}\right]$ leucine method are considered the reference methods to obtain reliable estimates of whole-body protein metabolism in most physiological conditions (20). In Chapter 7 we used phenylalanine and tyrosine kinetics to evaluate the effects of two infant formulas with different macronutrient content on whole body protein metabolism in critically ill infants in a double blind 
randomized intervention study. With this method we could show that the protein and energy enriched formula exerts a positive effect on whole body net protein balance by stimulation of protein synthesis. Protein breakdown however was also stimulated by the higher protein and energy intake but to a lesser degree while protein oxidation did not differ between groups. We deliberately chose to perform the protein kinetic study after a relatively short intervention period of 5 days for two reasons. First of all we were interested in the effects of a high protein and energy intake in the first days of admission to investigate if anabolism could be achieved in the acute phase of critical illness. Secondly, it would also have been difficult to perform the tracer studies in a later phase since the duration of mechanical ventilation in critically ill children and after extubation arterial and venous catheters are often removed making the study impossible without additional burden for the patient.

\section{Assessment of splanchnic amino acid utilization}

In Chapter 7 we simultaneously infused an intravenous and enteral phenylalanine tracer ( $\mathrm{L}-\left[\right.$ ring- $\left.{ }^{2} \mathrm{H}_{5}\right]$ phenylalanine and L- $\left[{ }^{13} \mathrm{C}\right]$ phenylalanine) to calculate the percentage of dietary phenylalanine taken up by the gut and liver during its first pass and metabolized via oxidation or protein synthesis. Splanchnic phenylalanine extraction was $40-50 \%$ of the total dietary phenylalanine intake in the critically ill infants in our study, which is in agreement with earlier reports in adults (21-23) and neonates (24).

Without correction for splanchnic extraction the rate of appearance of endogenous phenylalanine (reflecting protein breakdown) would have been underestimated by $15-18 \%$ while net protein balance would have been overestimated by $58-74 \%$. This demonstrates that correction for splanchnic amino acid extraction using a second enteral tracer is essential when whole body protein metabolism is assessed in enterally fed children.

\section{PROTEIN AND AMINO ACID METABOLISM IN CRITICALLY ILL CHILDREN}

\section{General}

The studies in this thesis show that critical illness in children is characterized by profound alterations in protein and amino acid metabolism as shown by alterations in plasma concentrations of anabolic and catabolic hormones involved in protein and amino acid metabolism (Chapter 4), alterations in plasma amino acid concentrations (Chapter 5) and altered rates of whole body protein turnover, breakdown and synthesis leading to net protein breakdown and negative nitrogen balance (Chapters 3,6 and 7). Although we could assess whole body protein metabolism, the increased protein synthesis probably reflects increased visceral protein synthesis, while the increased protein breakdown reflects increased muscle protein breakdown. All changes in protein and amino acid metabolism were strongly related to the severity of illness and more specifically the severity of the inflammatory response and less to the nature of the underlying illness (Chapters 3, 4 and 5). 


\section{Relationship with the underlying illness}

The nature of the protein catabolic response in adults has been shown to be remarkably uniform regardless of the underlying disease (25). Differences in metabolic alterations induced by various underlying diseases (for instance sepsis, trauma of burn injury) can be primarily explained by differences in the onset, severity and duration of the inflammatory response. This is supported by the short duration of metabolic alterations for instance in acute meningococcal sepsis (26) and the extended duration of metabolic alterations in burn injury, associated with an ongoing inflammatory stimulus induced by the extended wound tissue (27). It is further supported by our results in the studies presented in Chapter 3, 4 and 5. In Chapter 3 we demonstrated the relationship between whole body protein metabolism as measured by the $\left[{ }^{15} \mathrm{~N}\right]$ glycine method and severity of illness. In Chapter 4 we showed that the differences in plasma insulin levels between children with meningitis and children with meningococcal septic shock could be explained by differences in the severity of the inflammatory response (as expressed by plasma cytokine levels). Finally, in Chapter 5 we showed that the differences in plasma arginine and citrulline concentrations between children with viral disease, trauma or sepsis could be explained by the severity of the inflammatory response as expressed by the plasma CRP levels while there was no relation with the underlying disease. Furthermore, the slope of the regression line that described the relation between these amino acid levels and CRP was similar in children with viral disease and children with septic shock.

\section{Relationship with the phase of illness}

The results of Chapter 5 and 6 suggest that the alterations in protein and amino acid metabolism in critically ill children gradually change from an early protein catabolic phase to a later anabolic phase and that these changes are strongly related to changes in the severity of the inflammatory state. In Chapter 5 we show that plasma concentrations of several amino acids are strongly but inversely correlated with plasma CRP concentrations both in the acute phase of disease and during recovery. In other patients with different underlying diagnosis, but with a protracted course, we serially measured plasma arginine and citrulline levels up to 24 days after admission (Figure 2 $A$ and B) (DA van Waardenburg, unpublished data). Plasma arginine levels remained low as long as the CRP remained high and a comparable and strong inverse relationship between plasma arginine and CRP levels was found in these patients. These results give further evidence for the strong relationship between the protein catabolic response and the inflammatory response, independent from the nature of the underlying illness. 

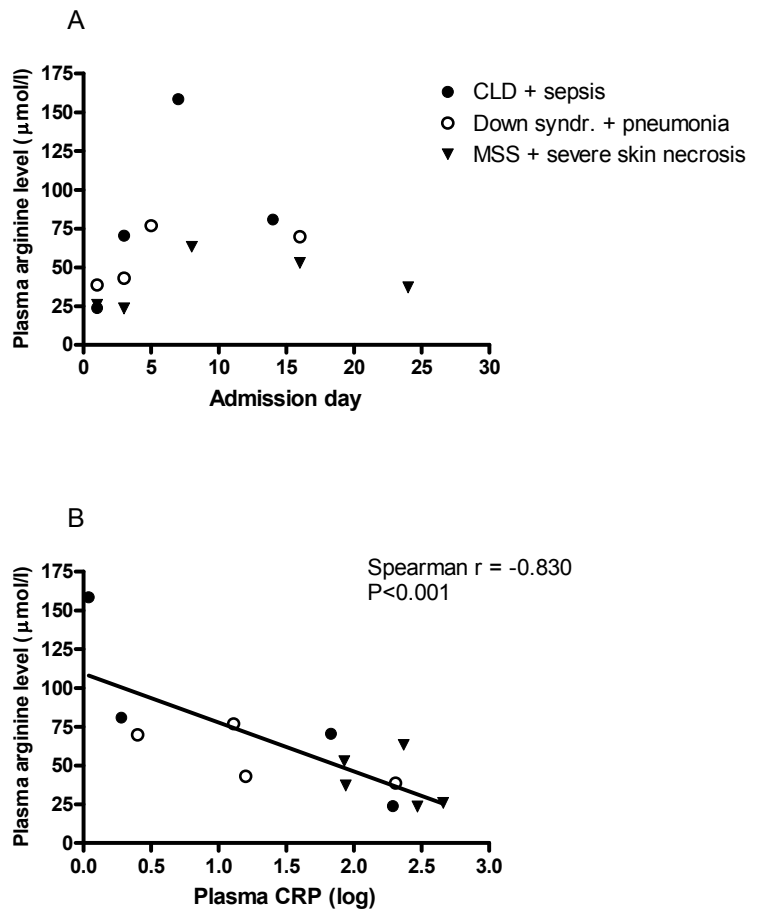

Figure 2. Plasma arginine levels during PICU admission in 3 patients with prolonged PICU stay. Panel A: plasma arginine levels on day 1-24 after admission. Panel $B$ relationship between plasma arginine levels and plasma CRP level. CRP, C-reactive protein; CLD, chronic lung disease; MSS, meningococcal septic shock.

\section{Consequences for nutritional support}

The alterations in protein and amino acid metabolism during acute illness and during recovery have consequences for nutritional support. In the acute phase of illness plasma levels of cytokines and cortisol are increased while anabolic hormones show decreased plasma levels or decreased action (Chapter 4). This is associated with low plasma amino acid levels (Chapter 5), increased (acute phase) protein synthesis, increased (muscle) protein breakdown and negative net protein balance (Chapter 3, 6 and 7). Although the low plasma amino acid levels were not significantly influenced by standard pediatric enteral formula, high protein and energy intakes were associated with increased plasma concentrations of (conditionally) essential amino acids (Chapter 6), increased protein synthesis and improved net protein balance (Chapter 6 and 7). This suggests that high protein and energy intakes may have beneficial effects on protein and amino acid metabolism in the acute phase of critical illness in children. 
It is generally accepted that the increased (muscle) protein breakdown delivers amino acids needed for the increased hepatic protein synthesis (acute phase proteins). Since the amino acid content of muscle protein is different from the content of acute phase proteins a larger amount of muscle protein has to be broken down for a comparable amount of protein synthesis (28). Therefore administration (of mixtures) of specific amino acids that closely resemble the amino acids needed for protein synthesis may be superior to increasing protein intake (28). However the validity of these theoretical benefits have not yet been established.

Increased protein breakdown also occurs to deliver amino acids for the increased gluconeogenesis that is primarily caused by increased levels of inflammatory mediators and alterations in the activity of anabolic and catabolic hormones. Since these last two factors cannot be easily influenced by nutritional support measures, other therapies, like for instance exogenous administration of anabolic hormones, may be of benefit.

When the underlying disease is cured, the inflammatory process will abate and the recovery phase ensues characterized by decreasing levels of cytokines, decreased acute phase protein synthesis and increasing anabolic hormonal action. In this phase requirements for dietary proteins and energy are necessary to restore the protein lost in the acute phase of the disease and for (catch up) growth. Ideally the provision of nutritional support should be adapted to the substrate needs in every phase of critical illness. However more studies are needed (using stable isotope methodology) to define the specific macronutrient needs in every phase of the disease. Given the close relationship between protein and amino acid metabolism and markers of inflammation, assessment of plasma cytokines or acute phase proteins in combination with hormonal markers (e.g. IGF-1) and plasma amino acid levels may help to identify the patient's phase of disease and eventually help to predict his nutritional needs.

\section{PROTEIN AND AMINO ACID METABOLISM IN CRITICALLY ILL CHILDREN: FROM NUTRITIONAL MODULATION TO NUTRITIONAL REQUIREMENTS.}

\section{General measures}

The inflammatory response to infection, accidental or surgical trauma, or burn injury plays a crucial role in the protein catabolic response. As long as the disease process continues, the inflammatory response to critical illness will sustain the protein catabolic response (27). Optimal treatment of the underlying disorder by antimicrobial therapy, wound closure or abscess drainage therefore is of utmost importance (29). The response to treatment should be evaluated by serial determination of markers of the inflammatory response (e.g. plasma CRP levels). If possible, drugs with known or possible catabolic effects should be avoided (glucocorticosteroids, catecholamines). Measures should also be taken to prevent secondary infections (ventilator associated pneumonia and catheter related infections) since these will reactivate the protein catabolic response. 


\section{Early administration of nutritional support}

Metabolic reserves of critically ill infants and children are very small compared to adults and therefore insufficient nutritional intake may have greater consequences in this age group (30). Several studies in critically ill children have emphasized the importance of early administration of nutritional support. Hulst et al. (1) prospectively studied energy and protein intake in pediatric ICU patients and demonstrated that significant cumulative nutritional deficits occurred in these children, which were associated with declined body weight and arm circumference. Since deficits accumulated most rapidly during the first days of admission, they emphasized that special attention should be paid to the adequacy of feeding during the first days of admission. Briassoulis et al. $(31,32)$ demonstrated the safety of early enteral feeding in critically ill children and its benefits on nutrition indices and outcome while Chaloupecky et al. (33) showed that early parenteral feeding in infants after cardiac surgery improved hypoaminoacidemia and decreased proteolysis as assessed with urinary 3methylhistidine excretion. In pediatric burn patients early aggressive feeding was shown to attenuate muscle catabolism and improved infectious outcomes (29). In extremely premature infants current evidence suggests that early administration of 3 $\mathrm{g}$ amino acids/kg/d is safe and effective in limiting proteolysis and producing protein accretion (34). However in most critically ill children the volume of enteral intake delivered during the first days of admission is low, mainly due to limitation of the volume of enteral nutrition to compensate for fluids given with drugs and infusions (35). This leads to prolonged periods of low protein and caloric intake.

In Chapter 6 and 7 we showed that early administration of a protein and energy enriched enteral formula to critically ill infants is well tolerated and promotes an adequate nutrient delivery within the first days of admission despite fluid restriction. Furthermore the higher protein and energy intake in the infants receiving the protein and energy enriched enteral formula improved cumulative nitrogen and energy balances and whole body protein synthesis and net protein balance as measured with phenylalanine and tyrosine kinetics.

Based on current knowledge as well as our own findings we advocate limiting the (semi-)starvation period in critically ill children as much as possible. This can be done by early introduction of enteral nutrition (as soon as possible and at least within 24 hours after admission). Furthermore, we advocate to use protein and energy enriched enteral formulas that improve nutrient delivery in the early phase of the disease when fluid restriction is an important barrier to adequate nutrient take (35).

\section{Enteral nutrition (EN) vs. parenteral nutrition (PN)}

The splanchnic organs play crucial roles in nutrient metabolism and utilization of specific amino acids. A number of amino acids (phenylalanine, methionine and citrulline) are also metabolized and converted into other amino acids within the intestine and/or liver upon first pass. Bypassing the intestine will lower systemic availability of these amino acids and thus increase requirements. Since dietary amino acids are the primary source of amino acids for the intestinal mucosa, enteral feeding 
is also obligatory for maintenance of the intestinal mucosal mass and integrity and for recovery after mucosal damage. In rats receiving isocaloric and isonitrogenous nutritional support by either the enteral or the parenteral route whole body protein metabolism, body weight and fractional synthesis of liver proteins were significantly higher in the enteral group compared to the parenteral group (36). Also in septic rats nitrogen balance was significantly higher in the orally fed rats compared to the parenterally fed rats (37). Although positive effects of early enteral nutrition (first 2448 hours of intensive care) versus parenteral nutrition on mortality were found in adult intensive care patients (38), no studies have compared the effects of enteral nutrition versus parenteral nutrition on protein metabolism or outcome in critically ill children. It is also not known if a combination of EN and PN, to improve nutrient intake in the first period of admission, offers benefit over EN alone in critically ill children although this was not the case in adult patients PN (39). More research is needed to determine effects of $\mathrm{EN}$ versus $\mathrm{PN}$ or a combination of $\mathrm{EN}$ and $\mathrm{PN}$ in critically ill children especially in those who are poorly tolerant to EN. In the mean time we advocate to use the enteral route (pre- or post pyloric) in all children whenever possible and to reserve parenteral nutrition for those children whose gastrointestinal tract is not intact or in whom EN cannot be introduced in sufficient amounts within 48 hours.

\section{Protein intake}

The recommended dietary allowance (RDA) for protein of healthy children is traditionally based on requirements for growth and maintenance. Dietary protein requirements for growth are very small in relation to maintenance needs except at a very young age $(0.15-0.4 \mathrm{~g} / \mathrm{kg} / 24 \mathrm{~h}$ in children $<1$ year, $0.1 \mathrm{~g} / \mathrm{kg} / 24 \mathrm{~h}$ between 1 to 3 years and $<0.05 \mathrm{~g} / \mathrm{kg} / 24 \mathrm{~h}>3$ years $(40)$ ).

In critically ill children growth will be attenuated due to the profound but often short lived hormonal alterations (26) in the acute phase of critical illness. After this period somatic growth and catch-up growth may resume early during recovery and will be associated with increased protein and energy requirements. In children recovering from severe malnutrition protein requirements were calculated based on maximum weight gain and increased up to $5 \mathrm{~g} / \mathrm{kg} / 24 \mathrm{~h}$ (41).

Maintenance requirements are based on the basal or obligatory nitrogen losses that occur even when no food is consumed. The major nitrogen losses are in urine (urea and ammonia from amino acid oxidation) and faeces (proteolytic enzymes and mucosal cell proteins (42)). Other losses are skin cells, hair and urinary amino acids. Most data on maintenance requirements have been obtained from analysis of nitrogen balance studies of healthy children $(40,43,44)$ and the mean value obtained was $0.68 \mathrm{~g}$ protein $/ / \mathrm{kg} / 24 \mathrm{~h}$. This value is very similar to the value obtained in a much larger dataset of adult studies $(0.66 \mathrm{~g}$ protein $/ \mathrm{kg} / 24 \mathrm{~h})$ and therefore seems to be independent of age.

Critical illness is characterized by increased nitrogen loss due to increased protein breakdown and amino acid oxidation for gluconeogenesis. The amount of nitrogen loss has been shown to be proportional to the severity of illness (45) and the severity 
of the inflammatory response (46). This implies that maintenance needs are related not only to the severity of the disease and the inflammatory response but will also depend on the phase of the disease, being highest in the most acute phase. Other factors that increase nitrogen loss, and should be accounted for, are loss of blood or plasma and loss of protein-containing fluids from wounds of fistulas. It is not established if nitrogen loss from the gut is increased during critical illness. Mickell et al. (47) investigated urinary urea nitrogen excretion in critically ill children and described that the variability in total urinary urea nitrogen excretion was independent of diagnostic or therapeutic subgroups and ranged from 28 to $584 \mathrm{mg} / \mathrm{kg} /$ day (mean $171 \pm 89 \mathrm{mg} / \mathrm{kg} / \mathrm{day}$ ). This means that a provision of 0.2 to $3.7 \mathrm{~g}$ protein $/ \mathrm{kg} / 24 \mathrm{~h}$ would have equilibrated nitrogen excretion in these children. This was confirmed in a more recent study by Joosten et al. (48) who found similar values (mean $230 \pm 120 \mathrm{mg} / \mathrm{kg} /$ day, range $68-494 \mathrm{mg} / \mathrm{kg} /$ day) in a heterogeneous group of critically ill children.

In healthy infants and children the recommended dietary allowance (RDA) for protein is defined as the amount of protein intake that covers the maintenance needs and protein requirements for growth of $97.5 \%$ of the children. Therefore estimated average requirements (EAR) obtained from nitrogen balance and growth studies are increased by an amount equal to two times its standard deviation (40). When we would apply the same calculations on the data from the studies of Mickell et al. (47) and Joosten et al. (48), the protein intake that would cover the maintenance needs of $97.5 \%$ of all critically ill children would be 2.2 and $3.0 \mathrm{~g}$ protein $/ \mathrm{kg} /$ day respectively. There are, however, few data on the relation between protein intake and clinical outcome and optimal protein intake therefore is not defined.

In severely septic adult patients Shaw et al. (49) studied the effect of glucose infusion and parenteral nutrition on whole body lysine and urea kinetics. No advantage was found in terms of protein sparing when protein was provided in amounts exceeding $1.5 \mathrm{~g} / \mathrm{kg} /$ day. Wolfe et al. (50) studied the effects of two levels of protein intake on leucine kinetics and $\mathrm{N}$-excretion in severely burned adults. The leucine data and the $\mathrm{N}$-excretion data indicated that a balance between protein synthesis and catabolism could be achieved with a protein intake of 1.4 protein $/ \mathrm{kg} / 24 \mathrm{~h}$. When protein intake was increased to $2.2 \mathrm{~g}$ protein $/ \mathrm{kg} / 24 \mathrm{~h}$ no further beneficial effect on net protein synthesis was found although the absolute rates of protein synthesis and catabolism were increased. The N-excretion data, on the other hand, indicated a significant improvement in net protein synthesis with higher protein intake. Cerra et al. (51) found that in hypermetabolic surgical ICU patients, higher protein intake (1.9 vs. 1.5 vs. $1.2 \mathrm{~g} / \mathrm{kg} / 24 \mathrm{~h}$ ) was associated with improved N-retention. In contrast, Ishibashi et al. (52) investigated changes in total body protein over a 10-day period in severe septic and posttraumatic patients using in vivo neutron activation and found that increasing protein intake above $1.2 \mathrm{~g} / \mathrm{kg} /$ day resulted in no further improvement of protein retention. These reports form the basis for recommendations $(53,154)$ in adult ICU patients that protein and amino intake should be between 1.2 and $1.5 \mathrm{~g} / \mathrm{kg} / 24 \mathrm{~h}$ and should not exceed $1.8 \mathrm{~g} / \mathrm{kg} / 24 \mathrm{~h}$. However since the results of these studies can be considered as the average responses of heterogeneous groups of patients in positive energy balance, they may not apply to all patients. Hoffer et al. (54) recently argued that due to concomitant energy deficits, most critically ill patients may benefit from at 
least $2 \mathrm{~g}$ amino acids/kg/24h to mitigate the loss of proteins caused by their energy deficiency. Further research into requirements of different groups of adult ICU patients is still necessary.

In preterm infants early nutritional supplementation with amino acids has been shown to improve net protein balance and growth by increasing whole body protein synthesis $(10,55,56)$ while neurodevelopmental outcome was also improved (57). Reynolds et al. (58) investigated whole body protein balance using leucine kinetics and nitrogen balance in neonates undergoing surgical procedures on the first day of life. Administration of higher amounts of parenteral amino acids ( $2.5 \mathrm{vs} .1 .5 \mathrm{~g} / \mathrm{kg} / 24 \mathrm{~h}$ ) in the immediate peri-operative period lead to a positive protein balance without evidence of protein intolerance. In infants after cardiac operations for congenital defects administration of parenteral amino acids $(0.8 \mathrm{~g} / \mathrm{kg} / \mathrm{d})$ versus glucose only was associated with improved nitrogen balance and decreased muscle proteolysis. In children with severe burn injury increasing protein intake $(2.9 \mathrm{vs} .1 .2 \mathrm{~g} / \mathrm{kg} / \mathrm{d})$ had positive effects on wound healing (59) while higher protein intakes (> $4 \mathrm{~g} / \mathrm{kg} / \mathrm{d}$ ) had beneficial effects on immunological function and outcome (60). Also in a heterogeneous group of critically ill children high protein intake (2.8 vs. $1.7 \mathrm{~g} / \mathrm{kg} / 24 \mathrm{~h})$ was associated with positive nitrogen balance (61). Further support for beneficial effects of high protein intakes in children in catabolic states can be found in the study of Geukers et al. (62) who found that the highest stimulation of whole body protein synthesis in patients with cystic fibrosis could be achieved with dietary protein intakes of $5 \mathrm{~g} / \mathrm{kg} / 24 \mathrm{~h}$ ).

Our results in Chapter 6 and 7 give further evidence for the beneficial effects of high protein intake in critically ill children. In these studies we compared the effects of high protein intake $(3.0 \mathrm{~g} / \mathrm{kg} / 24 \mathrm{~h})$ with normal protein intake $(1.6 \mathrm{~g} / \mathrm{kg} / 24 \mathrm{~h})$ on whole body protein metabolism in critically ill infants on the fifth day of admission. Infants receiving the high protein intake had increased plasma amino acid levels, higher and positive nitrogen balance, and increased rates of whole body protein synthesis and net protein balance as measured by phenylalanine and tyrosine kinetics when compared to the infants receiving the normal protein intake. Net protein anabolism was only achieved with the high protein intake and without signs of overfeeding. Although high protein intake is well tolerated and has shown beneficial effects, maintenance needs and protein requirements for (catch-up) growth will most certainly depend upon disease severity and the phase of illness. At this moment, however, insufficient data are available to relate the protein requirements directly to the severity of the metabolic alterations. We therefore advocate supplying high protein intakes $(1.5 \mathrm{~g} / \mathrm{kg} /$ day and increasing to $3.0 \mathrm{~g} / / \mathrm{kg} / 24 \mathrm{~h}$ within the first days of admission) to critically ill infants and children.

\section{Specific amino acids}

The nutritional quality of dietary protein depends on its amino acid composition. Restriction in the availability of even a single (essential) amino acid can limit the entire protein synthetic rate. During critical illness hepatic protein synthesis is increased and the synthesis of numerous acute phase proteins require the supply of 
specific amino acids according to their amino acid composition. However, the amino acids needed for acute phase protein synthesis are different from those provided by (muscle) proteolysis. This may be one of the major factors leading to the excessive mobilization of muscle proteins until the appropriate amount of the most limiting amino acid is reached. Reeds et al. (28) estimated that the amount of amino acids required for typical acute phase protein response of the adult is twice the amount present in the same quantity muscle protein implying that 2 gram of muscle must be degraded to synthesize 1 gram of acute phase proteins. Therefore, theoretically net muscle protein breakdown may be diminished by providing the specific amino acids needed for synthesis of acute phase proteins. The excessive degradation of muscle proteins also imbalances the free amino acid pool which directs amino acids into oxidation (63). It may therefore be necessary to establish the specific amino acid requirements for each clinical condition to be able to meet these requirements by specific amino acid supplementation. However, as long as the specific amino acid needs are not established, a generous nutritional supply of protein and thereby amino acids may be the best way to supply all necessary amino acids for (hepatic) protein synthesis. Indeed the results of our studies in Chapter 6 and 7 show the positive effects of high protein intake on plasma amino acid levels and also on nitrogen balance and net protein balance.

Amino acids also have other roles apart from their roles as substrate for protein synthesis, for instance as fuel for tissues as the gut, brain and the immune system. Specific amino acids can also exert regulatory effects at various levels of cell activity as mediators or signal molecules. Examples of amino acids that play important roles during critical illness are the branched chain amino acids, glutamine and also arginine and citrulline.

\section{Arginine}

The conditionally essential amino acid arginine plays a key role in many metabolic processes in health and disease (64) such as detoxification of ammonia (urea cycle), synthesis of polyamines and creatine, modulation of immune function, release of anabolic hormones and synthesis of nitric oxide (NO) (65). It is considered as conditionally essential since endogenous arginine synthesis may not be sufficient to meet metabolic needs, especially during growth (infants and children) (66) and during highly catabolic conditions such as sepsis $(67)$ and burns $(68,69)$. Children with critical illness may therefore be particularly at risk for the development of arginine deficiency. Low plasma arginine concentrations have indeed been described in children with various pathological conditions such as in premature infants with necrotizing enterocolitis (NEC) (70) and children with asthma (71), cerebral malaria (72), or sickle cell crisis (73). Low plasma arginine levels have also been described in critically ill adults (74). In critically ill children plasma arginine levels have not been described but Argaman et al. (67) and $\mathrm{Yu}$ et al. $(68,75)$ showed that arginine breakdown (for NO synthesis and for increased oxidation to urea and ornithine) was increased while de novo arginine synthesis (in the kidney) was unchanged leading to a negative arginine balance. 
In Chapter 5 we show that in critically ill children with different underlying disorders (severe viral disease, accidental or surgical trauma and septic shock) plasma levels of arginine, glutamine and citrulline are low. Arginine, citrulline and glutamine depletion occurred early in the course of critical illness and was proportional to the severity of illness and to the severity of the inflammatory state as expressed by the plasma CRP, a very sensitive non-specific biochemical marker of inflammation and tissue damage. During recovery the plasma concentrations of these amino acids normalized but the strong relationship with plasma CRP levels was maintained. During recovery plasma CRP level was the only significant determinant of plasma arginine and citrulline levels while the dietary protein intake from a standard pediatric enteral formula had little additional effect.

Several studies have shown that both oral and parenteral arginine supplementation can increase arginine concentrations in children $(73,76)$, although a high first-pass uptake of arginine in the gut mucosa and the liver (40\%) has been reported (77). Arginine supplementation has shown beneficial effects such as prevention of NEC in premature infants (76) and lowering of pulmonary pressure during sickle cell crisis (73). Few studies have addressed the effects of arginine supplementation in critically ill adults and none have been performed in children. Potential mechanisms for beneficial effects of exogenous administration of arginine in critical illness include enhanced protein metabolism but also improved microcirculation and organ function, effects on immune function and antibacterial effects, improved gut function, and an antioxidant role of arginine (78). Since arginine is the sole precursor for synthesis of NO, the most potent vasodilator of the body, there are concerns about exogenous arginine supplementation. Indeed studies have reported adverse haemodynamic effects after arginine supplementation by intravenous bolus (79). However continuous arginine infusion did not deteriorate the haemodynamic condition at all in patients with severe sepsis (80). Given the many pathways that may benefit from arginine supplementation and the relative safety of arginine supplementation, also in patients with severe sepsis, more studies into the effects of arginine supplementation in critically ill adults and children are warranted. In such studies the plasma CRP level may be a sensitive marker to predict arginine depletion and the need for supplementation. At this moment, however neither enteral nor parenteral arginine supplementation can be advocated.

\section{Glutamine}

Of all amino acids, glutamine has the highest plasma and intracellular concentrations under normal conditions. Most glutamine is formed in skeletal muscle from catabolism of the branched chain amino acids. Glutamine forms a substrate for glutathione synthesis and nucleotide synthesis, is an important fuel for enterocytes, lymphocytes and macrophages, and plays a major role in gluconeogenesis. During stress both plasma levels and intracellular levels drop and glutamine is considered a conditionally essential amino acid especially during catabolic conditions. Glutamine has been extensively studied as a potential treatment for muscle cachexia during critical illness. Animal studies have shown beneficial effects of glutamine supplementation on muscle protein breakdown, but also on gut barrier function and immune defense 
(81). Parenteral supplementation of glutamine however is complicated by the fact that glutamine is unstable in solution, although it can be administered parenterally as a dipeptide. Intravenous glutamine $(0.28-0.86 \mathrm{~g} / \mathrm{kg} / \mathrm{d})$ raises plasma glutamine concentration in a dose dependent way in adults but high doses are necessary in some patients to normalize the plasma glutamine concentration (20-60 g glutamine/d) (82). Enterally administered glutamine undergoes significant first pass splanchnic metabolism and does not raise plasma glutamine levels in adults (81). A number of studies have demonstrated the efficacy of either enteral or parenteral glutamine in adults with a variety of conditions on infectious complications $(81,83-85)$ while other studies found no benefit (86). A systemic review of these studies (87) concluded that glutamine-enriched diets are well tolerated and improve immunological aspects in multiple trauma patients, lead to cost reduction in critically ill patients, and improves mucositis in post-chemotherapy patients but do not effect mortality. Intake of at least 20 to $30 \mathrm{~g} / \mathrm{d}$, early initiation of diet, and maintenance for $5 \mathrm{~d}$ or longer were recommended.

In preterm infants, inclusion of glutamine in parenteral feeding was shown to be beneficial with respect to gastrointestinal function (88), risk of sepsis, tolerance to subsequent enteral feedings (days with no oral intake), and duration of hospital stay (89). However systematic review of these and five other studies investigating the effect of parenteral and enteral glutamine supplementation on morbidity in preterm infants found no significant differences between glutamine-supplemented and nonsupplemented babies for the number of invasive infection, prevalence of necrotizing enterocolitis, time to achieve full enteral nutrition, or duration of hospital stay (90). In critically ill infants, data on the effects of glutamine supplementation are scarce, while data in older children are altogether lacking. In a small prospective randomized study in critically ill infants enteral glutamine supplementation $(0.3 \mathrm{~g} / \mathrm{kg} / \mathrm{d})$ was safe and tended to be associated with less infectious morbidity and mortality (91). Albers et al. (92), however, studied the effects of glutamine supplementation of parenteral nutrition $(0.4 \mathrm{~g} / \mathrm{kg} / \mathrm{d})$ in newborns and infants after major digestive-tract surgery in a double blind randomized way. No beneficial effects on intestinal permeability, nitrogen balance, urinary 3-methylhistidine excretion or clinical outcome were found. In our studies (Chapter 5) low plasma glutamine levels were found in critically ill infants and in children with different underlying diagnosis. Plasma glutamine levels were related to the severity of the underlying illness and the severity of the inflammatory response as expressed by the plasma CRP level. However, more research is necessary into possible beneficial effects of glutamine supplementation in different groups of critically ill infants and children before enteral or parenteral glutamine supplementation can be advocated.

\section{Branched chain amino acids (BCAA)}

BCAA are an important energy source for skeletal muscle and stimulate muscle protein synthesis. Many animal studies confirm the positive effects of BCAA on muscle protein synthesis and net muscle protein balance but clinical studies have not consistently done so. In a recent paper De Bandt et al. (93) review all available studies and conclude that the disappointing results may be due to the fact that of the three 
BCAA (leucine, valine and isoleucine) only leucine has regulatory properties and should be studied separately. Leucine also acts like a pharmaconutrient, which means that leucine supplementation should be given in addition to, and not as a replacement of sufficient and balanced nutritional support.

The results in Chapter 5, 6 and 7 indirectly support the important role of the BCAA in critical illness in children. In Chapter 5 we found that the plasma levels of BCAA are low in critically ill children and related to the severity of illness. In Chapter 6 we showed that a higher enteral protein and energy intake in critically ill infants increases plasma BCAA concentrations and is associated with an increased cumulative nitrogen balance. In Chapter 7 we showed a significant positive relationship between the plasma BCAA levels and whole body protein synthesis measured by stable isotope kinetics. The exact role of BCAA or leucine supplementation in critically ill children remains to be established.

\section{Energy intake}

Provision of a sufficient energy intake is important since energy deficiency worsens nitrogen balance both in adults and children $(1,54,94)$. In critical illness hypocaloric feeding is associated with increased catabolism of lean body mass (95) and increased infectious complications (96), while several randomized clinical trials have shown beneficial effects and improved clinical outcome of increasing the amount of enteral nutrition in adult ICU patients (see for review Stapleton et al. (97)) and also in pediatric ICU patients $(61,98)$.

In adults, critical illness is characterized by a state of hypermetabolism, proportional to the severity of the injury (99). Endogenous catecholamines are the primary mediators of this hypermetabolic response (100) by inducing a hyperdynamic circulation, tachycardia, and increased cardiac work (101).

Studies of critically ill children with various underlying disorders have produced contradictory results, and resting energy expenditure (REE) was found to be either higher (102-104) or similar to predicted values (105-107). This controversy between studies may be due to differences in: 1) the phase of the disease (acute phase or recovery phase; 2 ) the severity of illness; 3 ) the treatment (mechanical ventilation, sedation or muscle paralysis) and 4) the environment in these studies (temperature). Although REE may be increased during critical illness, physical activity is low due to immobility for instance in sedated or paralyzed mechanically ventilated children. Growth is probably also attenuated during the acute phase of critical illness $(1,108)$ although the duration of this growth faltering is not established. Since the acute metabolic response to severe stress resolves rapidly $(<48 \mathrm{hrs})$ in most forms of critical illness in infants and children, normal growth and/or catch-up growth may resume at an early stage.

The optimal energy intake in critical illness in both adults and children is still not defined. It is our opinion that the REE should be seen as the minimum level of intake and not the optimal intake for critically ill children because it does not take into account the general activity level, the deposition of energy for growth (up to 50 $\mathrm{kcal} / \mathrm{kg} / 24 \mathrm{~h}$ in infants (109)), catch-up growth and increased energy losses (110) via 
stools or wound tissue. It is probably safer to increase energy intake well above REE in order to prevent unnecessary catabolism of body protein stores and improve anabolism and (catch-up) growth.

Provision of hypercaloric feeding during critical illness should probably also be avoided (111). Overfeeding can be defined as the provision of calories and/or substrates in excess of the requirements to maintain metabolic homeostasis. Especially carbohydrate overfeeding is associated with adverse effects like hyperglycemia, lipogenesis (with liver steatosis) and increased $\mathrm{CO}_{2}$ production (112) which may increase ventilator dependency (113) and may have negative effects on outcome (114116). Carbohydrate overfeeding is characterized by a respiratory quotient $>1.0$ as measured by indirect calorimetry. In Chapter 6 we show that early enteral administration of a protein and energy enriched formula improves energy delivery to critically ill infants and improves the energy balance. Even an energy intake $(112 \mathrm{kcal} / \mathrm{kg} / 24 \mathrm{~h})$ well above measured REE (54 kcal/kg/24h) was well tolerated and was only seldom associated with signs of carbohydrate overfeeding (hyperglycemia or an RQ > 1.0). Our results suggest that early administration of sufficient energy is beneficial and that provision of high enteral energy intakes may be well tolerated and (in combination with sufficient protein) improve anabolism.

Based on the current literature we therefore advocate to increase enteral energy intake early during admission (within 48 hours) to meet targets of REE $+30 \%$. Measurement of the individual REE with indirect calorimetry should be performed whenever possible as this is superior to estimation of REE with prediction equations.

\section{Carbohydrate and fat intake}

In healthy subjects gluconeogenesis and lipolysis are increased during starvation but can be effectively inhibited by exogenous administration of glucose (due the effects on glucagon and insulin levels). During critical illness, however, administration of carbohydrates does not or only minimally diminishes the rate of gluconeogenesis $(112,117)$ probably caused by increased plasma levels of TNF- $\alpha$, IL-1, glucagon and catecholamines $(118,119)$. Still, carbohydrates can exert a positive effect on protein and amino acid metabolism by their effect on insulin secretion. Indeed, in studies of severely burned children high-carbohydrate $(80 \%)$ versus high fat feeding resulted in decreased muscle protein breakdown, due to stimulation of endogenous insulin secretion (29) (120). However, high carbohydrates intakes, especially when parenterally administered may be responsible for increased lipogenesis and fat tissue deposition together with liver steatosis. Furthermore, high carbohydrate intake increases $\mathrm{CO}_{2}$ production and minute ventilation (112). High glucose intake also leads to hyperglycemia, which is associated with adverse outcome (114) and even death in adults $(121,122)$ and also in children (116). The optimal amount of carbohydrate in critically ill children waits to be defined but should have as target an optimal stimulation of insulin secretion while avoiding the negative effects of carbohydrate overfeeding.

Dietary fat also stimulates insulin secretion $(123,124)$. In adult intensive care and surgical patients nitrogen balance can be similarly improved with total parenteral nutrition with lipid or lipid-glucose mixtures as long as energy requirements are met 
(125). Fat also has a "carbohydrate sparing effect", preventing the consequences of excessive glucose supply. No studies of critically ill children have been performed to determine the optimal amount of glucose and fat intake. The most appropriate way to determine the amount of glucose and fat supply may be to determine first the energy requirements and then to calculate carbohydrate requirements as $40-50 \%$ of total energy intake in infants and children and fat requirements of $45-50 \%$ in infants and $20-40 \%$ in older children.

Besides an important source of energy, dietary fat also supplies essential fatty acids like linoleic acid and alpha-linolenic acid, as well as the polyunsaturated fatty acids (PUFA's), including omega 6 fatty acids (e.g. arachidonic acid) and omega 3 fatty acids (e.g. eicosapentaenoic acid (EPA) and docosahexaenoic acid (DHA)). Omega 3 fatty acids have been the focus of many studies due to its immune modulatory function and especially their anti-inflammatory effects. Few studies, however, have investigated the effect of omega 3 fatty acids on protein metabolism in humans. In animal studies omega 3 fatty acids have been shown to inhibit muscle proteolysis during starvation and cachexia by decreasing cytokine production (126) and by downregulating ubiquitin-dependent proteolysis (127). However, studies of adults with cancer cachexia have been disappointing $(128,129)$. López-Alarcón et al. (130) studied the effects of DHA supplementation on nutritional status of septic neonates. DHA supplementation was associated with increased fat gain but no effects on length growth were found. At this moment the use of nutrition enriched with omega 3 fatty acids in critically ill children cannot be advocated.

\section{Anabolic therapies}

Nutritional support in critical illness cannot abolish the protein catabolic response although it may be able to prevent some of its negative consequences. Adjunctive therapies have been studied to improve and support the anabolic effects of nutrition. The catabolic state of critical illness is partly due to resistance to anabolic hormones like insulin and growth hormone and leads to low IGF-1 levels. Pro-inflammatory cytokines (e.g. TNF- $\alpha$, IL-1 and IL-6) probably play important roles in these alterations.

\section{Insulin}

Insulin is the most important anabolic hormone and exerts its anabolic effects by stimulating muscle protein synthesis and inhibiting protein breakdown both in health and during disease (see paragraph 2.8.1). Exogenous insulin administration therefore is considered potentially useful to promote anabolism and prevent muscle wasting in critically ill patients in addition to nutritional support measures.

Critical illness in adults however is associated with a resistance to the actions of insulin as shown by high blood glucose levels despite increased insulin levels (131). Insulin resistance occurs in insulin dependent tissues (liver, skeletal and heart muscle, adipose tissue and kidney) and can be seen as an adaptive response promoting release of gluconeogenic amino acids from muscle for hepatic and kidney gluconeogenesis and facilitating glucose uptake in non-insulin-dependent tissue (brain, wound) and as such important for survival. The benefits of exogenous insulin 
administration are therefore controversial. Although insulin therapy has been shown to decrease morbidity and mortality in critically ill patients in surgical intensive care units (ICU) (114) and is widely propagated, high doses of insulin in the acute setting of critical illness have also been associated with adverse outcome (132). In burned children insulin therapy decreases the prolonged hepatic acute phase response, but has no positive effects on the hepatic constitutive proteins (133). In extreme low birth weight infants (ELBW) insulin reduced protein breakdown but did not enhance protein synthesis when not administered together with amino acids (134). In neonates on extracorporeal membrane oxygenation insulin improved net protein balance, mainly by reduction of protein breakdown $(135,136)$. In critically ill children with another diagnosis than burn injury the effect of insulin therapy on protein metabolism and lean body mass remains to be investigated.

In Chapter 4 we investigated the alterations in insulin secretion and function in relation to the inflammatory response in children with meningococcal sepsis in order to obtain more insight into the hormonal mechanisms of the protein catabolic response. We found striking differences between the hormonal response in children and the response most often reported in adult critically ill patients. In adults hyperglycemia is associated with insulin resistance (hyperinsulinemic hyperglycemia) while in critically ill children we found evidence for hypoinsulinemic hyperglycemia and increased insulin sensitivity in the acute phase of the disease. Further analysis of the inflammatory response in these children suggested a suppression of the proinflammatory response on insulin secretion. Therefore we conclude that in critically ill children in the acute phase of meningococcal septic shock hyperglycemia associated with hypoinsulinemia rather than insulin resistance seems to be the normal pathophysiologic response. Our results are supported by the results in Chapter 5. Insulin levels and insulin/glucose ratios were significantly lower in the children with meningococcal septic shock compared to children with viral disease and increased over the next seven days (Figure 3)(D.A van Waardenburg, unpublished results).
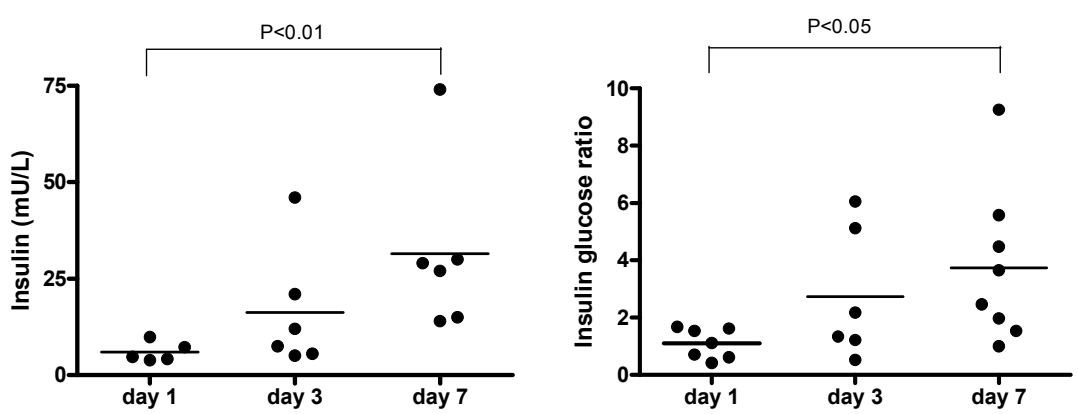

Figure 3. Plasma insulin concentrations and insulin/glucose ratios in children with meningococcal septic shock on day 1, 3 and 7 of admission. (Kruskal Wallis with Dunn's Multiple Comparison Test) 
A limitation of both studies, however, is that we did not standardize for differences in intravenous glucose intake, which may have affected insulin levels, and to a lesser degree the insulin/glucose ratios. Furthermore our results were obtained in children with severe meningococcal septic shock receiving inotropic support with dopamine and norepinephrine. The applicability of these results to other patients groups remains therefore to be established. If confirmed in larger groups of critically ill children however our results have serious implications for the use of exogenous insulin therapy in critically ill children since the risk for hypoglycemia would be strongly increased in these patients.

Although exogenous insulin therapy may be a potentially useful adjunct to nutritional support in critically ill children to promote anabolism, its use cannot be advocated until more studies have determined its safety in critically ill children especially in the acute phase of critical illness.

\section{Growth hormone $(\mathrm{HGH})$}

The actions of $\mathrm{HGH}$ are mediated directly by way of peripheral $\mathrm{HGH}$ receptors and indirectly through the enhanced hepatic synthesis of insulin-like growth factor 1 (IGF1). $\mathrm{HGH}$ is the second most important anabolic hormone and has been used in a number of studies of critically ill adults. Administration of high doses of $\mathrm{HGH}$ (5-20 times the dose needed for replacement therapy in growth hormone deficient adults) has been associated with increased circulating IGF-1 levels, improvement in nitrogen balance, attenuation of the decrease in muscle glutamine, improved protein synthesis rates and preservation of lean body mass. However the study of Takala et al. (137) demonstrated that $\mathrm{HGH}$ treatment of critically ill adults during the first few weeks of the acute illness was associated with a significant increase in mortality and prolongation of weaning times (from mechanical ventilation), duration of intensive care, and length of hospital stay.

In a study in preterm infants with bronchopulmonary dysplasia and growth faltering due to dexamethason treatment, high-dose $\mathrm{HGH}$ treatment $(0.3 \mathrm{mg} / \mathrm{kg} / 24 \mathrm{~h})$ did not improve growth (138). In studies of pediatric burn patients daily intramuscular administration of $\mathrm{HGH}$ during acute burn care has shown favorable effects on the hepatic acute phase response, increased serum concentrations of IGF-I (139), improved muscle protein kinetics, maintained muscular growth, and decreased donor site healing time (140). Patients receiving $\mathrm{HGH}$ treatment, demonstrated increases in serum IGF-I and IGFBP-3 (141). Evidence for adverse outcome and excess mortality was not found in these severely burned children (142). Given the beneficial effects in children with burn injury further studies into the effects of $\mathrm{HGH}$ in other disorders like sepsis and trauma may be warranted, although its use as an anabolic agent cannot be advocated at the present moment.

\section{IGF-I}

Studies of IGF-1 administered alone have proved disappointing (143) perhaps because of inadequate levels achieved after subcutaneous administration or counterregulatory changes in IGF-binding proteins. When administered in combination with IGFBP-3, IGF-1 increased muscle protein synthesis in severely burned adults and had 
no adverse effects on plasma glucose (144). Also in pediatric patients with burn injury recombinant human IGF-1 and IGFBP-3 improved protein metabolism with significantly less hyperglycemia than GH itself (145). In a recent study in premature infants the effects of enteral IGF-1 (added to the infant formula) was investigated during the first months of life. No significant effects were found on the primary end points: days to full enteral feeding, days to regain birth weight, and growth rate (146). At the present moment IGF-1 cannot be advocated to promote protein anabolism in critically ill children.

\section{Catecholamine antagonists}

Direct catabolic effects of increased catecholamines on protein metabolism during critical illness have not been consistently shown. However in burn injury patients a close association between increased energy expenditure and muscle protein catabolism exists (147). Propanolol treatment, to block the effects of raised catecholamine levels in children with severe burn injury, increased the net protein balance and fat free mass (101). However, in animal models of sepsis, the use of propranolol or other nonselective beta-blockers during the treatment of sepsis has also been shown to worsen net muscle protein balance by impairing protein synthesis and by delaying recovery (148). Furthermore, this treatment was also associated with alterations of cellular immune functions, deterioration in the clinical situation and reduced survival (149). Further studies are necessary before propranolol treatment can be advocated in critically ill children.

\section{CLINICAL IMPLICATIONS}

\section{General}

As mentioned before, the target of nutritional support in critically ill children should be to supply the body with sufficient energy and substrates to prevent catabolism of body stores, to stimulate synthesis of proteins involved in immune defense and injury repair and promote (catch-up)-growth in the recovery phase. This may be achieved by several measures (Table 2).

\section{General measures}

As long as the disease process continues, the hormonal and inflammatory response to critical illness will sustain the protein catabolic response. Therefore adequate, (aggressive) treatment of the underlying disease is of utmost importance. The response to treatment should be evaluated by serial determination of markers of the inflammatory response (e.g. plasma CRP levels). If possible, drugs with known or possible catabolic effects should be avoided (glucocorticosteroids, catecholamines). Measures should also be taken to prevent secondary infections as much as possible (e.g. ventilator associated pneumonia and catheter related infections). 


\section{Macronutrient intake during critical illness}

\section{Early introduction of protein and energy enriched enteral nutrition}

In order to avoid development of protein and energy deficits, enteral nutrition should be started on the first day of PICU admission by continuous intragastric drip-feeding. The rate of drip-feeding should then be increased every 8 to 12 hours to achieve target intakes of protein and energy within 48 hours after admission. The use of protein and energy enriched formulas (100-150 kcal $/ \mathrm{kg}$, P: E ratio $10 \%)$ is advocated to promote sufficient intake despite fluid restriction in the first days after admission. In the case of gastric intolerance (gastric retentions, gastric distension or vomiting) postpyloric feeding should be given. Alternatively erythromycin $(1-3 \mathrm{mg} / \mathrm{kg} / 24 \mathrm{~h}$ intravenously) may be used to stimulate gastric emptying although the benefits of this treatment in children have not been firmly established. When enteral feeding is not possible within 48 hours or when contraindications for enteral feeding exist, parenteral feeding should be started as soon as possible.

\section{Energy Intake}

Energy intake should be sufficient to minimize the consumption of internal energy stores of the body while avoiding the negative effects of excess intake. In the acute phase of critical illness energy needs should preferably be determined by measuring REE with indirect calorimetry. If this is not possible, REE can be estimated using prediction equations (Schofield (150)). Target energy intake (TEI) is then calculated by adding $30 \%$ to account for variability in daily energy expenditure, energy losses via the gastrointestinal tract and patient activity related to nursing care. During the recovery phase of the disease, energy intake should be increased to account for the extra energy needs for physical activity and the energy deposition in tissues for (catch-up) growth. In this phase energy intake can be guided by nutritional guidelines (40) based on growth charts of healthy children and the ideal body weight. When growth is still insufficient energy intake should be further increased. In some cases energy intake has to be increased up to $200 \%$ of RDA.

\section{Protein and amino acids}

Protein intake should deliver the optimal amount of protein and amino acids that promotes net protein balance by stimulating protein synthesis and/or limiting (muscle) protein breakdown. We advocate supplying high protein intakes with the target of achieving a protein intake of $1.5 \mathrm{~g} / \mathrm{kg} /$ day after 48 hours and then a further increase up to $3.0 \mathrm{~g} / \mathrm{kg} / 24 \mathrm{~h}$ within the first 5 days of admission in all critically ill infants and children. Blood urea nitrogen can be used to monitor protein intolerance. At the present moment the requirements for specific amino acids in critically ill children are not defined.

\section{Protein to energy ratio}

The required protein to energy ratio (defined as the energy intake by protein divided by the total energy intake) of children depends on the additional energy and protein needs during critical illness and the rate and composition of catch-up growth. Dose 
response interventions studies in critically ill children, however, are lacking. Based on our data and those of others $(40,44,110,155)$ the protein to energy ratio should be 9 $11.5 \%$ for wasted infants and children with catch-up growth and may increase up to $16 \%$ in stunted children or critically ill children.

\section{Carbohydrates}

Carbohydrates are a readily available form of energy and stimulate insulin secretion. However increased dietary carbohydrate intake cannot prevent the increased protein breakdown for hepatic gluconeogenesis. Carbohydrate overfeeding on the other hand is associated with lipogenesis and hyperglycemia especially when administered intravenously. Although the optimal carbohydrate intake is not defined, a carbohydrate intake of $40-50 \%$ of total energy intake as supplied by most pediatric enteral formulas is usually well tolerated. Intravenous carbohydrate intake should probably not exceed 4-6 mg/kg/min. in children below $30 \mathrm{~kg}$ and $2-4 \mathrm{mg} / \mathrm{kg} / \mathrm{min}$. in children above $30 \mathrm{~kg}$ (115). Carbohydrate overfeeding can be monitored by measuring the RQ $(R Q>1.0)$ using indirect calorimetry, the occurrence of hyperglycemia and glucosuria. Since no randomized clinical trials in children have been performed and given the increased risk for hypoglycemia in children, strict glycemic control with exogenous insulin (blood glucose between 4.4-6.1 mmol/L) cannot be advocated. Although maximal acceptable blood glucose levels for children are not defined, a prolonged blood glucose concentration of $8.3 \mathrm{mmol} / \mathrm{L}$ is proposed as a limit to treat hyperglycemia with insulin (115).

\section{Fat intake}

The optimal dietary fat intake during critical illness in children is not defined. Most pediatric enteral formulas supply $45-50 \%$ of total energy intake as fat in infants and 20$40 \%$ in older children. Parenteral lipid intake should be limited to $3-4 \mathrm{~g} / \mathrm{kg}$ per day in infants and 2-3 g/kg per day in older children (151). When parenteral lipids are administered plasma levels of triglycerides should be monitored. Reduction of the dosage of lipid emulsions should be considered if serum or plasma triglycerides concentrations during infusion exceed $2.5 \mathrm{~g} / \mathrm{L}$ in infants or $4.0 \mathrm{~g} / \mathrm{L}$ in older children (151). Infant and pediatric formulas as well as parenteral nutrition should contain a sufficient amount of essential fatty acids according to RDA for healthy infants (40).

\section{Other measures}

The benefit of administration of anabolic hormones in critically ill children is not defined. Although potentially beneficial, these therapies cannot be advocated at the present moment. This is also the case for other experimental therapies such as betablockers. 


\section{CHAPTER 8}

Table 2 Summary of measures to promote anabolism in critically ill children

\begin{tabular}{|c|c|}
\hline Measures & Recommendations \\
\hline General measures & $\begin{array}{l}\text { - } \quad \text { Treat the underlying illness aggressively, avoid secondary infections } \\
\text { - } \quad \text { Monitor response to treatment (e.g. plasma CRP concentration) } \\
\text { - } \quad \text { Avoid catecholamines and steroids if possible }\end{array}$ \\
\hline Early nutritional support & $\begin{array}{l}\text { - } \quad \text { Start enteral nutrition as soon as possible }(<24 \text { hour after admission) } \\
\text { - } \quad \text { Define the individual's target macronutrient intakes } \\
\text { - } \quad \text { Use nutrient enriched formulas (nutrient condensed) } \\
\text { - } \quad \text { Start PN if EN not possible within } 48 \text { hours }\end{array}$ \\
\hline Energy & $\begin{array}{l}\text { - } \\
\text { - } \\
\text { - } \\
\text { Reasine target energy intake }(\mathrm{TEI}=\mathrm{REE}+30 \%) \\
\text { hours })\end{array}$ \\
\hline Protein intake & $\begin{array}{l}\text { Define target protein intake: minimal intake } 1.5 \mathrm{~g} / \mathrm{kg} / 24 \mathrm{~h} \text {, maximal intake } \\
3.0 \mathrm{~g} / \mathrm{kg} / 24 \mathrm{~h} \text {, reach target intake of } 1.5 \mathrm{~g} / \mathrm{kg} / 24 \mathrm{~h}<48 \mathrm{~h} \text {. } \\
\text { Increase to maximal intake in next } 3 \text { days while monitoring blood urea } \\
\text { nitrogen } \\
\text { During catch-up growth further increase intake up to } 5 \mathrm{~g} / \mathrm{kg} / 24 \mathrm{~h} \text { with } \\
\text { concomitant increase of energy intake } \\
\text { - Protein energy to total energy ratio } 10-15 \%\end{array}$ \\
\hline Carbohydrates & $\begin{array}{l}\text { - Define target carbohydrate intake: } 40-55 \% \text { of TEI } \\
\text { Increase to maximum while monitoring RQ }(<1.0) \text { with indirect } \\
\text { calorimetry. }\end{array}$ \\
\hline Fat & $\begin{array}{l}\text { - } \quad \text { No specific target of fat intake possible } \\
\text { - } \quad \text { Use fat to reach target energy intake } \\
\text { Omega } 3 \text { fatty acids enriched formulas are not recommended due to } \\
\text { insufficient evidence }\end{array}$ \\
\hline $\begin{array}{l}\text { Specific amino acids } \\
\text { (Arginine, glutamine, } \\
\text { citrulline, BCAA) }\end{array}$ & $\begin{array}{l}\text { - } \quad \text { Potentially beneficial } \\
\text { - } \quad \text { No recommendations possible due to insufficient evidence } \\
\text { - } \quad \text { More studies needed }\end{array}$ \\
\hline $\begin{array}{l}\text { Anabolic hormones } \\
\text { (insulin, HGH, IGF- } \\
\text { 1/IGFBP-3) }\end{array}$ & $\begin{array}{l}\text { - } \quad \text { Potentially beneficial } \\
\text { - } \quad \text { No recommendations possible due to insufficient evidence } \\
\text { - More studies needed }\end{array}$ \\
\hline Beta Blockers & $\begin{array}{ll}\text { - } & \text { Benefits unclear } \\
\text { - } & \text { Not advocated at the present moment (possible exception: burn injury) }\end{array}$ \\
\hline
\end{tabular}

$P N$, parenteral nutrition; $E N$, enteral nutrition; TEl, total energy intake; $R E E$, resting energy expenditure; $R Q$, respiratory quotient; $B C A A$, branched chain amino acids.

\section{FUTURE PERSPECTIVES}

The presented studies in this thesis show that critical illness in children is associated with increased rates of protein synthesis and breakdown, negative protein balance and nitrogen loss. Amino acid metabolism is characterized by increased plasma amino acid extraction and specific amino acid deficiencies. Both processes are strongly related to disease severity and/or severity of the inflammatory response. Our findings suggest that the quantity and quality of protein and amino acid needs may be related to the severity of the inflammatory response and thus also to the severity and phase of the disease. An important finding in our studies is that high protein and 
energy intakes can promote protein anabolism in critically ill infants by stimulating protein synthesis.

Future research should focus on the following topics:

- The alterations of protein and amino acid metabolism in critically ill children with different disease severity, different underlying disorders, with different age and in different phases of the disease (during the acute phase of critical illness and during recovery) in relation to alterations in inflammatory (acute phase proteins and inflammatory cytokines) and hormonal parameters (insulin, cortisol, $\mathrm{HGH}$ and IGF-1). Methods that can be used are 1) determination of plasma amino acid concentrations, 2) assessment of whole body protein metabolism (preferably using multiple stable isotope methods at the same time), 3) muscle protein breakdown (using urinary 3-methylhistidine excretion or stable isotopes of 3-MEH), 4) splanchnic amino acid metabolism (using the dual tracer approach) and 5) assessment of amino acid metabolism (using specific amino acid tracers, e.g. arginine, citrulline, glutamine). These studies will provide us a more complete picture of the alterations in protein and amino acid metabolism during different phases of critical illness in children and will also further establish the relationship with severity of illness and inflammatory and hormonal mediators. This knowledge will make it better possible to define and evaluate further studies into the effects of nutritional or therapeutic interventions.

- The effects of nutritional and/or therapeutic interventions on protein and amino acid metabolism also in critically ill children with different underlying disorders, in different age groups and in different phases of the disease. Possible interventions are: 1) different levels of protein and/or energy intake, 2) supplementation of specific amino acids (glutamine, arginine, citrulline and BCAA) and 3) anabolic hormones (insulin, $\mathrm{HGH}$, IGF-1).

- Finally, studies are also necessary to evaluate the effects of nutritional and other therapeutic interventions on clinical endpoints. Possible relevant clinical endpoints would be: days on the ventilator, days on the intensive care and in hospital, the number of infectious episodes and complications, and eventually longterm outcome at follow up.

\section{CONCLUDING REMARKS}

The results of our studies emphasize the importance of investigation of protein and amino acid metabolism in critically ill children. Future research should further explore the relationship between the hormonal and inflammatory response to acute stress, alterations in protein and amino acid metabolism and role of nutritional support on these processes. The ultimate goal will be to tailor nutritional support to the exact needs of the child during the different phases of critical illness and thereby improve outcome and further growth and development. 


\section{CHAPTER 8}

\section{REFERENCES}

1. Hulst JM, van Goudoever JB, Zimmermann LJ, et al. The effect of cumulative energy and protein deficiency on anthropometric parameters in a pediatric ICU population. Clin Nutr 2004;23:1381-9.

2. McLaughlan JM, Illman WI. Use of free plasma amino acid levels for estimating amino acid requirements of the growing rat. J Nutr 1967;93:21-4.

3. Heird WC, Dell RB, Helms RA, et al. Amino acid mixture designed to maintain normal plasma amino acid patterns in infants and children requiring parenteral nutrition. Pediatrics 1987;80:401-8.

4. Cynober LA. Plasma amino acid levels with a note on membrane transport: characteristics, regulation, and metabolic significance. Nutrition 2002;18:761-6.

5. van Eijk HM, Rooyakkers DR, Deutz NE. Rapid routine determination of amino acids in plasma by highperformance liquid chromatography with a 2-3 microns Spherisorb ODS II column. J Chromatogr 1993;620:143-8.

6. Van Eijk HMH, DeJong CHC, Deutz NEP, Soeters PB. Influence of storage conditions on normal plasma amino-acid concentrations. Clinical Nutrition 1994;13:374.

7. Beisel WR. Magnitude of the host nutritional responses to infection. Am J Clin Nutr 1977;30:1236-47.

8. Vente JP, von Meyenfeldt MF, van Eijk HM, et al. Plasma-amino acid profiles in sepsis and stress. Ann Surg 1989;209:57-62.

9. Wolfe RR. Regulation of skeletal muscle protein metabolism in catabolic states. Curr Opin Clin Nutr Metab Care 2005;8:61-5.

10. te Braake FW, van den Akker CH, Wattimena DJ, Huijmans JG, van Goudoever JB. Amino acid administration to premature infants directly after birth. J Pediatr 2005;147:457-61.

11. Waterlow JC, Golden MH, Garlick PJ. Protein turnover in man measured with $15 \mathrm{~N}$ : comparison of end products and dose regimes. Am J Physiol 1978;235:E165-74.

12. Matthews DE, Motil KJ, Rohrbaugh DK, Burke JF, Young VR, Bier DM. Measurement of leucine metabolism in man from a primed, continuous infusion of L-[1-3C]leucine. Am J Physiol 1980;238:E473-9.

13. Thompson GN, Pacy PJ, Merritt H, et al. Rapid measurement of whole body and forearm protein turnover using a [2H5]phenylalanine model. Am J Physiol 1989;256:E631-9.

14. Marchini JS, Castillo L, Chapman TE, Vogt JA, Ajami A, Young VR. Phenylalanine conversion to tyrosine: comparative determination with L- [ring-2H5]phenylalanine and L-[1-13C]phenylalanine as tracers in man. Metabolism 1993;42:1316-22.

15. Arnold J, Campbell IT, Samuels TA, et al. Increased whole body protein breakdown predominates over increased whole body protein synthesis in multiple organ failure [published erratum appears in Clin Sci (Colch) 1993 Dec;85(6):following xxv]. Clin Sci (Colch) 1993;84:655-61.

16. Castillo L, Beaumier L, Ajami AM, Young VR. Whole body nitric oxide synthesis in healthy men determined from [15N] arginine-to-[15N]citrulline labeling. Proc Natl Acad Sci U S A 1996;93:11460-5.

17. Rennie MJ. Muscle protein turnover and the wasting due to injury and disease. Br Med Bull 1985;41:25764.

18. Kinney JM, Elwyn DH. Protein metabolism and injury. Annu Rev Nutr 1983;3:433-66.

19. Fern EB, Garlick PJ, McNurlan MA, Waterlow JC. The excretion of isotope in urea and ammonia for estimating protein turnover in man with [15N]glycine. Clin Sci 1981;61:217-28.

20. Wagenmakers AJ. Tracers to investigate protein and amino acid metabolism in human subjects. Proc Nutr Soc 1999;58:987-1000.

21. Hoerr RA, Matthews DE, Bier DM, Young VR. Leucine kinetics from [2H3]- and [13C]leucine infused simultaneously by gut and vein. Am J Physiol 1991;260:E111-7.

22. Biolo G, Tessari P, Inchiostro S, et al. Leucine and phenylalanine kinetics during mixed meal ingestion: a multiple tracer approach. Am J Physiol 1992;262:E455-63.

23. Matthews DE, Marano MA, Campbell RG. Splanchnic bed utilization of leucine and phenylalanine in humans. Am J Physiol 1993;264:E109-18.

24. Riedijk MA, van Goudoever JB. Splanchnic metabolism of ingested amino acids in neonates. Curr Opin Clin Nutr Metab Care 2007;10:58-62.

25. Campbell IT. Limitations of nutrient intake. The effect of stressors: trauma, sepsis and multiple organ failure. Eur J Clin Nutr 1999;53 Suppl 1:S143-7.

26. de Groof F, Joosten KF, Janssen JA, et al. Acute stress response in children with meningococcal sepsis: important differences in the growth hormone/insulin-like growth factor I axis between nonsurvivors and survivors. J Clin Endocrinol Metab 2002;87:3118-24.

27. Hart DW, Wolf SE, Mlcak R, et al. Persistence of muscle catabolism after severe burn. Surgery 2000;128:312-9. 
28. Reeds PJ, Fjeld CR, Jahoor F. Do the differences between the amino acid compositions of acute-phase and muscle proteins have a bearing on nitrogen loss in traumatic states? J Nutr 1994;124:906-10.

29. Hart DW, Wolf SE, Chinkes DL, et al. Effects of early excision and aggressive enteral feeding on hypermetabolism, catabolism, and sepsis after severe burn. J Trauma 2003;54:755-61; discussion 761-4.

30. Cunningham JJ. Body composition and nutrition support in pediatrics: what to defend and how soon to begin. Nutr Clin Pract 1995;10:177-82.

31. Briassoulis G, Zavras N, Hatzis T. Malnutrition, nutritional indices, and early enteral feeding in critically ill children. Nutrition 2001;17:548-57.

32. Briassoulis GC, Zavras NJ, Hatzis MT. Effectiveness and safety of a protocol for promotion of early intragastric feeding in critically ill children. Pediatr Crit Care Med 2001;2:113-21.

33. Chaloupecky V, Hucin B, Tlaskal T, et al. Nitrogen balance, 3-methylhistidine excretion, and plasma amino acid profile in infants after cardiac operations for congenital heart defects: the effect of early nutritional support. J Thorac Cardiovasc Surg 1997;114:1053-60.

34. Denne SC. Regulation of proteolysis and optimal protein accretion in extremely premature newborns. Am J Clin Nutr 2007;85:621S-624S.

35. Rogers EJ, Gilbertson HR, Heine RG, Henning R. Barriers to adequate nutrition in critically ill children. Nutrition 2003;19:865-8.

36. Enrione EB, Gelfand MJ, Morgan D, Sperling M, Wagner SC, Popp MB. The effects of rate and route of nutrient intake on protein metabolism. J Surg Res 1986;40:320-5.

37. Kudsk KA, Carpenter G, Petersen S, Sheldon GF. Effect of enteral and parenteral feeding in malnourished rats with E. coli-hemoglobin adjuvant peritonitis. J Surg Res 1981;31:105-10.

38. Heyland DK, Dhaliwal R, Drover JW, Gramlich L, Dodek P. Canadian clinical practice guidelines for nutrition support in mechanically ventilated, critically ill adult patients. JPEN J Parenter Enteral Nutr 2003;27:355-73.

39. Dhaliwal R, Jurewitsch B, Harrietha D, Heyland DK. Combination enteral and parenteral nutrition in critically ill patients: harmful or beneficial? A systematic review of the evidence. Intensive Care Med 2004;30:1666-71.

40. Macronutrients RotPo. Dietary Reference Intakes for Macronutrients. Washington: US National Academie of Sciences, 2005.

41. Beaufrere B, Bresson JL, Briend A, et al. [Protein and energy needs of the infant with severe malnutrition. Application in a hospital environment for the treatment of malnutrition caused by deficient intake]. Arch Pediatr 1998;5:763-71.

42. Fuller MF, Reeds PJ. Nitrogen cycling in the gut. Annu Rev Nutr 1998;18:385-411.

43. Organization WH. Energy and protein requirements: report of joint FAO/WHO/UNU expert consultation. 1985:(Technical Report Series no. 724).

44. Dewey KG, Beaton G, Fjeld C, Lonnerdal B, Reeds P. Protein requirements of infants and children. Eur J Clin Nutr 1996;50 Suppl 1:S119-47; discussion S147-50.

45. Clague MB, Keir MJ, Wright PD, Johnston ID. The effects of nutrition and trauma on whole-body protein metabolism in man. Clin Sci 1983;65:165-75.

46. Cone JB, Wallace BH, Lubansky HJ, Caldwell FT. Manipulation of the inflammatory response to burn injury. J Trauma 1997;43:41-5; discussion 45-6.

47. Mickell JJ. Urea nitrogen excretion in critically ill children. Pediatrics 1982;70:949-55.

48. Joosten KF, Verhoeven JJ, Hop WC, Hazelzet JA. Indirect calorimetry in mechanically ventilated infants and children: accuracy of total daily energy expenditure with 2 hour measurements. Clin Nutr 1999;18:149-52.

49. Shaw JH, Wildbore M, Wolfe RR. Whole body protein kinetics in severely septic patients. The response to glucose infusion and total parenteral nutrition. Ann Surg 1987;205:288-94.

50. Wolfe RR, Goodenough RD, Burke JF, Wolfe MH. Response of protein and urea kinetics in burn patients to different levels of protein intake. Ann Surg 1983;197:163-71.

51. Cerra FB, Shronts EP, Raup S, Konstantinides N. Enteral nutrition in hypermetabolic surgical patients. Crit Care Med 1989;17:619-22.

52. Ishibashi N, Plank LD, Sando K, Hill GL. Optimal protein requirements during the first 2 weeks after the onset of critical illness. Crit Care Med 1998;26:1529-35.

53. Jolliet P, Pichard C, Biolo G, et al. Enteral nutrition in intensive care patients: a practical approach. Intensive Care Med 1998:848-859.

54. Hoffer LJ. Protein and energy provision in critical illness. Am J Clin Nutr 2003;78:906-11.

55. van Lingen RA, van Goudoever JB, Luijendijk IH, Wattimena JL, Sauer PJ. Effects of early amino acid administration during total parenteral nutrition on protein metabolism in pre-term infants. Clin Sci (Lond) 1992;82:199-203. 


\section{CHAPTER 8}

56. Rivera A, Jr., Bell EF, Bier DM. Effect of intravenous amino acids on protein metabolism of preterm infants during the first three days of life. Pediatr Res 1993;33:106-11.

57. Poindexter BB, Langer JC, Dusick AM, Ehrenkranz RA. Early provision of parenteral amino acids in extremely low birth weight infants: relation to growth and neurodevelopmental outcome. J Pediatr 2006; 148:300-305.

58. Reynolds RM, Bass KD, Thureen PJ. Achieving positive protein balance in the immediate postoperative period in neonates undergoing abdominal surgery. J Pediatr 2008;152:63-7.

59. Patterson B, Nguyen T, Pierre E, Herndon D, Wolfe R. Urea and protein metabolism in burned children: effect of dietary protein intake. Metabolism 1997;46:573-578.

60. Alexander JW, MacMillan BG, Stinnett JD, et al. Beneficial effects of aggressive protein feeding in severely burned children. Ann Surg 1980;192:505-17.

61. Coss-Bu JA, Klish WJ, Walding D, Stein F, Smith EO, Jefferson LS. Energy metabolism, nitrogen balance, and substrate utilization in critically ill children. Am J Clin Nutr 2001;74:664-9.

62. Geukers VG, Oudshoorn JH, Taminiau JA, et al. Short-term protein intake and stimulation of protein synthesis in stunted children with cystic fibrosis. Am J Clin Nutr 2005;81:605-10.

63. Soeters PB, de Jong $\mathrm{CH}$, Deutz NE. The protein sparing function of the gut and the quality of food protein. Clin Nutr 2001;20:97-9.

64. Wu G, Morris SM, Jr. Arginine metabolism: nitric oxide and beyond. Biochem J 1998;336 (Pt 1):1-17.

65. Morris SM, Jr. Arginine: beyond protein. Am J Clin Nutr 2006;83:508S-512S.

66. Wu G, Jaeger LA, Bazer FW, Rhoads JM. Arginine deficiency in preterm infants: biochemical mechanisms and nutritional implications. J Nutr Biochem 2004;15:442-51.

67. Argaman Z, Young VR, Noviski N, et al. Arginine and nitric oxide metabolism in critically ill septic pediatric patients. Crit Care Med 2003;31:591-7.

68. Yu YM, Sheridan RL, Burke JF, Chapman TE, Tompkins RG, Young VR. Kinetics of plasma arginine and leucine in pediatric burn patients. Am J Clin Nutr 1996;64:60-6.

69. Yu YM, Ryan CM, Castillo L, et al. Arginine and ornithine kinetics in severely burned patients: increased rate of arginine disposal. Am J Physiol Endocrinol Metab 2001;280:E509-17.

70. Zamora SA, Amin HJ, McMillan DD, et al. Plasma L-arginine concentrations in premature infants with necrotizing enterocolitis. J Pediatr 1997;131:226-32.

71. Morris CR, Poljakovic M, Lavrisha L, Machado L, Kuypers FA, Morris SM, Jr. Decreased arginine bioavailability and increased serum arginase activity in asthma. Am J Respir Crit Care Med 2004;170:148-53.

72. Lopansri BK, Anstey NM, Weinberg JB, et al. Low plasma arginine concentrations in children with cerebral malaria and decreased nitric oxide production. Lancet 2003;361:676-8.

73. Morris CR, Morris SM, Jr., Hagar W, et al. Arginine therapy: a new treatment for pulmonary hypertension in sickle cell disease? Am J Respir Crit Care Med 2003;168:63-9.

74. Luiking YC, Poeze M, Dejong CH, Ramsay G, Deutz NE. Sepsis: an arginine deficiency state? Crit Care Med 2004;32:2135-45.

75. Yu YM, Young VR, Castillo L, et al. Plasma arginine and leucine kinetics and urea production rates in burn patients. Metabolism 1995;44:659-66.

76. Amin HJ, Zamora SA, McMillan DD, et al. Arginine supplementation prevents necrotizing enterocolitis in the premature infant. J Pediatr 2002;140:425-31.

77. Castillo L, Chapman TE, Yu YM, Ajami A, Burke JF, Young VR. Dietary arginine uptake by the splanchnic region in adult humans. Am J Physiol 1993;265:E532-9.

78. Luiking YC, Poeze M, Ramsay G, Deutz NE. The role of arginine in infection and sepsis. JPEN J Parenter Enteral Nutr 2005;29:S70-4.

79. Lorente JA, Landin L, De Pablo R, Renes E, Liste D. L-arginine pathway in the sepsis syndrome. Crit Care Med 1993;21:1287-95.

80. Luiking YC, Deutz NE. Exogenous arginine in sepsis. Crit Care Med 2007;35:S557-63.

81. Ziegler TR, Szeszycki EE, Estivariz CF, Puckett AB, Leader LM. Glutamine: from basic science to clinical applications. Nutrition 1996;12:S68-70.

82. Tjader I, Rooyackers O, Forsberg AM, Vesali RF, Garlick PJ, Wernerman J. Effects on skeletal muscle of intravenous glutamine supplementation to ICU patients. Intensive Care Med 2004;30:266-75.

83. Houdijk AP, Rijnsburger ER, Jansen J, et al. Randomised trial of glutamine-enriched enteral nutrition on infectious morbidity in patients with multiple trauma [see comments]. Lancet 1998;352:772-6.

84. Griffiths RD. Outcome of critically ill patients after supplementation with glutamine. Nutrition 1997; 13:752-4.

85. Conejero R, Bonet A, Grau T, et al. Effect of a glutamine-enriched enteral diet on intestinal permeability and infectious morbidity at 28 days in critically ill patients with systemic inflammatory response syndrome: a randomized, single-blind, prospective, multicenter study. Nutrition 2002;18:716-21. 
86. Hall JC, Dobb G, Hall J, de Sousa R, Brennan L, McCauley R. A prospective randomized trial of enteral glutamine in critical illness. Intensive Care Med 2003;29:1710-6.

87. Garcia-de-Lorenzo A, Zarazaga A, Garcia-Luna PP, et al. Clinical evidence for enteral nutritional support with glutamine: a systematic review. Nutrition 2003;19:805-11.

88. Lacey J, Crouch J, Benfell K, al e. The effects of glutamine-supplemented parenteral nutrition in premature infants. JPEN 1996;20:74-80.

89. Neu J, Roig JC, Meetze WH, et al. Enteral glutamine supplementation for very low birth weight infants decreases morbidity. J Pediatr 1997;131:691-9.

90. Tubman TR, Thompson SW. Glutamine supplementation for preventing morbidity in preterm infants. Cochrane Database Syst Rev 2000:CD001457.

91. Barbosa E, Moreira EA, Goes JE, Faintuch J. Pilot study with a glutamine-supplemented enteral formula in critically ill infants. Rev Hosp Clin Fac Med Sao Paulo 1999;54:21-4.

92. Albers MJ, Steyerberg EW, Hazebroek FW, et al. Glutamine supplementation of parenteral nutrition does not improve intestinal permeability, nitrogen balance, or outcome in newborns and infants undergoing digestive-tract surgery: results from a double-blind, randomized, controlled trial. Ann Surg 2005;241:599606.

93. De Bandt JP, Cynober L. Therapeutic use of branched-chain amino acids in burn, trauma, and sepsis. J Nutr 2006;136:308S-13S.

94. Millward DJ, Jackson AA. Protein/energy ratios of current diets in developed and developing countries compared with a safe protein/energy ratio: implications for recommended protein and amino acid intakes. Public Health Nutr 2004;7:387-405.

95. Biolo G, Ciocchi B, Stulle M, et al. Calorie restriction accelerates the catabolism of lean body mass during 2 wk of bed rest. Am J Clin Nutr 2007;86:366-72.

96. Villet S, Chiolero RL, Bollmann MD, et al. Negative impact of hypocaloric feeding and energy balance on clinical outcome in ICU patients. Clin Nutr 2005;24:502-9.

97. Stapleton RD, Jones N, Heyland DK. Feeding critically ill patients: what is the optimal amount of energy? Crit Care Med 2007;35:S535-40.

98. Briassoulis G, Filippou O, Hatzi E, Papassotiriou I, Hatzis T. Early enteral administration of immunonutrition in critically ill children: results of a blinded randomized controlled clinical trial. Nutrition 2005;21:799807.

99. Hart DW, Wolf SE, Herndon DN, et al. Energy expenditure and caloric balance after burn: increased feeding leads to fat rather than lean mass accretion. Ann Surg 2002;235:152-61.

100. Wilmore D, Long J, Mason A, Skreen R, Pruitt B. Catecholamines: Mediator of the hypermetabolic response to thermal injury. Ann Surg 1974;180:653-669.

101. Herndon DN, Hart DW, Wolf SE, Chinkes DL, Wolfe RR. Reversal of catabolism by beta-blockade after severe burns. N Engl J Med 2001;345:1223-9.

102. Coss-Bu JA, Jefferson LS, Walding D, David Y, Smith EO, Klish WJ. Resting energy expenditure in children in a pediatric intensive care unit: comparison of Harris-Benedict and Talbot predictions with indirect calorimetry values. Am J Clin Nutr 1998;67:74-80.

103. Gore DC, Rutan RL, Hildreth M, Desai MH, Herndon DN. Comparison of resting energy expenditures and caloric intake in children with severe burns. J Burn Care Rehabil 1990;11:400-4.

104. Phillips R, Ott L, Young B, Walsh J. Nutritional support and measured energy expenditure of the child and adolescent with head injury. J Neurosurg 1987;67:846-51.

105. Briassoulis G, Venkataraman S, Thompson AE. Energy expenditure in critically ill children. Crit Care Med 2000;28:1166-72.

106. Turi RA, Petros AJ, Eaton S, et al. Energy metabolism of infants and children with systemic inflammatory response syndrome and sepsis. Ann Surg 2001;233:581-7.

107. Oosterveld MJ, Van Der Kuip M, De Meer K, De Greef HJ, Gemke RJ. Energy expenditure and balance following pediatric intensive care unit admission: a longitudinal study of critically ill children. Pediatr Crit Care Med 2006;7:147-53.

108. Rutan RL, Herndon DN. Growth delay in postburn pediatric patients. Arch Surg 1990;125:392-5.

109. Butte NF. Energy requirements of infants. Public Health Nutr 2005;8:953-67.

110. Jackson M, Poskitt EM. The effects of high-energy feeding on energy balance and growth in infants with congenital heart disease and failure to thrive. Br J Nutr 1991;65:131-43.

111. Chwals WJ. Metabolism and nutritional frontiers in pediatric surgical patients. Surg Clin North Am 1992;72:1237-66.

112. Tappy L, Schwarz JM, Schneiter P, et al. Effects of isoenergetic glucose-based or lipid-based parenteral nutrition on glucose metabolism, de novo lipogenesis, and respiratory gas exchanges in critically ill patients. Crit Care Med 1998;26:860-7. 


\section{CHAPTER 8}

113. Piedboeuf B, Chessex $P$, Hazan J, Pineault M, Lavoie JC. Total parenteral nutrition in the newborn infant: energy substrates and respiratory gas exchange. J Pediatr 1991;118:97-102.

114. van den Berghe G, Wouters P, Weekers F, et al. Intensive insulin therapy in the critically ill patients. N Engl J Med 2001;345:1359-67.

115. Verbruggen SC, Joosten KF, Castillo L, van Goudoever JB. Insulin therapy in the pediatric intensive care unit. Clin Nutr 2007;26:677-90.

116. Faustino EV, Apkon M. Persistent hyperglycemia in critically ill children. J Pediatr 2005;146:30-4.

117. Long CL, Kinney JM, Geiger JW. Nonsuppressability of gluconeogenesis by glucose in septic patients. Metabolism 1976;25:193-201.

118. Petit F, Bagby GJ, Lang $\mathrm{CH}$. Tumor necrosis factor mediates zymosan-induced increase in glucose flux and insulin resistance. Am J Physiol 1995;268:E219-28.

119. Roh MS, Moldawer LL, Ekman LG, et al. Stimulatory effect of interleukin-1 upon hepatic metabolism. Metabolism 1986;35:419-24.

120. Hart DW, Wolf SE, Zhang XJ, et al. Efficacy of a high-carbohydrate diet in catabolic illness. Crit Care Med 2001;29:1318-24.

121. Capes SE, Hunt D, Malmberg K, Gerstein HC. Stress hyperglycaemia and increased risk of death after myocardial infarction in patients with and without diabetes: a systematic overview. Lancet 2000;355:773-8.

122. Malmberg K, Ryden L, Efendic S, et al. Randomized trial of insulin-glucose infusion followed by subcutaneous insulin treatment in diabetic patients with acute myocardial infarction (DIGAMI study): effects on mortality at 1 year. J Am Coll Cardiol 1995;26:57-65.

123. Dobbins RL, Chester MW, Stevenson BE, Daniels MB, Stein DT, McGarry JD. A fatty acid- dependent step is critically important for both glucose- and non-glucose-stimulated insulin secretion. J Clin Invest 1998;101:2370-6.

124. Vahl T, D'Alessio D. Enteroinsular signaling: perspectives on the role of the gastrointestinal hormones glucagon-like peptide 1 and glucose-dependent insulinotropic polypeptide in normal and abnormal glucose metabolism. Curr Opin Clin Nutr Metab Care 2003;6:461-8.

125. de Chalain TM, Michell WL, O'Keefe SJ, Ogden JM. The effect of fuel source on amino acid metabolism in critically ill patients. J Surg Res 1992;52:167-76.

126. Grimble RF. Nutritional modulation of immune function. Proc Nutr Soc 2001;60:389-97.

127. Whitehouse AS, Tisdale MJ. Downregulation of ubiquitin-dependent proteolysis by eicosapentaenoic acid in acute starvation. Biochem Biophys Res Commun 2001;285:598-602.

128. Dewey A, Baughan C, Dean T, Higgins B, Johnson I. Eicosapentaenoic acid (EPA, an omega-3 fatty acid from fish oils) for the treatment of cancer cachexia. Cochrane Database Syst Rev 2007:CD004597.

129. Fearon KC, Von Meyenfeldt MF, Moses AG, et al. Effect of a protein and energy dense N-3 fatty acid enriched oral supplement on loss of weight and lean tissue in cancer cachexia: a randomised double blind trial. Gut 2003;52:1479-86.

130. Lopez-Alarcon M, Bernabe-Garcia M, Del Prado M, et al. Docosahexaenoic acid administered in the acute phase protects the nutritional status of septic neonates. Nutrition 2006;22:731-7.

131. Mizock BA. Alterations in fuel metabolism in critical illness: hyperglycaemia. Best Pract Res Clin Endocrinol Metab 2001;15:533-51.

132. Finney SJ, Zekveld C, Elia A, Evans TW. Glucose control and mortality in critically ill patients. Jama 2003;290:2041-7.

133. Wu X, Thomas SJ, Herndon DN, Sanford AP, Wolf SE. Insulin decreases hepatic acute phase protein levels in severely burned children. Surgery 2004;135:196-202.

134. Poindexter BB, Karn CA, Denne SC. Exogenous insulin reduces proteolysis and protein synthesis in extremely low birth weight infants. J Pediatr 1998;132:948-53.

135. Agus MS, Javid PJ, Piper HG, et al. The effect of insulin infusion upon protein metabolism in neonates on extracorporeal life support. Ann Surg 2006;244:536-44.

136. Agus MS, Javid PJ, Ryan DP, Jaksic T. Intravenous insulin decreases protein breakdown in infants on extracorporeal membrane oxygenation. J Pediatr Surg 2004;39:839-44; discussion 839-44.

137. Takala J, Ruokonen E, Webster NR, et al. Increased mortality associated with growth hormone treatment in critically ill adults [see comments]. N Engl J Med 1999;341:785-92.

138. Huysman MW, Hop WC, Cromme-Dijkhuis AH, Sauer PJ, Hokken-Koelega AC. A randomized, placebocontrolled $\mathrm{GH}$ trial in very preterm infants who were at risk for bronchopulmonary dysplasia and were treated with dexamethasone. Pediatr Res 2005;58:705-12.

139. Jeschke MG, Barrow RE, Herndon DN. Recombinant human growth hormone treatment in pediatric burn patients and its role during the hepatic acute phase response. Crit Care Med 2000;28:1578-84.

140. Hart DW, Herndon DN, Klein G, et al. Attenuation of posttraumatic muscle catabolism and osteopenia by long-term growth hormone therapy. Ann Surg 2001;233:827-34. 
141. Klein GL, Wolf SE, Langman CB, et al. Effects of therapy with recombinant human growth hormone on insulin-like growth factor system components and serum levels of biochemical markers of bone formation in children after severe burn injury. J Clin Endocrinol Metab 1998;83:21-4.

142. Ramirez RJ, Wolf SE, Barrow RE, Herndon DN. Growth hormone treatment in pediatric burns: a safe therapeutic approach. Ann Surg 1998;228:439-48.

143. Goeters C, Mertes N, Tacke J, et al. Repeated administration of recombinant human insulin-like growth factor-I in patients after gastric surgery. Effect on metabolic and hormonal patterns. Ann Surg 1995;222:646-53.

144. Debroy MA, Wolf SE, Zhang XJ, et al. Anabolic effects of insulin-like growth factor in combination with insulin-like growth factor binding protein-3 in severely burned adults. J Trauma 1999;47:904-10; discussion 910-1.

145. Herndon DN, Ramzy PI, DebRoy MA, et al. Muscle protein catabolism after severe burn: effects of IGF1/IGFBP-3 treatment. Ann Surg 1999;229:713-20; discussion 720-2.

146. Corpeleijn WE, van Vliet I, de Gast-Bakker DA, et al. Effect of enteral IGF-1 supplementation on feeding tolerance, growth, and gut permeability in enterally fed premature neonates. J Pediatr Gastroenterol Nutr 2008;46:184-90.

147. Hart DW, Wolf SE, Chinkes DL, et al. Determinants of skeletal muscle catabolism after severe burn. Ann Surg 2000;232:455-65.

148. Lang $\mathrm{CH}$, Nystrom G, Frost RA. Beta-adrenergic blockade exacerbates sepsis-induced changes in tumor necrosis factor alpha and interleukin- 6 in skeletal muscle and is associated with impaired translation initiation. J Trauma 2008;64:477-86.

149. Schmitz D, Wilsenack K, Lendemanns S, Schedlowski M, Oberbeck R. beta-Adrenergic blockade during systemic inflammation: impact on cellular immune functions and survival in a murine model of sepsis. Resuscitation 2007;72:286-94.

150. Schofield WN. Predicting basal metabolic rate, new standards and review of previous work. Hum Nutr Clin Nutr 1985;39 Suppl 1:5-41.

151. Koletzko B, Goulet O, Hunt J, Krohn K, Shamir R. 1. Guidelines on Paediatric Parenteral Nutrition of the European Society of Paediatric Gastroenterology, Hepatology and Nutrition (ESPGHAN) and the European Society for Clinical Nutrition and Metabolism (ESPEN), Supported by the European Society of Paediatric Research (ESPR). J Pediatr Gastroenterol Nutr 2005;41 Suppl 2:S1-87.

152. Lan Tjiong $H$, Swart $R$, Rietveld $T$, et al. Whole body protein turnover in peritoneal dialysis patients: a comparison of the $[15 \mathrm{~N}$ \}glycine end product and [13C]leucineprecursor methods. Nephrol Dial Transplant 2008; 0:1-6 Epub ahead of print

153. Van Goudoever, J. B., Sulkers, E. J., Halliday, D., Degenhart, H. J., Carnielli, V. P., Wattimena, J. L. \& Sauer, P. J. (1995) Whole-body protein turnover in preterm appropriate for gestational age and small for gestational age infants: comparison of [15N]glycine and [1-(13)C]leucine administered simultaneously. Pediatr Res 37: 381-388

154. Kreymann, K. G., Berger, M. M., Deutz, N. E., Hiesmayr, M., Jolliet, P., Kazandjiev, G., Nitenberg, G., van den Berghe, G., Wernerman, J. et al. (2006) ESPEN Guidelines on Enteral Nutrition: Intensive care. Clin Nutr 25: 210-223.

155. Kabir, I., Malek, M. A., Mazumder, R. N., Rahman, M. M. \& Mahalanabis, D. (1993) Rapid catch-up growth of children fed a high-protein diet during convalescence from shigellosis. Am J Clin Nutr 57: 441-445. 

CHAPTER 9

Summary and conclusions 
CHAPTER 9 
Nutritional support is an essential aspect of the clinical management of critically ill infants and children. Disease-related malnutrition and nutrient store depletion is a frequent finding in pediatric intensive care patients and is associated with increased morbidity and mortality. Disease related malnutrition is predominantly caused by the profound alterations in protein and amino acid metabolism during critical illness characterized by increased muscle protein breakdown, negative nitrogen balance and loss of lean body mass. This increased protein catabolism is aggravated by insufficient protein and energy intake due to inadequate nutrient prescription and/or delivery by the doctors and nurses.

The targets of nutritional support in critically ill children are: 1) preventing protein catabolism and loss of lean body mass as much as possible by promoting protein synthesis and/or diminishing protein breakdown; 2) preventing under- and overfeeding; 3) improving clinical outcome and ascertain normal growth and development.

The optimal nutritional intake of critically ill children to achieve these targets is not defined but will differ from those of healthy children and changes during the course of the disease. In order to be able to define the nutritional requirements of these children more insight is necessary into the alterations of protein and amino acid metabolism and into the effects of nutritional interventions both in the acute phase of the disease and during recovery.

Chapter 1 describes several aspects of disease related malnutrition in critically ill children and outlines the importance of adequate nutrition.

Chapter 2 provides a general overview of the most important aspects of protein and amino acid metabolism in health and during critical illness. It also gives a description of the methods that can be used to assess protein and amino acid metabolism and/or to evaluate the effects of (nutritional) interventions in critically ill children.

Assessment of whole body protein metabolism in children is difficult because the methods most often used are invasive and not acceptable for the children or their parents. Chapter 3 describes the assessment of whole body protein metabolism using the non-invasive stable isotope tracer method, the $\left[{ }^{15} \mathrm{~N}\right]$ glycine-single-oral dose method, in healthy children, children with pneumonia and in critically ill children with meningococcal sepsis (MS). Whole body protein turnover, protein synthesis and breakdown were all increased in the children with MS in the acute phase of the disease when compared to the healthy children. Protein breakdown exceeded protein synthesis in the most severely ill children leading to a negative protein balance. A close relation was found between the alterations in whole body protein metabolism and differences in severity of illness as expressed by the pediatric index of mortality (PIM score). The results obtained with this non-invasive method were comparable to results found in earlier reports in critically ill children and adults using more invasive intravenous stable isotope tracer methods. Although the $\left[{ }^{15} \mathrm{~N}\right]$ glycinesingle-oral-dose method has practical advantages over intravenous tracer methods, it needs further validation before it can be advocated for the assessment of whole body protein metabolism in critically ill children. 
Critical illness is characterized by profound hormonal and metabolic alterations. These alterations are a physiologic adaptation to severe stress and injury to release amino acids from muscle protein for gluconeogenesis, protein synthesis in other organs and energy production. Hyperglycemia and insulin resistance often occur and are associated with increased morbidity and mortality. Chapter 4 describes this hyperglycemic response in children with meningococcal sepsis with septic shock (MSS) and without shock (MS) with emphasis on the roles of the most important anabolic hormone, insulin, and inflammatory mediators. Children with MSS and MS showed frequent hyperglycemic episodes during the first 72 hours after admission and the severity of hyperglycemia was strongly correlated with severity of illness as expressed by the physiologic stability index (PSI). In children with MSS, hyperglycemia was associated with low plasma insulin levels while in MS patients normal to high insulin levels were found. Plasma insulin levels in both patient groups were strongly but inversely correlated with plasma levels of the soluble cytokine receptors sTNF-R55 and R75 suggesting a suppressive effect of pro-inflammatory mediators on insulin secretion. The relationship between insulin levels and severity of illness was also illustrated by the strong inverse correlation between insulin and PSI. Our findings of hypoinsulinemic hyperglycemia and increased insulin sensitivity in the MSS patients in the acute phase of the disease implicates that these children have increased risk for hypoglycemia when intensive insulin therapy is applied.

Protein and amino acid metabolism in critically ill children can also be investigated by assessment of plasma amino acid concentrations. Plasma amino acid concentrations are determined by the influx of amino acids from protein breakdown and dietary intake and from the efflux of amino acids for protein synthesis and oxidation. They give a reflection of the underlying metabolic processes and may give an indication of specific amino acid depletions and requirements. Chapter 5 describes plasma amino acid levels at admission (acute phase) and during treatment (recovery phase) in critically ill children with different underlying disorders (viral bronchiolitis, accidental or surgical trauma and sepsis) with emphasis on the amino acids arginine and citrulline, amino acids that play key roles in many metabolic processes during health and disease. The acute phase of critical illness was characterized by decreased plasma levels of several amino acids (generalized hypoaminoacidemia) and particularly those of arginine, citrulline and glutamine. During recovery plasma levels of these amino acids increased to normal levels. The decrease in plasma arginine, citrulline and glutamine levels was related to the severity of illness but most strongly to the severity of the inflammatory state as expressed by the plasma C-reactive protein (CRP) level. This strong relation persisted also during recovery (on days 3 and 7). The plasma Creactive protein (CRP) level gave a good indication of the plasma arginine and citrulline levels in the children with different underlying disorders and in different phases of their disease. Standard pediatric enteral nutrition did not have a significant influence on the increase in plasma arginine and citrulline levels during recovery demonstrating that the amount of arginine and/or citrulline in the standard nutritional support these children received was not sufficient to correct for this depletion. 
Chapter 6 and 7 report the results of a double-blind randomized controlled study that investigated the nutritional and metabolic effects of a protein and energy enriched enteral formula (PE-formula, providing $2.6 \mathrm{~g}$ protein and $100 \mathrm{kcal} / 100 \mathrm{ml}$ ) compared to a standard infant formula (S-formula, providing $1.4 \mathrm{~g}$ protein and $67 \mathrm{kcal} / 100 \mathrm{ml}$ ) administrated early ( $<24$ hours) after admission in mechanically ventilated infants with viral bronchiolitis.

Chapter 6 describes the effects of the two enteral infant formulas on gastrointestinal tolerance, nutrient delivery, cumulative nitrogen and energy balances, substrate utilization (using indirect calorimetry), plasma amino acid profiles and biochemical parameters. The results were: 1 ) both formulas were equally well tolerated; 2 ) with the PE-formula a higher and adequate nutrient delivery and positive cumulative energy balance could be achieved on the third day after admission despite significant fluid restriction measures by the treating physicians; 3) the higher protein and energy intake in the PE-fed infants resulted in a significantly higher and positive net cumulative nitrogen balance on the second day of admission suggestive of improved protein accretion early during admission, considered the most important target of nutritional support; 4) plasma concentrations of several essential amino acids, especially the branched chain amino acids were higher in PE-fed infants but still normal limits; 5) signs of carbohydrate overfeeding (RQ $>1.0$ ) were seen in two patients in the PEgroup but only on a single occasion in each patient, while blood glucose, insulin levels and blood urea nitrogen levels did not differ between groups. In conclusion, early enteral administration of a PE-formula to critically ill infants is well tolerated and safe, promotes an adequate nutrient delivery early in admission despite fluid restriction and improves energy and nitrogen balances without adverse metabolic effects.

Chapter 7 describes the effects of the two enteral infant formulas on whole body phenylalanine and tyrosine kinetics and splanchnic amino acid extraction on the fifth day of admission. Stable isotopes of phenylalanine and tyrosine were infused both enterally and intravenously at the same time. Protein and energy intakes during assessment of whole body protein metabolism were $1.6 \mathrm{~g} / \mathrm{kg} / \mathrm{d}$ and $84 \mathrm{kcal} / \mathrm{kg} / \mathrm{d}$ in the S-group (equivalent to recommended dietary allowance for healthy infants) and $3.0 \mathrm{~g}$ $/ \mathrm{kg} / \mathrm{d}$ and $118 \mathrm{kcal} / \mathrm{kg} / \mathrm{d}$ in the PE- group respectively. Results show that in the PEformula fed infants net protein balance was positive (=anabolic state) and significantly higher than in the $S$ fed infants. This was caused by a higher rate of protein synthesis in the PE-infants compared to the S-infants despite an also increased rate of protein breakdown. Phenylalanine hydroxylation to tyrosine as a measure of amino acid oxidation was not increased in the PE fed infants and did not induce a rise in plasma urea suggesting that the level of protein intake did not exceed amino acid requirements for protein synthesis. Splanchnic phenylalanine extraction amounted to $50 \%$ of phenylalanine intake and did not differ between groups. Our results show that when phenylalanine and tyrosine kinetics are investigated in enterally fed subjects, the influence of first pass splanchnic phenylalanine utilization should be taken in account or else protein breakdown will be underestimated and so whole body protein 
balance will be overestimated. In conclusion, high protein and energy intakes in critically ill infants in the first days of admission using a protein and energy enriched formula lead to protein anabolism by stimulating whole body protein synthesis in spite of a concomitant increase in whole body protein breakdown and without signs of protein intolerance.

In Chapter 8 we discuss the results of our studies in context with the literature and elaborate on the implications of our studies for clinical practice. Furthermore we make recommendations for nutritional and other measures to promote anabolism in critically ill children and suggestions for future research.

The main conclusions obtained from the studies described in this thesis are the following:

- Rates of whole body protein turnover, synthesis and breakdown as measured with the $\left[{ }^{15} \mathrm{~N}\right]$ glycine-single-oral-dose method are increased in children with meningococcal sepsis when compared to healthy children and related to the severity of illness.

- The $\left[{ }^{15} \mathrm{~N}\right]$ glycine-single-oral-dose method has practical advantages over intravenous tracer methods but needs further validation in critically ill children.

- Plasma insulin levels are inversely correlated with levels of soluble cytokine receptors suggesting a suppressive effect of pro-inflammatory mediators on insulin secretion.

- Hyperglycemia associated with hypoinsulinemia rather than insulin resistance seems to be the normal pathophysiological response in acute meningococcal septic shock in children.

- Plasma concentrations of arginine and citrulline are low during the acute phase of critical illness in children and normalize again during recovery.

- Plasma arginine and citrulline levels are strongly related to the severity of inflammation indicated by plasma CRP levels, independent of the underlying disorder or phase of the disease.

- Early enteral administration of a protein and energy enriched formula to critically ill infants is well tolerated and safe, promotes an adequate nutrient delivery early during admission and improves energy and nitrogen balances without adverse metabolic effects.

- High protein and energy intakes in critically ill infants in the first days of admission lead to protein anabolism by stimulating whole body protein synthesis in spite of a concomitant increase in whole body protein breakdown and without signs of protein intolerance. 


\section{CHAPTER 10}

Samenvatting en conclusies 
CHAPTER 10 
Voeding is een essentieel onderdeel van de klinische behandeling van ernstig zieke zuigelingen en kinderen. Ziekte gerelateerde ondervoeding komt frequent voor bij pediatrische intensive care patiënten en is geassocieerd met verhoogde morbiditeit en mortaliteit. Ziekte gerelateerde ondervoeding wordt voor een belangrijk deel veroorzaakt door de ingrijpende veranderingen van het eiwit- en aminozuurmetabolisme die optreden tijdens een ernstige ziekte. Deze veranderingen worden gekenmerkt door een verhoogde spiereiwitafbraak, een negatieve stikstofbalans en afname van de vet vrije massa. Deze katabole respons wordt verergerd door een insufficiënte inname van eiwitten en calorieën door het inadequaat voorschrijven en toedienen van voeding door de medische en verpleegkundige staf.

De belangrijkste doelen van het voeden van ernstig zieke kinderen zijn: 1) tegengaan van eiwitkatabolisme en verlies van vetvrije massa door het stimuleren van eiwitsynthese en/of het afremmen van eiwitafbraak; 2) voorkomen van ondervoeding maar ook overvoeding; 3) bevorderen van ziekteherstel en bevorderen van de normale groei en ontwikkeling.

De optimale hoeveelheid voeding die aan ernstig zieke kinderen toegediend moet worden om deze doelen te bereiken is niet bekend maar verschilt van die van gezonde kinderen en verandertd tijdens het beloop van de ziekte. Om de voedingsbehoefte van ernstig zieke kinderen te kunnen bepalen is meer inzicht nodig in de veranderingen van het eiwit- en aminozuurmetabolisme tijdens ernstige ziekte en in de effecten van voedingsinterventies zowel in de acute fase van de ziekte als tijdens de herstelperiode.

Hoofdstuk 1 beschrijft diverse aspecten van ziekte gerelateerde ondervoeding in ernstig zieke kinderen en het belang van adequate voeding.

Hoofdstuk 2 geeft een algemeen overzicht van de belangrijkste aspecten van eiwiten aminozuurmetabolisme in gezondheid en tijdens ernstige ziekte. Tevens wordt een beschrijving gegeven van methoden die gebruikt kunnen worden om bij ernstig zieke kinderen het eiwit- en aminozuurmetabolisme te onderzoeken en de effecten van (voeding)interventies te evalueren.

Het meten van het eiwitmetabolisme op lichaamsniveau bij kinderen is moeilijk aangezien de methoden die meestal gebruikt worden invasief zijn en daarom door kinderen of de ouders vaak niet geaccepteerd worden. Hoofdstuk 3 beschrijft een studie waarin we met behulp van een niet invasieve methode, de $\left[{ }^{15} \mathrm{~N}\right]$ glycine-singleoral-dose method, het eiwitmetabolisme op lichaamsniveau hebben bepaald in 4 groepen kinderen: gezonde kinderen, kinderen met longontsteking en ernstig zieke kinderen met meningococcen sepsis (MS). Bij kinderen met MS waren de eiwitturnover, de eiwitsynthese en de eiwitafbraak op lichaamsniveau in de acute fase van de ziekte verhoogd ten opzichte van gezonde kinderen. In de ziekste kinderen was de eiwitafbraak hoger dan de eiwitsynthese resulterend in een negatieve netto eiwitbalans. Een nauwe relatie werd gevonden tussen de veranderingen van het eiwitmetabolisme en verschillen in ernst van ziekte uitgedrukt door de pediatric index of mortality (PIM score). De resultaten verkregen met deze niet-invasieve methode 
kwamen goed overeen met eerder gepubliceerde studies van ernstig zieke kinderen en volwassenen waarbij gebruikt werd gemaakt van invasieve (intraveneuze) stabiele isotopen methoden. Alhoewel de $\left[{ }^{15} \mathrm{~N}\right]$ glycine-single-oral-dose method grote praktische voordelen heeft ten opzichte van de intraveneuze methoden, dient deze methode nog verder gevalideerd te worden voordat het aanbevolen kan worden voor het bepalen van het eiwitmetabolisme op lichaamsniveau in ernstig zieke kinderen.

Tijdens ernstige acute ziekten treden uitgebreide hormonale en metabole veranderingen op. Deze veranderingen vormen een fysiologische reactie op ernstige stress of letsel waardoor aminozuren worden vrijgemaakt uit spiereiwitten die vervolgens gebruikt worden in andere organen onder andere voor gluconeogenese, synthese van andere eiwitten of gebruikt als energiebron. Hierbij treden hyperglycemie en insuline resistentie vaak hetgeen geassocieerd is met een verhoogde morbiditeit en mortaliteit.

In Hoofdstuk 4 beschrijven we deze hyperglycemische response bij kinderen met meningococcensepsis met septische (MSS) en zonder shock (MS) met nadruk op de rol van het belangrijkste anabole hormoon, insuline, en inflammatoire mediatoren. Hyperglycemie kwam frequent voor bij de kinderen met MSS en MS in de eerste 72 uur van de opname waarbij de ernst van de hyperglycemie sterk gerelateerd was aan de ernst van de ziekte, uitgedrukt door de Physiologic Stability Index ( PSI). Kinderen met MSS vertoonden hyperglycemie in combinatie met lage plasma insuline concentraties terwijl in kinderen met MS hyperglycemie met normale of verhoogde insuline concentraties werden gezien. De plasma insuline concentraties in beide groepen vertoonden daarbij een sterke maar negatieve correlatie met de plasma concentraties van oplosbare cytokinen receptoren, sTNF-R55 and R75, hetgeen suggereert dat de pro-inflammatoire cytokinen een remmend effect hebben op de insuline secretie. De relatie tussen de insuline concentraties en de ernst van de ziekte werd ook geïllustreerd door de sterke negatieve correlatie tussen insuline en de PSI. Onze bevinding van hypoinsulinemische hyperglycemiëen en verhoogde insulinegevoeligheid bij kinderen met MSS in de acute fase van de ziekte impliceert dat deze kinderen een verhoogd risico hebben op hypoglycemiëen wanneer intensieve insuline therapie wordt toegepast.

Het eiwit- en aminozuurmetabolisme bij ernstig zieke kinderen kan ook worden onderzocht door het bepalen van de aminozuurconcentraties in plasma. Plasma aminozuur concentraties worden bepaald door de instroom van aminozuren vanuit eiwitafbraak en eiwitinname en door de uitstroom van aminozuren door eiwitsynthese en aminozuur oxidatie en vormen daardoor een afspiegeling van deze onderliggende metabole processen en kunnen een ook indicatie geven van specifieke aminozuurtekorten en behoeften. In Hoofdstuk 5 beschrijven we de plasma aminozuurconcentraties bij opname (acute fase) en tijdens de klinische behandeling (herstelfase) van ernstig zieke kinderen met verschillende onderliggende ziekten (virale bronchiolitis, accidenteel of chirurgisch trauma en sepsis) met de nadruk op de aminozuren arginine and citrulline, die een sleutelrol vervullen in vele metabole processen in ziekte en gezondheid. De acute fase van ernstige ziekte was gekenmerkt 
door verlaagde plasma concentraties van verschillende aminozuren maar vooral arginine, citrulline and glutamine. In de herstelfase stegen deze concentraties weer naar normale waarden. De daling van de plasmaconcentraties van arginine, citrulline en glutamine was sterk gerelateerd aan de ernst van de onderliggende ziekte maar vooral aan de ernst van de inflammatoire toestand uitgedrukt in de plasma C-reactive protein (CRP) concentratie. Deze sterke relatie was niet alleen aanwezig in de acute fase maar ook tijdens de herstelfase (op dag 3 en 7). De hoogte van de plasma CRP concentratie gaf een goede indicatie van de plasma arginine en citrulline concentratie bij kinderen met verschillende ziekten en in verschillende fase van hun ziekte. De standaard pediatrische sondevoeding die de kinderen kregen had geen significante invloed op plasma arginine en citrulline concentraties tijdens de herstelfase. Dit geeft aan dat de hoeveelheid arginine en citrulline in deze voeding niet voldoende is om de daling van de plasma arginine en citrulline concentraties te corrigeren.

Hoofdstuk 6 en 7 rapporteren de resultaten van een dubbelblind gerandomiseerd onderzoek bij ernstig zieke en beademde zuigelingen met virale bronchiolitis. In dit onderzoek werden de metabole effecten onderzocht van het toedienen van een eiwit- en energieverrijkte zuigelingenvoeding (PE-voeding, samenstelling $2.6 \mathrm{~g}$ eiwit en $100 \mathrm{kcal} / 100 \mathrm{ml}$ ) in vergelijking met een standaard zuigelingenvoeding (S-voeding, samenstelling $1.4 \mathrm{~g}$ eiwit en $67 \mathrm{kcal} / 100 \mathrm{ml}$ ) beide toegediend vanaf de vroege fase van de opname (<24 uur).

Hoofdstuk 6 beschrijft de effecten van de twee zuigelingenvoedingen op voedingstolerantie, de hoeveelheid macronutriënten die werden toegediend, de cumulatieve stikstof- en energiebalans, het substraatgebruik (door middel van indirecte calorimetrie), de plasma aminozuurconcentraties en biochemische parameters. De resultaten waren als volgt: 1) beide voedingen werden even goed verdragen; 2) met de PEvoeding kon al op de derde dag van opname een adequate macronutrienten inname en een positieve cumulatieve energiebalans bereikt woorden ondanks een vochtbeperking die de meeste zuigelingen hadden; 3) in de PE-groep was de cumulatieve stikstofbalans al op de tweede dag van opname positief en hoger dan in de S-groep hetgeen suggereert dat er al na enkele dagen sprake was van een anabole toestand, een belangrijk doel van voeding bij ernstig zieke kinderen; 4) plasma concentraties van verschillende essentiele aminozuren (vooral de vertakte keten aminozuren) waren hoger in de PE-groep maar nog binnen de normaalwaarden; 5) tekenen koolhydraatovervoeding $(R Q>1.0)$ werden gezien in twee zuigelingen in de PE-groep maar in beide slechts tijdens een enkele meting terwijl plasma concentraties van glucose, insuline and ureum niet verschillend waren tussen de beide groepen. Geconcludeerd wordt dat het toedienen van een eiwit- en calorie verrijkte zuigelingenvoeding aan ernstig zieke zuigelingen vroeg tijdens de opname goed wordt verdragen en veilig is. Het verbetert de macronutrienten inname ondanks vochtbeperking en leidt tot een positieve energie- en stikstofbalans zonder metabole bijwerkingen.

Hoofdstuk 7 beschrijft de effecten van de twee zuigelingenvoedingen op het eiwitmetabolisme op lichaamsniveau en op de splanchnische aminozuurextractie op de 
vijfde dag van opname. Hierbij werden oplossingen van stabiele isotopen van phenylalanine and tyrosine gelijktijdig intraveneus en enteraal toegediend. De eiwiten energieinname tijdens de metingen waren $1.6 \mathrm{~g} / \mathrm{kg} / \mathrm{d}$ en $84 \mathrm{kcal} / \mathrm{kg} / \mathrm{d}$ in de S-groep (hetgeen overeenkomt met de aanbevolen dagelijks inname van gezonde zuigelingen) en $3.0 \mathrm{~g} / \mathrm{kg} / \mathrm{d}$ en $118 \mathrm{kcal} / \mathrm{kg} / \mathrm{d}$ in de PE-groep. De resultaten laten zien dat de netto eiwitbalans positief was in de PE--groep (=anabole toestand) en significant hoger dan in de S-groep. Dit werd veroorzaakt door een hogere eiwitsynthese in de PE-groep dan in de S--groep ondanks dat de eiwitafbraak in de PE-groep ook verhoogd was. Hydroxylatie van phenylalanine tot tyrosine (als maat voor de aminozuuroxidatie) was niet verhoogd in de PE-groep en gaf ook geen stijging van de plasma ureum concentratie hetgeen suggereert dat de eiwitinname niet hoger was dan de aminozuurbehoefte voor eiwitsynthese. De extractie door de darm van de enteraal toegediende phenylalanine was ongeveer $50 \%$ en was niet verschillend in beide groepen. Onze resultaten laten zien dat, als men bij gevoede patiënten het eiwitmetabolisme meet met behulp van phenylalanine en tyrosine tracers, rekening dient te worden gehouden met deze extractie omdat anders de eiwitafbraak onderschat wordt en daardoor de netto eiwitbalans overschat wordt.

Geconcludeerd wordt dat een hoge enterale eiwit- en calorieinname vroeg tijdens de opname door middel van eiwit- en energie verrijkte voeding een anabole toestand bereikt kan worden bij ernstig zieke zuigelingen zonder tekenen van eiwitovervoeding. Deze anabole toestand wordt bewerkstelligd door stimulatie van de eiwitsynthese ondanks dat de eiwitafbraak eveneens toeneemt.

Hoofdstuk 8 bespreekt de resultaten van de verschillende studies in samenhang met de bestaande literatuur en wordt ingegaan op de implicaties voor de klinische praktijk. Tevens worden aanbevelingen gedaan voor maatregelen die een anabole toestand in ernstig zieke kinderen kunnen stimuleren. Ook worden suggesties gedaan voor toekomstig onderzoek.

De voornaamste conclusies van dit proefschrift zijn:

- De snelheid van eiwitturnover, eiwitsynthese en de eiwitafbraak, gemeten met de $\left[{ }^{15} \mathrm{~N}\right]$ glycine-single-oral-dose methode, zijn verhoogd in kinderen met meningococcen-sepsis ten opzichte van gezonde kinderen en gerelateerd aan de ernst van de ziekte.

- De $\left[{ }^{15} \mathrm{~N}\right]$ glycine-single-oral-dose methode heeft praktische voordelen ten opzichte van intraveneuze tracermethoden maar dient nog nader gevalideerd te worden in ernstig zieke kinderen.

- Plasma insuline concentraties en plasma concentraties van de oplosbare cytokine receptoren zijn negatief aan elkaar gecorreleerd. Dit suggereert een remmend effect van de proinflammatoire cytokinen op de insuline secretie.

- In kinderen met acute meningococcen sepsis en septische shock lijkt de normale pathofysiologische respons hyperglycemie op basis van hypoinsulinisme te zijn en niet hyperglycemie op basis van insuline resistentie.

- Plasma arginine en citrulline concentraties zijn laag tijdens de acute fase van ernstig ziekte bij kinderen en normaliseren tijdens herstel. 
- De daling van de plasma arginine en citrulline concentraties is sterk gecorreleerd met de ernst van de inflammatie (plasma CRP concentratie) onafhankelijk van de onderliggende ziekte en de fase van de ziekte.

- Vroege enterale toediening aan ernstig zieke zuigelingen van een eiwit- en energieverrijkte voeding wordt goed verdragen, bevordert een adequate macronutriënten inname in de vroege fase van opname en verbetert de energie- en eiwitbalans zonder negatieve metabole effecten.

- Een hoge eiwit- en energieinname van ernstig zieke zuigelingen in de eerste dagen van de opname leidt tot anabolisme door stimulatie van de eiwitsynthese ondanks een gelijktijdige verhoging van de eiwitafbraak en zonder tekenen van eiwitintolerantie.

- $\quad$ Bij het bepalen van het eiwitmetabolisme op lichaamsniveau bij enteraal gevoede kinderen met de phenylalanine en tyrosine methode, dient men rekening te houden met de splanchnische extractie van de phenylalanine in de voeding. 



\section{Dankwoord}

Promoveren doe je alleen, maar niet in je eentje. Steun is onontbeerlijk en was altijd voldoende aanwezig. Ik dank mijn begeleiders en (co)promotoren, Philip Forget, Raymond Donckerwolcke, Mick Deutz, Yvette Luiking, Wim Buurman, Luc Zimmermann en Koen Joosten voor hun inhoudelijke bijdrage en begeleiding in de verschillende fasen van mijn promotieonderzoek. Ik dank mijn directe collega kinderartsintensivisten, Gijs Vos, Piet Leroy, Monique Engel en, niet als laatste, onze secretaresse Anja Lemmerlijn, voor hun morele en praktische steun. Mijn bijzondere dank gaat uit naar de kinderen en hun ouders voor hun bereidheid mee te werken aan mijn onderzoeken aangezien zonder hen alle onderzoek onmogelijk was geweest. Verder gaat mijn dank uit naar de verpleging van de PICU voor hun positieve houding ten aanzien van mijn onderzoek en hun hulp bij de afhandeling van buisjes, briefjes en potjes. Ook dank ik Carlijn de Betue voor haar hulp en inzet bij mijn, en inmiddels ook haar, onderzoek. Natuurlijk dank ik speciaal mijn ouders, mijn familie en vrienden voor hun onvoorwaardelijke steun, vertrouwen en geduld. En als laatste dank ik hen die mij het dierbaarst zijn: mijn vrouw Lusanne en mijn kinderen, Laure en Marijn. 



\section{Curriculum vitae}

Dirk Adriaan van Waardenburg

Born on November $14^{\text {th }} 1961$ in Bennebroek, The Netherlands.

Married to Lusanne A.M. Delen

Children: Laure (1992) and Marijn (1993)

Department of Pediatrics, Division Pediatric Intensive Care

Maastricht University Medical Center

PO Box 5800, 6202 AZ Maastricht

The Netherlands

E-mail: d.vanwaardenburg@mumc.nl

\section{Faculty Position}

1997 - $\quad$ Pediatric Intensivist, Maastricht University Medical Center, The Netherlands

\section{Residency and Pediatric training}

1995 - 1997 Pediatric Intensive Care Fellowship: Maastricht University Medical Center, Maastricht, The Netherlands

1990 - 1995 Pediatric Training: Erasmus Medical Center / Sophia Children's Hospital, Rotterdam, The Netherlands (Head: Prof. dr. H.K.A. Visser)

1989 - 1990 Residency Pediatrics: Erasmus Medical Center / Sophia Children's Hospital, Rotterdam, The Netherlands

\section{University}

1981 - 1988 Faculty of Medicine, University of Amsterdam, Amsterdam, The Netherlands

$1980-1981$ Faculty of Biology, University of Amsterdam, Amsterdam, The Netherlands

\section{High school}

$1974-1980 \quad$ VWO, Coornhert Scholengemeenschap, Haarlem, The Netherlands 



\section{Publications}

\section{THIS THESIS}

van Waardenburg DA, Deutz NE, Hoos MB, Jansen NJ, van Kreel BK, Vos GD, Wagenmakers AJ, Forget PP.

Assessment of whole body protein metabolism in critically ill children: can we use the $\left[{ }^{15} \mathrm{~N}\right]$ glycine single oral dose method?

Clin Nutr. 2004 Apr;23(2):153-60.

van Waardenburg DA, Jansen TC, Vos GD, Buurman WA

Hyperglycemia in children with meningococcal sepsis and septic shock: the relation between plasma levels of insulin and inflammatory mediators.

J Clin Endocrinol Metab. 2006 Oct;91(10):3916-21.

van Waardenburg DA, de Betue CT, Luiking YC, Engel M, Deutz NE.

Plasma arginine and citrulline concentrations in critically ill children: strong relation with inflammation.

Am J Clin Nutr. 2007 Nov;86(5):1438-44.

van Waardenburg DA, de Betue CT, van Goudoever JB, Zimmermann LJ, Joosten KF.

Nutritional effects of early administration of a protein and energy enriched formula in critically ill infants; a randomized controlled trial

Submitted for publication

van Waardenburg DA, de Betue CT, Deutz NE, van Eijk HM, van Goudoever JB, Luiking YC, Zimmermann LJ, Joosten KF.

High protein and energy intakes promote anabolism in critically ill infants; a randomized controlled trial.

Submitted for publication

\section{OTHER PUBLICATIONS}

Bosch SFJ, Derikx JPM, Thuijls G, van Bijnen AA, van Waardenburg DA, van Heurn LWE, Buurman WA, Heineman E.

FABP's als nieuwe plasma- en urinemarkers voor intestinale epitheliale celschade.

Nederlands tijdschrift voor Heelkunde (in press)

Vos G, Engel M, Ramsay G, van Waardenburg D.

Point-of-care blood analyzer during the interhospital transport of critically ill children.

Eur J Emerg Med. 2006 Oct;13(5):304-7. 
Smeets EE, Julu PO, van Waardenburg D, Engerström IW, Hansen S, Apartopoulos F, Curfs LM, Schrander-Stumpel CT.

Management of a severe forceful breather with Rett syndrome using carbogen.

Brain Dev. 2006 Nov;28(10):625-32.

Spruijt L, Hoefsloot LH, van Schaijk GH, van Waardenburg D, Kremer B, Brackel HJ, de Die-Smulders CE.

Identification of a novel EYA1 mutation presenting in a newborn with laryngomalacia, glossoptosis, retrognathia, and pectus excavatum.

Am J Med Genet A. 2006 Jun 15;140(12):1343-5.

Derikx JP, van Waardenburg DA, Granzen B, van Bijnen AA, Heineman E, Buurman WA.

Detection of chemotherapy-induced enterocyte toxicity with circulating intestinal fatty acid binding protein.

J Pediatr Hematol Oncol. 2006 Apr;28(4):267-9.

Vos GD, Buurman WA, van Waardenburg DA, Visser TP, Ramsay G, Donckerwolcke RA.

Interhospital paediatric intensive care transport: a novel transport unit based on a standard ambulance trolley.

Eur J Emerg Med. 2003 Sep;10(3):195-9.

Vos GD, Nissen AC, Nieman FH, Meurs MM, van Waardenburg DA, Ramsay G, Donckerwolcke RA.

Comparison of interhospital pediatric intensive care transport accompanied by a referring specialist or a specialist retrieval team.

Intensive Care Med. 2004 Feb;30(2):302-8.

Vos GD, Nieman FH, Meurs AM, Van Waardenburg DA, Ramsay G, Donckerwolcke RA.Problems in interhospital pediatric intensive care transport in The Netherlands: results from a survey of general pediatricians.

Intensive Care Med. 2003 Sep;29(9):1555-9

Rubio-Gozalbo ME, van Waardenburg DA, Forget PP, Spaapen LJ, Verrips A, Vroomen PC.

Neuroleptic malignant syndrome during zuclopenthixol therapy in X-linked cerebral adrenoleukodystrophy.

J Inherit Metab Dis. 2001 Oct;24(5):605-6.

de Priester JA, Vos GD, van Waardenburg DA, Oei TK.

Congenitally short trachea with compression of the left mainstem bronchus: MRI findings.

Pediatr Radiol. 1998 May;28(5):342-3. 
Derikx JPM, Bijker EM, Vos GD, van Bijnen AA; Heineman E, Buurman WA, van Waardenburg DA.

Gut mucosal cell damage in the early phase of meningococcal sepsis in children: relation with clinical outcome.

Submitted for publication

Derikx JPM, van Waardenburg DA, Thuijls G, Willigers HM, Koenraads M, van Bijnen AA, Heineman E, Ambergen T, van Ooij A, van Rhijn LW, Buurman WA.

Loss of gut wall integrity during major non-abdominal surgery.

Submitted for publication 